University of South Florida

DIGITAL COMMONS

Digital Commons @ University of

@ UNIVERSITY OF SOUTH FLORIDA

South Florida

KIP Theses and Dissertations

KIP Research Publications

January 2007

\title{
Land use policy and practice in karst terrains
}

E. Spencer Fleury

Follow this and additional works at: https://digitalcommons.usf.edu/kip_etd

\section{Recommended Citation}

Fleury, E. Spencer, "Land use policy and practice in karst terrains" (2007). KIP Theses and Dissertations.

16.

https://digitalcommons.usf.edu/kip_etd/16

This Article is brought to you for free and open access by the KIP Research Publications at Digital Commons @ University of South Florida. It has been accepted for inclusion in KIP Theses and Dissertations by an authorized administrator of Digital Commons @ University of South Florida. For more information, please contact digitalcommons@usf.edu. 

Land Use Policy and Practices in Karst Terrains by E. Spencer Fleury

A dissertation submitted in partial fulfillment of the requirements for the degree of

Doctor of Philosophy

Department of Geography

College of Arts and Sciences

University of South Florida

\author{
Major Professor: Robert Brinkmann, Ph.D. \\ Bogdan Onac, Ph.D. \\ Philip Reeder, Ph.D. \\ Elizabeth Strom, Ph.D. \\ Graham Tobin, Ph.D.
}

Date of Approval:

November 15, 2007

Keywords:

Human-environment interaction; environmental hazards; protected area management; planning; groundwater

(C) 2007, E. Spencer Fleury 
For my parents, who passed to me their love of reading and learning, and for my wife Ann, whose love and support made this all possible. 


\section{Acknowledgements}

I would like to take this opportunity to thank several individuals whose help was instrumental in writing this dissertation. They are Alin Mos, of the Apuseni Natural Park; Jim Rebmann, of Lexington-Fayette County Urban Government; Percy Doughtery, formerly of Kutztown University; Todd Chavez, of the University of South Florida library; the Karst Research Group at the University of South Florida; Dr. Bogdan Onac; Dr. Philip Reeder; Dr. Elizabeth Strom; Dr. Graham Tobin; and in particular Dr. Robert Brinkmann, my advisor, mentor and friend. 


\section{TABLe OF CONTEnTS}

$\begin{array}{lll}\text { ABSTRACT } & \text { viii }\end{array}$

1. INTRODUCTION 1

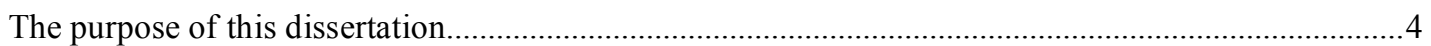

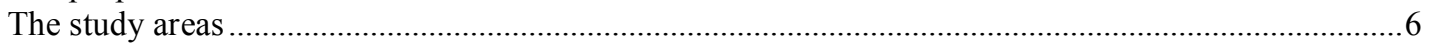

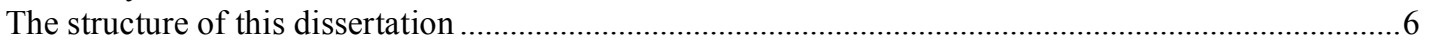

2. KARST PROCESSES, LANDFORMS AND ISSUES $\quad 8$

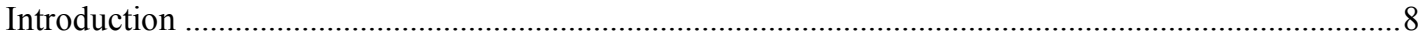

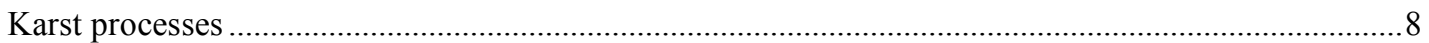

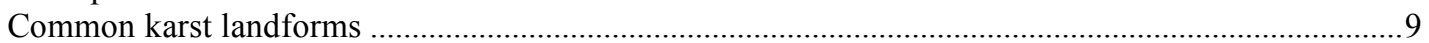

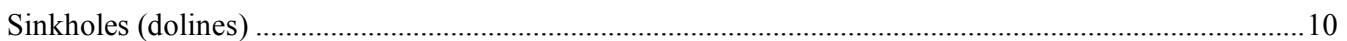

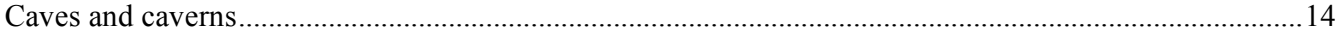

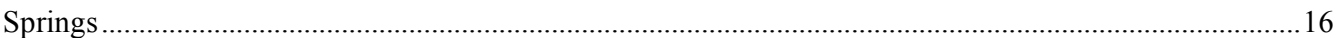

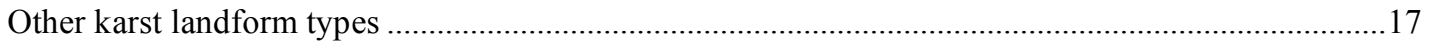

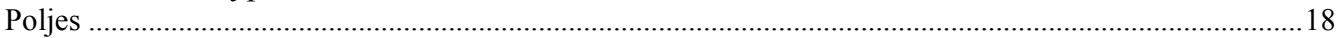

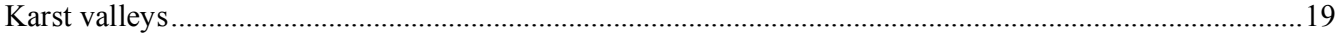

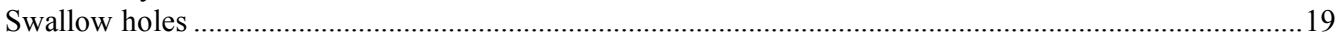

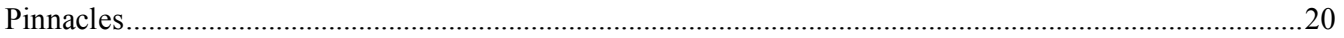

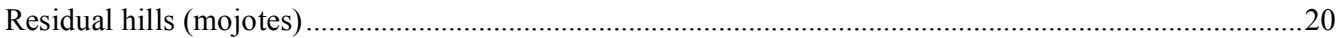

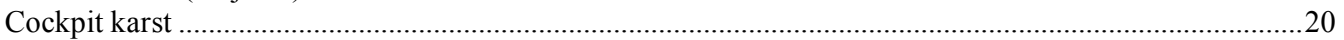

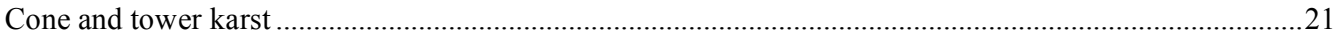

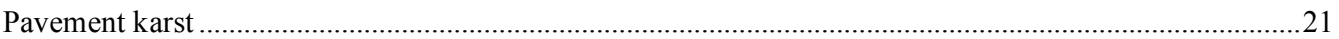

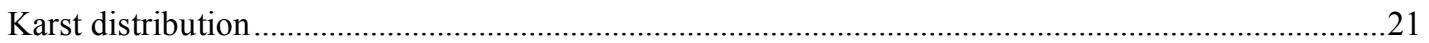

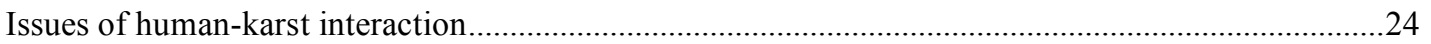

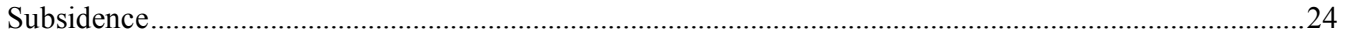

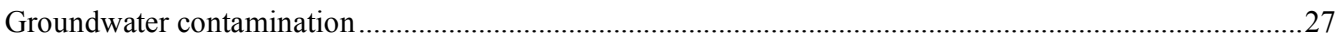

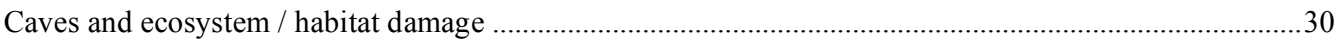

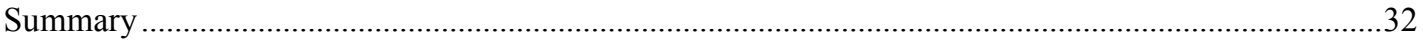

3. PERSPECTIVES ON POLICY ANALYSIS 33

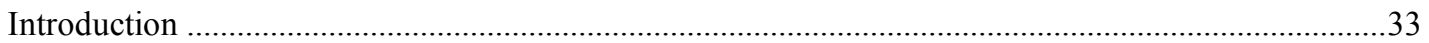

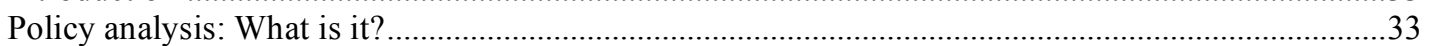

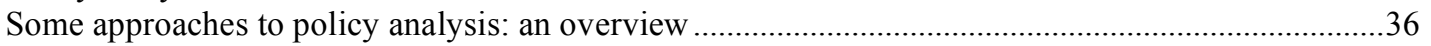

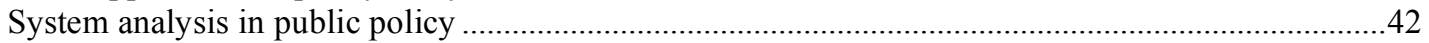

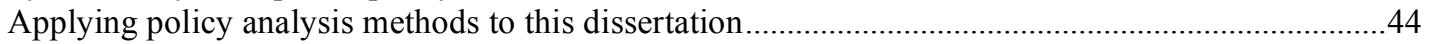

4. KARST, LAND USE AND GEOGRAPHY: WHERE THIS RESEARCH FITS IN THE

GEOGRAPHIC TRADITION $\quad 48$

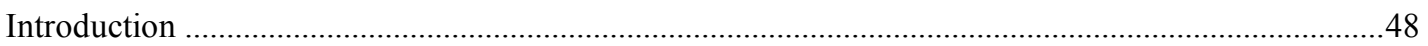

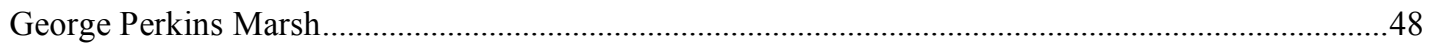

Carl Sauer and the Berkeley school ........................................................................................

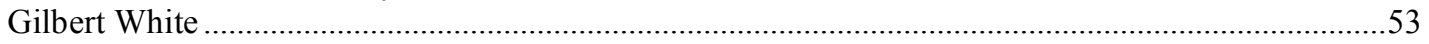

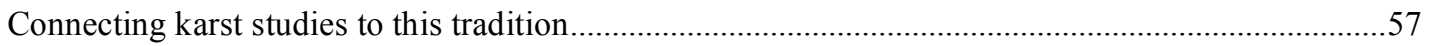

5. REGULATORY TECHNIQUES USED IN MANAGING DEVELOPMENT ON KARST:

AN OVERVIEW

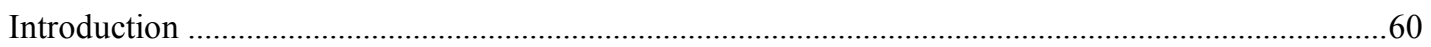

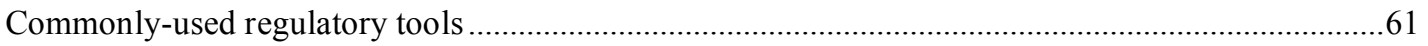




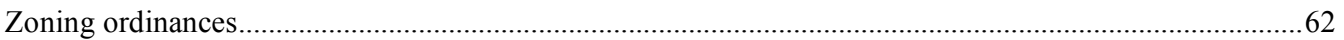

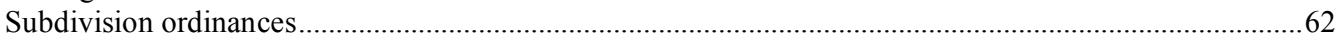

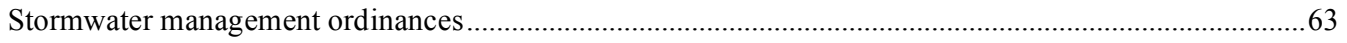

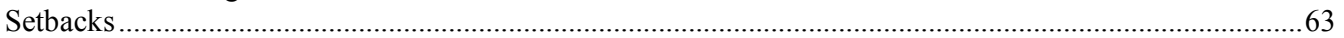

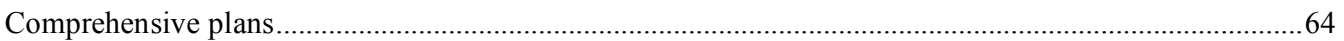

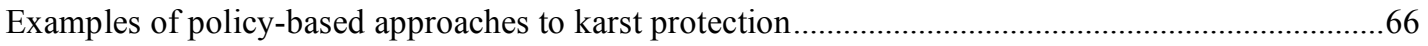

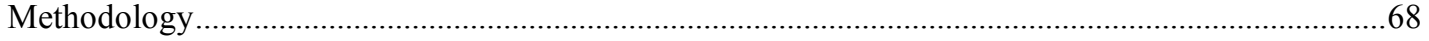

Appalachian belt (Virginia, Pennsylvania, Maryland, New York, New Jersey, eastern Tennessee

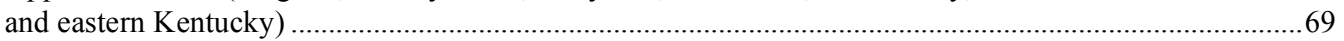

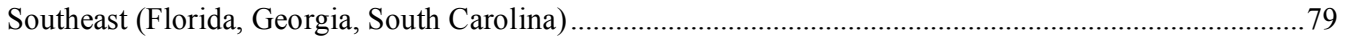

South-central (Kentucky, Tennessee, northern Alabama, Missouri) ........................................................8 84

Great Lakes (Indiana, Illinois, Iowa, Minnesota, Wisconsin, Ohio) .............................................................8 87

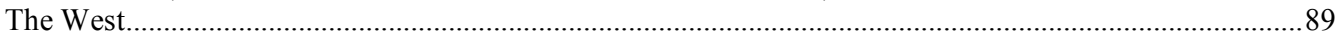

What it all means

\section{HOW PLANNERS AND LAND USE PROFESSIONALS UNDERSTAND KARST AND}

KARST-AWARE LAND USE REGULATION 93

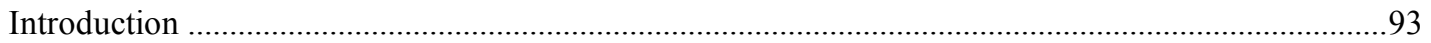

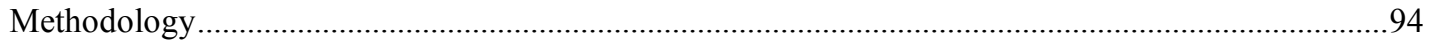

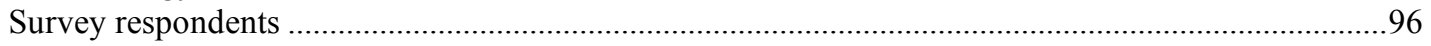

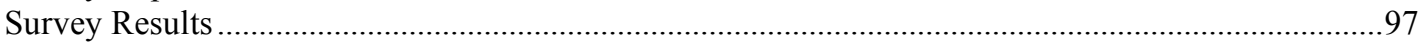

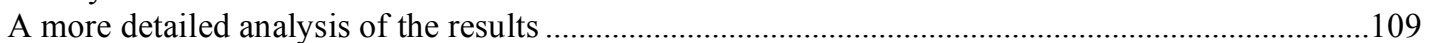

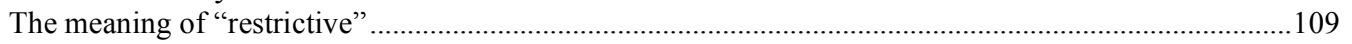

Goals, effectiveness and the potential for improvement ....................................................................111

How the extent of the local karst affects choice of regulatory technique ................................................114

Preventative or reactive implementation and regulatory restrictiveness ..................................................117

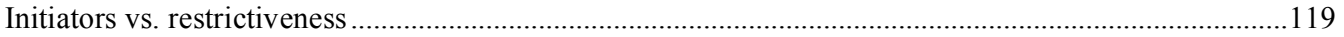

The influence of non-elected professionals vs. regulatory restrictiveness .................................................122

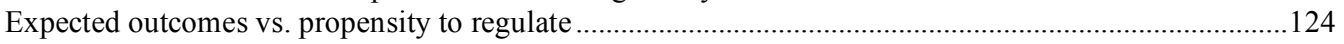

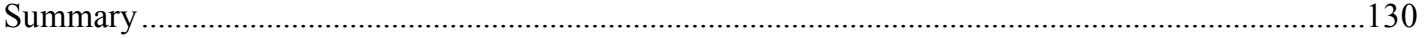

7. SETBACK ORDINANCES: ARE THEY EFFECTIVE IN CONTROLLING DENSITY

IN KARST AREAS? A CASE STUDY FROM KENTUCKY AND MISSOURI 132

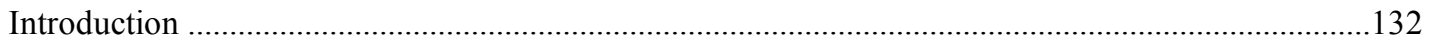

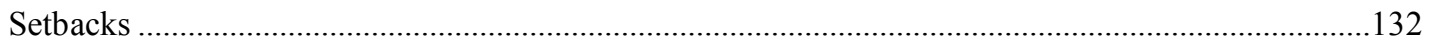

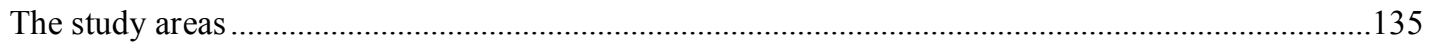

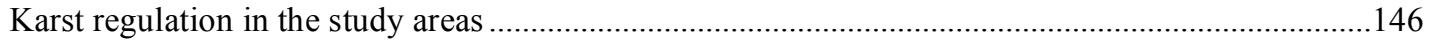

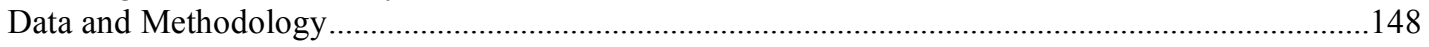

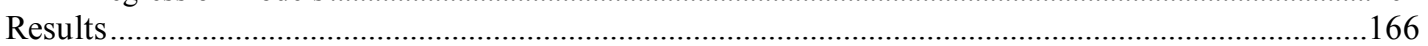

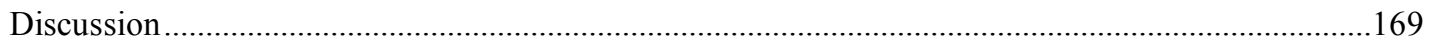

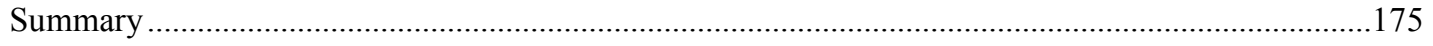

8. STRATEGIC BEHAVIOR IN THE DEVELOPMENT OF KARST REGULATIONS: DOES IT PAY OFF? A CASE STUDY FROM PENNSYLVANIA 176

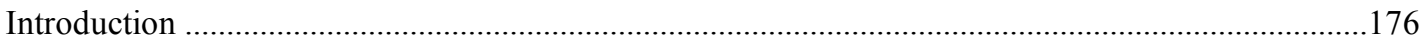

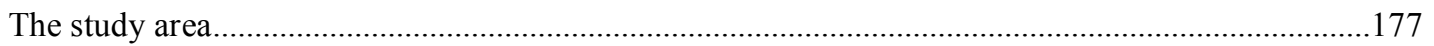

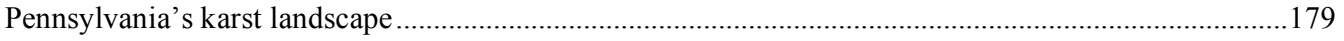

Land use regulation in Pennsylvania, and how karst relates ........................................................184

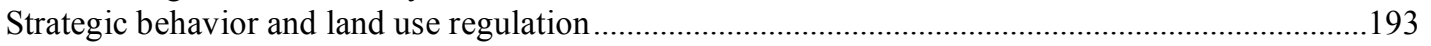

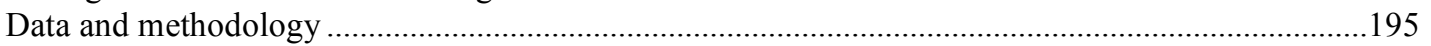

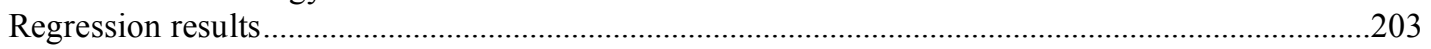

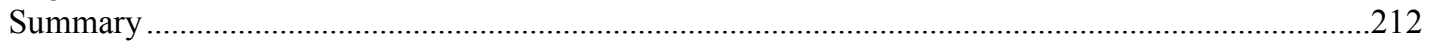

9. THE DEVELOPMENT OF A PROTECTED AREA APPROACH TO KARST

PROTECTION AND MANAGEMENT: A CASE STUDY FROM APUSENI NATURAL

PARK, ROMANIA

Introduction 


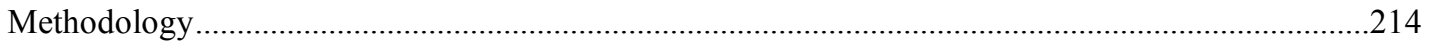

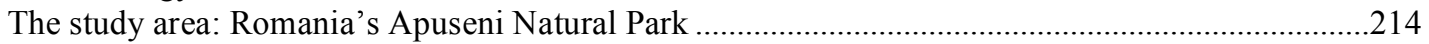

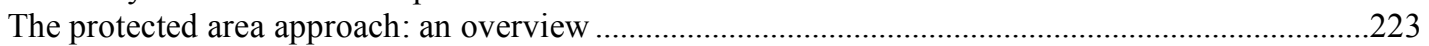

Viewpoints on the effectiveness of the protected area approach..................................................................226

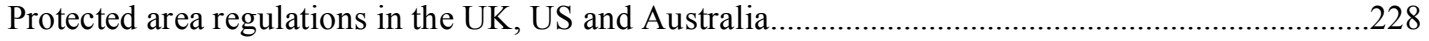

Mammoth Cave National Park, Kentucky, USA …………………………………………………….....22

Mole Creek Karst National Park and Conservation Area, Tasmania, Australia .............................................2232

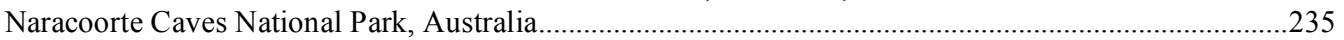

Yorkshire Dales National Park .......................................................................................................226

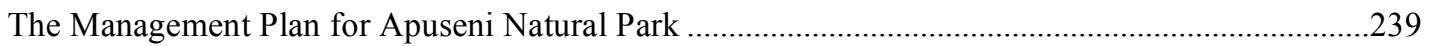

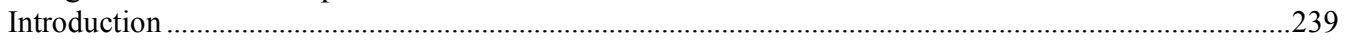

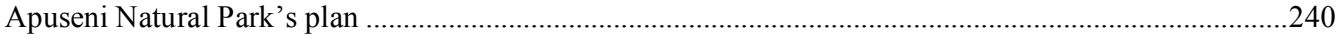

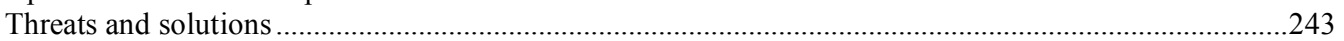

Growing tourism and protecting the natural environment: are they mutually exclusive goals? ..............249

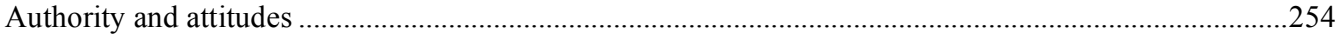

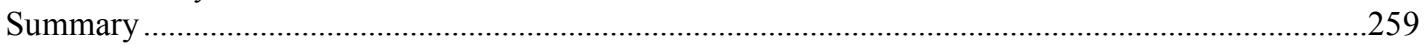

\section{CONCLUSION: MOVING TOWARD A FRAMEWORK FOR KARST LAND USE} REGULATIONS

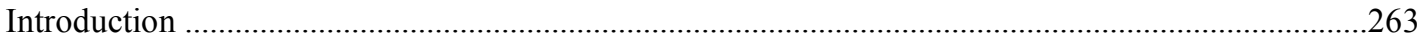

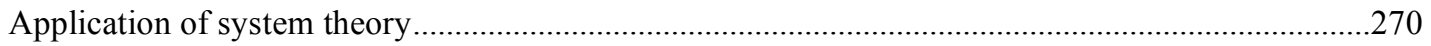

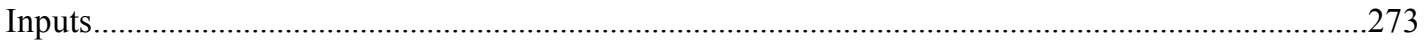

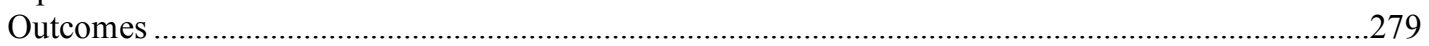

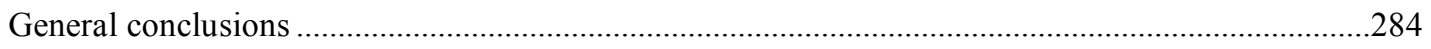

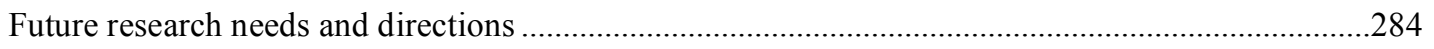

$\begin{array}{ll}\text { REFERENCES } & 286\end{array}$

$\begin{array}{lr}\text { APPENDICES } & 298\end{array}$

APPENDIX A: SURVEY OF LAND USE PROFESSIONALS IN KARSTIC AREAS IN THE UNITED STATES 


\section{LIST OF TABLES}

Table 5-1 Examples of municipalities employing setback-based karst land use regulations.

Table 5-2 New Jersey municipalities relying exclusively on the structural stormwater requirements of the NJ model karst ordinance.

Table 5-3 Most commonly-used regulatory techniques in each region.....

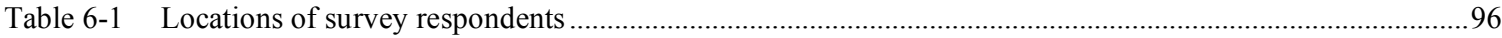

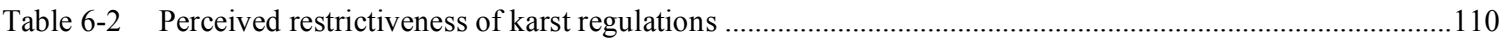

Table 6-3 Relationship between regulatory goals and perceived regulatory effectiveness.

Table 6-4 Relationship between perceived regulatory effectiveness and perception of potential improvement in local regulations

Table 6-5 Relationship between the extent of local karst systems and the regulatory techniques used.

Table 6-6 Relationship between the extent of the local karst system and the perceived restrictiveness of local karst regulations .

Table 6-7 Relationship between the nature of local regulations and their perceived restrictiveness 118

Table 6-8 Relationship between the nature of local regulations and their perceived effectiveness ......

Table 6-9 Relationship between initiators of local karst regulations and perceived restrictiveness.

Table 6-10 Relationship between regulatory techniques used and identity of regulatory initiators

Table 6-11 Relationship between levels of influence of non-elected professionals and the perceived restrictiveness of the resulting regulations

Table 6-12 Relationship between regulatory techniques employed and the level of influence over the regulatory process displayed by non-elected professionals

Table 6-13 Differences in expected outcomes of karst regulation between towns that do regulate and towns that do not

Table 6-14 Differences between expected outcomes and observed outcomes of regulating karst (municipalities that regulate only)

Table 7-1 Summary of data used for regressions. 163

Table 7-2 Sinkhole counts for each city in the study area 163

Table 7-3 Ordinary Least Squares regression results. 167 


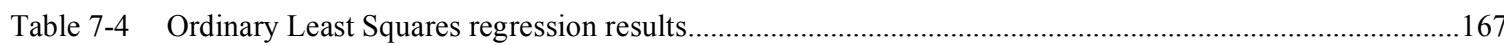

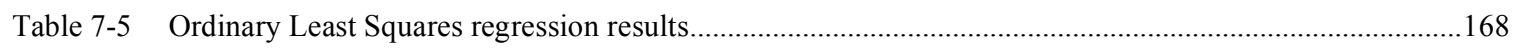

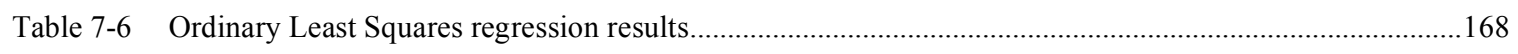

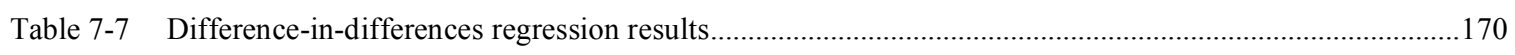

Table 8-1 Municipalities in Lehigh and Northampton Counties underlain by karst ...........................................178

Table 8-2 Year 2000 demographic data for the six Pennsylvania counties in the study area ..................................181

Table 8-3 Municipalities included in the sample where land use in karst terrains faces additional

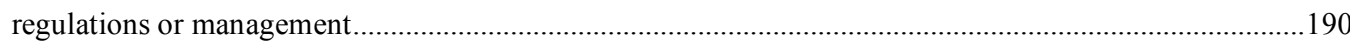

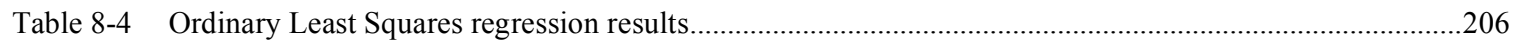

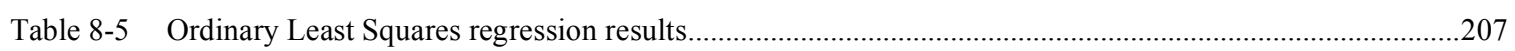

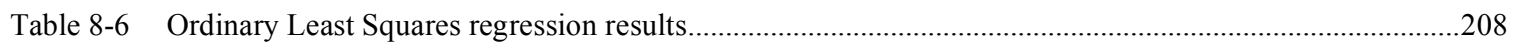

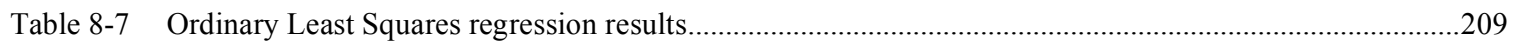

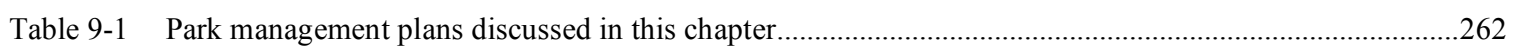




\section{LIST OF FIGURES}

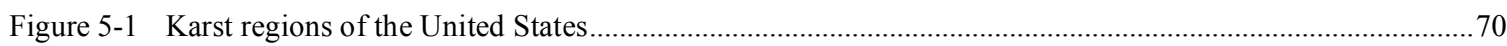

Figure 7-1 The study area (Lexington-Fayette County, KY; Louisville, KY; Springfield, MO; St. Louis, MO) .......134

Figure 7-2 Potential for karst landform development in Lexington-Fayette County, KY and vicinity ......................136

Figure 7-3 Potential for karst landform development in Louisville, KY and vicinity ..............................................137

Figure 7-4 Bedrock composition in Springfield and Greene County, MO ..............................................................138

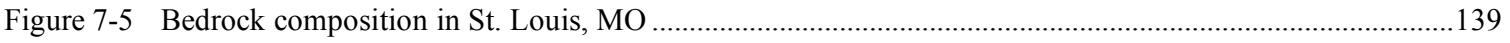

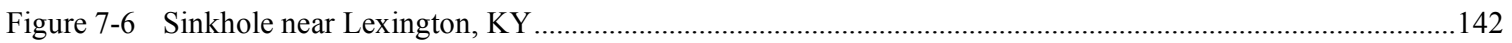

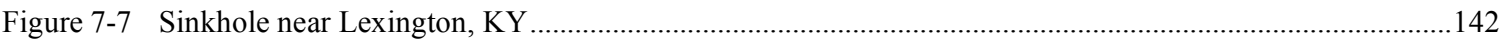

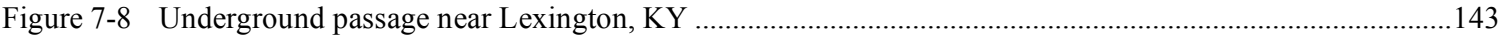

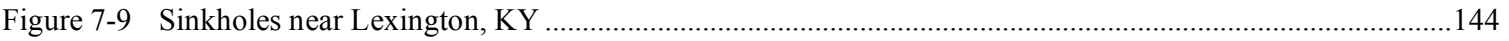

Figure 7-10 Census block-level housing density in Lexington-Fayette County, KY, in 2000 ....................................151

Figure 7-11 Sinkhole locations in Lexington-Fayette County, KY ........................................................................152

Figure 7-12 Census block-level sinkhole density in Lexington-Fayette County, KY ................................................153

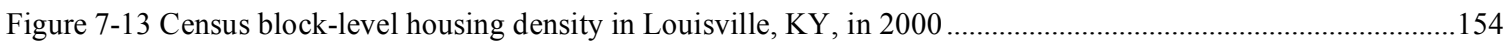

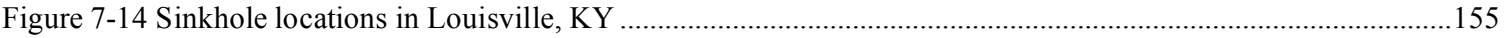

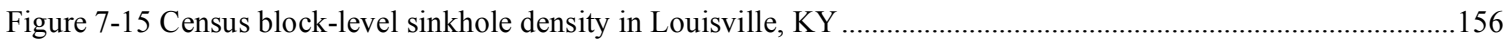

Figure 7-16 Census block-level housing density in Springfield, MO in 2000............................................................157

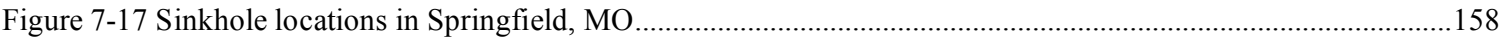

Figure 7-18 Census block-level sinkhole density in Springfield, MO .....................................................................159

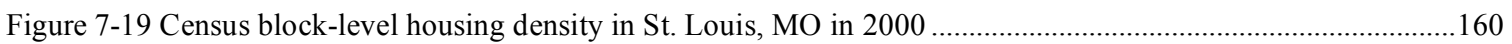

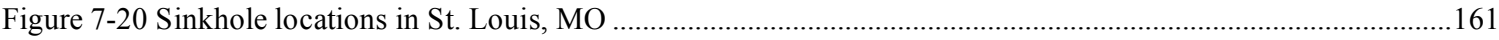

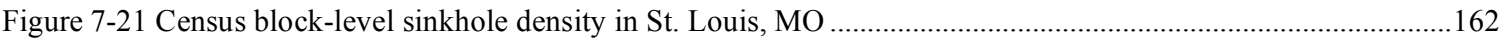

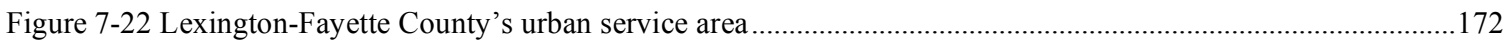

Figure 8-1 Mapped karst points in the six counties of the study area ......................................................................180

Figure 8-2 Distribution of karst and regulation practices in selected Pennsylvania municipalities...........................188

Figure 8-3 Changes in median home value for municipalities in sample, 1990-2000 …........................................204

Figure 8-4 Total residential permits issued for municipalities in sample, 1990-2000 .............................................205

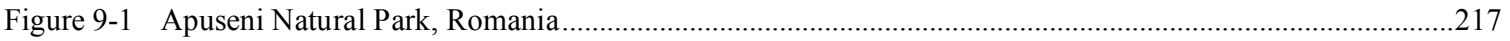


Figure 9-2 Land use management zones in Apuseni Natural Park .....................................................................218

Figure 9-3 Agriculture in a doline near Scarisoara, Apuseni Natural Park ...........................................................220

Figure 9-4 Agriculture in a doline at Scarisoara, Apuseni Natural Park...............................................................221

Figure 9-5 Newer structures near Scarisoara, Apuseni Natural Park ...................................................................221

Figure 9-6 Farmhouse and road near Scarisoara, Apuseni Natural Park ............................................................222

Figure 9-7 Padis karst plateau, Apuseni Natural Park .........................................................................................241

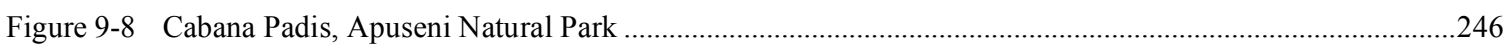

Figure 9-9 Illegal construction near Cabana Padis, Apuseni Natural Park ...........................................................246

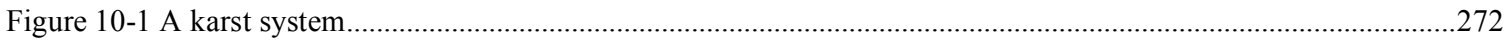

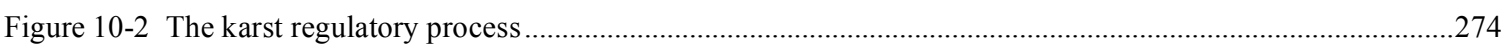




\title{
Land Use Policy and Practice in Karst Terrains
}

\author{
E. Spencer Fleury
}

\begin{abstract}
Karst topography is the result of a specific combination of geological conditions, precipitation, biota, and temperature, and is characterized by the gradual solution of the underlying bedrock and the development of underground drainage routes for surficial runoff. Many of these karst landscapes are found in urbanized areas, where the potential for anthropogenic impact is quite high. In many instances, municipalities on karst terrains choose to mitigate these impacts by implementing ordinances that place restrictions on permissible land uses near karst landforms. This dissertation asks the question: are the impacts of karst-related land use regulation on human / social systems significant enough to merit consideration during the regulation writing and implementation process? In the process of answering this question, it is hoped that a broader understanding will be developed of how land use regulations are used to control and regulate human activity on karst lands, particularly (but not exclusively) in the United States; and that the conclusions drawn from that overview might serve as the beginnings of a generally applicable framework for the development of karst regulation.
\end{abstract}




\section{Introduction}

Karst landscapes are widespread throughout the world. Specific estimates of the worldwide extent of karst vary: Williams (1993) places the figure at $25 \%$ of the earth's surface, with $40 \%$ of all humans drawing drinking water from karst aquifers; White, et al (1995) put the worldwide figure at $20 \%$ of the earth's dry land surface, including fully $40 \%$ of the United States east of the city of Tulsa, Oklahoma. Regardless of the actual percentage, it is clear that hundreds of millions of people live on karst landscapes. Despite this, karst and karst-related issues are frequently ignored or overlooked by the general public, including those who live in heavily karstified areas.

Karst topography is the result of a specific combination of geological conditions, precipitation, biota and temperature. Karst landscapes are characterized by the gradual solution of the underlying bedrock and the development of underground drainage routes for surficial runoff. These processes often produce landforms that are familiar even to people who have never heard the word "karst," including sinkholes, springs and caves.

Many of these karst landscapes are found in urbanized areas, where the potential for anthropogenic impact is quite high. Uncontrolled interaction between human populations and karst landscapes can result in serious environmental problems. Karst aquifers are common sources of drinking water, not only for people who live on the karst lands themselves, but also for people who live nearby and lack convenient access to other water sources. Water from karst aquifers is frequently used for industrial and agricultural 
purposes, and is thus an important input into many local or regional economies. But because of the specific physical characteristics of karst, these aquifers are particularly susceptible to contamination or other anthropogenic impact; such degradation can have severe effects on drinking water supplies and can even render water useless for industrial and agricultural purposes.

Other karst-related issues are not directly tied to groundwater quality issues, but are important nonetheless. Overpumping groundwater from a karst aquifer can lead to land subsidence; these subsidence events can then threaten public and private property, roads, sewers and other infrastructure, and occasionally even human life. And karst landforms - caves in particular — often offer a wealth of information for a variety of scientific disciplines (geology, geomorphology, biology, climatology, etc). Damage to karst landforms often negatively impacts the ability of scientists to conduct new research in these and other fields.

Ultimately, the issue reduces to this: karst landscapes are simultaneously valuable and fragile, and humans have a long history of inadvertently damaging or destroying karst systems through inappropriate use or inadvertent impact (Back, 1983). Karst landscapes can be considered systems in and of themselves, with a specific set of conditions required to maintain equilibrium; regardless of whether this equilibrium means stasis or change at a given rate, the necessary conditions include environmental factors such as temperature, water availability and the presence of carbon dioxide in the overburden. Similarly, human societies can also be viewed as systems, with another set of conditions required for equilibrium. Without intervention via the regulatory process, it may be difficult if not impossible for both systems to maintain their respective equilibria. 
Therefore, it may be necessary to regulate and limit certain types of human activities in some karst terrains.

As in the rest of the world, karst is often found within densely populated urban or suburban areas in the United States; in these locations, one can always find examples of land use or other human activity that pose a potential danger to karst systems. Many jurisdictions therefore find it worthwhile to impose some limitations on how land may be used in the vicinity of karst landforms. Sometimes these restrictions are serious; more frequently, they are not especially significant and as a result are much less likely to impact land use patterns in any noticeable or meaningful way. This divergence can be attributed factors including differences in the availability of data or specialized technical knowledge, differences in local political climates and priorities, and differences in the extent of the karst systems in question. Other factors may be the absence of a generally accepted approach to developing karst-related land use regulation, or the lack of a comprehensive understanding of how karst land use regulation works. Local governments and other regulating entities are usually left to their own devices to create an appropriate scheme for regulating land use and land development in karst terrains. This situation can lead to duplicated effort across jurisdictions, as well as regulatory schemes that are inappropriate for the karst system in question.

As with any form of land use regulation, attempts to implement development restrictions based on the proximity of karst can face serious resistance. One of the most likely sources of such resistance is the community of land speculators and developers who fear their projects will be directly affected by the regulation. Here, questions of land economics can and do drive policy, often via political pressure exerted by groups that 
fear losing potential profits as the result of new regulation. Ultimately, any regulatory scheme to be implemented must be a) appropriate to the karst system, and b) of minimal (or as minimal as possible) impact to the social systems that operate above the karst; this is more true of urbanized karst areas than it is of protected areas like national parks, which generally have low population densities.

\section{The purpose of this dissertation}

There does exist a body of literature relating to regulating land use in karst terrains (e.g., Dougherty, 1989; Rubin, 1992; Dougherty, 1993; LaMoreaux, et al, 1997; Urich, 2002; Richardson, 2003); the literature regarding karst protection policy within protected areas is particularly robust. However, there is no single, comprehensive overview of karst land use regulation techniques from which to draw insight regarding how land use regulations govern the interaction between human systems and karst systems. Because of the extent, importance and fragility of karst landscapes, such an overview would be quite valuable in efforts to protect karst resources like aquifers, springs and caves from the effects of unchecked human encroachment. The goals of this

dissertation are therefore twofold: first, to develop a broad understanding of how land use regulations are used to control and regulate human activity on karst lands, particularly (but not exclusively) in the United States; and second, to draw conclusions from that overview that can serve as the beginnings of a generally applicable framework for the development of karst regulation.

It is ultimately the relationship between karst systems and their accompanying land use regulations on the one hand, and human / social systems (like cities and economies) on the other, that is under examination here. Some theoretical frameworks- 
particularly those used in economics - would suggest that karst-related land use regulations are likely to have an impact on certain aspects of these human / social systems, like housing densities or overall economic health. But does that happen? Can examples of this impact be identified and quantified? Are these impacts significant to the point that land use planners and policymakers should consider them during the regulation writing and implementation process?

To answer this overarching question, I will address in this dissertation five related, more focused research questions, each of which examines a distinct aspect of my overall research question and has gone largely unaddressed in the existing literature. These are:

- How do local karst land use regulations differ across the US from state to state or region to region?

- What can the attitudes, opinions and experiences of planners explain about local karst land use regulation?

- Do setback ordinances have a perceptible effect on housing density?

- Is it worthwhile for planners to engage in "strategic behavior" in the regulation development process?

- How can social and economic factors affect the development of protected area management plans?

In answering these five questions, my contribution to the field of karst geography will be not only to provide the illumination of the answers to these specific questions, but also to begin generating a big-picture understanding of how myriad factors in the karst- 
aware land use regulation process impact the human / social systems that choose to implement them.

\section{The study areas}

The specific study areas examined in this dissertation change with each research question. In question one, I examine karst-related components of land use regulations throughout the United States. Question two is somewhat more limited, as I surveyed land use planners from six states (Florida, Kentucky, Missouri, New Jersey, Pennsylvania and Tennessee). In question three, I examine setback regulations using sinkhole-prone areas in four American cities: Lexington-Fayette County, Kentucky; Louisville, Kentucky; Springfield, Missouri and St. Louis, Missouri. For question four-on strategic behavior in the regulatory process-I look for answers in the cities, towns and boroughs of the karstic regions of southeastern Pennsylvania. Finally, Romania's Apuseni Natural Park serves as the primary study area for question five, with parks in Australia, the United Kingdom, and the United States also included as controls. Specific justifications for these choices can be found in the respective chapters, as those justifications are best understood in context of the specifics of the research questions themselves; however, the issue of data availability played a major role in the selection of each study area.

\section{The structure of this dissertation}

The dissertation begins with the literature review, which is broken into three chapters: first, a survey of the relevant karst literature, with an emphasis on developing an understanding of what karst is, how karst systems develop and work, and the specific nature of the anthropogenic threats they face; next, a review of the policy analysis 
literature, with special attention paid to analytical techniques used in the dissertation; and finally, a discussion of this dissertation's place within the discipline of geography.

Chapter Five consists of an overview of regulatory techniques used in karst terrains throughout the United States, followed by the results of an online survey of land use professionals and policymakers working in karst areas in six states (Chapter Six). In Chapters Seven and Eight, I explore the localized impacts on human systems that can occur as the result of the implementation of karst land use regulation. Chapter Nine develops the theme of protected area management and how it applies to karst lands, both within the United States and abroad. Finally, in Chapter Ten, I apply the conclusions reached in the preceding chapters to the task of developing a framework for karst land use regulation.

Some of the methods used to conduct this research include: archival / textual analysis; linear and multiple regression; and online surveys. A wide array of geographic and socioeconomic data were used, including sinkhole maps, population density data, population change rates and home values, among others. Despite the fact that all the research questions examined in this dissertation are related, they all have different data and analysis requirements. For this reason, all methodological descriptions are contained within the appropriate research chapter. These methodological descriptions are more useful when presented within the context of the specific research questions they are designed to answer. 


\section{Karst processes, landforms and issues}

\section{Introduction}

Before any discussion can take place on land use regulation in karst terrains, a more thorough understanding of the unique characteristics of karst landscapes is necessary. This chapter will describe the basic processes by which karst landscapes evolve, the landforms that are created during these processes, and the environmental issues that must be considered whenever humans occupy karst lands.

\section{Karst processes}

Karst is a landscape type characterized by the presence of carbonate bedrock that has been subjected to slow dissolution processes caused by a particular combination of temperature, chemistry and soil acidity. Karst processes typically result in the development of any number of visible surface and subsurface features, including landforms like sinkholes, caves, and springs. Generally speaking, the dominant geomorphologic process in karst lands is solution, leaving mechanical erosion processes with a less significant role than is common elsewhere (White, 1988; White et al., 1995; Palmer, 2007; Ford and Williams, 2007).

A critical component of karst feature development is the acidity of the solution coming into contact with the bedrock. Karst forms primarily (but not exclusively) in limestone bedrock, which usually consists mainly of calcite (other carbonate minerals may also be present). The acidity comes from carbon dioxide left by decaying biological 
material in the overburden; surface water seeps through the overburden, picking up the carbon dioxide and becoming slightly acidic. When this acidic water comes into contact with the carbonate bedrock, it seeks cracks and fissures in the rock, which are then gradually widened as the calcite reacts with the carbonic acid. This water is generally able to dissolve between 0.07 and $0.17 \mathrm{~cm}^{3}$ of calcite per liter (Palmer, 2007). This reaction can take as long as several minutes to begin, depending on specific site conditions like temperature and acidity (Dreybrodt, 2004). However, when this reaction first occurs, most of the water's dissolution potential is spent over the space of just a few meters (Dreybrodt, 1988). Once dissolution of the bedrock begins, a network of grooves, pillars and clefts forms on the bedrock's surface and permits faster descent of surface water into the subsurface, where it expends the remainder of its dissolution potential in the bedrock's joints and fractures. Dissolution conduits then form along these fractures, which grow larger as slightly acidic water continues to drain into them (White, et al, 1995). This is a long-term occurrence; the dissolution process generally must work for thousands of years to produce an opening in the bedrock extending for 100 meters or more (Ford and Williams, 2007). These gaps in the bedrock can then serve as a collector for insoluble surface material washing through the drain, leading to the formation of a sinkhole (White, 1988).

\section{Common karst landforms}

Karst landscapes are characterized by a number of distinct landforms. In areas where geologic and climatic conditions are ideal for karst development, the actual physical form taken by karst features is highly dependent on specific local conditions. While some karst landforms (for example, canyons, gorges and cliffs) can be quite 
spectacular and imposing, the landforms at the center of this dissertation generally have a lower profile — both physically and in the minds of most people - than landforms like mountains, flood plains and rivers. These karst landforms also generally lack the viewshed provided by other, better-known landforms, which may be a factor in the regulatory process: i.e., a lack of widespread public awareness of karst landforms may translate into a lack of political will to regulate nearby development and land use.

In order to discuss land use regulations that are tied to the presence of particular landforms, some knowledge of these landforms is required. In particular, understanding the characteristics of karst landforms is a prerequisite to understanding the issues involved in human-karst interaction. Additionally, developing this kind of understanding can help clarify why karst-aware land use regulation takes the form that it does in a given location, and why it takes another form somewhere else. The following section provides descriptions of several types of karst landforms, focusing on those most relevant to the dissertation: sinkholes, caves and springs. A summary of some other karst landform types is also included.

\section{Sinkholes (dolines)}

Sinkholes are an extremely common type of karst landform, created by the subsidence of soils and rock at or near the land surface into subsurface voids. Wherever sinkholes are found, the underlying karst system can be assumed to be fully developed; however, the absence of sinkholes does not imply a lack of developed karst beneath the surface (Ford and Williams, 2007). They are often located in areas where soluble rock is near the surface, either completely exposed or beneath a layer of topsoil. The resulting depressions tend to have the shapes of bowls or funnels. There is no "standard" sinkhole 
size: diameters can range from one to 1000 meters, and depths of several hundred meters have been reported; however, depths of less than a meter are far more common (White, 1988; Upchurch and Randazzo, 1997; Berndt, Oaksford, and Mahon, 1998; Ford and Williams, 2007, Palmer, 2007).

The formation of a closed sinkhole requires three components: a drain, through which internal runoff is carried away from the land surface and through the bedrock below; a zone of bedrock modified by solution (carried downward by the drain) located at or near the surface; and a cover of soil or some other material making up the land surface, though in some areas this cover may be absent (when that cover is absent, open sinkholes can still form). Where these three components are present, sinkholes can form through any of three distinct processes: a gradual dissolution of the carbonate bedrock, usually occurring very near the bedrock surface but sometimes extending lower; the transport of insolubles into voids in the subsurface via piping, in-washing and gravitational collapse; and bedrock transporting into underground passages or cavities when the roof above such a void collapses (White, 1988). Sinkhole development can then be triggered by "any mechanism that increases the head differential between the artesian water in the limestone and the perched water in the surface sands," because the downward flow and downwashing of sediment are both increased as well (Beck, 1986, p. 12).

Different resources will often provide conflicting numbers and descriptions of sinkhole types. These definitions are generally based on the specific processes by which a sinkhole was formed; however, Ford and Williams (2007) point out that in fact most sinkholes have a polygenetic origin. Nevertheless, for simplicity's sake, it is common to define sinkhole types by the genetic process that predominated during the formation 
stage. In a widely-cited paper, Waltham and Fookes (2003) identified and described six sinkhole types: dissolution sinkholes, collapse sinkholes, caprock sinkholes, dropout sinkholes, suffosion sinkholes, and buried sinkholes. Dissolution sinkholes evolve over geologic timescales and occur where bedrock is exposed at the surface; the formation process begins with depressions in the exposed bedrock. The dissolution process is continuous, occurring as water moves down the sides of the depression and into the bedrock, through the sink's drain. Dissolution sinks are usually circular, but they can elongate instead if they are located along major fractures. These sinks can (and often do) continue to expand until the edge reaches the edge of another sink. In some cases the sink's drain may become plugged by debris that has washed into it. When that happens, water flowing into the sink cannot escape into the subsurface, and ponds or wetlands can form (White, 1988; USGS, 1999; Waltham and Fookes, 2003; Ford and Williams, 2007).

Collapse sinks form via collapse within the bedrock above a pre-existing cave passage or solution cavity. Collapse sinkholes are not common, and are generally smallscale events. There are some exceptions: Xiaozhai tinakeng, in southwestern China, is a collapse sinkhole that is over 500 meters deep and 600 meters across. Other impressive examples of large-scale collapse sinkholes can be found in Papua New Guinea and Croatia (Ford and Williams, 2007). When they do develop, collapse sinks can form very quickly — sometimes in a matter of hours — and usually occur where the surface sediments contain a high percentage of clay. These clayey sediments spall into the void below, eventually weakening the cavity's roof beams. Once the beams have weakened enough, the cavity's bedrock roof collapses into it. The presence of vertical solution passages along joints or fractures can work to facilitate this process, as can pressure from 
structures on the land surface itself (White, 1988; White et al., 1995; USGS, 1999; Waltham and Fookes, 2003). Caprock sinkholes are similar to collapse sinks, except for the presence of insoluble caprock above the limestone cavity. These sinkholes are generally limited to paleokarst terrains (Waltham and Fookes, 2003).

Ford and Williams (2007) distinguish collapse sinkholes from subsidence sinkholes on the basis that the latter rarely include dramatic breaks in the overburden. Dropout sinkholes are a type of subsidence sinkhole that form when surface water washes sediments downwards through fissures or pipes in the underlying karst beneath a cohesive soil cover. Once enough sediment has been piped away, the ground surface can collapse into the void very quickly. These sinkholes do not involve any collapse in the actual bedrock, as is seen in the formation of collapse sinks (Waltham and Fookes, 2003; Williams, 2003). They can form as a result of groundwater overpumping or natural processes like flooding (Ford and Williams, 2007). Suffosion sinkholes (also known as cover-subsidence sinkholes) are similar to dissolution sinks in that they develop gradually over long periods of time, but are formed via processes similar to those that cause dropout sinkholes. The primary difference is that suffosion sinkholes are formed in areas of permeable, sandy sediment, which is prone to pipe into cavities instead of transforming the remaining covering sediment into a structural arch. As a result, the land surface subsides gradually as the sand pipes into the void below (White, et al, 1995; USGS, 1999; Waltham and Fookes, 2003; Williams, 2003).

Buried sinkholes are remnants of ancient sinkholes that have since re-filled with sediment. In some cases surface subsidence may be evident as the sediment fill gradually compacts or is washed out through the drain. However, in many cases there are no 
surface indications that these sinkholes are present (Waltham and Fookes, 2003; Williams, 2003).

With some exceptions, sinkholes are generally not large or spectacular landforms; however, sinkholes are important to understand in the context of karst systems because they act as recharge routes for the aquifer below. The fact that surface water receives no natural filtering when entering a karst aquifer via a sinkhole means that contaminants on the surface are easily carried into the groundwater (White, 1988; White et al., 1995;

USGS, 1999). This issue is explored in greater detail later; for now, suffice it to say that it offers a compelling argument for more stringent management of land uses in the vicinity of sinkholes.

\section{Caves and caverns}

The exact definition of a cave is a topic of some debate among geographers, geomorphologists and geologists. However, White (1988), Gillieson (1996) and Palmer (2007) define them as a natural opening in the earth that is large enough to be entered by a human. Some underground caves_-like, for example, Carlsbad Caverns in Carlsbad, New Mexico — formed via a solution process involving sulphuric acid. The cave formation process occurs at, above and below the water table, frequently simultaneously, and it begins with a series of conduits and other small openings in the bedrock. These openings are quite narrow in the earliest stages of cave development, which means that water moves through them very slowly and becomes saturated very quickly; for that reason, the cave formation process generally begins very slowly (Palmer, 2005). Gradually, some of these conduits expand, drain, and are then filled with air, forming an opening that could be large enough to be classified as a cave. This often occurs in the 
narrow zone where the water table fluctuates, as groundwater seeks out the shortest path to its ultimate destination (a spring) and expands fractures via turbulent flow or abrasive sediment transport (White, 1988; Palmer, 2007). Note that this process does not guarantee that any surface opening will be created —in fact, it's statistically and logically likely that there is a large class of caves that have no entrances at all (under the definition provided at the beginning of this section, however, these would not be caves at all because of the inability of humans to enter them). When they do appear, cave entrances do not have to be related to the solution processes that formed the cave in the first place. Sinkhole collapse, connection to well-developed vertical shafts in the bedrock, human excavation, and the random generation of upward-sloping cave passages are common ways in which a cave entrance can form; however, thick soil covers can prevent entrances of these types from forming (White, 1988; Palmer, 2007).

The formation process is followed by the "decoration stage" of cave development. These decorations take the form of speleothems - also known as dripstone and flowstone — which form along cave walls, ceilings and floors. Stalactites form from water draining into the cavern and dripping down from the roof, leaving behind calcite deposits; stalagmites are formed the same way, but grow upwards from the floor instead. These deposits occur when carbon dioxide contained in water diffuses into the cave atmosphere - the calcite is then left behind. In some cases, stalactites and stalagmites can connect to form a pillar (Bloom, 1998; McKnight and Hess, 2002; Palmer, 2007).

There is a wide variation in the size and length of caves. However, the fact that a cavern narrows to the point where humans can no longer explore it should not suggest that the karst drainage system ends there as well. Water draining through caves will 
continue through these passage terminations, sometimes to a spring outlet (Ritter, Kochel and Miller, 1995; Palmer, 2007).

Cave protection is important because of the twin scientific roles played by caves: they are records of the paleoclimate, and they are ecosystems unto themselves. Speleothems within caves often contain enough uranium to calculate their ages, and the oxygen isotopes they contain enable them to be used as geothermometers. This climate information is also highly localized, and can be dated from speleothems with a good deal of precision and accuracy (Palmer, 2007). Ecosystems not found elsewhere are able to develop in caves because of their extremely stable, long-term environmental and climatic conditions; cave degradation can occur as the result of contact with point source or dispersed pollution sources, and often means damage to or destruction of these fragile ecosystems (White et al., 1995; Gillieson, 1996). Indeed, even changes to the environment or landscape outside a cave can have severe consequences within the cave; for example, pavement for roads or parking lots above a cave will in almost all cases reduce the total amount of water passing through the karst drainage system or redirect it through new drainage routes, and the installation of nearby toilet facilities for tourists can result in bacterial contamination of the waters that sustain the cave's ecosystem.

However, careful planning and modern cave management techniques can help mitigate the damage caused to caves by activities like these (Gillieson, 1996).

\section{Springs}

Springs are formed at the spots where karst waters emerge from the local underground drainage system. They can be found on the surface or in caves, and are often used as sources of drinking water and as recreation areas. Ford and Williams (2007) list 
three types of springs: free draining springs, which are fed by gravity, as the karst rocks are at a higher elevation than and slope down towards the spring itself; dammed springs, which are formed by some impediment to drainage; and confined springs, which are artesian springs formed along fault planes or at breach points of otherwise impervious caprock. Spring formation is a direct result of carbonate rock dissolution, creating large conduits and caves that can then channel groundwater up to the land surface. Processes of spring formation are similar to the processes causing sinkholes, and in Florida, many of the state's 320 springs — including major springs like Silver Springs and Homosassa Springs - are actually sinkholes that became springs as sea level rose, thus forcing the zone of coastal aquifer discharge further inland and the water table higher. Classification of springs can be done according to the outflow, according to geologic and tectonic conditions, or according to origin of the water itself. Springs can serve as hydrological trend indicators, and are very stable in terms of water quality, temperature and flow, though even short-term variation in rainfall can be reflected by a spring's flow (Bögli, 1980; White, 1988; Upchurch and Randazzo, 1997; Field, 2002). However, in his study of Florida's karst, Florea (2006) found that individual rain events are not generally reflected in spring levels of peninsular Florida; instead, recharge to the karstic Floridan aquifer is generally driven by large-scale and widespread precipitation events like hurricanes. Large withdrawals of groundwater nearby can have serious impact on spring flow, including stopping it completely (Berndt, Oaksford, and Mahon, 1998).

\section{Other karst landform types}

Karst landforms go beyond sinkholes, springs and caves. This section offers a brief description of several other karst landforms. Many of these landforms could be 
described in much greater detail than they are here, but since they do not play a major role in this dissertation, these descriptions have been kept brief.

\section{Poljes}

Poljes - the largest karst hollows — are wide, closed depressions with flat floors, which are often adjacent to steep enclosing walls. Extremely thick and geographically extensive carbonate bedrock is required for polje formation, due to their size: the Likapolje in Croatia, for example, measures 700 square kilometers in area (Bögli, 1980). Dinaric polje landscapes (characterized by widespread karst depressions of all types; Kranjc, 2006) are scattered throughout the world, but the vast majority are found in the area once occupied by Yugoslavia. Poljes have their own internal drainage systems and will generally feature complex hydrogeological characteristics, including swallow holes and disappearing streams. However, Ford and Williams (2007) caution that they should be viewed as subsystems of the overarching karst drainage system, rather than independent systems of their own, due primarily to their hydrologically interconnected nature. They are frequently used for farmland, and tend to flood at least once a season, sometimes more frequently. These floods can be severe, to the point where the entire polje floor becomes a lake. Flooding can sometimes be controlled and used for purposes of irrigation or hydroelectric power (Bögli, 1980; White, 1988; Bloom, 1998; Field, 2002; Ford and Williams, 2007).

The originating processes behind poljes have been the subject of debate for quite some time. It has been suggested that poljes may have a tectonic origin, as they often occur along faults; there is some evidence to suggest a mixed karstic-tectonic origin. Some geomorphologists consider poljes to be the conclusion of a genetic sequence of 
karst landform development (that sequence being: doline $\rightarrow$ uvala $\rightarrow$ polje, as first proposed by Cvijic, 1893). Bögli (1980) writes that this theory had been completely discarded by that point; he argues instead that there is no common factor in polje development. Again, there is disagreement on this point (White, 1988; Bloom, 1998); Ford and Williams (2007) point to proximity to the local water table as the common factor in the development of all poljes. They also argue that most poljes show evidence of both tectonic and karst dissolution processes in their formation, with the relative importance of each varying on a case-by-case basis.

\section{Karst valleys}

Karst valleys form when a developing underground drainage system diverts water away from the rivers feeding into the valley. A karst valley has all the properties of a stream valley except the stream itself. Karst valleys are more common in areas of flat, interbedded limestone, sandstone and shale (White, 1988; Bloom, 1998; Field, 2002).

\section{Swallow holes}

Also known as ponors, swallow holes are the point at which a sinking stream heads underground. Swallow holes are surface drainage features that direct runoff into an underground channel — in other words, they are sinkholes that form in a stream bed, often with a large vertical shaft beneath. In poljes, the original ponors are often dry, but still act as a conduit to the karst aquifer (Bögli, 1980; Bloom, 1998; McKnight and Hess, 2002; Ford and Williams, 2007). 


\section{Pinnacles}

Pinnacles are isolated limestone blocks that stand several meters above the surrounding land surface. They are the result of long-term weathering and of solution processes along joints and fractures. Their side walls are generally grikes. They are not all that common, but can be found along cliffs in more temperate areas, and as taller, standalone features in tropical climates (Bögli, 1980; White, 1988; Field, 2002).

\section{Residual hills (mojotes)}

These can sometimes be found where thick layers of limestone are exposed on hillsides. Runoff may carve drainage pathways out of the side of one of these hills, as it is a more efficient method of transporting the water to the hill's base. These pathways can take the form of vertical shafts, solution chimneys or even open joints or fractures (White, 1988).

\section{Cockpit karst}

Cockpit karst landscapes are generally found in thick limestone, usually in tropical climes - the most notable cockpit landscapes are found in Jamaica and on Java. They are genetically similar to sinkholes - both landforms share a solution-driven genetic process - but are morphologically separate from temperate-climate dolines. Cockpit landscapes can also be quite wide, with diameters of a kilometer or more, and will sometimes grow large enough to develop subsidiary channel systems (White, 1988, Day and Chenoweth, 2004; Ford and Williams, 2007). 


\section{Cone and tower karst}

Cone and tower karst is closely related to cockpit karst. These landscapes typically evolve from residual hills and have almost completely vertical sides, as well as a distinct uniformity of size: at Gunung Sewu in Java, for example, most hills are close to 50 meters high. Deep pits can often be found at the tops of these hills; in some cases, high concentrations of caves can also be found. They seem to be found primarily in tropical regions, like Cuba, Puerto Rico, South China, Vietnam, and New Guinea (White, 1988;

Field, 2002). They are usually present in areas where karst processes have been underway for a considerable amount of time (McKnight and Hess, 2002).

\section{Pavement karst}

Pavement karsts occur in alpine or other northern regions with thin or nonexistent soils. This soil deficiency is often the result of glaciation. Here too, drainage is exclusively karstic, via joints and fractures in the exposed bedrock. Soils, once stripped, do not usually return, as they are flushed downward by rainstorms before they can reestablish themselves (White, 1988; Field, 2002).

Certainly, local climatic and geographical conditions are major determinants of which types of karst landforms, if any, will develop in a given location. The next section describes the global distribution of karst landscapes, as well as the difficulties in predicting the distribution of karst landforms on a more localized scale.

\section{Karst distribution}

Limestone regions are found throughout the world, at all latitudes and in every climate. However, presence of limestone bedrock does not necessarily mean that a karst landscape has developed, or will ever develop there. Karst regions are much more likely 
to develop in temperate regions, as opposed to areas with polar climates. There are also several notable karst regions in tropical zones, including the Yucatan Peninsula area of Mexico and Central America, western Cuba, and parts of southeast Asia and Indonesia (McKnight and Hess, 2002).

The reasons karst landscapes are more likely to develop in tropical zones than polar zones are well understood. The formation of karst landscapes requires the presence of water containing dissolved carbon dioxide. Ambient temperature has a significant effect on the ability of water to dissolve carbon dioxide from the atmosphere, with colder water having a greater potential to carry carbon dioxide in solution. This would suggest that karst landscapes would be more likely to develop in polar zones than tropical zones; however, soils in warmer areas can produce more carbon dioxide than colder soils, and the overall rate of solution is greater in warmer areas. The fact that karst areas are more likely to be found in tropical than polar regions suggests that higher carbon dioxide production and higher solution rates are more important to karst landform development than is the ability of water to hold higher quantities of carbon dioxide. Areas without adequate groundwater, regardless of climate, are not likely to develop karst landforms“deserts,” Bloom writes, “are not karst prone (1998, p. 153).” However, inactive karst formations are often found in arid areas, indicating the presence of wetter climates in the past. That said, it should be kept in mind that chemical solution of carbonate rocks is a complex process, so much so that it makes climate-based prediction of karst outcroppings difficult and unreliable (Bloom, 1998; McKnight and Hess, 2002).

While global and regional distributions of karst landforms can be explained by the presence of limestone and by the values of certain temperature-related parameters, local 
distribution of karst landforms is a bit trickier to pin down. Spatial distribution can be plotted by looking at depression density, doline areas, relative spacing between dolines, and through use of other spatial techniques. However, an explanation of spatial distribution has been elusive. Local distribution has been shown to be independent of the bedrock; further, a study of the karst of northern Iowa showed that depression density (measuring the number of entry points of internal runoff water into the subsurface) increases rapidly with the age of glacial drift covering, but levels off soon thereafter (White, 1988, citing McConnell and Horn, 1972, Palmquist et al., 1976, and Kemmerly, 1982). Nevertheless, there are some guidelines for determining which sites in a given karst region are more prone to sinkhole development. First, areas with steep slopes tend to produce fewer dolines — chances of their formation are better on flat valley floors or open plains with little relief. Second, areas in which denser, less porous limestone is found are more likely to feature sinkhole development where joints in the dense limestone promote drainage at specific locations. And finally, areas with soil and vegetation cover usually promote solution processes, due to the presence of carbon dioxide in the soil (Ritter, Kochel and Miller, 1995).

Localized cave distribution is a bit easier to examine, though it is not without its difficulties. Most large groups of caves-like those found in the Potomac River Basin or in Alabama, for example - produce smooth distribution functions when grouped by length. The distribution of caves according to length can be analyzed using certain statistical processes that eventually generate a "karst constant," which describes the cave length distribution for a given area or region. One should bear in mind, however, that there are some shortcomings in cave length distribution measurement as well: the 
definition of a cave can vary from state to state, and there is likely a large class of caves with no entrances at all that are not included (White, 1988).

\section{Issues of human-karst interaction}

Rarely are human societies able to avoid having an impact on the landscape they occupy; this is even truer for societies in fragile environments, like karst terrains. In striving to achieve their own equilibria, human systems located above or near karst systems often alter the conditions necessary for equilibrium in those systems; it takes surprisingly little for human society to noticeably affect caves, groundwater, and land subsidence in karst landscapes. In turn, these impacts often define how and to what extent humans can interact with the karst landscapes they occupy. This section will address three significant issues in human-karst interaction: land subsidence, groundwater contamination, and damage to caves and karst ecosystems.

\section{Subsidence}

In karst terrains, subsidence is generally observed in the form of new sinkholes. Subsidence is a common occurrence in karst areas experiencing rapid urbanization, and has been observed in numerous karst terrains undergoing urbanization throughout the world. In the 1970s, Spain's Central Ebro Basin underwent the beginning of large-scale urbanization and industrial development. The presence of karst was generally not taken into account during either the planning or construction phases of development, and over the next several years a high number of sinkholes developed in the area. In the ensuing decades, these dolines have caused significant damage to buildings, roads, and water supply systems, as well as the loss of arable farmland (Soriano and Simon, 2002). Subsidence incidents in the Chattanooga, Tennessee area also experienced a significant 
increase in frequency during the late 1970s; this spike was coincident with increased groundwater pumping for industrial uses in the area (Wilson, 1984).

The subsidence events in the Central Ebro Valley and in the Chattanooga area were most likely a direct result of aquifer drawdown that accompanies the urbanization process in karst regions. In many karst areas, the underlying aquifer comes under severe pressure as a result of rapid urbanization, when water requirements increase at a seemingly exponential rate. The most common response is to increase the pumping of groundwater out of the aquifer, to what often turns out to be an unsustainable rate. Such overextraction of groundwater can cause the formation of voids in the aquifer as spaces that once held water are emptied. This aquifer compaction can then lead to subsidence and collapse (Patton and DeHan, 1998).

Urbanization can also cause subsidence in karst landscapes in ways unrelated to aquifer drawdown. For example, the extra weight and pressure applied to the land surface via the addition of new structures and infrastructure can cause collapse sinkholes to develop long before they may otherwise have formed. Construction and development that results in the shifting of surface water drainage patterns can also induce new sinkholes by increasing flow velocity into the bedrock via existing drains. An example of this is the February 2002 Dishman Lane collapse, in Bowling Green, Kentucky, which was caused by the concentration of stormwater runoff. The result was a sinkhole that measured 60 meters across and 7 meters deep at its deepest point (Kambesis, et al., 2003). Water and sewer pipelines in karst areas are also more susceptible to damage from compacting or piping of soils. When these pipelines do crack or break, the erosion process can be accelerated by the increased amount of solution coming from the leak, and new sinks 
may appear (USGS, 1999). A dramatic example of this took place in Allentown, Pennsylvania in 1994, beneath the Corporate Plaza Building, which was the city's newest downtown office building. The sinkhole opened up overnight and consumed portions of the office building as well as the entire paved surface of North $7^{\text {th }}$ Street immediately adjacent to the building. In this particular case, the principal cause was determined to be a natural soil sink that had been settling for at least several days prior to the event (occupants of the office building had reported evidence of subsidence during the preceding week); an overnight underground water leak accelerated the process and enlarged the sinkhole (Gillespie, 1999).

Many of these same issues are found outside urbanizing karst areas. The need for vast amounts of groundwater can lead to rapid and excessive aquifer drawdown-and thus subsidence - in agricultural areas facing water pressures as easily as in urbanizing areas. For six consecutive nights in January 1977, strawberry growers in the Dover, Florida area worked to prevent their crops from freezing by continuously applying warm water to their plants (this forms a protective sheet of ice over the plants and protects them from sub-freezing temperatures). The water used was pumped directly from the Floridan aquifer, and the sudden spike in pumping activity resulted in a total aquifer drawdown of 2.9 meters. Area residents immediately began reporting the development of new sinkholes, some of which were large enough to cause property and infrastructure damage. A total of 22 new sinkholes attributable to the freeze response were catalogued; others may have gone unreported (Hall and Metcalf, 1984). 


\section{Groundwater contamination}

The absence of an effective bedrock filtering system in karst aquifers, coupled with rapid transport times and the ability to store pollutants for long periods of time, means that karst groundwater is highly vulnerable to contamination (Field, 1992). When surface water drains rapidly through cracks and fissures in the bedrock, it is able to enter the aquifer without seeping through the bedrock itself, which is what would occur in areas underlain by bedrock with higher permeability (in soil-covered areas, the overburden can act as a rudimentary filter, but its effectiveness is limited (Field, 1992)). Seeping through the bedrock ordinarily acts as a filtration process for the surface water, and is usually effective at keeping surface-level contaminants out of the aquifer. But such protection is not available in karst terrains, leaving aquifers at the mercy and wisdom of the people who live above them. Unfortunately, wisdom doesn't always win out. Back (1983) describes how karst aquifers were inadvertently destroyed by three earlier civilizations in the Yucatan Peninsula, western Ireland, and southern China; Drew (1984) and Drew (1996) add more detail on occurrences of aquifer degradation in Ireland's County Galway and County Clare, respectively. Contributing factors to the destruction of all these aquifers were anthropogenic causes like overpumping, deforestation, land drainage, agricultural practices and atmospheric pollution. In a counterintuitive move, Betson (1977) concluded that urbanization processes do not generally have a significant effect on groundwater quality in karst terrains; only the year before, Turk (1976) had argued precisely the opposite.

In many places, sinkholes and caves are often used as garbage dumps; this happens all over the world, from Turkey (Kacaroglu, 1999) to the American Midwest (Legrand, 1984; Mitchem, et al., 1988). When this happens, contaminants are rapidly 
transported downward into the aquifer, damaging the groundwater resources (Kacaroglu, 1999; White, 1988; Day and Reeder, 1989). Once surface-level contaminants have entered a karst aquifer, they often do not decompose or become absorbed into the aquifer. One widely-held notion is that contaminants will be more rapidly flushed out of a karst aquifer, due to their faster transport times; this is not always the case (Field, 1992). White (1988) laments that "today, attempts to explain the relation between sinkhole dumps and water supplies still often fall on deaf ears" (p. 391). He recommends a series of steps to manage the problem, beginning with the cessation of dumping and followed by tracing and monitoring groundwater and filling the sink with clay-rich soil (White, 1988).

Even when sinkholes are not used for dumping, their presence can lead to aquifer contamination. As discussed earlier, sinkholes sometimes provide surface runoff with direct passage from the surface to the aquifer; any surface-level contaminants contained in the runoff can then make their way into the aquifer (this is not always the case, however; impervious layers beneath the sinkhole can prevent this from occurring). Additionally, sinkholes directly beneath holding ponds or rivers can channel surface water directly into the aquifer below, as happened in Pinellas County, Florida in 1988 (USGS, 1999) and near Allentown, Pennsylvania in 1979 (Memon and Azmeh, 2001). In the Pinellas County case, the sinkhole developed under an area containing heavy loads of effluent used for irrigation, and the Allentown sink was used as an industrial wastewater lagoon. Incidents of this type are extremely expensive to clean up, and in some cases remediation is simply not possible (Rubin, 1992; Field, 1992).

Landfill placement in karst areas where background studies are not conducted can be particularly problematic, especially in areas of active karst development. This is 
because of the potential for subsidence to occur directly beneath a landfill. But even properly sited landfills and waste storage areas in karst areas can pose potential aquifer pollution problems. Precipitation or groundwater can mix with the garbage in any landfill, and then seep through the bottom into the aquifer, carrying with it bacterial and chemical pollutants that would quickly contaminate the aquifer (Davis, 1997). Many municipalities in karst areas attempt to guard against waste-driven contamination of the aquifer by strengthening environmental requirements for landfills.

Farming and other agricultural operations are often implicated in karst aquifer contamination. The most common contamination agent is fertilizer, which typically manifests itself as high concentrations of nitrates in the groundwater. One symptom of this type of contamination is that water from wells tapping the upper bedrock may have strange smells and a cloudy appearance. In northern Iowa, high levels of nitrate contamination were occurring in areas with numerous sinkholes, suggesting that fertilizers were running off into the sinks (Mitchem et al., 1988). This type of contamination is common in rural areas—other examples include the nitrate contamination of groundwater in Florida's Woodville Karst Plain (Katz, Chellete, and Pratt, 2004) and in Romania (Gatzweiler and Hagedorn, 2003), where a decrease in chemical fertilizer use since the early 1990s has not been followed by a corresponding drop in nitrate levels in the groundwater. In fact, in some areas, water from wells exceeds maximum allowable limits of pollutant concentrations, making the water unsafe for human or animal consumption. Gatzweiller and Hagedorn (2003) noted that some of Romania's karst aquifers had been so damaged by agriculture as to render the groundwater undrinkable for humans or animals. Similar contamination has occurred in 
the karstic lands of rural Appalachia, where the presence of nitrates in local well water has been linked to the so-called "blue baby syndrome," an affliction that was particularly common in the mid-20 $0^{\text {th }}$ century (Smith, 2000).

Another significant threat to karst aquifers is the presence of mining operations. When expansion of the extractive lime rock mines in Miami-Dade County, Florida was proposed, there was concern that the move would heighten the risk of pathogen contamination in the karstic Biscayne aquifer. Studies of the area found that high transport velocities were occurring along preferential flow paths within the aquifer, resulting in a greater ease of contaminant movement than was previously supposed (Renken et al., 2005). Eastern Europe has also experienced karst aquifer damage from mining operations, usually from careless disposal of waste materials. This is a particular concern in Romania's Apuseni Mountains, where mining has been a traditional economic activity for centuries (Turnock, 2000; Forray, 2002). LaMoreaux, et al. (1997) cite the case of a Polish zinc-lead ore mine suffering contamination from paper factory fluid waste discharged over $5 \mathrm{~km}$ away in a karstic area. In many cases, pollutants in karst aquifers do not decompose or become absorbed into the aquifer.

\section{Caves and ecosystem / habitat damage}

Caves are particularly fragile karst environments that are very susceptible to contamination or damage. This is due in large part to their integrated nature - the health of the overall system depends on the maintenance of a particular balance between atmosphere, water, vegetation and soil factors. Obviously, direct human use of caves can result in alteration of the physical structure of the caves themselves, changes in the water chemistry or hydrology within the cave, or destruction of cave decorations and cave- 
dwelling organisms (Watson et al., 1997). But many of the human activities already discussed in this overview-i.e., activities that do not involve direct use of caves- have an impact on at least one of these factors in nearby cave environments (Gillieson, 1996; Watson, et al., 1997). Dripwater flows are critical both to cave biota and to the microclimates of the caves themselves. Since caves are part of a larger karst drainage system, they receive groundwater flow and all that is contained within that groundwater-including pollutants. Any surficial human activities that pose a potential threat to the aquifer-like, for example, careless disposal of wastes, or excessive fertilization in agricultural areas - can have devastating impacts on cave life by altering the water chemistry (Gillieson, 1996; Watson et al., 1997). White (1988) points out that a certain level of dissolved oxygen must be maintained in cave waters in order for aquatic organisms to survive; should this equilibrium be disrupted, it could have disastrous effects on these cave ecosystems. Though it rarely happens, caves can also be destroyed by aquifer drawdown, as sinkholes can then form on the surface and fill them in. Mining poses a threat to caves as well, though the nature of that threat is even more severe than that faced by aquifers: the complete destruction of caves in a quarry area (Davis, 1997). Restoring damaged caves after they have been degraded by human activity will not generally return a cave to its previous ecological state; for that reason, protection is a preferred strategy (Elliott, 2005).

Ultimately, any processes that can alter soil composition, plant population and water flow patterns could have significant impacts on caves. Indeed, even cleaning processes used to remove the excess dust and lint that inevitably accompanies humans into caves can have a deleterious effect on speleothem development (Gillieson, 1996). 
While the excessive groundwater pumping and heavy nitrate use common to major agricultural zones could easily upset the delicate balance of factors required for healthy caves, urbanization processes are perhaps even more of a threat; not only are overpumping and groundwater contamination likely to occur, but construction on the surface has the potential to redirect surface runoff flows in ways that can negatively impact caves and cave ecosystems. Brucker (2003) considers the threat posed by the Trimodal Transpark project to Mammoth Cave in Kentucky. Project developers and government sponsors downplay the threat by emphasizing the modern construction techniques designed to prevent contamination of the cave's headwaters, located a mere 13 kilometers from the project; however, critics note that the project is located in an area identified by the Center for Cave and Karst Studies as the highest-risk area for

contamination, flooding and collapse in the entire state. Even the government sponsors of the project - the InterModal Transportation Authority—cannot rule out contamination to the cave. As of this writing, the project is still on track.

\section{Summary}

The physical characteristics of karst landscapes render them extremely susceptible to damage and degradation. The demands of sustaining human settlements on karst are all but guaranteed to have some effect on these fragile landscapes; however, whether out of carelessness or ignorance, humans have been abusing karst landscapes for centuries. In many cases human societies have suffered consequences as a result of anthropogenic impacts on the karst below them; the goal of this dissertation is to provide a tool that can help mitigate both the damage caused by humans and the ensuing consequences. 


\section{Perspectives on Policy Analysis}

\section{Introduction}

While it may seem that the focus of this dissertation is on karst, that aspect is really only half the equation. Ultimately, this dissertation is really conducting public policy analysis as it applies to human interaction with karst terrains; therefore, we must first understand what policy analysis is, how it is generally conducted, and how it can help inform the research contained here.

\section{Policy analysis: What is it?}

Dye (1987) defines public policy as "whatever governments choose to do or not to do" (p.3); it follows that policy analysis is therefore the breaking down and examination of the institutions and processes that create public policy. As an academic discipline, policy analysis is still quite young. Most scholars of policy analysis will likely point Lerner and Lasswell's work in 1951 as the point where policy analysis began to stake out its own disciplinary territory. In the six decades that have followed, the field has

not developed an especially cohesive theoretical core; however, that shouldn't necessarily be surprising, given the discipline's broad reach. It is also a deficiency that has received a good deal of attention from policy theorists since the 1980s, and as a result, the old descriptions of policy analysis as largely a-theoretical are not as pointed and stinging as they once were. 
Ultimately, there is no single, agreed-upon approach to policy analysis, or even a uniform recognition of what the discipline's goals should be (though differences on these questions are perhaps not as significant as they at first appear). Dery (1984) sees the goal of policy analysis as achieving an understanding both of what is achievable through policy implementation and of the constraints faced in the implementation process. White (1979) writes that policy analysis should have two objectives: first, to identify and communicate to policymakers and the public the likely consequences of making a particular policy decision; and second, to identify, evaluate and compare alternative policy choices. In order to achieve these objectives, at least three questions must be answered: "Are the anticipated consequences likely to occur? Are there also likely to be consequences which have not been anticipated? If either these anticipated and/ or unanticipated consequences occur, how serious will they be? (p.97)"

As White sees it, the four major components or conceptual elements developed to answer these questions and achieve these objectives are: A general conceptual framework; an interdisciplinary team; the active involvement of numerous outside experts and stakeholders; and an issue-systems policy analysis framework. Once these components are in place, there are three steps to the actual process of political analysis: identification and definition of problems and issues; description of the social and political context; and identification, evaluation, and comparison of alternative policies and implementation strategies. The first step is really an ongoing process, or at least a step that is revisited at various stages in the policymaking process. The second step relates potential problems to the social and political context in which they are likely to occur. In step three, the number of alternatives must be reduced to a manageable number, which is 
accomplished by applying a number of filters, based on the probable distributive effects (with regard to costs, risks and benefits) of each alternative. Any alternatives passing through the filters are then evaluated and compared, based on specified criteria (White, 1979). Dery (1984) suggests a six-step process as sort of a loose set of guidelines: define the problem, collect the data, identify any alternative policy choices, determine the consequences of any viable course of action, explore the tradeoffs involved, and finally, tell the story. This, he writes, is a variant on a theme that is common in the policy analysis literature, though the number of steps differs from author to author: Gupta's (1994) description of the process contains five steps that are very similar to Dery's, while Bobrow and Dryzek (1987) see the policy design process as consisting of three central components to be analyzed: values, context, and the creation of appropriate approaches. Effective policy analysis will also typically include input from several different disciplines. A solid understanding of economics, sociology, or the physical sciences is frequently required to make effective policy. As White (1979) put it, "[a]pplied policy analysis is inherently interdisciplinary because societal problems seldom if ever fall within the boundaries of any single discipline" (p. 96). In that, White concurs with Sabatier (1991a) on the importance of substantive policy information in the analysis process: Sabatier argues that such information is critical to the process, because policy actors spend a significant amount of time discussing the technical minutiae of the policy choices before them. Weiss (2000), on the other hand, argues that the institutional setting and values of interested political actors are better explanations for policy outcomes than are the specific features or characteristics of the policies themselves. 


\section{Some approaches to policy analysis: an overview}

As mentioned earlier, there is no generally-accepted "right" way to conduct policy analysis. Perhaps some of the differing views on what policy analysis is and how it should be conducted can be explained by the field's long reliance on the stage heuristic, the framework in which so much policy analysis research seems to be rooted. In this conception, the policy process is broken down into four discrete stages: agenda setting, policy formulation and adoption, implementation, and evaluation. An analyst can focus on the definition of the problem to be solved with a policy solution, the identification and analysis of potential alternative courses of action and their likely consequences, the implementation of a given policy solution, or the evaluation of a program's effectiveness once it's had time to work. Sabatier (1991a) offers a description of the four types of policy research that bears the unmistakable imprint of the stage heuristic: substantive area research, in which the researcher attempts to understand the politics of a particular policy topic; evaluation and impact studies; policy process; and policy design (of the four, Sabatier suggests that policy process studies have been the most fruitful). These are all very different enterprises, requiring very different tools and mindsets, yet they all find refuge under the policy analysis umbrella. It's no wonder that the policy analysis field can at first appear murky and confusing to outsiders.

The stage heuristic has long been a fixture in policy analysis research. While this construction can certainly provide a useful for studying policy problems, its explanatory powers are limited by the fact that the stage heuristic is in no way a causal theory. It offers no assumptions or mechanisms for driving the policy process from one stage to the next (Sabatier, 1991a). Instead, the stage heuristic lends itself to a more solution-oriented process, which Weiss (2000) suggests was a necessary and natural outgrowth of the lack 
of a strong theoretical base. Weiss is not alone in continuing to criticize the depth (or lack thereof) of theory in policy analysis; even such a theorist as Sabatier (1991a) has acknowledged the validity of some of these critiques, and that a significant amount of modern policy analysis research still amounts to little more than overdressed case studies.

Dye (1987) includes the stages heuristic (or, as he calls it, the process model) in his list of eight prominent model types in policy analysis. It is not the only one with limited explanatory potential; the institutional model, which describes specific governmental institutions but does not take a systematic view of their respective roles in the policy process, seems beset with a similar problem. Other models described by Dye do in fact explore causal mechanisms within the policy process: the group model, for example, posits that it is interaction between interest groups, in the form of struggle or cooperation, that is the driving force of politics and policy; the elite model describes a policy environment in which policy reflects the values and desires of a society's elites, and not those of the people. The incrementalist perspective argues that policymaking is based on the gradual modification of existing programs or policies, while the rational model takes a more normative approach: it argues that governments should choose policies where the difference between costs and gains is the most favorable, and likewise should not adopt policies where the costs are larger than the gains to society. As sensible as this approach seems, it is often easier said than done, due to the impossibility of actually identifying costs and the fact that benefits usually accrue to one or more interest groups, instead of to society at large.

Most of the models described by Dye were in use when the first edition of his book was published in 1972. A more recent framework with much explanatory power is 
the policy streams approach, developed by John Kingdon. This framework has become very influential in policy circles since its introduction in 1984. It is, however, limited to addressing the agenda-setting stage of the policy process, and is silent on the others. In Kingdon's framework, policy issues can move from purgatory to the top of the policy agenda by the convergence of three "streams" of processes: the problem stream, the policy stream, and the political stream. When these three streams all happen to deal with the same issue at the same time, policy participants may see the opening of a policy window. Kingdon describes this window is "an opportunity for advocates to push their pet solutions or to push attention to their special problems" (Kingdon, 1995, p. 203). If a particular policy or solution is ready and tied (or "coupled," to use Kingdon's terminology) to a problem or political event, it can ride through the policy window when the opportunity presents itself. It is possible for an issue to achieve agenda status without the convergence of all three streams, but it's not easy or common.

One crucial difference between the policy streams model and the classic problemsolution approach is that in this model, solutions and policies exist independent of actual problems; advocates of these various solutions are always looking for problems to which they can be coupled. The classic problem-solution approach holds that policy solutions are developed in response to specific policy problems. The policy streams approach is an extremely flexible method for analysis of the agenda setting process, in that it can accommodate participants at multiple agencies and at multiple levels of government. However, its inability to analyze other stages of the policy process means that other theoretical tools must be used in situations where analysis is required beyond the agendasetting stage. 
The advocacy coalition framework was developed by Paul Sabatier in the late 1980s. At its core, the framework reflects Sabatier's (1991a) belief that substantive policy knowledge is, and must be, a key part of the policy process. He writes that in order to develop policy theory, a theorist needs an understanding of the behavior of governmental institutions, interest groups, the media, and the general public. He claims that empirical study has shown that a wide range of agencies and interest groups are involved in the policy development and implementation process in the United States, and that this fact renders the standard "iron triangle" approach, as well as institution-specific research, mostly superfluous. Instead, the analyst must examine a much larger policy community (or "subsystem") in order to understand the policy process (Sabatier, 1991b). These policy subsystems are composed of all actors who are concerned with a particular cause or policy issue. These actors can come from a wide spectrum of public or private institutions, and need not all exist on the same level of government, or even within government at all. There can be more than two policy coalitions at work in the subsystem, with each typically working against the others to some degree or another. Each coalition has a core set of beliefs, which informs its choices of policy solutions (Sabatier, 1988).

The importance of policy subsystems is directly tied to the importance of specific technical information to the policy process. Specialist knowledge, and the commitment to the issues that usually comes with such knowledge, give members of these subsystems the ability to shape policy over longer periods of time. Central to the policy process is the idea of policy-oriented learning, which is based on increasing one's level of specialist knowledge and is supported by feedback loops within the model (Sabatier, 1988). 
One major shortcoming of the advocacy coalition framework is that it neglects actor interests; Sabatier (1991b) recognizes this and has worked to address the situation. Additionally, the advocacy coalition framework assumes that policy decisions cannot be adequately analyzed over time frames shorter than a decade. This stipulation makes the advocacy coalition model somewhat more difficult to apply to some of the cases studied in this dissertation.

Public choice theory is an approach to policy analysis with roots in both political science and economics. Despite its ties to economics, public choice is not wedded to the standard market-based approach so prevalent in that discipline (though the influence certainly does exist). Instead, it explores what happens when people leave the marketplace in order to pursue the maximization of utility through influencing public decision structures. Or, as Bobrow and Dryzek (1987) write, it "applies deductive reasoning based on individual rational maximizing behavior in order to determine collective consequences under different circumstances (p. 49).”

Public choice theory takes an entirely different view of government than is presented in welfare economics or in traditional political science theory. Government is not inherently public-spirited or benevolent; instead, because it is composed of rational utility-maximizing humans, its policies and programs reflect acts taken by individual government actors in pursuit of their personal professional goals (more power, bigger budgets, etc). And instead of viewing policy through the lens of the Pareto condition, public choice acknowledges that collective choice-making endeavors, like policymaking, are often—but not always—zero-sum games (Buchanan and Tullock, 1965; Mueller, 2003). In the late 1980s and early 1990s, Elinor Ostrom's work focused on developing a 
theory of institutional analysis within the field of public choice. She was motivated by the inability of existing models (specifically, the tragedy of the commons, the prisoner's dilemma, and collective action theory) to provide a satisfactory framework for examining problems related to the management and provision of common pooled resources, which are simply resources from which users cannot be excluded (Ostrom, 1990, p. 29).

Ostrom's work, like much of public choice theory, has deep roots in the field of game theory. Game theory provides a way to model and predict rational decisions made under interactive conditions - i.e., situations in which two or more participants are attempting to maximize their own utility and minimize risk (Dye (1987) describes it as rational strategic decisionmaking). There is a significant body of literature in economics that deals with game theory and its application to the problems and situations most common to that discipline. It should come as no surprise that game theory often carries with it some of the inherent limitations in economic thought, i.e. the assumption that all actors behave in a rational manner. However, relaxing these rules for analyzing any particular game is a simple matter. In demonstrating how cooperative behavior might evolve on its own in a purely self-interested group, Axelrod (1984) cleverly demonstrates how game theory can be applied in a way that avoids unrealistic assumptions like universal rationality.

Dye (1987) notes that while game theory is generally useful for analysis purposes, it is not generally an effective tool for policy formulation; this may be related to the assumption of rational behavior in policy actors. Likewise, critics of public choice have found empirical evidence to suggest that bureaucratic behavior is often more consistent with the idea of public service than with budget maximization. Additionally, public 
choice has a strong inclination toward market-type mechanisms (it is, after all, a branch

of economics). Another criticism is that public choice makes unrealistic and contradictory assumptions about the capabilities of the policy process (Bobrow and Dryzek, 1987).

\section{System analysis in public policy}

The eighth policy framework discussed by Dye is the systems model, which is the framework that plays the most significant role in this dissertation. He argues that the "policy system" consists of information flows between three "black box" components: these are labeled "institutions, processes, behaviors," "social and economic conditions," and "public policies" (Dye, 1987). Within the systems model, the environment determines (at least in part) the nature of inputs (i.e., demands and support) to the box labeled "The Political System," which then uses those inputs to produce outputs (decisions and actions) and discharge them back into the environment; these outputs then provide feedback onto the environment itself, and may impact the nature of future inputs (Easton, 1951; Hofferbert, 1974; Dye, 1987).

Easton (1951) argued that politics and policy can be studied in one of two ways: in a piecemeal fashion, where every component is examined in isolation from other components with which it interacts, or as a system of interrelated components that influence and affect each other. It is this latter approach, he writes, that is the appropriate one: "The operation of no one part can be understood without reference to the way in which the whole itself operates" (p. 383); Hofferbert (1974) describes the policy process as dynamic interplay between the units it contains. The first step in understanding a policy system is therefore to identify the units that compose the system. In a political system, these units are simply political actions and actors; input units are required for the 
system to continue working, and output units are generated by any system that is actually functioning. Any political system has at least a minimum amount of differentiation between the roles and activities of its units. Political systems must also be integrated, at least to the point where individual units are not working at cross purposes. The second step in delineating a policy system is identifying the boundaries of that system. How can the boundaries of a political system be determined? Is it even possible to separate a policy system from the rest of the society in which it operates? Easton argues that it is, and that the appropriate way to do this is to exclude activities and institutions that are not involved in the process of making binding decisions for a society (Easton, 1951).

Dye (1987) sees the systems model as a useful framework in which to ask several policy-related questions:

"1. What are the significant dimensions of the environment that generate demands on the political system?

2. How do environmental inputs affect the character of the political system?

3. What are the significant characteristics of the political system that enable it to transform demands into public policy and to preserve itself over time?

4. How do characteristics of the political system affect the content of public policy?

5. How do environmental inputs affect the content of public policy?

6. How does public policy affect, through feedback, the environment and the character of the political system?" (Dye, 1987, p. 42)

It could be argued that many, if not most, of the other approaches to policy analysis described in this chapter are following the systems template to some extent. Kingdon's policy streams approach, for example, describes the processes by which particular inputs combine to produce an output. In that, he is really making an argument in favor of a specific type of system, and not for a departure from system theory. 


\section{Applying policy analysis methods to this dissertation}

Ultimately, in this dissertation I am not seeking to understand the policy process per se. Rather, I am more interested in the ways in which certain inputs and conditions affect the outcome of the development of a particular type of policy, and the outcomes of these policies as they relate to the human systems above the karst. In order to conduct this sort of analysis, it will be necessary to draw from multiple analytical frameworks.

As discussed earlier in the chapter, White (1979) conceived of the policy analysis process as consisting of three stages: problem identification and definition; description of the social and political context; and identification and evaluation of potential policy solutions. Certainly, the development of local land use policy for karst terrains can be fit into White's three-step framework:

Identification and definition of problems and issues: Perhaps the most important step is articulating an understanding of the specific problem that may require a policybased solution. In what way is the presence of karst an issue? Is subsidence the primary problem, or is groundwater contamination? Or perhaps the most significant karst-related issue is cave degradation. Regardless, answering these and similar questions as precisely as possible is critical to identifying and implementing appropriate regulatory remedies.

Description of the social and political context: Policy solutions are never attempted or implemented in a void. Every place has a different demographic and cultural makeup that affects the policy development process to some degree; in order to understand the impact on policy, a thorough investigation into the municipality in question is required. Is it urban or rural? Is the political culture such that residents and policymakers are open to the idea of regulation, or do they generally take a more laissezfaire toward land use issues? What kind of political influence is enjoyed by the various 
interest blocks involved? What categories of solutions, if any, are the more influential blocks most likely to accept?

\section{Identification, evaluation, and comparison of alternative policies and}

implementation strategies: Once potential policy alternatives have been identified, both the nature of the problem to be solved and the social and political context must be considered as part of the decision-making process. The interplay between inputs and actors can be complex to work through. For example, while the urban character of a given municipality may make a zoning overlay strategy appropriate, the political situation may be one in which the building and construction industry has a significant amount of influence and will work to block such legislation. Likely compromise solutions can then be identified and planned for.

White's (1979) framework can be used to understand how and why karst land use policy developed the way that it did in a given location; however, it is not useful for analyzing outcomes of policy. For that, it is probably more appropriate to use a systemsbased approach. When studying systems of any type, one is ultimately examining the interrelation between components within the larger system (Boulding, 1956; von Bertalannfy, 1973). Karst topography is a system; the components of that system were described in Chapter 2 (water, temperature, carbon dioxide, and limestone bedrock). The

process of creating karst depends on the interaction of all these components; alterations to any one of them can result in long-term alterations in the way the system functions.

Likewise, from tiny farming villages all the way to large and complex cities, human settlements are also systems, dependent on the interaction of all components to function. When a human settlement system is located above a karst system, they form a larger 
system that incorporates all the components of each. For example, industrial activity produces toxic waste, which leaches into the karst aquifer and contaminates the groundwater, which in turn will have other effects on the urban system. Or increased agricultural production creates a growing demand for water, which is pumped directly from the aquifer at a rapid rate, which then leads to subsidence problems in the region. The human system affects the karst system, which then affects the human system.

It is in this context that we can best understand the role of land use regulation in generating outcomes. Land use regulation is really just another component of the human system on the surface; essentially, examining the role of land use regulation in a humankarst system boils down to examining how changes to a single component in a system affect the whole. A systems approach to policy analysis therefore seems appropriate to any examination of how land use regulations govern the interaction between human systems and karst systems

Beyond White's (1979) basic framework and systems theory, many of the other frameworks and models described in this chapter have components that are worth borrowing for this research. For example, Sabatier's Advocacy Coalition Framework pushes the idea that expert knowledge is a critical component within the policy process; as we will see in Chapter 6, expert knowledge does play such a role in karst land use policy formation. Another is the idea (borrowed from Kingdon (1984)) that creating policy sometimes requires a near-perfect convergence of political and social conditions (this may help explain why some localities choose to implement karst regulations and others do not). Kingdon's (1984) idea that advocates of policy solutions are constantly seeking out problems to which they might attach their favored solutions suggests another 
possibility: that karst-related land use regulations might simply be a convenient way to control development in certain locations, irrespective of the presence of karst. Indeed, even the shopworn stages heuristic may still offer a useful perspective on the policy process; for example, it may suggest the most effective points at which certain stakeholders should become involved in the process. 


\section{Karst, land use and geography: Where this research fits in the geographic tradition \\ Introduction}

In this chapter, I will argue that this dissertation can be placed within the "manland" tradition of geographic thought, popularized by Carl Sauer in the 1920s but actually begun by George Perkins Marsh (1864). However, it has little relation to Sauer's (1930, $1936,1962)$ later work in cultural geography; instead, it follows most closely in the applied tradition of Gilbert White. This judgment is made based on the theme of the dissertation - the relationship between humankind and the landscape it inhabits, and ways in which the impacts flow in both directions - and on the more empirical approach taken to exploring the research questions. This dissertation carries that tradition forward by applying its approach and methods to the study of karst landscapes, which have been historically under-represented in this tradition of geographical study. This chapter examines the work of Marsh, Sauer and White, as well as some more recent developments in karst studies, in an attempt to define the dissertation's place within the discipline of geography.

\section{George Perkins Marsh}

George Perkins Marsh's Man and Nature (1864) is generally considered to be the first comprehensive work focusing on the ways in which humankind's actions affect the earth; certainly it was the first by an American geographer. Its publication marked the beginning of an intellectual tradition within the discipline that has continued, in one form 
or another, to this day. In the book, Marsh argued that changes to the earth are "products of a complication of conflicting or coincident forces, acting through a long series of generations; here, improvidence, wastefulness, and wanton violence; there, foresight, and wisely guided persevering industry" (Marsh, 1864, p. 19). High up on the list of conflicting or coincident forces are the actions of human beings; as an example, Marsh cited the lands of the former Roman Empire, and how much of that territory (which at one time included some of the most fertile and productive agricultural lands on earth) had fallen into a state of neglect and disrepair. In Marsh's opinion, responsibility for this travesty rested squarely on the shoulders of humankind; he cited "man's ignorant disregard of the laws of nature" (Marsh, 1864, p. 11), wars and the presence of oppressive political conditions as causes of the decline. Marsh also held that it was critically important to be aware of the unintended and sometimes difficult-to-trace impacts on the earth's systems from human activities like draining lakes or clearing forests, which also have more obvious direct consequences (the connection between deforestation and desertification is one of the book's major, recurring themes).

It should be noted that Marsh did not believe that humankind was capable of only negative impacts on the natural environment; indeed, he alluded to the positive potential for human agency on the land when he cited "foresight, and wisely guided persevering industry" (Marsh, 1864, p. 19) as forces that exert an influence on the earth and its features. Still, he did seem to believe that humanity would not act in a benevolent manner toward the earth unless and until great and obvious damage had already been done: "[T]he destructive agency of man becomes more and more energetic and unsparing as he 
advances in civilization, until the impoverishment ... as last awakens him to the necessity of preserving what is left" (Marsh, 1864, p. 39-40).

\section{Carl Sauer and the Berkeley school}

Marsh's themes would be revisited and expanded upon by Carl Sauer some sixty years later. The origins of the "Berkeley school" in American geography can be placed at the 1925 publication of Sauer's The Morphology of Landscape. Here, Sauer continued with Marsh's human-environment interaction theme, while simultaneously arguing for geographers to adopt a different methodological approach. When he wrote Morphology of Landscape, Sauer saw the discipline of geography as resting at the crossroads of three very distinct fields: the study of the earth itself and its physical processes; the study of life forms and their interactions with their environment; and chorology, or the study of areal or habitat differentiation. Sauer did not believe all three fields were compatible enough to be considered branches of a single discipline, mainly because the phenomena under examination by each field are so different. Only chorology could be studied independently as a separate discipline; Sauer felt the other two fields were too reliant on phenomena from other disciplines too far removed from areal studies, and that viewing chorology as a separate discipline is appropriate, based on the fact that the phenomena that make up an area are interdependent and related: "The objects which exist together in the landscape exist in interrelation. We assert that they constitute a reality as a whole that is not expressed by a consideration of the constituent parts separately . .." (Sauer, 1925, p. 24). The objective seems to be to study these as part of a system, for it is their interconnected nature that makes geography different from other, related disciplines, like geology or biology. 
This work also marked Sauer's introduction and development of the concept of the landscape, which is defined by the association of various "place facts." The landscape itself has an organic quality; the land and the life it sustains should be considered and understood in terms of each other. Sauer argued that landscapes all have their own individuality, as well as a set of characteristics in common with other landscapes; this last characteristic is what makes a systematic study of landscapes possible. Ultimately, the individual identity of any landscape is determined by what form it takes, and that form is determined by not only the physical characteristics of the landscape, but also by how humankind understands and uses it: "Geography is based on the reality of the union of physical and cultural elements of the landscape. The content of landscape is found therefore in the physical qualities of area that are significant to man and in the forms of his use of the area" (Sauer, 1925, p. 29).

Clearly, Sauer was arguing for more attention to be paid to the human aspect of geography, and humanity's role in shaping and changing landscapes. Up to that point, however, the geomorphologist had been considered to be the archetypal geographer. Sauer did not agree. Instead, he saw geomorphologists as historical geologists who study a late geologic period; at most, the geomorphologist could be regarded as a link between geography and geology. Sauer's use of the word "morphology" makes clear that he does not consider it to be synonymous with geomorphology; the latter term had by 1925 come to mean a separate branch of science almost solely concerned with the genetic process of landforms. On the other hand, morphology as Sauer saw it was a more complex and elemental process, encompassing far more than the relief of physical landscapes. In particular, he argued that a landform's significance is not necessarily related to the 
process by which it developed, and it is this significance (rather than genesis) that geography concerns itself with (in fact, he described the tendency to redefine morphology in terms of the causal study of relief forms as "a perversion of geographic ends") (Sauer, 1925). Ultimately, morphology as defined by Sauer includes human agency; geomorphology does not.

The concept of morphology can then be extended into the cultural landscape as well, as humanity constantly works to transform the landscape it finds itself in. Echoing Marsh, Sauer points out that people have always acted in ways that alter the physical landscape of the earth, sometimes to humanity's benefit, other times to its detriment. As far back as the Paleolithic, humans were already engaging in environmental alteration through the use of fire, not only through the use of the fires themselves, but also through the acquisition of fuel (stripping trees of barks and limbs, or simply using whole trees). An examination of human history reveals that a handful of basic themes - most notably, territorial expansion and modification of the landscape for various agricultural purposes - are repeated over and over through modern times, though the exact nature of the modification changes (higher levels of nitrates in the soil, shifting away from subsistence crops and toward money crops). Sauer argued that it is important to understand how humankind has disturbed and displaced so much of the organic world, or how it has become the primary ecological force in more and more places across the globe, or how it has actually impacted the course of organic evolution (Sauer, 1956): "We are concerned with the importance of the site to man, and also with his transformation of the site" (Sauer, 1925, p. 53). Worthwhile examples of Sauer's application of this approach include Sauer (1930, 1936, 1962). 
By 1941, Sauer's perception of geography had begun to show a distinct influence from anthropology; much of his work after this point falls into the realm of cultural geography, and is not particularly applicable to this dissertation. Instead, we turn to an intellectual tradition that ran parallel to the Berkeley school and emphasized empiricism and human interaction with the physical landscape: the Chicago school and the work of Gilbert White.

\section{Gilbert White}

White's work was concerned with humankind's relationship to the earth and with decision-making issues as they relate to environmental degradation and natural hazards. Like Sauer, White used methods rooted in system analysis to approach and understand issues of human-environment interaction (White, 1962). White justified the use of a systems-based approach in this context by pointing out that natural systems and humanbased systems can interact in ways that increase the risk posed by certain natural events (Burton, Kates and White, 1978). This interaction is at the heart of any natural or environmental hazard, all of which involve an interaction between humans and the earth. Indeed, there could be no hazards if not for humans - the word "hazard" implies a threat, and without humans, who would be threatened? (White, 1993) In this viewpoint, White reveals a shared perspective with Sauer, in that the presence of human beings is a prerequisite for the study of geography.

White's perspective on environmental problems was based on six trends in scientific thinking: looking at environments in holistic frameworks; devoting more attention to life support systems; developing an appreciation for a wider array of resource management choices; refining and improving risk assessment methods; streamlining ways of assessing environmental change; and thinking globally. He tied this approach to that 
practiced by Marsh and other environmental researchers in the 1880s (though White asserted his approach was more "refined" than that older tradition). White characterized that earlier era as a time of "critical inquiry into consequences in terms of interrelationships of people and resources within areas" (White, 1980, p. 183), which was the field addressed by much of White's work.

Beginning with his earliest published articles, White took an empirical approach to studying questions of human-nature interaction and natural hazards. White (1936) asked the question: are the costs of protecting areas from floods higher or lower than the costs of allowing floods to occur unimpeded? He then outlined a method for measuring the costs and benefits of flood-protection projects involving classes and characterizations of benefits, and how they are measured. In the process, he tied together cost-benefit analyses, land use planning issues, and hazards studies, using a multidisciplinary approach that would reappear throughout his career (for other examples of White's empirical approach, see White, 1949, 1960, 1962).

White's approach to hazards and geography stressed the role of humans in (usually inadvertently) generating or exacerbating threats (White, 1993). For example, land use patterns have been singled out as a culprit in the 1970 Bangladesh cyclone-flood event, for their role in placing an excessive number of people at risk (White, 1987). In addressing issues and events like this one, White "always asked what are the ways in which society can adjust to the distinctive characteristics of any natural setting in terms of place and location. This requires ... looking at what would be the constraints that would be set by that natural or social environment to activities that could be carried on" (White, 1993, p. 67). 
This position could be interpreted as placing the blame for disastrous outcomes on the victims themselves, who may have been too poor to live elsewhere or to get out of the way of the disaster, or on society at large for its inherent lack of equitability. White argues that such an interpretation would be mistaken; rather, it should be interpreted as healthy skepticism of heavy-handed human interventions in natural systems. "Management interventions ... are likely to provoke unexpected results and require dynamic alteration" (White, 1980, p. 188), since nature is a large and complex system we do not fully understand; it is easy to realize that change to an input can therefore have significant and unforeseen effects, but quite difficult to accurately predict what those effects might be. In a paper written with Burton and Kates (1987), White writes that engineered structural solutions and other technological changes deserve much of the blame for natural hazards and disaster events, simply because their presence often leads to societal responses that place too much stress on a given location. Building structural protections against natural hazards can be more costly than allowing the damage to occur, because those structural protections encourage more development in hazardous areas by offering an illusion of protection. White felt that locally-focused hazard management programs would be more appropriate and effective: "The kind of approach that I would hope will be adopted in time is one in which communities develop combinations of solutions that are suited to their particular conditions and history and that a federal policy could be one that encouraged rather than discouraged it" (White, 1993, p. 59).

Prominent themes running through much of White's work were resource management, resource depletion, and their effects on society and humankind. His 
empirical approach to these questions could lead a casual or careless reader to gloss over the cultural geography components of his work; however, the link is plainly present:

"The way in which resources and technologies are used will be guided by the cultural pattern and the institutional structure of society. In small-scale, pre-literate societies, concern with natural resources tends to be local; contemporary industrial civilization, however, has freed itself largely from the bonds of local environment, and tends to concern itself with natural resources in terms of regional, national or global location. Much depends upon the decision-making process of the individual and society. . .

application of available technologies, then, is dependent to a large extent upon the basic motivations and values of the culture ..." (White, 1962, p. 12).

White (1962) saw processes of economic growth and development as being inextricably linked to social transformation in less-developed countries. For one thing, exploitation of a given resource can itself have impacts on a culture, in terms of aggregate changes in skill levels or education levels, or in terms of gender-related labor force participation issues. Changes in these areas can generate creativity and innovation, which in turn can lead to more effective resource exploitation. Culture certainly plays a role in the ways human societies choose to address resource and hazard issues: "Human preferences and habit may block certain actions or indicate need for technical modifications ... why is it that some innovations, like hybrid corn, spread rapidly and widely while some others are very slow in finding acceptance?" (p. 34-35). In this attention to the cultural aspect of resources and hazards geography, White provides another link to Sauer's work; however, White's approach to studying questions of cultural geography was quite empirical, and did not resemble Sauer's superorganic idea of culture. 


\section{Connecting karst studies to this tradition}

In recent years, karst has emerged as a growing focus of study from various disciplines, including geography, geology, biology, climatology, and public policy. Fratesi, et al. (2006) found a clear upward trend in the number of karst-related scientific publications from 1960 to 2005, with the largest share coming from the subfields of geomorphology and geology. Clear examples of the interdisciplinary nature of contemporary karst research can be seen in the growing literature on management of karst lands (see Day, 1996; Urich, Day and Lynagh, 2001; Jepson, et al., 2002; Kueny and Day, 2002; Duval, 2006; Fistanic, 2006; Hamilton-Smith, 2006), and in the expanding list of karst-related conferences ("Cave and Karst Science Conference;" "Growing Communities on Karst;" "Climate Change and the Karst Record;" "International Transdisciplinary Karst Conference").

Thematically, this dissertation is representative of larger trends in karst research at the University of South Florida, where karst has become a research priority over the last three to five years. Recent work in karst studies at USF exists within a traditional physical geography or geology context (Polk, van Beynen, and Reeder, 2007; Florea, 2006; Soto, 2005). However, karst in urban environments is a major developing focus of karst studies at USF (Ranalli, 2004; Wilson, 2004; Seale, 2005; van Beynen and Townsend, 2005; Brinkmann et al., 2007; Fleury, 2007; North, 2007; Seale et al., 2007; Vacher, et al., 2007; Fleury et al., in press; Brinkmann et al., in review); by definition, research in this area is concerned with questions of human-environment interaction. Much of this work examines important and specific issues of karst within urbanized environments. This dissertation builds upon this trend by looking at the regulatory 
environment in which these interactions take place, and attempting to develop a more complete understanding of that environment.

This trend in karst research—connecting the physical landscape to human activities, particularly relating to questions of protecting karst resources from human encroachment - fits neatly into the geographic tradition of Marsh, Sauer and White, that of the study of interaction between humans and the natural environment. Marsh's work addressed questions about ways in which humankind's actions affected the earth, and the unintended consequences of those actions. This theme is also prevalent in this dissertation: how can land use regulation control the impact of human settlements and activities on karst systems, and what might some of the unintended consequences of either action (regulating or opting not to regulate)? In that broad sense, it should be apparent that this dissertation fits into the same tradition; however, there are also a number of further linkages beyond the thematic level.

The empirical nature of the dissertation invokes much of White's work; while the specific landscapes under study differ (White focused on floodplains, while this dissertation looks at karst landscapes and events that lead to groundwater contamination and land subsidence), the questions asked in this document are not so different in their objectives than those White asked throughout his career. But going further, the dissertation shares with the work of Sauer and White certain perspectives and understandings of humankind's relationship to the natural landscape. Sauer argued that objects existing together in the landscape exist in interrelation, and that the land and the life it sustains should be understood in terms of each other. This dissertation takes that perspective as a starting point, understanding it in terms of the interconnectedness of 
human settlements and the karst systems located beneath them. Certainly, in places where both exist, each system has an impact on the other to the point where it does more good to understand them as a single system. The idea of this interrelationship is central to the entire dissertation.

Likewise, White understood that human and natural systems can interact in ways that increase the dangers and risks posed by certain natural events, and that human actions often play a major role in generating or exacerbating stress on the environment. Finally, a recurring theme in White work was the question of how society can adjust to the distinctive nature of the landscape it finds itself a part of; in other words, what constraints on human behavior can be implemented. He also argued that the best approach is one in which local communities develop solutions that best fit their particular circumstances. The entire concept of land use regulation is rooted in the idea that human activities on the land must be controlled to some extent, in at least some circumstances. In accepting this framing of the purpose of land use regulation, this dissertation aligns itself with White's arguments.

Finally, the approach described in this chapter has been taken by many geographers in the past; in itself, it is nothing new. However, this approach has never been applied to a large-scale study of karst landscapes. It is the application of this approach to an examination of human interaction with karst landscapes that makes this dissertation an original contribution to the field of geography. 


\section{Regulatory techniques used in managing development on karst: an overview}

\section{Introduction}

Human societies can simultaneously threaten and be threatened by karst

landscapes. In many karstic areas with human populations, there are no municipal codes or ordinances that manage how humans and karst systems interact (Day and Reeder, 1989; Rubin, 1992); however, an obvious way to manage this interaction and minimize the risks of subsidence, groundwater contamination and cave destruction is to regulate how construction, development and settlement can take place on karst terrains. While policy-based solutions have demonstrated success in some locations, there are also many examples of land use policies that are not effective, or not very effective, in protecting karst environments. As with other types of policy efforts, in many cases this failure is a result of lack of appropriate policy tools, weak or nonexistent enforcement, vaguely defined goals, poor conception or execution, or one of the other standard traps that bedevil policy-based solutions. By their very nature, solving problems generated by human-karst interaction often requires input from multiple disciplines. In most cases, regulatory agencies have more narrowly focused areas of responsibility that make taking an interdisciplinary approach difficult. Under those circumstances, organizations without any actual regulatory power-geological surveys, for example, or karst-related research institutes - can act as catalysts for policy-based solutions and as clearinghouses for the data required to shape such solutions; Vineyard (1976) cites the Geological Survey for 
the state of Missouri as an example of a successful government catalyst. There is no reason to assume that karst protection is inherently too complex an issue to benefit from a policy-based approach. However, as demonstrated by examples provided in this chapter, much existing karst protection regulation has important flaws that hamper effectiveness.

This chapter provides a survey of karst-related land use regulations in the United States. In so doing, it also addresses the question of how and why these regulations differ between municipalities. Do municipalities near each other-with presumably similar karst issues — generally choose similar approaches to regulating karst? What about municipalities in the same regions? And if these similarities do exist, what is the most likely reason?

\section{Commonly-used regulatory tools}

When policy protection for karst is implemented in the United States, it is often done through the zoning and land development approval processes. Because of the potential to impact flooding, surface and groundwater contamination, and sinkhole formation and collapse, municipalities certainly have an interest in enacting karst-related regulation. Different localities use different regulatory tools to manage growth in karst terrains; this is entirely appropriate, due to the differences in physical and social landscapes between individual cities and towns. However, there are several regulatory techniques that are used with more frequency than others. This section will briefly discuss four of them—zoning codes, subdivision ordinances, stormwater management rules, and setbacks - as well as comprehensive plans, which are a significant influence on land use decisions but cannot by themselves be considered an effective tool for managing development in karst landscapes. 


\section{Zoning ordinances}

Generally, zones that include areas where threats to local karst formations are higher —or where threats from the local karst formations are higher-may be subject to certain additional construction requirements that could potentially work to mitigate that threat. These are often related to stormwater or surface water drainage and runoff, or to implementing mandatory setbacks between human-built structures and karst landforms, usually sinkholes. In some cases, zoning overlays are used. An overlay is simply a set of zoning requirements that is added to the zoning rules of one or more existing zones; in essence, they are appended to whatever regulations currently exist. Using overlays makes sense in cases where existing zoning laws would be difficult to change, or where the karst system spans multiple zones.

\section{Subdivision ordinances}

Subdivision ordinances can appear similar to zoning ordinances at first, but they have a different focus. Zoning is an effort to manage land use by identifying which land uses are permitted in what specific places, and is usually tied to the goals of the local comprehensive plan; subdivision ordinances, on the other hand, address the administrative process of subdividing large tracts of land into smaller plats, and then building on them (of course, the exact nature of the differences between zoning and subdivision ordinances can vary between states). Subdivision ordinances are often weaker than zoning ordinances, even though both types of regulation frequently use some of the same tools and techniques to accomplish their goals-for example, many subdivision and land development ordinances in Pennsylvania include stormwater management components, which are also commonly found in zoning codes. In some 
localities, the differences between subdivision ordinances and zoning ordinances are not clear; for example, both may be incorporated into a larger Land Development Code, particularly in smaller municipalities.

\section{Stormwater management ordinances}

Stormwater management is a very commonly-used tool for regulating development and growth in karst terrains. Essentially, stormwater management regulations and ordinances describe how surface water drainage patterns may or may not be altered by human-built structures or anthropogenic changes to the physical landscape; in the context of karst, these often forbid directing surface runoff directly into sinkholes, and in some cases require some sort of passive filtering system (gravel, wild grasses, etc.) be placed around the perimeter of a sinkhole near new construction or development. The popularity of stormwater management as a tool for managing development on karst landscapes seems to be an approach borne of practicality: Surface water is a source of contaminants and is simultaneously a contributing factor in sinkhole development; further, the consequences of poor or ineffective stormwater management practices are often highly visible, and thus it is often easier to build a political consensus to do something about it than it is with other karst-related regulatory tools.

\section{Setbacks}

Setbacks are another widely-used approach to karst protection and land use management, though not as common as stormwater management. Setbacks are simply buffer zones placed between karst landforms, usually sinkholes, and buildings or other human-built structures; construction may not occur within these buffers. Usually the idea is to protect the structure from the karst (specifically, from any threat of subsidence) 
rather than the other way around. One advantage to the use of setbacks is that they are easy to understand conceptually, and theoretically require only a tape measure to enforce. However, they also tend to make it more difficult for landowners to develop parcels with karst features (which is often the intent of the regulations in the first place); this places the setbacks under heavy political pressure from developers or property owners who are seeking waivers or exemptions from setback requirements. Rubin (1992) points out another serious shortcoming of the setback tool: because sinkholes are only one part of an underlying karst system, it is likely that contaminants will be able to find their way into the karst system by seeping through the epikarst and any surrounding permeable soilmantle. In other words, while setbacks may be an effective method of protecting humanbuilt structures from subsidence dangers, they are not appropriate for protecting entire karst systems from anthropogenic impacts. Some examples of communities using setback-style regulation can be found in Table 5-1.

\section{Comprehensive plans}

Comprehensive plans are some of the most visible, high profile examples of local land use planning. Often, the development of a comprehensive plan is a process that incorporates significant community input; this process can easily take several years to complete. They are usually intended to lay out plans for future growth and development over the course of fifteen, twenty, or twenty-five years.

The reason comprehensive plans are not considered to be land use regulations in this dissertation is that their recommendations and goals are usually not binding; comprehensive plans typically do not have the power of law. Because there is no power 
Table 5-1

Examples of municipalities employing

setback-based karst land use regulations

\begin{tabular}{|c|c|c|}
\hline Municipality & Setback size & Setback stipulations \\
\hline Pasco County, FL & $500 \mathrm{ft}$ & $\begin{array}{l}\text { Applies to new construction near karst features with } \\
\text { the potential to drain directly into aquifer }\end{array}$ \\
\hline Des Moines, IA & $500 \mathrm{ft}$ & $\begin{array}{l}\text { Contaminated soil cannot be applied within } 500 \mathrm{ft} \text { of } \\
\text { a sinkhole }\end{array}$ \\
\hline Amherst County, VA & $200 \mathrm{ft}$ & $\begin{array}{l}\text { Hogs or chickens may not be kept within } 200 \mathrm{ft} \text { of a } \\
\text { spring }\end{array}$ \\
\hline High Springs, FL & $200 \mathrm{ft}$ & $\begin{array}{l}50 \mathrm{ft} \text {. no-build zone, with the balance requiring } \\
\text { guarantees of no damage to the sinkhole }\end{array}$ \\
\hline $\begin{array}{l}\text { Catasauqua, PA } \\
\text { Lower Macungie, PA } \\
\text { Lower Saucon, PA }\end{array}$ & $100 \mathrm{ft}$ & $\begin{array}{l}\text { Applies to construction near any karst features } \\
\text { within township limits }\end{array}$ \\
\hline Alachua County, FL & $35-150 \mathrm{ft}$ & $\begin{array}{l}\text { Setback size depends on specific nature of karst } \\
\text { feature }\end{array}$ \\
\hline Farragut, TN & $50 \mathrm{ft}$ & $\begin{array}{l}50 \mathrm{ft} \text { buffer applies to sinkholes only; aquatic buffer } \\
(25 \mathrm{ft}) \text { applies to springs }\end{array}$ \\
\hline Huntsville, AL & $25 \mathrm{ft}$ & Applies to karst features throughout city limits \\
\hline $\begin{array}{l}\text { Godfrey, IL } \\
\text { Maryville, IL }\end{array}$ & $25 \mathrm{ft}$ & $\begin{array}{l}\text { Stormwater mgt. rules applied to any land } \\
\text { disturbance within } 25 \mathrm{ft} \text { of a sinkhole }\end{array}$ \\
\hline $\begin{array}{l}\text { Rome, GA } \\
\text { Savannah, GA }\end{array}$ & $25 \mathrm{ft}$ & $\begin{array}{l}\text { Land disturbance buffer applies to all waters of the } \\
\text { state; this includes springs. Protects karst, but not } \\
\text { karst-specific }\end{array}$ \\
\hline $\begin{array}{l}\text { Montgomery County, } \\
\text { VA }\end{array}$ & $20 \mathrm{ft}$ & $\begin{array}{l}\text { Route } 177 \text { Corridor zone requires a } 20 \mathrm{ft} \text { setback } \\
\text { from sinkhole edges }\end{array}$ \\
\hline Springfield, MO & $\begin{array}{l}\text { Outline of } \\
\text { sinkhole }\end{array}$ & $\begin{array}{l}\text { Applies to construction near any sinkholes within } \\
\text { city limits }\end{array}$ \\
\hline $\begin{array}{l}\text { Lexington-Fayette } \\
\text { County, KY }\end{array}$ & $\begin{array}{l}\text { Outline of } \\
\text { sinkhole }\end{array}$ & $\begin{array}{l}\text { Applies to construction near any sinkholes within } \\
\text { the county }\end{array}$ \\
\hline Johnson City, TN & Varies & $\begin{array}{l}\text { Applies in city's Sinkhole Overlay Zone; each } \\
\text { sinkhole has a unique no-build line based on } \\
\text { flooding potential }\end{array}$ \\
\hline
\end{tabular}


vested in comprehensive plans to compel developers and landowners to act in any particular way, they cannot really be considered a regulatory tool in this context.

\section{Examples of policy-based approaches to karst protection}

Karst-related land use regulations and ordinances are in use in various locations throughout the United States, and have been since the mid-1980s (Richardson, 2003). Often, these ordinances will address a single aspect of human-karst interaction, like imposing strict controls on new construction or management of groundwater inflow. At the same time, "multi-concerned" karst ordinances that focus on new development impacts on groundwater and the structural integrity of new buildings are becoming more common (North Jersey Resource Conservation \& Development Council, 1993); examples of such an ordinance can be found in Johnson City, Tennessee, where an interim multiconcerned policy statement was adopted in 1994, immediately following an extended period of excessive rainfall and flooding (Reese et al., 1997), and in Austin, Texas, where a combination of land use management techniques and engineering controls are employed to protect the Edwards Aquifer from the consequences of urbanization (Butler, 1987). Karst regulations are not universal because governments are often not given a sufficiently wide range of tools with which to manage karst. The available tools are typically limited to the comprehensive plan, the zoning ordinance, the subdivision ordinance, and the stormwater management ordinance. However, since the general public is largely unaware of karst and the planning issues that go with it, local governments are typically forced to handle karst issues in a reactive, rather than proactive, manner (Richardson, 2003). 
Growing human populations inevitably raise the issue of waste disposal. As we have seen, the presence of karst can make disposal operations more challenging, particularly in terms of maintaining groundwater quality levels. Requirements and regulations for handling the potential contamination of aquifers by landfills differ from state to state; however, all such regulations must meet certain minimum standards imposed by the US Environmental Protection Agency (EPA). For example, states take different approaches to defining karst areas, with only a handful specifically mentioning karst — the rest use vague definitions of "unstable areas." Landfill definitions also differ across states. All landfills must have a groundwater monitoring system in place in the immediate vicinity of landfills, as per the EPA. Florida regulations suggest a double liner for landfills but do not require one; Kentucky, on the other hand, does require the use of such a design. Florida law specifies maximum distances for monitoring wells on both the up and downgrades (Davis, 1997). The benefit of such an approach is that regulations can be tailored to meet local needs; the drawback is that local political culture is more likely to influence the process, and can potentially do so in a way that is not consistent with karst protection.

Policy-based approaches face even greater challenges when they are designed for implementation across multiple jurisdictions. The European Water Framework Directive, published in 2000, served as the catalyst for efforts to develop an effective and consistent European approach to groundwater protection in karst areas. The scientists working on this had the goal of integrating karst groundwater protection into the land use planning process throughout Europe. However, such integration had to be applicable to all karstic areas in Europe, which can vary greatly in terms of geologic and political conditions. 
Because of the difficulties in achieving this, they were forced to abandon the conceptual framework goal and instead attempt to develop a more general, common European approach to karst waters that was less comprehensive and less binding than they had originally intended (Zwahlen, 2003).

The remainder of this chapter examines regional differences in karst land use regulations in the United States. The goal is to identify any regional patterns or similarities in the types of karst-related land use ordinances in place in various locations throughout the US, with the hope of understanding the local and regional forces, if any, that shape the development of these regulations and ordinances.

\section{Methodology}

In order to identify any potential location-driven patterns of similarity in karst regulation, I first had to obtain the codes of ordinances from municipalities in karstic areas. Publicly-accessible databases of county and municipal codes (including, among others, American Legal, MuniCode, and Lexis Nexis) were queried and examined for local land use regulations pertaining to karst and karst-related issues. The query terms employed in these searches were karst, sinkhole, spring, cave, limestone and carbonate. "False positive" results were common, especially relating to the search term "spring," this particular term would often bring up weapons-related ordinances that mention spring-loaded knives or guns. These karst-related regulations were then inventoried, and the municipalities that employed them were broken down along regional lines.

Using the National Karst Map (Davies et al., 1984), the United States was divided into several regions as a means of simplifying analysis (Figure 5-1). These regions

generally consist of groups of entire states; however, the extent and characteristics of the 
underlying karst were also taken into consideration. As a result, the karst regions of eastern Tennessee are included in the Appalachian Belt region as opposed to the SouthCentral region (which includes the rest of the state), due to the fact that the karst in eastern Tennessee has more in common with the karst of western Virginia than it does with the karst beneath Nashville.

Once these regulations were all assigned to the appropriate regions, I compared regulations based on components and strength. It should be noted from the outset that this survey of existing karst-related land use regulations in the United States should not be considered comprehensive, as the sample was limited to municipalities which have their municipal codes accessible online.

\section{Appalachian belt (Virginia, Pennsylvania, Maryland, New York, New Jersey, eastern Tennessee and eastern Kentucky)}

Karst-related ordinances are common in cities and townships in Pennsylvania and New Jersey. Expansion of residential development in the metro New York and New Jersey area since the 1970s has helped drive the passage of these ordinances. Motivations for enacting such laws differ - for some, it's a desire to limit (or close) population growth in the town itself, and to force new development to surrounding areas; for others, it's a desire to prevent groundwater contamination and to ensure structural integrity of new buildings; still others spring from a desire to eliminate the municipality's legal liability for karst-related damages. Of the variety of ordinance types in effect in this part of the country, Fischer (1997) feels that the North New Jersey Resource Conservation and Development Council (NNJRCD) Model Ordinance works best to achieve the oftenopposing goals of protecting its water resources and structures, and still permitting access 
Figure 5-1

Karst regions of the United States

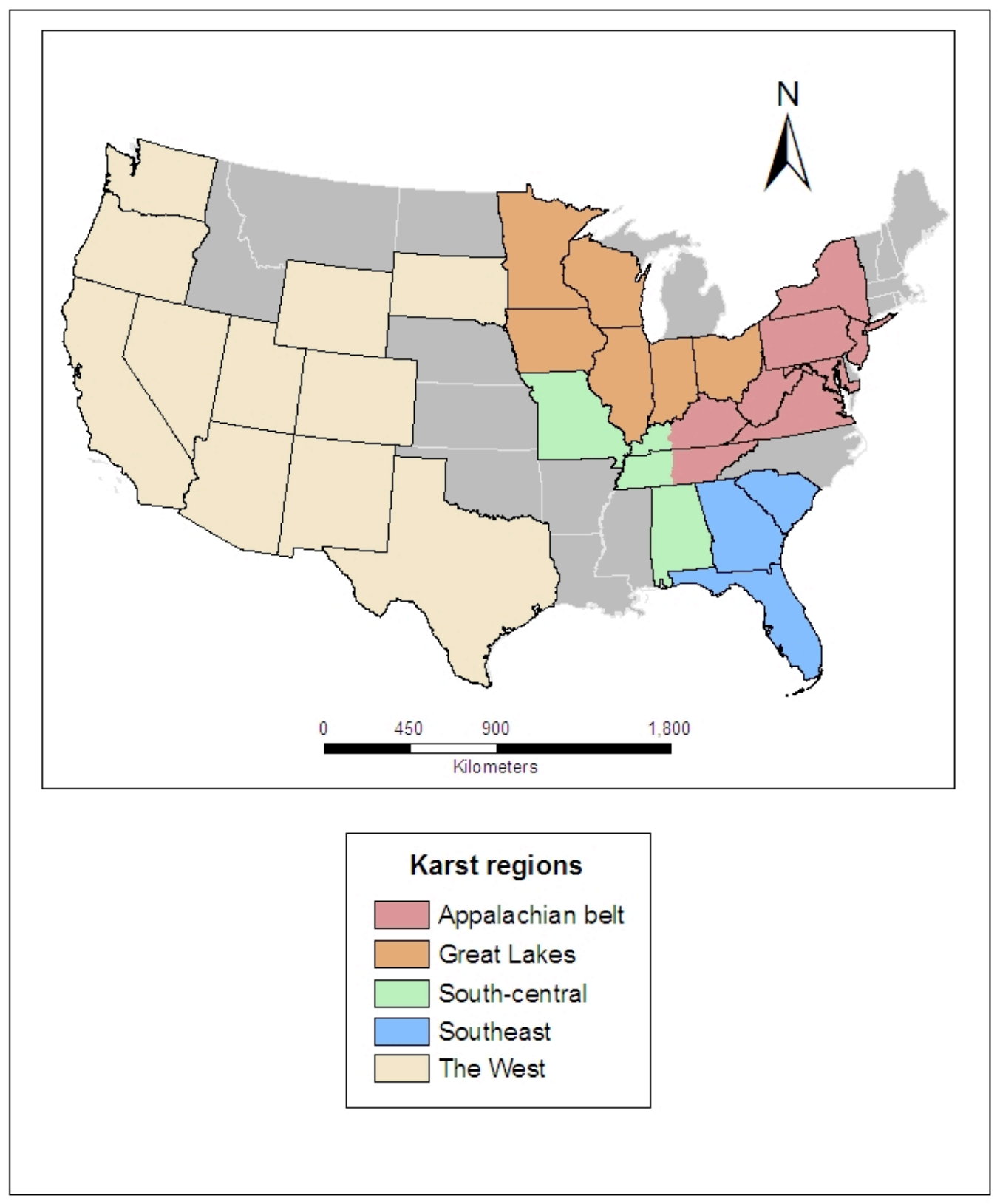

Source: US Census Bureau 
for new residents to the municipality in question.

Indeed, karst land use ordinances based on the NNJRCD's model ordinance can be found in several boroughs and townships in northern New Jersey, including Franklin Township (Warren County), Lebanon, Lopatcong, Pohatcong, Vernon, and Washington Township (both Morris and Warren counties). The ordinance itself depends on the use of a Carbonate Area zoning district for areas where carbonate rocks or carbonate drainage can be found (in the case of Franklin Township, the overlay district covers the entire town). Within these areas, additional karst-related data gathering and testing is required; this data shall be collected by direct means (to include site reconnaissance, test probes, test pits, and test borings) as well as indirect means (aerial photography and various geophysical methods). Once the data have been incorporated into the development plan, these geotechnical aspects are then subject to a separate review and, if found lacking, can serve as the basis for the denial of a permit. Failure to comply with the requirements of the model ordinance can result in a stop-work order, a necessary component if the ordinance is to have much effect on development and land use on karst. There are also many townships and boroughs that do not take the comprehensive approach to karst land use regulation provided by the NNJRCD's model ordinance. Many of these municipal codes contain a virtually identical passage that stipulates structural stormwater drainage measures must take into account the presence of limestone or carbonate rocks (though how this should be done is left unsaid); I counted no fewer than 23 municipalities (Table 5-2) that relied exclusively on this particular ordinance for karst land use management. 
Pennsylvania's karst country extends across much of the southeastern part of the state. The frequency with which sinkholes occur in the region has spurred some cities and townships to craft legislation regulating the land development process in karst areas. This began in the late 1980s, when the township of Lower Macungie, near Allentown, incorporated a set of karst-related development regulations into the township's land development code. Lower Macungie is a small municipality of about 24,000 residents in Pennsylvania's Lehigh County (population 326,000). It is important to note that in Pennsylvania, planning, zoning and subdivision responsibilities fall to local government, rather than to counties or to the state. This makes it easier for localities to deal with any karst-related issues they may face, which are almost never replicated on a statewide level (and indeed, often not even on a county level). The ordinance relies heavily on the use of overlay districts to impose extra burdens on developers hoping to build in sensitive areas. In drafting the Lower Macungie ordinance, existing ordinances in the area were examined by local government and outside consultants in order to identify provisions that were typically utilized by localities facing the same karst issues. Only two other ordinances were found, and both were subdivision ordinances, as opposed to zoning ordinances. Both ordinances had serious shortcomings: one was too restrictive on new development, and thought to be unenforceable; the other was not particularly detailed, and likely unable to restrict development in karst areas. Another problem common to both is that they are subdivision ordinances, which are easier to overrule or waive than are zoning ordinances (Dougherty, 1993).

Karst hazards are addressed in Section 794 of Lower Macungie Township's Subdivision and Land Development Ordinance (SALDO). In addition to establishing a 
Table 5-2

New Jersey municipalities relying exclusively on the structural stormwater requirements of the NJ model karst ordinance

\begin{tabular}{|c|c|}
\hline Alexandria & Holland \\
\hline Andover & Hopcatong \\
\hline Berkley Heights & Independence \\
Boonton & Jefferson \\
\hline Branchville & Little Falls \\
\hline Chatham & Madison \\
\hline Clifton & Morris \\
\hline Florham Park & New Brunswick \\
\hline Franklin & Paterson \\
\hline Glen Ridge & Rockaway \\
\hline Hamburg & Sayerville \\
\hline Hampton & \\
\hline
\end{tabular}


local Karst Hazard Map, this section describes additional procedures and requirements that must be met as part of the Preliminary Plan process for developments in karst areas. These developments require the participation of a licensed geologist to determine what steps the developer should take in order to mitigate any threat to the local karst (or, in the parlance of the ordinance, to meet the performance standards); the geologist's recommendations are then subject to review by the Town Engineer. The performance standards generally involve a 100-foot setback from the edge of any karst feature for proposed buildings, storm water detention facilities, swales or pipes, septic systems or tile fields, swimming pools, solid waste disposal areas, transfer areas or facilities, oil, gasoline, salt or chemical storage areas, and or blasting for quarrying or well enhancement activities (Lower Macungie Township, PA, SALDO, 2004).

Beyond Lower Macungie, there are several other cities and townships in Pennsylvania's karst areas that have some karst-related ordinances on their books. Many of these are quite limited: Allentown's requires that the possibility of sinkhole existence be taken into account when creating a stormwater detention plan (Allentown, PA, Code of Ordinances, $12779 \S 14,1987)$; Williams Township requires the disclosure of any karst features on property for which a grading permit is sought (Williams Township, PA, Grading Ordinance, 2005); and the extent of the city of Bethlehem's karst regulation is to require a bond from the developer intended to cover the cost of any sinkholes that form in the first year (Bethlehem, PA, Subdivision and Land Development Ordinances, 1349.13). Hanover Township's ordinance is not much stronger-it states that the presence or formation of a sinkhole under or very near a foundation or footing, the Building Official may withhold building or occupancy permits (if he or she feels the sinkhole poses a risk) 
until the developer explains exactly how that problem will be rectified (Hanover Township, PA, Code of Ordinances, Chapter 53). Other townships-like Catasauqua and Lower Saucon—have taken a more aggressive approach to regulating development in karst areas. Catasauqua's Code of Ordinances prohibit waste disposal in sinkholes if the property is accessible to the sewer system (Catasauqua Township, PA, Code of Ordinances, Chapter 210), and their Wellhead Protection plan requires new development to minimize the risk of sinkhole formation through design techniques and adequate site planning practices. Additionally, the Wellhead Protection Plan prohibits the redirection of stormwater into a sinkhole, prohibits the alteration of drainage patterns through regarding if such alteration would increase sinkhole risk, and mandates 100-foot setbacks from karst features (Catasauqua Township, PA, Code of Ordinances, Chapter 275). Lower Saucon has taken the overlay approach implemented by Lower Macungie. Lower Saucon's zoning ordinance defines a Carbonate Geology overlay district which includes the following restrictions: on-lot sewer system drainfields, underground propane tanks, or stormwater control basins are to be kept a minimum of 100 feet from the rim of any depressions, sinkholes and disappearing streams, and 50 feet from lineaments, fracture traces and pinnacles; outflow generated by the result of development cannot be directed into karst features; buildings or accessory structures must be 100 feet from any sinkhole, in most cases (likewise any toxic or hazardous substances); underground water, sewer and stormwater lines must have an impervious liner; most underground storage tanks are prohibited; and public sewers should be provided whenever possible and required—when they are not, applicant must provide a primary on-lot sewage system drainfield. There are 
also procedures in place for instances when a sinkhole appears after development approval has been granted (Lower Saucon Township, PA, Code of Ordinances, 180-95.C).

Other karst-related provisions within land use regulations and ordinances predate the Lower Macungie ordinance. District Township has perhaps the oldest verifiable karstrelated ordinance in the sample (passed in 1975), but it is also one of the weakest and most narrowly focused: it addresses permits for on-site sewage systems on property where sinkhole-related depressions exist within the absorption area (District Township, PA, Code of Ordinances, 1975).

While some regulatory techniques—like stormwater management—are employed by rural and urban communities alike, some tools are seemingly intended to address issues more common to one type of environment than the other. Through a shared zoning ordinance, the rural communities of Heidelsburg, Womelsdorf and Robesonia impose setbacks on manure storage facilities not otherwise covered by state regulation. This is the only karst-related provision found in this zoning code, and is one that is very unlikely to appear in the codes of more urbanized municipalities. Another regulatory tactic seen in rural areas is requiring setbacks for mining operations from sinkholes or karst features; in some cases, no other karst-related provisions are included. Some municipalities toward the center of the state impose riparian buffers around sinkholes and require filtering mechanisms to prevent unfiltered runoff from running directly into a sinkhole (for example, Halfmoon Township). This is not generally seen in ordinances passed in the Lehigh Valley region.

Karst-aware land use regulations are also present in Maryland, but often seem open-ended and vague; there also seem to be fewer of them than in Pennsylvania. 
Overlay-style karst management techniques are used in smaller towns like Hampstead and New Windsor. In New Windsor, for example, developments in areas of carbonate rock are required to incorporate design elements that are intended to accommodate the geological conditions. This is very similar to the way Taneytown approaches the issue, requiring subdivisions be designed in such a way that environmental resource areas (including areas of karst geology) are protected. The presence of these environmental resource areas must be included in certain plans during the pre-approval process. In Hagerstown, the city code stipulates that the presence of karst geology shall guide the selection of best management practices for stormwater drainage techniques. However, specific methods for accomplishing this are not identified, and a high level of leeway for developers and builders is present.

By contrast, karst regulations in Virginia are very strongly tilted toward informational requirements and setbacks. By far the most common karst-related land use requirements in Virginia are for the disclosure of sinkhole and spring locations at various points during the permitting process: Blacksburg requires such disclosure during the development of the stormwater management plan, and both the city of Roanoke and Franklin County stipulate that this information be included on the comprehensive site development plans themselves. In most cases, karst-related setbacks are related to agricultural land uses, like the location of swine facilities or chicken plants. Radford, Waynesboro and Montgomery County are exceptions to this, with more broadly applied setback / no-build rules. Montgomery County's Route 177 Corridor Overlay District stipulates a minimum 20 -foot setback from the edges of any sinkholes that occur there. In Radford, no land with sinkholes or caves can be platted for subdividing, due to flooding 
concerns, while these same lands are simply described as "unsuitable" for construction in Waynesboro. One interesting thing about Virginia's karst-aware land use regulations is that many places outside the state's western karst belt also seem to have them on the books. Springs are the most commonly mentioned karst feature to be protected; this could be because the regulations in question are meant to apply to all watercourses, regardless of whether or not they are actually present in the area (hence, springs are mentioned in some areas' ordinances as features meriting protection even though they are not actually found there).

Johnson City, Tennessee, employs setbacks in an unusual way. The setbacks only apply within the city's Sinkhole Overlay Zone, which was implemented as part of a larger set of floodplain regulations as a means of addressing flooding and groundwater contamination concerns. Within the overlay zone, development near sinkholes is constrained by a "25-year no-build line," which differs for every sinkhole depending on its capacity to handle runoff from a storm event of a specific intensity. Generating a unique line for each sinkhole requires a high level of understanding of the local drainage system, and can thus be an exacting process. The code does contain provisions for altering the location of these lines, should such an action be deemed appropriate. Additionally, zoning appeals board can consider requests for variances within both zones. Farragut (a suburb of Knoxville) has a fairly well-developed set of setback rules, which generally mandate a 50-foot buffer from the edge of any sinkhole; a different buffer (25 feet) applies to springs. Outside Farragut, Knox County itself employs setbacks in a much more limited fashions, applying them only to landfill siting. The city of Knoxville permits land containing sinkholes to be platted and developed only if the developers have 
taken steps to eliminate the potential for sinkhole-related flooding damage to buildings and other structures. The specific nature and character of these "steps" is never clearly spelled out.

\section{Southeast (Florida, Georgia, South Carolina)}

Karst regulations in Florida are extremely common in local governments of all sizes, from large urbanized county governments to smaller, rural communities. There is no single dominant method of regulation: overlays, setbacks, stormwater runoff and drainage and basic informational requirements are all employed throughout the state. That said, there are several areas in which karst-related land use regulation is stronger or better developed than most other cities or counties. Areas in which this is particularly true include Alachua County, Leon County, and Marion County.

Alachua and Leon counties are very similar demographically. Both contain midsized cities (Gainesville and Tallahassee, respectively) alongside large stretches of undeveloped, rural land; indeed, in 2000 Alachua and Leon counties had nearly identical populations (217,000 and 239,000, respectively) (U.S. Census Bureau, 2000). These social and physical similarities suggest that both areas might take similar approaches to karst land use management. In both counties, we see city and county regulations working in tandem to manage different aspects of the development of karst lands. Alachua County's regulations emphasize the control of stormwater runoff as an approach to karst terrains development: stormwater management systems must provide treatment to sinkhole runoff before discharging it into a sinkhole, and must be designed in a way that minimizes the risk of new sinkhole development. In some cases, wastewater may not be discharged into sinkholes at all. Additionally, the county does impose a setback around 
karst features, covering anywhere between 50 and 150 feet, depending on the specific characteristics of the feature in question. Within the city of Gainesville, environmental overlay zones are the primary tool for managing development on karst: the city's Significant Ecological Communities environmental overlay zone is used to protect sinkholes. Within these overlay zones, the city has the right to set aside up to 10 percent of a lot's area in order to facilitate clustered development that would protect the ecologically sensitive features.

In Leon County, there is somewhat more overlap between city and county regulations. Both the county and the city of Tallahassee apply an identical conservation area regulatory overlay to lands with active karst features. Within this overlay, all uses permitted by the underlying zoning classification are still permitted, with the additional stipulation that uses must be "compatible with the environmental conditions," and thus subject to additional restrictions if necessary (additionally, off-site density transfers are not permitted within the conservation area overlay). The city and county both use setbacks as well, though they are applied differently in each jurisdiction. The county's setback regulation (which does not actually use the word "setback") requires around any active karst feature a 35-foot buffer, inside which the land will remain in a natural state. Tallahassee's no-build requirement is nearly identical to Gainesville's in that it mandates that any land with karst features be given over to the city in the form of a conservation easement. The city also has detailed regulations on how stormwater runoff may be handled in karst terrains.

Historically, Marion County has maintained a more rural character than Alachua or Leon counties. Located just south of Alachua County, in recent years Marion County 
has been undergoing rapid urbanization. Marion County is unusual among Florida's rural areas in that it employs overlay zones as a means to control growth in karst terrains. The county's Environmentally Sensitive Overlay Zone (ESOZ) is applied to many of the area's springs; like the overlays used in Alachua and Leon counties, Marion County's code states that within the ESOZ all requirements of the underlying zone apply, with the added stipulation that development or usage cannot impair or diminish the condition of the natural features. The ESOZ also requires larger minimum lot sizes ( 1 acre) for any new developments, as well as 75 -foot setbacks from water bodies, including springs. Setbacks are also applied outside the ESOZ: residential developments must be set back 50 feet from any sinkhole edge, while non-residential land uses cannot be closer to a sinkhole than 200 feet.

In terms of population, Florida is one of the largest states in the country, and is naturally home to several major metropolitan areas. Orlando's approach to karst land use management stands out among these large cities in that it uses an environmental overlay to protect karst features. The overlay mandates the inclusion of more open space in developments in karstic terrains, implements a cap on the impervious surface ratio, and requires the use of best practices in managing stormwater and golf course runoff as well as the generation of an environmental assessment that details the locations of all sinkholes and springs in the area. This stands in contrast to large cities like Tampa or St. Petersburg, where no similar regulations are found: in Pinellas County, sinkholes cannot be considered as adequate positive outfall for runoff from new subdivisions, while Hillsborough County regulates runoff in wellhead protection areas and forbids 
excavations and landfills from sinkhole-prone areas (though it should be noted that sinkholes are historically less of a problem in Pinellas County than in central Florida).

On the other end of the spectrum, many of Florida's rural counties and towns have basic karst protection on the books; however, it's often not quite commensurate with the amount of karst that underlies the municipality in question. Citrus County, for example, seems only to require a 300 -foot setback between sinkholes and domestic septic systems, despite the high number of caves and sinkholes found there. Brooksville requires only the inclusion of karst landform information on various plans and maps; Lake Mary requires such information only on the drainage plan. Leesburg's code forbids landfills from being located in sinkhole-prone areas. Levy County requires a geologic analysis for any development over five acres in size, or for any development located in sinkhole-prone areas; however, there are no other restrictions spelled out in the county code. And the small town of Casselberry explicitly reserves the right to address karstrelated issues on a case-by-case basis.

However, a hands-off approach to regulating the use of karst lands is not universal among rural communities. Some rural communities are more aggressive in controlling their karst problems. Inverness reserves the right to declare a plot of land unsuitable for development because of the presence of sinkholes. Pasco County's code grants Special Protection Area status to karst features with the potential to drain directly into the aquifer; that designation includes a 500-foot setback from the edge of the feature, which was the largest setback found in the state. Neighboring Hernando County takes a similar approach by granting protected status to sinkholes and caves found within the county's designated wellhead protection areas; both Pasco and Hernando Counties regulate runoff and 
discharge into sinkholes as well. High Springs, a rural community in Alachua County, employs a set of well-developed setback regulations. Lands within 200 feet of a sinkhole edge are considered to be in a development constraint area. This includes a 50-foot nobuild zone, with any development occurring within the remaining 150 feet requiring professional certification that no damage will occur to the sinkhole as a result of development. Beyond that, it is also not permitted to direct stormwater runoff straight into sinkholes.

Communities in karstic southern Georgia tend to rely on either overlay districts or setback ordinances for karst land use management. Auburn, Bainbridge and Norcross are all examples of towns that rely on groundwater recharge overlay districts for this purpose; these districts are intended to protect "significant recharge areas" (a definition that includes karst landforms) from the negative impacts of human activity in the recharge zone. Of these three examples, Norcross' ordinance is the most comprehensive: development density is limited within the recharge overlay district, and is generally controlled by the imposition of larger minimum lot sizes. Further, "dangerous" land uses such as landfills or waste dumps are prohibited from being sited within the overlay; design standards are also employed to manage the impact of the development that does occur there. Bainbridge's ordinance is similar, but is somewhat more limited in its application: only residential developments where septic systems will be used are subject to the larger minimum lot size requirements. By contrast, Auburn's overlay does not restrict development or density at all within the groundwater recharge zone, but is instead solely concerned with the dumping of contaminants. 


\section{South-central (Kentucky, Tennessee, northern Alabama, Missouri)}

Throughout the south-central region, stormwater runoff and informational ordinances are commonly used as means of controlling development on karst. Some localities go a bit further and rely on setbacks (examples include Farragut, TN;

Lexington, KY; Springfield, MO; and Huntsville, AL). These setback ordinances are not uniform, with the most significant differences being the minimum distance between land disturbing activities and the sinkhole edge (Lexington requires a 100-foot buffer zone, while Springfield's no-build zone applies only to the sinkhole itself, and not to the surrounding area). Overlay districts are employed in smaller cities like Germantown, TN and Danville, KY; Danville's overlay specifically includes sinkholes as part of an ecological hazard district, while Germantown's wellhead protection overlay applies tobut never specifically mentions - karst landscapes. Regardless on the methods used, the goals are often related to flood prevention more than aquifer protection. Throughout the region, ordinances tend to be implemented primarily at the city level, as opposed to the county level.

In Kentucky, sedimentation is often the process that karst-aware land use regulations attempt to control, as in Bowling Green, Madisonville, Mayfield and Murray. This suggests very strongly that flood control is usually the primary concern of these stormwater management regulations. Indeed, stormwater problems were the initial driving force behind Lexington-Fayette County's sinkhole ordinance. In 1985, the Lexington-Fayette government passed an ordinance to regulate development with respect to sinkholes, karst features and their associated groundwater flow systems. This was in response to the revelation that many stormwater problems in the areas were caused by development in close proximity to sinkholes. The 1980 comprehensive plan contained the 
first serious attempts at regulating development in sinkhole areas in the Lexington region, but was eventually found to be too general to effectively manage development in karst areas. The 1985 ordinance sidestepped this problem by providing a definition of sinkholes, identifying specific maps for use in the field determination process, identifying specific types of testing and studies that must be done prior to development (as well as who is capable to perform them), and laying out acceptable modes of development near karst features. This approach facilitates the regulation of stormwater disposal from affected properties and the minimization of potential subsidence damages from sinkholes via regulation of development in their vicinity (Dinger and Rebmann, 1986). Opinions differ on whether or not the Lexington regulations have been effective; Rebmann notes that residential development still occurs on lots adjacent to those which are rendered unsuitable for construction by the presence of karst features, and because residential lots are on average significantly smaller than they were when the ordinance was first passed, impact on the karst system is not especially unlikely (Rebmann, pers. comm.., 2006).

Most of Alabama's karst is found in the northern part of the state, with another belt stretching through the middle and running to the northeast. The city of Huntsville is located in this northern karst belt. Huntsville's approach combines simple information requirements with actual setbacks: descriptions of all karst landforms and their locations must be included in various planning documents, and the city code mandates a 25-foot setback from the edge of any sinkhole for all new construction. This restriction is applicable citywide, but is also specified in the development requirements of the city's slope development district. Nearby Muscle Shoals' ordinance is clearly designed with flooding issues in mind, and takes an unusual approach in addressing them: the ordinance 
stipulates that no construction can occur in a sinkhole floodway, unless the developer removes a volume of material from the floodway that is equal to or greater than the volume of the structure erected in the floodway - in other words, no net loss of volume can occur as a result of construction.

In contrast to communities in the eastern part of the state, karst-related land use ordinances in central and western Tennessee commonly relate to stormwater drainage and runoff issues, trying to prevent sewage or sediment from draining directly into sinkholes (sewage for groundwater quality purposes, sediment for purposes of keeping sinkholes unblocked and thereby preventing flooding). Towns like Brentwood, Clarksville, and Colliersville do not go beyond this basic level of karst protection. Germantown was mentioned earlier as an example of a town using overlay districts; the nearby city of Nashville, on the other hand, employs no karst regulations whatsoever.

The fast-growing city of Springfield, Missouri, passed an ordinance in 1989 to more effectively manage the increased stormwater runoff that was a consequence of the rapid urbanization and population growth in sinkhole drainage areas. Prior to the ordinance, one method commonly used to control stormwater runoff in karst areas was to simply drain directly into sinkholes, which carried with it the possibility of introducing contaminants into the aquifer. The ordinance required that developers obtain an additional permit for projects proposed within sinkhole drainage areas; the permit application must address various geologic and structural issues to the satisfaction of the permitting authority before construction may proceed (Barner, 1999). Other places in Missouri, including rural Stone County, have embarked on similar projects (Barner, 1997); Springfield's experience points to potential shortcomings in their own approach, 
including the description of enforcement procedures and an oversimplified understanding of the spatial patterns of urban growth in the Springfield area (Barner, 1999). Jackson is another Missouri city that relies on setbacks or no-build areas to prevent damage to the local karst. In Jackson, any sinkholes on land undergoing subdivision will be given easements as a means to protect the landforms from human encroachment.

Throughout Missouri, it is not uncommon to find stormwater-related regulations that are very narrowly focused. St. Louis County forbids the installation of sewage tanks or soil absorption systems in the drainage area of a sinkhole, while Ballwin specifically permits sinkholes to be used for drainage as long as there's an outfall pipe installed (in case the sinkhole cannot handle the excess runoff). Hannibal exempts one- and twofamily residential developments from the requirements of the onsite stormwater management plan, unless the development adversely impacts a sinkhole; in that case, the plan is required. In most other cases, the only requirements relating to karst are for information about location of sinkholes or springs, and in some cases even those requirements are limited to very specific circumstances, like the location of sanitary landfills.

\section{Great Lakes (Indiana, Illinois, Iowa, Minnesota, Wisconsin, Ohio)}

In this region, karst-related land use regulations tend to be focused on either information requirements or stormwater management and drainage. Aquifer protection seems to be a stronger focus here than in, say, the south-central region: there are more regulations specifically mentioning sewage discharges, bio-solids or contaminants from construction sites draining into sinkholes, as well as limitations on the use of septic systems in areas with inadequate depths of overburden covering the limestone bedrock. 
When setback regulations are found, they are often quite specific and narrowly focused, usually regulating the placements of human or animal waste facilities. Regulations and ordinances seem to exist mostly at the city or town level, and are less common at the county level.

Indiana's regulations are almost exclusively information requirements or related to stormwater runoff, and include nothing not discussed elsewhere in this chapter. One interesting and immediately noticeable characteristic of Indiana's karst-aware land use ordinances is that many, if not all, of the karst provisions are identically worded between towns, strongly suggesting that most towns are working from the same basic set of templates. This isn't all that surprising, really—it suggests that these provisions have been found to be legal or are thought to be most likely to be able to withstand court challenges in the future.

In Illinois, the more comprehensive karst-related land use regulations are found in towns located in the southwestern part of the state, near St. Louis, MO. This is the location of one of two large karstic zones (the other is in the northeast, near Chicago). Here again, one sees a great deal of repetition in karst regulations between towns. Maryville and Godfrey, both near St. Louis, have several identical components to their karst-aware land use regulations; these include the requirement that stormwater not be redirected into a sinkhole, or that stormwater drainage basins be set a minimum of 100 feet from a sinkhole edge. Both towns also mandate that "special precautions" be taken to prevent damage to sinkholes as the result of necessary development activity. As in many other locations, neither "special precautions" or "necessary development activity" are specifically defined. 
Municipalities in the northern Great Lakes seem to rely on setbacks more frequently than in Indiana or Illinois; these setbacks generally relate to facilities for storing human or animal waste (Ottumwa, IA; Oconomowoc, WI; Pepin County, WI; Waushara County, WI). Work in southwestern Wisconsin conducted by Day and Reeder (1989) suggests that even in the absence of local regulations or ordinances, landowners will adjust their own land use strategies to conform to the presence of sinkholes. Generally they are left alone, though in some cases they are used for waste disposal, as the waste often fills a secondary purpose of providing infill material for the sinkhole (Day and Reeder, 1989).

\section{The West}

Karst-aware land use regulations and ordinances are less commonly found in the western United States. This is likely due to any number of factors, including the lower population densities, the more scattered distribution of karstic lands, the fact that so much of it is paleokarst, and the so-called "western ethic" of land use regulation. However, there are still isolated instances of karst land use regulations. Moab, Utah uses drinking water protection zones that mandate tighter restrictions on development as it gets closer to the wellhead. However, in no case is building and development completely forbidden within a protection zone; instead, discharges of pollutants or contaminants are regulated and controlled. In Santa Fe, New Mexico, density transfers are suggested as a method of protecting springs (a density transfer occurs when a developer is given permission to exceed density requirements on another project elsewhere, in exchange for not developing in a sensitive area). 
Austin, Texas provides a stark contrast to the prevailing western approaches to regulating karst land use. In Austin, increasing rates of urbanization had begun to seriously threaten the karstic Edwards Aquifer by the early 1980s. In response, the city enacted a series of ordinances and regulations that approached the issue of aquifer contamination from several different angles. These included the management of stormwater runoff with additional engineered solutions (i.e., stormwater control basins with filtering mechanisms), the development of a three-tiered watershed zone system designed to manage the types and intensities of land use that are permitted along waterways within the watershed, and the ability to transfer development rights (and therefore shift land use intensity) from the Buffer watershed zone to the Uplands zone, where development is less likely to negatively impact the karst aquifer (no development is permitted within the watershed's designated Critical zones). Butler (1987) cites two advantages to relying on such an interdisciplinary approach: first, uncertainty as to the effectiveness of either the land use management approach or the engineered controls approach is reduced; and second, each approach has advantages the other does not (Butler, 1987).

\section{What it all means}

Table 5-3 provides a summary of the most commonly-used regulatory techniques in each region. As mentioned earlier, there are some important limitations to the data presented in this chapter. Despite these limitations, however, there are several important conclusions we can make:

1. Regulations seem to display more within-state similarity than within-region similarity. This suggests that municipalities may be more concerned with implementing 
regulations that will withstand legal challenges within their own states than they are with the specific physical nature of the karst system below (because these systems often cross state lines, we would expect to see strong within-region, interstate regulatory similarities if the strongest driving factor was the physical characteristics of the karst itself). The one exception to this is the case of Tennessee, in which communities in the eastern part of the state tend to take a more proactive approach to managing karst problems through regulation.

2. There does not seem to be any relationship between levels of urbanization and regulatory methods used, or indeed between urbanization and the existence of karst regulations or ordinances. Several large, highly urbanized areas on karst-Tampa, Florida and Nashville, Tennessee are good examples — either have rudimentary karst protections on the books, or none at all, while some rural locales (for example, High Springs, Florida) have taken a much more proactive approach to regulating development on karst terrains. However, it is difficult to argue that there is an inverse relationship between government sophistication and regulatory sophistication, since urban areas like Lexington, Kentucky and Huntsville, Alabama also use the regulatory system to manage development on or near karst landscapes; likewise, there are many examples of rural communities in karst terrains where no regulatory mechanisms exist.

3. Stormwater runoff is a very common way-indeed, perhaps the most common way - to regulate land use in karst areas. Possible reasons for this are explored in the next chapter.

4. Overlay zones, while not in especially wide use, are applied in rural settings as well as urban areas. This is surprising, as it seems reasonable to assume that the lower 
demands and pressures on rural lands should not require a regulatory tool as blunt as an overlay zone.

Table 5-3

Most commonly-used regulatory techniques in each region

Region Dominant regulatory techniques

\begin{tabular}{l|c|}
\hline Appalachian belt & $\begin{array}{r}\text { Setbacks; stormwater management; extended pre- } \\
\text { development review requirements }\end{array}$ \\
Southeast & $\begin{array}{r}\text { Stormwater management; setbacks; overlay zones } \\
\text { Stormwater management; informational requirements }\end{array}$ \\
South-central & Stormwater management; informational requirements \\
Great Lakes & Groundwater protection \\
\hline Western U.S. & G
\end{tabular}




\section{How planners and land use professionals understand karst and karst-aware land use regulation}

\section{Introduction}

The preceding chapter presents an overview and examination of karst land use regulations throughout the United States. This examination was conducted in the hopes of identifying any regional factors that might influence the form of these regulations in places where they are used. Ideally, any understanding of the larger karst-related land use regulatory situation should be informed by written laws and regulations, and an awareness of how these regulations have actually affected conditions "on the ground." In order to accomplish this, I felt it necessary to supplement the analysis conducted in Chapter 5 by drawing upon the professional educations and years of experience of land use planning professionals in karst areas throughout the United States. Certainly their insights into the regulations they work, and helped design, would be valuable.

What can be learned about karst land use regulation from land use professionals? To find out, I designed and implemented a survey intended to explore the opinions, attitudes and experiences of this group. Specifically, I had identified several general themes that I planned to address in the survey:

- How widespread is karst knowledge in the planning community?

- How widespread was the practice of regulating development in karst areas? 
- What kinds of karst regulations were most common? What mechanisms were included in these regulations? Are there differences from region to region?

- What motivated the implementation of these regulations? What problems were they intended to address?

- Which groups had the most influence on the process of regulatory development? Which groups had the least?

- What's the actual effect of these regulations? Do they work? What do they actually accomplish?

The survey itself was designed with the goal of casting a wide net and collecting a broad cross section of data. Ultimately, some survey questions provided little in terms of illumination, while others proved to be more revealing than initially expected.

\section{Methodology}

The first step in creating and deploying this survey was to identify potential respondents and gather contact information. I identified seven states in which karst landscape was present: Florida, Kentucky, Missouri, New Jersey, Pennsylvania, Tennessee and Texas. Using various geological maps, I then identified in each state towns, cities, and counties where karst was likely to be found. Finally, I visited the official websites for as many of these municipalities as possible, searching for contact information for individuals likely to be involved in land use planning or in fields that may require some knowledge of karst. This includes people working in planning, zoning and growth management departments, water departments, public works departments, and environmental services departments. In some cases, people working in relevant state, regional or federal agencies (for example, the Southwest Florida Water Management District, the Pennsylvania Department of Conservation and Natural Resources, or the 
U.S. Geologic Survey) were also included in this list of potential respondents. However, the number of these contacts was intentionally kept low; I felt their input could be valuable, but wanted to ensure that the data and opinions provided by those working at the local level were more dominant in the results presented here.

Since I had decided early on that the survey would be administered over the Internet, the most logical type of contact information to collect was email addresses. In some cases, email addresses for a specific individual were not available. In those instances, contact was attempted via a department email address (i.e., info@,cityplanningdept.gov), or via a browser-based contact form provided on the agency website.

The survey itself was developed in October 2006 and conducted using the SurveyMonkey web-based survey design and data collection service. The survey was accessible from November 25, 2006, to January 2, 2007. There were a total of 35 questions included in the survey, most of which were in multiple-choice format, often with a free response component included as an option. Several questions were in free response format only, with no multiple-choice component. "Survey logic" was employed in this survey, which means that a respondent's answers to certain questions determined which additional questions he or she would have the opportunity to answer. The first question of the survey — "are you familiar with karst?"-was included as a "weeding out" question: if a respondent indicated that he or she was not familiar with karst, the survey ended immediately (Patton, 1980; Weisberg, et al., 1989).

Approximately 575 attempts at contact were made. 66 responses were received from respondents in six states (no responses from Texas were received), generating about 
a response rate of 11.5 percent. 16 of these respondents indicated they would be willing to participate in follow-up interviews via email after the survey was concluded; these were conducted beginning the week of January 15, 2007. The survey itself is included at the end of this dissertation as Appendix A.

\section{Survey respondents}

Table 6-1 below describes the makeup of the sample and provides a breakdown of the location of respondents. The largest number of responses came from Florida, almost certainly due to the fact that nearly half the total attempts at contact made were directed to land use professionals in that state. Tennessee had the highest overall response rate. Nine respondents declined to state a location.

Table 6-1

Locations of survey respondents

\begin{tabular}{|l|c|c|c|c|}
\hline & $\begin{array}{c}\text { Attempts at } \\
\text { contact made }\end{array}$ & \multicolumn{2}{c}{$\begin{array}{c}\text { Responses } \\
\text { Response } \\
\text { rate }\end{array}$} & $\begin{array}{c}\text { Pct. of total } \\
\text { responses }\end{array}$ \\
\hline Florida & 232 & 24 & 10.3 & 36.36 \\
\hline Kentucky & 41 & 6 & 14.6 & 9.09 \\
\hline Missouri & 143 & 8 & 5.6 & 12.12 \\
\hline New Jersey & 42 & 2 & 4.8 & 3.03 \\
\hline Pennsylvania & 74 & 13 & 17.6 & 19.69 \\
\hline Tennessee & 21 & 4 & 19.0 & 6.06 \\
\hline Texas & 22 & 0 & 0 & 0 \\
\hline No location stated & & 9 & & 13.63 \\
\hline Total & 575 & 66 & 11.5 & 100 \\
\hline
\end{tabular}




\section{Survey Results}

In this section, the survey responses are examined in aggregate, broken down along six general thematic lines: familiarity with karst; the nature of karst-related issues in the respondents' areas; the nature of karst land use regulations; general characteristics of the implementation process; expected and actual outcomes of implementing karst regulations; and the appropriateness and effectiveness of regulating development on karst lands.

\section{Location of respondents and familiarity with karst.}

The survey began with a series of questions designed to offer a glimpse into exactly who had responded to the survey, and whether their insights were likely to be useful in developing the framework. 65 percent of respondents were from either Florida or Pennsylvania. The balance was split between Kentucky, Missouri, New Jersey, and Tennessee. There were no responses from anyone working in Texas. 82 percent of respondents work in local government.

Eighty-nine percent of the survey respondents indicated having some familiarity with karst. This is not especially surprising, since some effort was made to target respondents from karstic areas. 56 percent of respondents indicated that they are aware of some form of karst regulation on the books in their municipalities. The question was phrased in very broad language, which means that these ordinances likely encompass a wide variety of regulatory techniques and may differ significantly in terms of regulatory scope and strength.

Respondents who indicated that they were not aware of any karst-related land use regulations in their communities were asked for their opinions regarding this lack of regulation (Question 7). The absence of karst geology within municipal boundaries was 
cited by 11 percent of respondents; approximately 17 percent cited either philosophical opposition to regulation or pressure from developers as the primary reasons for the lack of regulation. In the free response segment of this question, a lack of information on or understanding of karst was cited as a reason; many respondents indicated that they did not feel the issue of karst was significant enough to merit such a high level of attention:

- "The lack of sufficient information regarding active sinkhole areas is the biggest reason that no specific regulations have been developed. Although this area is considered karst topography, it has not presented a major problem with development."

- "Not an issue that has been raised to the level of needing to be addressed."

- "There has been no driving force to implement such regulations."

- "Lack of knowledge on the subject and no directive from policy makers to make it an item of discussion."

- "Our SALDO (subdivision and land development ordinance) is very old and has not been updated for some time. This has not been a significant issue for our development."

- "Allocation of time and resources to other pressing issues."

2. Characteristics of the local karst, and the nature of karst-related issues

Seventy-five percent of respondents indicated that karst underlies more than 30 percent of their municipality's land area, with 32 percent indicating the presence of extensive karst beneath their municipalities ("extensive" is defined here as existing beneath at least 51 percent of their municipality's territory). The obvious implication of 
this is that many of these cities, towns and counties are prime candidates for karst-related land use regulation.

Different types of karst landforms seem to be evenly distributed among the sample. All respondents working in municipalities underlain by karst say that sinkholes are present in their municipalities; 94 percent have springs in their municipalities, while both caves and sinking streams are present in 74 percent. This level of similarity suggests that any differences in regulatory techniques will be driven by factors other than the nature of karst landforms in the municipality.

48 percent of respondents point to groundwater contamination as the most serious karst-related problem in their municipality; 63 percent say that cave protection is the least important karst-related problem. These results are more or less mirrored in another question that asked respondents to rate the severity of various karst-related problems; options were "very serious," “somewhat serious" and "not serious." Here again, groundwater contamination was seen to be the most serious karst-related issue, and cave protection the least.

\section{The regulations themselves: components, restrictiveness and goals}

A majority of respondents indicate that karst regulations in their jurisdictions have some teeth. Fully 54 percent of respondents perceive the karst-related land use regulations in their municipalities as at least somewhat restrictive, with 11 percent describing them as "very restrictive." No definition of "restrictive" was offered; this was intentional, as I was more interested in determining what the survey subjects themselves consider the word to mean. This point is expanded and addressed in the next section of this chapter. 
Groundwater protection, general environmental protection, and a desire to limit structural damage from sinkholes were most common reasons for implementing such regulation in the first place; far less commonly-cited reasons included cave protection and avoiding litigation (only 7 percent cited cave protection as a motivation for passing karst regulations). Stormwater drainage regulations are by far the most common regulatory technique employed to accomplish these goals (cited by 90 percent of respondents), followed by mandatory setbacks ( 58 percent), dumping and waste disposal rules (55 percent), and additional steps in the permitting process (52 percent). 67 percent say that karst-related land use regulations were implemented in their municipalities as a reactive measure to address pre-existing problems, rather than as a preventative measure to forestall problems from developing. Respondents who answered that their regulations were reactive in nature were asked to describe the specific nature of the problems that led to the implementation of the regulations. Contamination of groundwater resources and damage to property were the most common themes:

- "Sinkholes have caused extensive damage to buildings, highways, utilities and public facilities. Sinkholes have even led to death in connection with natural gas lines."

- "County growth made the regulations necessary for ground water protection, flooding, property damage, and general environmental conservation."

- "A backyard collapsed due to development over a karst system. At the time the house was worth 62 thousand and it cost about 175 thousand to fix the problem." 
- "Flooding of new lakeside homes where developer illegally diverted stormwaters into an injection well/sinkhole without a TDEC Class V injection well permit. Sinkhole backed up and also flooded downstream before waters entered lake."

- "Mostly preventative, except for issue of groundwater/aquifer impact, which had been ongoing."

- "No storm sewer system; sinkholes used for storm water disposal."

- "Excessive nitrates in groundwater and stormwater affecting surface water quality."

- "Often communities try to pass a carbonate ordinance when they are faced with a potential development coming to town."

- "Sinkhole activity had contributed to destruction of roadway surfaces, detention ponds and drainage courses. There was additional impact on private wells and a public water supply."

4. The implementation process: stakeholders, time, and other factors

It is difficult to understand the regulatory process without knowing who drives it. According to the survey, 39 percent of the time, proposals for regulating land use in karst terrains came from a branch of local government; 21 percent of the time, it came from state or federal government instead. In most cases (62 percent), these regulations were ultimately approved and implemented by a commission or other elected body, with a single elected official being responsible for ultimate implementation 21 percent of the time. 
When asked about the length of time it took for karst-related land use regulations to be implemented in their jurisdictions, nearly 40 percent say that this occurred within two years of the initial proposal (33 percent either don't know or don't remember how long it took, which was the second-most popular response). This suggests that certain policy analysis tools that focus on the long term, like Sabatier's Advocacy Coalition Framework (Sabatier, 1988, 1991a), may not be completely appropriate for use in analyzing the implementation process of karst-related land use regulations.

In many cases, there was a varied mix of people and entities that contributed some input into the process of developing these regulations; of the options provided, the two that were selected least frequently are the building and construction industry (18 percent) and the federal government (15 percent). Local government departments were generally recognized as having the most influence the process (52 percent); the federal government was recognized as the least influential (52 percent).

Non-elected professionals were influential: Forty-seven percent of respondents said they had a strong influence on the development of the regulations that were ultimately implemented. Some representative comments from this group of respondents include:

- "Geologist, soil scientist, hydro geologist, biologist, and others all have had a significant role in conducting solid science to be used in development of the rule;"

- "Regulations reflected credible engineering and geologic knowledge and experience;" 
- "Provision of the science base for understanding groundwater, the aquifers in the state, the rate of recharge, etc., affected decisions prioritizing areas that are karst sensitive and in developing the land use regulations to protect them."

Local residents, on the other hand, did not seem to have much influence on the regulations: 33 percent of respondents described local residents' influence as "slight," while 18 percent described it as nonexistent. In cases where local residents had a greater influence on the regulation development process, no real pattern emerges; one respondent suggests that citizen participation is tied to the level of danger posed to residences by karst, but this theme is not repeated in other responses:

- "Where houses have been subject to flooding, there was major clamoring to solve problems...buy-outs and identification of flood limits around sinkholes."

- "Local residents participated in the process; were generally supportive."

- "Public input was a continuing part of the process of developing land use regulations, through the comprehensive planning review process."

- "The reporting of the various incidents provided sufficient documentation to warrant investigation of appropriate regulations and safeguards."

- "Clearly, the public is concerned about the occurrence of sinkholes as it is a regular 'phenomenon' due to subsurface conditions, location between three bodies of water, and the early, dense urban development of the City prefederal, state or local land use regulation. City Planning, Zoning and Engineering personnel took the lead develop and enforce regulations in the interest of the public health, safety and welfare." 
Respondents indicate that generally, these regulations were not affected by other land use regulations already in place. Thirty-nine percent of respondents indicated that pre-existing land use regulations and ordinances had no influence on the development of the karst-related regulations; 24 percent described this influence as slight. Several respondents offered more information in the free response section; those listed here are from respondents who felt that existing land use regulations had either no impact or only a slight influence on the development of karst-related land use regulations in their jurisdictions:

- "City had previously passed Creek regulations governing increased setbacks."

- "Karst regulations represented a new field of regulation."

- "[Regulations were] part of comprehensive plan."

- "State already had regulations about setback of septic systems from karst areas (sinkholes etc.) which were incorporated in development reviews."

- "Knowledge of related state regulations was used in pressuring the local elected officials to push for adopting similar regulation."

\section{Expected outcomes and actual outcomes of karst regulation}

Some of the more interesting findings of this survey are the differences between what respondents say they would expect to come from implementing additional regulation on development in karst terrains, and what actually happened. For example, 34 percent of respondents indicated they would expect the implementation of karst regulations to lead to an increase in housing costs; but only 11 percent actually witnessed this. Likewise, 18 percent say they would anticipate the number of new development projects in a town that regulates development on karst to decline. However, only seven 
percent claim to have seen new projects locate elsewhere as a result of the presence of karst-related land use regulations. 14 percent indicated they would expect population density to decline; again, a much smaller percentage ( 2 percent) actually saw this happen as a result of implementing karst regulations. Perhaps most surprisingly, fully 75 percent or respondents said they would expect to see an improvement in groundwater quality as a result of the implementation of karst regulations; only 19 percent actually did see such an improvement.

The free response segment of Question 32 elicited a wide range of expected outcomes of adding additional regulatory requirements to developing in karst terrains. Qualitatively speaking, expectations expressed here tended to be distinctly positive or distinctly negative; very few incorporated both the positive and the negative. The list below is a representative sampling of responses:

- "Effects on development could vary; could reduce development \& increase housing costs, but karst features could also become a valued amenity to property."

- "Lower property insurance rates; a decline in structures collapsing or subsiding into the karst features."

- "A decline in build-out population and structural density due to better treatment of stormwater and the need for more space for surface water treatment. 2) More groundwater recharge areas. 3) Open space dedications in very karst areas, spring protection zones."

- "Improved public safety, preservation of land values, landscape appropriate development, increased environmental quality." 
- "None. Karst regulations carry the same weight as other design criteria found in local land use ordinances, i.e. stormwater management, traffic, improvements layout, floodplains, watercourses, etc."

- "It would be very difficult to isolate areas that this type of regulation would apply. Developers in Florida are required to do hydrogeological tests to determine subsurface conditions. Even with these tests, sinkhole activity in Florida is hard to predict."

- "Increase in development related lawsuits. Also, increase in number of variances requested (to develop where karst exists)."

- "Increase in development costs. Level or declining tax base."

Interestingly enough, when subjects were asked what outcomes of implementing karst regulations were actually observed (Question 34), one notices a sharp difference in tone and content from the expectations set forth above. Regulations were not seen to have significant impact on development costs, and some respondents felt the regulations improved the quality of development decisions:

- "A slight increase in cost of permitting for a small number of developments."

- "Housing costs have increased in the last 15 or so years since the initial regulations were put in place, but I don't think there is any correlation between these costs and the regulations."

- "Better development decisions can be made due to the requirement that karst features be identified on subdivision plats."

- "More environmentally appropriate development." 
Additionally, 70 percent of respondents say that the presence or absence of karst regulations in neighboring towns had no impact at all on their decisions regarding the implementation of such regulations in their own municipality. This sort of strategic behavior will be examined in more detail later in this dissertation.

\section{Appropriateness and effectiveness of regulating development on karst}

Survey respondents are overwhelmingly friendly to the concept of regulating development on karst: 97 percent said it is appropriate for municipalities to do so (one respondent either didn't know or had no opinion; nobody indicated that they felt such regulation is inappropriate). 68 percent said the karst-related regulations in force in their jurisdiction are effective; 18 percent say they are not, with the balance expressing no opinion. Even so, 70 percent of respondents indicated that they feel there is room for improvement in their municipality's karst regulation strategy. In the free response segment of this question, recurring themes included tightening restrictions on development in karst areas, improving information flow (both between government and the public, and between different branches of government), and enforcement and followthrough by regulating agencies:

- "I'm not sure that building sites are always well selected in relation to karst ... implication: potential review with building permit, especially on pre-existing subdivisions (prior to setback provisions that are currently called for with newer subdivisions)."

- "Get more municipalities to adopt [karst land use regulations]."

- "Provide more restrictions and not allowing the filling in of sinkholes unless approved via a public hearing." 
- "We could require further setback from 'inactive' karst features; we could require 'high performance' septic tanks or central sewer systems as a minimal requirement for low density residential development, to remove nitrates and reduce their impact to groundwater/aquifer."

- "We need to add buffering or preserves around known sinks and other karst areas. Right now we rely heavily on the Flood Damage Prevention Resolution to protect all waters of the state, the Illicit Discharge Detection and Eliminary Resolution to regulate illegal dumping, and more specifically holding up all construction plan approval until the State's geologist can approve any new subdivisions where sinkholes and caves have been identified, thus requiring injection well permits if stormwater diverted to sink or at least protection around the cave/sink during construction. We definitely can stand to improve our regs."

- "Better mapping of karst areas and stronger follow-up by the regulating agencies."

- "Could expand consideration to all development situations, particularly commercial site plans."

- "Mapping karst area and grading their vulnerability to sinkhole formation and ground water contamination and making these maps available to the public."

- "Educating the general public to the necessity of it. More can always be done."

- "Larger karst feature setbacks, and larger setbacks in general for environmentally sensitive areas, i.e. riverine corridors." 
- "Better coordination between sectors of government and other government entities.”

\section{A more detailed analysis of the results}

While these results are certainly useful if we wish to generalize about karst land use regulation, developing a deep understanding of karst regulation will require more detailed information. The remainder of this chapter is dedicated to seeking out patterns and meaning within the survey responses.

\section{The meaning of "restrictive"}

In Question 14, subjects were asked to provide their opinions on the restrictiveness of the karst land use regulations in place in their jurisdictions. While it is clear that the vast majority of respondents consider the regulations to be either "not very restrictive" or "somewhat restrictive," those results are of limited use unless the terms can be more precisely defined. By cross-referencing responses to Question 14 with responses to Question 16 ("To the best of your knowledge, which of the following karst-related regulatory components are present in your jurisdiction's land use and development regulations?"), the relationship between perceived regulatory restrictiveness and the use of specific regulatory tools among the sample can be described. Table 6-2 shows that municipalities with regulations perceived as very strong are more likely to employ nearly every regulatory tool listed. In particular, mandatory setbacks and extra administrative steps in the permitting and building process are more common in jurisdictions with higher perceived regulatory restrictiveness. This suggests that the respondents' views of what constitutes "restrictiveness" is not completely subjective, and does in fact seem to be tied to the implementation of certain regulatory techniques. 
Table 6-2

Perceived restrictiveness of karst regulations

\begin{tabular}{|c|c|c|c|c|}
\hline & $\begin{array}{l}\text { Not at all } \\
\text { restrictive }\end{array}$ & $\begin{array}{l}\text { Not very } \\
\text { restrictive }\end{array}$ & $\begin{array}{l}\text { Somewhat } \\
\text { restrictive }\end{array}$ & $\begin{array}{l}\text { Very } \\
\text { restrictive }\end{array}$ \\
\hline $\begin{array}{l}\text { Total observations in each } \\
\text { category }\end{array}$ & 2 & 12 & 15 & 4 \\
\hline \multicolumn{5}{|l|}{ Techniques used } \\
\hline Mandatory setbacks & 0 & $5(41.66 \%)$ & $10(66.66 \%)$ & $4(100 \%)$ \\
\hline Single extra step & 0 & $3(25 \%)$ & $9(60 \%)$ & $4(100 \%)$ \\
\hline Multiple extra steps & 0 & $2(16.66 \%)$ & $4(26.66 \%)$ & $2(50 \%)$ \\
\hline Stormwater drainage & $2(100 \%)$ & $10(83.33 \%)$ & $14(93.33 \%)$ & $4(100 \%)$ \\
\hline $\begin{array}{l}\text { Dumping and waste } \\
\text { disposal }\end{array}$ & $1(50 \%)$ & $5(41.66 \%)$ & $9(60 \%)$ & $3(75 \%)$ \\
\hline $\begin{array}{l}\text { Fertilizer and chemical } \\
\text { application }\end{array}$ & 0 & 0 & $4(26.66 \%)$ & $2(50 \%)$ \\
\hline Other options & \multicolumn{4}{|c|}{$\begin{array}{c}\text { (the following regulatory tools were mentioned in the free } \\
\text { response segment of this question) }\end{array}$} \\
\hline Zoning overlay & 0 & 0 & $1(6.66 \%)$ & 0 \\
\hline $\begin{array}{l}\text { Designation of non- } \\
\text { buildable areas }\end{array}$ & 0 & $1(8.33 \%)$ & 0 & $1(25 \%)$ \\
\hline $\begin{array}{l}\text { Sinkhole area excluded } \\
\text { from minimum lot size } \\
\text { requirements }\end{array}$ & 0 & $1(8.33 \%)$ & 0 & 0 \\
\hline
\end{tabular}

Numbers in parentheses reflect the percentages of communities in each restrictiveness category that employ a given regulatory technique 
One exception to this pattern is stormwater drainage regulations. Stormwater regulations are almost universally applied, regardless of the overall restrictiveness of the karst regulations. Within the sample, stormwater regulations are used in the majority of communities with regulations perceived as "not at all restrictive" and "not very restrictive;" no other regulatory tool is used in more than half of these communities. Responses from follow-up interviews indicate that the popularity of stormwater regulations as a development tool in karst areas stems from the relatively high visibility of un-addressed runoff-related problems (politicians are more likely to respond to issues that are more visible and immediate), as well as the comparative ease of getting developers to comply with such regulations.

\section{Goals, effectiveness and the potential for improvement}

In any endeavor, it is difficult to identify success or failure without a clear idea of what the goals of the endeavor are. By identifying the specific goals of regulating development on karst terrains, questions relating to the comparative effectiveness of these regulations can be examined. For one, are these regulations more effective in achieving some goals than others? Are some of the most frequently-cited goals of karst land use regulation perhaps too large to resolve via the regulatory tools available to local governments?

Table 6-3 lists five common goals of karst land use regulation, alongside the number of respondents who indicated each goal as one that their own karst regulations were intended to address (question 17). Multiple answers to question 17 were permitted, and some respondents selected all five options. The two right-hand columns break out the responses given for question 31 ("In your opinion, are the karst-related land use 
Table 6-3

Relationship between regulatory goals and perceived regulatory effectiveness

\begin{tabular}{|c|c|c|c|}
\hline \multirow[t]{2}{*}{ Regulatory goals } & \multirow{2}{*}{$\begin{array}{l}\text { Number of respondents } \\
\text { citing each goal }\end{array}$} & \multicolumn{2}{|c|}{ Effective? } \\
\hline & & Yes & No \\
\hline Environmental protection & 22 & 14 & 4 \\
\hline Groundwater protection & 30 & 19 & 6 \\
\hline Cave protection & 7 & 4 & 2 \\
\hline $\begin{array}{l}\text { Limit structural damage } \\
\text { from sinkholes }\end{array}$ & 28 & 21 & 5 \\
\hline $\begin{array}{l}\text { Limit governmental } \\
\text { liability in lawsuits }\end{array}$ & 11 & 9 & 2 \\
\hline
\end{tabular}

Table 6-4

Relationship between perceived regulatory effectiveness and perception of potential improvement in local regulations

Are local karst land use regulations effective?
Is there room for improvement in local karst land use regulation?

\begin{tabular}{|c|c|c|}
\hline & Yes & No \\
\hline Yes & 13 & 5 \\
\hline No & 3 & 1 \\
\hline
\end{tabular}

regulations in your jurisdiction effective?") based on how each respondent answered question 17. For example: of the 30 subjects who said that groundwater protection was 
one of the goals of their jurisdictions' karst regulations, 19 felt those regulations were effective, while six felt they were not. Cave protection is not a common goal in regulating development in karst terrains via municipal land use ordinances: only seven respondents cited it as a goal of their jurisdictions' karst regulations. Of those who expressed an opinion on the regulations' effectiveness in achieving that goal, 66 percent said they were effective. This was the lowest rate of effectiveness for any of the five goals provided, but it was only ten percent lower than the next-lowest response (groundwater protection).

Responses for questions 17 and 31 provide no clear relationship between the number of goals and the perceived effectiveness of the regulations. Almost certainly, part of the reason for this is that there seems to be a general consensus in the sample that these regulations are effective: over 67 percent of respondents feel that way, with the remainder almost evenly split between dissenters (17.65 percent) and those with no opinion (14.71 percent). It is clear from these results that respondents generally feel that karst-related land use regulations are effective in achieving commonly expressed goals of such regulation. This high level of satisfaction poses a problem in comparing the effectiveness of various regulatory techniques, since there are simply not enough "ineffective" votes to generate a response pattern that instills confidence. For this reason, examinations of the perceptions of regulatory effectiveness throughout this chapter will be limited.

That said, I would like to look at the effectiveness responses and how they correlate with responses for question 35 ("In your opinion, can anything be done to improve the effectiveness of karst land use regulation in your jurisdiction?"). Table 6-4 displays responses for four combinations of responses to questions 31 and 35: yes to both; no to both; yes to 31 and no to 35 ; and no to 31 and yes to 35 . It should not surprise 
anyone that respondents who see their jurisdictions' regulations as ineffective would say that these regulations could be improved. However, it may be surprising to see that respondents who consider their jurisdictions' karst regulations to be effective also feel that there is room for improvement in those regulations, by a nearly three-to-one margin.

At first glance, this appears to be a tricky contradiction to reconcile: if a regulation or ordinance is effective, then why would it require improvement? Certainly the word "effective" in this context implies that the regulation or ordinance has achieved its goal, either in full or in part. And perhaps this is the explanation: respondents may be interpreting the word "effective" as meaning "at least partially successful in achieving its goals." If that is the case, perhaps this reflects the political realities of implementing laws and regulations that use the presence of an obscure (to the general public, at least) geologic phenomenon to restrict development and growth: in other words, something is preferable to nothing, but more would have been even better.

\section{How the extent of the local karst affects choice of regulatory technique}

Certainly, the amount of karst found beneath a given municipality should factor into the final shape taken by any karst regulations implemented there. For example, more comprehensive regulatory approaches may not be appropriate for locations where the extent of karst is limited; likewise, areas with significant karst should probably consider passing more than a simple stormwater runoff management ordinance. By comparing responses to question 16 with responses to question 12 ("In your opinion, how extensive is the karst system in your area?"), we can identify the regulatory components that are more commonly used in areas with extensive karst, as well as those used in locations with limited karst geology. 
It is clear from Table 6-5 that stormwater drainage rules are the most preferred regulatory technique. These rules are widely applied in the sample, regardless of the amount of karst present. Mandatory setbacks become a more preferred regulatory technique as the amount of karst present increases. In fact, setbacks, waste disposal and dumping, and chemical application are used most frequently by jurisdictions with the most extensive karst systems, while extra steps in the permitting and building process seem to be preferred in communities with moderate (31percent - 50percent) karst.

The only respondent to indicate that a zoning overlay is in use, also indicates that less than 10 percent of the land area within his or her jurisdiction is underlain by karst. A zoning overlay would, on the surface, seem to be one of the more restrictive approaches to development in karst terrains; the fact that it is employed by a jurisdiction with such low levels of karst is interesting, and may indicate that the specific requirements of that particular zoning overlay district are modest.

It would also be interesting to compare the subjects' perception of regulatory restrictiveness to the extent of karst present in their jurisdictions. We would expect the results, shown in Table 6-6, to track closely with the results from the previous comparison. Very generally speaking, one could make the argument that the perceived restrictiveness of a jurisdiction's regulations is loosely related to the extent of the local karst. However, this generalization holds more clearly at the extremes than in the midranges of restrictiveness; and even on the extremes of perceived restrictiveness, the low numbers of respondents makes it difficult to definitively conclude anything. 
Table 6-5

Relationship between the extent of local karst systems

and the regulatory techniques used

\begin{tabular}{|c|c|c|c|c|}
\hline & \multicolumn{4}{|c|}{ Extent of karst } \\
\hline & $<10 \%$ & $10 \%-30 \%$ & $31 \%-50 \%$ & $>50 \%$ \\
\hline $\begin{array}{l}\text { Total observations in } \\
\text { each category }\end{array}$ & 2 & 6 & 15 & 11 \\
\hline \multicolumn{5}{|l|}{$\begin{array}{l}\text { Regulatory } \\
\text { techniques used }\end{array}$} \\
\hline Mandatory setbacks & 0 & $3(50 \%)$ & $9(60 \%)$ & $7(63.63 \%)$ \\
\hline Single extra step & $1(50 \%)$ & $3(50 \%)$ & $9(60 \%)$ & $5(45.45 \%)$ \\
\hline Multiple extra steps & 0 & $1(16.66 \%)$ & $5(33 \%)$ & $3(27.27 \%)$ \\
\hline Stormwater drainage & $2(100 \%)$ & $6(100 \%)$ & $12(80 \%)$ & $10(90.9 \%)$ \\
\hline $\begin{array}{l}\text { Dumping and waste } \\
\text { disposal }\end{array}$ & 0 & $3(50 \%)$ & $6(40 \%)$ & $9(81.81 \%)$ \\
\hline $\begin{array}{l}\text { Fertilizer and } \\
\text { chemical application }\end{array}$ & 0 & 0 & $1(6.66 \%)$ & $4(36.36 \%)$ \\
\hline Other options & \multicolumn{4}{|c|}{$\begin{array}{c}\text { (the following regulatory tools were mentioned in the free } \\
\text { response segment of this question) }\end{array}$} \\
\hline Zoning overlay & 1 & 0 & 0 & 0 \\
\hline $\begin{array}{l}\text { Designation of non- } \\
\text { buildable areas }\end{array}$ & 0 & 0 & 2 & 0 \\
\hline $\begin{array}{l}\text { Sinkhole area } \\
\text { excluded from } \\
\text { minimum lot size } \\
\text { requirements }\end{array}$ & 0 & 0 & 1 & 0 \\
\hline
\end{tabular}

Numbers in parentheses reflect the percentages of communities in each restrictiveness category that employ a given regulatory technique 
Table 6-6

Relationship between the extent of the local karst system and the perceived restrictiveness of local karst regulations

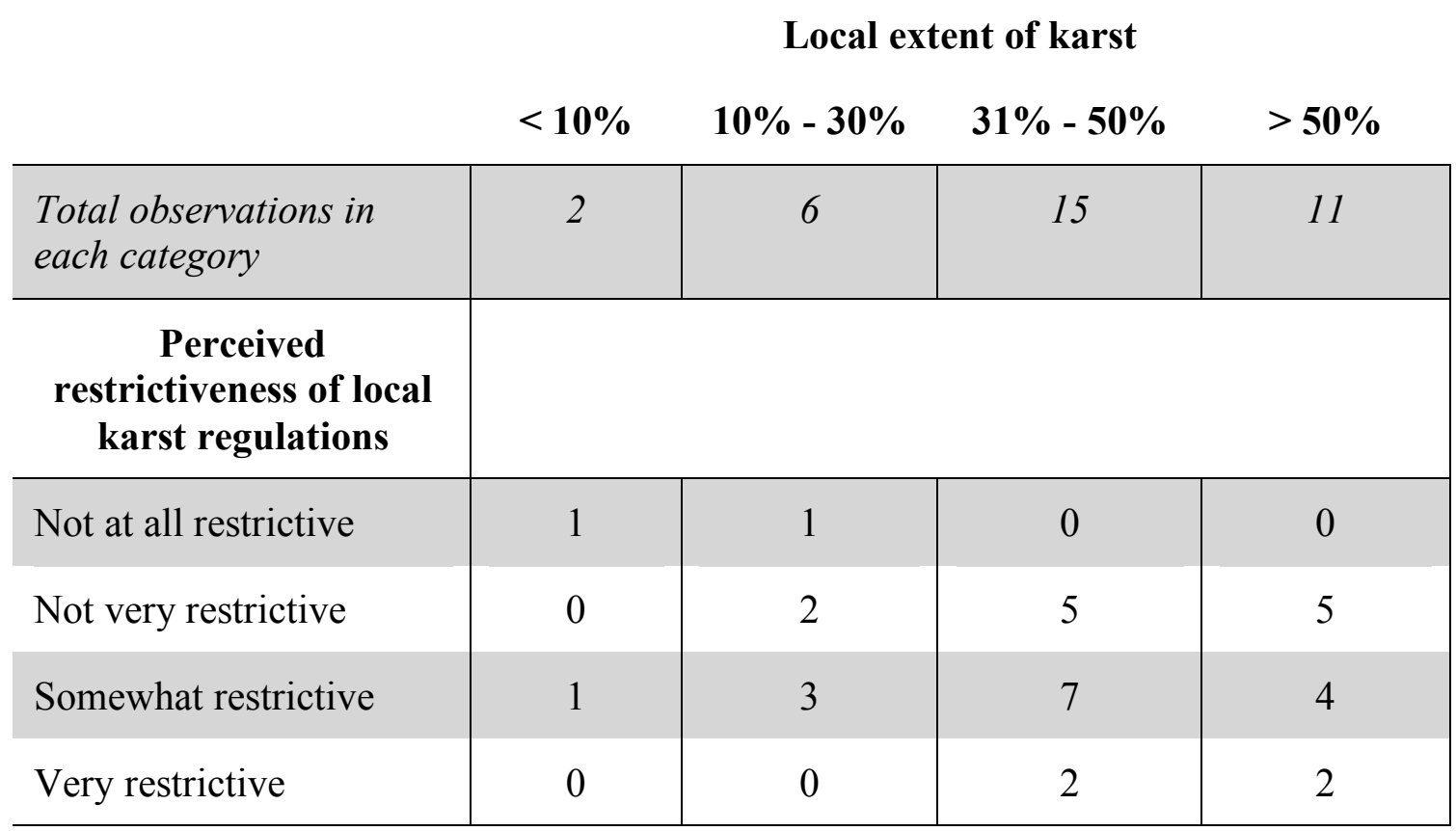

\section{Preventative or reactive implementation and regulatory restrictiveness}

Question 18 of the survey asked if karst regulations were enacted in the subjects' communities as a preventative measure or in response to a specific, ongoing issue. The majority of respondents indicated regulations had been implemented reactively rather than preventatively. This is of interest because of the possibility that the circumstances surrounding the implementation of the regulations may have affected the form the regulations took: if, for example, a town's karst regulations were hurriedly passed in response to a serious, recently discovered problem with groundwater quality, those regulations may be too restrictive or otherwise inappropriate as a method of addressing the groundwater problem. By comparing answers for question 18 with those for question 
14, we can see if there are differences within the sample in the restrictiveness and effectiveness of karst regulations between those that were enacted as a preventative measure, and those that were implemented reactively. The results are shown in Tables 67 and 6-8.

Table 6-7 suggests that regulations enacted in response to a specific problem that is already occurring tend to be more restrictive than those implemented as a preventative measure. This does lend some weight to the idea that reactively-passed regulations may be a bit too restrictive; conversely, it could also be reflective of the fact that more restrictive regulations are required to repair an established, entrenched problem than to head off a potential future issue. Even more striking than that is the effective / not effective split shown in Table 6-8: respondents in jurisdictions where karst regulations were implemented in a reactive manner are far more likely to consider those regulations to be effective than are respondents from communities that enacted preventative karst

Table 6-7

Relationship between the nature of local regulations and their perceived restrictiveness

Perceived restrictiveness $\quad \begin{gathered}\text { Were local karst regulations implemented to be } \\ \text { preventative or reactive? }\end{gathered}$ Preventative Reactive

\begin{tabular}{l|c|c|}
\hline Not at all restrictive & 1 & 1 \\
\hline Not very restrictive & 3 & 7 \\
\hline Somewhat restrictive & 6 & 9 \\
\hline Very restrictive & 0 & 4 \\
\hline
\end{tabular}


Table 6-8

Relationship between the nature of local regulations and their perceived effectiveness

\begin{tabular}{l|c|c|}
\multicolumn{1}{c}{ Perceived effectiveness } & $\begin{array}{c}\text { Were local karst regulations implemented to be } \\
\text { preventative or reactive? }\end{array}$ \\
\hline & Preventative & Reactive \\
\hline Effective & 6 & 17 \\
\hline Not effective & 3 & 2 \\
\hline
\end{tabular}

regulations instead. At first glance, this may appear to bolster the idea that reactive regulations are more restrictive because they have to be. However, it may simply be another illustration of the general perception that more restrictive regulation tends to be more effective. Another possible explanation is that cases where preventative measures were taken, the karst-related problems they were intended to prevent were in fact inevitable; their eventual occurrence could then be seen as "proof" that the preventative regulations were inadequate. Certainly, this is an area where more research would be welcome and appropriate.

\section{Initiators vs. restrictiveness}

Different actors may begin the process of implementing karst-related regulations for different reasons, and may have distinctly different goals. Those differences may make themselves apparent in the specific forms taken by the resulting regulations. In order to explore that possibility, I compared responses for question 14 on regulatory restrictiveness with responses for question 19 ("Who initiated the process of developing these regulations?"). The results are displayed in Table 6-9, which shows that responses 
are normally distributed around "not very restrictive." Branches of local government were by far the most frequent initiators of regulation; most of these regulations came down squarely in the middle measures of regulatory restrictiveness. Certainly, one thing this table does tell us is that the initiator of karst land use regulations has little, if anything, to do with the overall level of perceived restrictiveness of those regulations.

We can probe this question a bit further by comparing initiators to the individual components used in these regulations. The results are provided in Table 6-10. From these results, it is difficult to generalize about the influences of the different regulatory

\section{Table 6-9 \\ Relationship between initiators of local karst regulations and perceived restrictiveness}

\section{Initiators of local karst regulations}

\section{Perceived restrictiveness}

\begin{tabular}{|l|c|c|c|c|}
\multicolumn{1}{|c|}{$\begin{array}{c}\text { Not at all } \\
\text { restrictive }\end{array}$} & $\begin{array}{c}\text { Not very } \\
\text { restrictive }\end{array}$ & $\begin{array}{c}\text { Somewhat } \\
\text { restrictive }\end{array}$ & $\begin{array}{c}\text { Very } \\
\text { restrictive }\end{array}$ \\
\hline Branch of local government & 2 & 6 & 5 & 1 \\
\hline Branch of state or fed government & 1 & 4 & 2 & 0 \\
\hline County commission or equivalent & 1 & 2 & 2 & 0 \\
\hline Environmental or science groups & 0 & 2 & 0 & 0 \\
\hline Other & 0 & 1 & 0 & 1 \\
\hline
\end{tabular}

Note: in two cases, respondents chose "other" as their answer for question 19, yet it was clear from their free response answers that one of the provided responses would have been perfectly appropriate. Those two responses were changed to the appropriate categories. 
Table 6-10

Relationship between regulatory techniques used and identity of regulatory initiators

\section{Regulatory initiators}

\begin{tabular}{ccccc}
$\begin{array}{c}\text { Branch or } \\
\text { department } \\
\text { of local }\end{array}$ & $\begin{array}{c}\text { Branch of } \\
\text { state or } \\
\text { federal }\end{array}$ & $\begin{array}{c}\text { County or } \\
\text { city } \\
\text { government }\end{array}$ & $\begin{array}{c}\text { Environmental } \\
\text { commission }\end{array}$ & $\begin{array}{c}\text { or science } \\
\text { groups }\end{array}$ \\
\hline
\end{tabular}

\begin{tabular}{|c|c|c|c|c|c|}
\hline $\begin{array}{l}\text { Total } \\
\text { observations } \\
\text { in each } \\
\text { category }\end{array}$ & 15 & 7 & 6 & 2 & 2 \\
\hline \multicolumn{6}{|l|}{$\begin{array}{c}\text { Regulatory } \\
\text { techniques } \\
\text { used }\end{array}$} \\
\hline $\begin{array}{l}\text { Mandatory } \\
\text { setbacks }\end{array}$ & 10 & 2 & 4 & 1 & 1 \\
\hline $\begin{array}{l}\text { Single extra } \\
\text { step }\end{array}$ & 7 & 6 & 2 & 1 & 1 \\
\hline $\begin{array}{l}\text { Multiple extra } \\
\text { steps }\end{array}$ & 4 & 2 & 2 & 1 & 0 \\
\hline $\begin{array}{l}\text { Stormwater } \\
\text { drainage }\end{array}$ & 13 & 7 & 5 & 2 & 2 \\
\hline $\begin{array}{l}\text { Dumping and } \\
\text { waste } \\
\text { disposal }\end{array}$ & 8 & 4 & 2 & 1 & 1 \\
\hline $\begin{array}{l}\text { Fertilizer and } \\
\text { chemical } \\
\text { application }\end{array}$ & 2 & 3 & 0 & 1 & 0 \\
\hline Other & 5 & 0 & 1 & 0 & 0 \\
\hline
\end{tabular}


initiators in the final form of the regulations themselves. It does seem clear that regulations initiated by state and federal levels of government are less likely than those initiated by more local entities to incorporate mandatory setbacks than other techniques, like stormwater runoff and drainage management or additional steps in the permitting and building process.

\section{The influence of non-elected professionals vs. regulatory restrictiveness}

It would be unrealistic to expect elected officials to have detailed knowledge and understanding of karst and the challenges it poses to human settlements above it. Therefore, input from people with subject-specific expertise could easily become a critical factor both in the development of karst regulations, and in the form they ultimately take. In particular, it would be very easy for elected officials to either overestimate or underestimate the severity of karst-related problems without input from non-elected professionals, like engineers, geologists, or hydrologists, among others. By comparing answers for question 14 ("In your opinion, how restrictive are the karst-related land use and development regulations in your jurisdiction?") to question 23 (“To what degree were these regulations influenced by non-elected professionals (i.e. scientists or engineers for example) working for or in conjunction with local government?"), a rough idea of the impact of professional input can be reached; this is displayed in Table 6-11. There seems to be no relationship at all between the amount of influence exerted by nonelected professionals and the restrictiveness of the resulting regulation. At all levels of professional influence (other than "none," which was not selected by even one respondent), the distribution of regulatory restrictiveness is once again centered around 
"not very restrictive." It is interesting to note that there is not a trend toward excessive regulation as the influence of non-elected professionals increases.

Table 6-11

Relationship between levels of influence of non-elected professionals and the perceived restrictiveness of the resulting regulations

Level of influence

from non-elected

professionals
Perceived restrictiveness of karst regulations

\begin{tabular}{l|c|c|c|c|}
\multicolumn{1}{|c}{} & $\begin{array}{c}\text { Not at all } \\
\text { restrictive }\end{array}$ & $\begin{array}{c}\text { Not very } \\
\text { restrictive }\end{array}$ & $\begin{array}{c}\text { Somewhat } \\
\text { restrictive }\end{array}$ & $\begin{array}{c}\text { Very } \\
\text { restrictive }\end{array}$ \\
\hline None & 0 & 0 & 0 & 0 \\
\hline Slight & 0 & 3 & 1 & 0 \\
Moderate & 1 & 5 & 1 & 0 \\
\hline Strong & 3 & 8 & 3 & 1 \\
\hline
\end{tabular}

As when examining the role of regulatory initiators in the previous section, this question can be examined in more detail by including a comparison between levels of non-elected professional influence with the appearance of specific regulatory tools in the karst land use ordinances; this comparison is shown in Table 6-12. As the influence of non-elected professionals increases, so too does the likelihood that extra steps are included in the permitting and development process for projects in karst areas. In regulations that had been strongly influenced by non-elected professionals, the frequency with which several other listed components occur is either comparable or lower than in regulations that had only enjoyed a moderate level of influence from non-elected professionals. This does not extend to dumping and waste disposal, or to fertilizer and 
chemical application, as they were not included in regulations that were only slightly influenced by non-elected professionals.

\section{Expected outcomes vs. propensity to regulate}

As we have seen elsewhere in this dissertation, regulating land use is often a politically charged endeavor, with many strongly-held opinions on both sides of the issue. One might wonder how these opinions affect the process of implementing karst land use ordinances and regulations: is it possible that towns in which land use professionals and policymakers have negative expectations regarding the outcomes of karst land use regulations are less likely to implement such regulations? In Table 6-13, I compared responses for question six, on the presence of karst regulations, and question 32, on the respondents' expected results of the implementation of these regulations. In this table, outcomes that could subjectively be described as "positive" are connotated by a $(+)$ symbol; subjectively negative outcomes are connotated by a (-) symbol (the "decline in density" option could be very easily seen as either positive or negative, and is thus not assigned a qualitative descriptor here). Note that the two negative responses-increasing housing costs and a decline in new development projects - were selected as likely outcomes significantly more often by respondents from jurisdictions where karst regulations are not in place. Likewise, two of the three positive responses (a decline in litigation filed against the city, and improved groundwater quality) were much more likely to be identified as expected outcomes by respondents from jurisdictions in which karst land use regulations had been enacted. 
Table 6-12

Relationship between regulatory techniques employed and the level of influence over the regulatory process displayed by non-elected professionals

Level of influence from non-elected professionals

\begin{tabular}{l|c|c|c|c|} 
& None & 4 & 7 & 16 \\
\hline $\begin{array}{l}\text { Total observations in each } \\
\text { category }\end{array}$ & 0 & & & \\
\hline $\begin{array}{l}\text { Regulatory } \\
\text { techniques used }\end{array}$ & 0 & 4 & 4 & 8 \\
\hline Mandatory setbacks & 0 & 1 & 4 & 11 \\
\hline Single extra step & 0 & 1 & 0 & 8 \\
\hline $\begin{array}{l}\text { Multiple extra steps } \\
\text { Stormwater drainage }\end{array}$ & 0 & 4 & 7 & 15 \\
\hline $\begin{array}{l}\text { Dumping and waste } \\
\text { disposal }\end{array}$ & 0 & 0 & 6 & 9 \\
\hline $\begin{array}{l}\text { Fertilizer and chemical } \\
\text { application }\end{array}$ & 0 & 0 & 2 & 4 \\
\hline \begin{tabular}{l} 
Other \\
\hline
\end{tabular} & 0 & 1 & 1 (overlay) & 3 \\
\hline
\end{tabular}


Table 6-13

Differences in expected outcomes of karst regulation between towns that do regulate and towns that do not

\begin{tabular}{|c|c|c|c|c|}
\hline $\begin{array}{l}\text { Total observations in } \\
\text { each categorv }\end{array}$ & \multicolumn{2}{|c|}{32} & \multicolumn{2}{|c|}{21} \\
\hline Expected outcome & & & & \\
\hline & Total & Pct & Total & Pct \\
\hline $\begin{array}{l}\text { Increasing residential } \\
\text { land values }(+)\end{array}$ & 5 & $15.6 \%$ & 4 & $19 \%$ \\
\hline Decline in litigation $(+)$ & 7 & $21.9 \%$ & 0 & $0 \%$ \\
\hline $\begin{array}{l}\text { Improved groundwater } \\
\text { quality }(+)\end{array}$ & 25 & $78.12 \%$ & 8 & $38.1 \%$ \\
\hline Decline in density & 3 & $9.4 \%$ & 4 & $19 \%$ \\
\hline $\begin{array}{l}\text { Increasing housing costs } \\
(-)\end{array}$ & $\begin{array}{c}4 \\
\text { (2 overlap) }\end{array}$ & $12.5 \%$ & $\begin{array}{c}11 \\
\text { (3 overlap) }\end{array}$ & $52.38 \%$ \\
\hline $\begin{array}{l}\text { Decline in new } \\
\text { development projects (-) }\end{array}$ & 2 & $6.25 \%$ & 7 & $33.3 \%$ \\
\hline Other outcome & 11 & $34.37 \%$ & 3 & $14.28 \%$ \\
\hline
\end{tabular}

A $(+)$ represents a positive outcome; a (-) represents a negative outcome. No sign indicates a neutral outcome, or one that could widely be perceived as either positive or negative. 
Individuals who selected the "some other outcome" response then were requested to describe the nature of the outcomes they anticipated. Expected outcomes identified by respondents from communities in which karst-related regulations were present expected to see the following outcomes:

- Less structural damage;

- more groundwater recharge space;

- more open space dedications;

- improved public safety;

- landscape appropriate development;

- lower property insurance rates;

- better education and communication between developers, state and county;

- reduced incidents of flooding and subsidence;

- increased public awareness; and

- nothing at all.

Respondents from communities where development on karst had no additional restrictions, on the other hand, provided the following list of expected outcomes:

- Increase in development costs;

- level or declining tax base;

- increase in development-related lawsuits; and

- increase in number of variances requested.

In terms of anticipating positive or negative outcomes, the qualitative difference in expectations between respondents from regulating areas and those from non-regulating areas is striking. This difference is apparent in the selection of provided options, but is most obvious in the breakdown of free response answers. While respondents from both groups selected both positive and negative outcomes from the list of supplied answers, there was no crossover at all in the free response answers: of the ten free response 
answers provided by respondents from regulating communities, only one ("nothing at all") can be construed as even a neutral response, with the remaining nine being positive expectations. Similarly, three of the four free response answers from respondents living in non-regulating areas are negative expectations, while the fourth ("increase in number of variances requested") can be seen as a neutral response.

There are two possible explanations for these results that spring immediately to mind: first, they may be representative of a divergence of attitudes toward regulation in general, which is already reflected in the difference in practice of karst regulation; second, with regard to respondents with positive expectations of the results of karst regulation, these results could be a matter of respondents projecting their current understanding of and attitudes toward karst regulation backwards.

By examining responses from individuals working in regulating municipalities only, we can now compare respondents' expected outcomes with the results they actually observed. Table 6-14 makes clear that in most cases, neither the positive nor the negative expected outcomes of karst-related land use regulation came to pass once the regulations were implemented. An improvement in groundwater quality was observed in five communities where karst-related regulation was implemented; all five of these respondents indicated that they would expect to see such an improvement ("overlap"). In no other case was the overlap quantity more than one. In only one instance did more respondents observe an outcome (a decrease in subsidence-related damage) than indicated they would expect such an outcome; even so, only one respondent overlapped between expectation and observation. Most of the negative expectations of respondents from non-regulating communities also did not materialize in towns that chose to regulate. 
Table 6-14

Differences between expected outcomes and observed outcomes of regulating karst (municipalities that regulate only)

\begin{tabular}{|l|c|c|c|}
\hline Potential outcomes & Expected & Observed & Overlap \\
\hline Higher housing costs & 4 & 1 & 1 \\
\hline Lost development opportunities & 2 & 1 & 1 \\
\hline Improved groundwater quality & 25 & 5 & 5 \\
\hline Decrease in subsidence-related damage* & 5 & 8 & 1 \\
\hline Decrease in density & 3 & 1 & 1 \\
\hline
\end{tabular}

* expectations were expressed in the free response section of this question

Eight respondents indicated they saw no impacts of the karst land use regulations implemented in their jurisdictions; four others offered observed outcomes in the free response section:

- A small increase in permitting costs for some developments;

- Better development decisions due to increased amount of information;

- More environmentally appropriate development; and

- Stronger ties between state and local development regulations and procedures.

A fifth respondent said that he or she had observed rising housing costs over the last fifteen years, but that there is probably not a direct connection to the karst regulations in place there.

Interestingly, the data shown in Table 6-14 above are contradicted by Table 6-3. In that table, we see that nearly two-thirds of respondents who cited groundwater protection as a motivating force for implementing karst land use regulation felt the 
regulation had been effective in achieving that goal. Yet in Table 6-14, only 20 percent of respondents who expected to see an improvement in groundwater quality could say that they had observed such an improvement. Why the discrepancy? The most obvious explanation is that these respondents simply assumed the regulations had been effective, despite not having observed any actual improvement.

The responses displayed on tables 6-13 and 6-14 have particularly interesting implications. First, there is a strong suggestion that attitudes of land use professionals could be a major factor in determining whether or not karst regulations are passed at all. Second, the expected results of karst land use regulation — both positive and negativeoften do not come to pass. One exception to this was a decrease in subsidence-related damage; more respondents observed this result than anticipated it. Both of these conclusions could in turn have significant implications in the process of implementing karst land use regulations.

\section{Summary}

The survey results presented in this chapter provide useful data regarding land use planners' opinions and observations regarding karst-oriented land use regulations. Some of the more interesting results include:

- Stormwater drainage and runoff regulations are the most popular method of regulating development on karst terrains;

- Employing mandatory setbacks as a regulatory tool is more common in municipalities with more extensive karst formations; 
- Attitudes held by planners on the likely outcomes and impacts of karst land use regulation seem to have an influence on whether or not such regulations are imposed;

- The expected results of karst regulation, particularly "secondary effects," like changes in population density or growth rates, often do not come to pass;

- Seeking input from non-elected professionals (for example, geologists, engineers, hydrologists) does not lead to inherently more restrictive regulations;

- No clear relationship can be identified between the restrictiveness of the regulations and the identity of the initiator of the regulation implementation process;

- "Reactive" regulations tend to be more restrictive than preventative regulations;

- Often, respondents will say that karst regulations are effective methods of achieving a particular goal, even if they haven't actually witnessed it;

- Strategic behavior does not seem to be an issue in the process of deciding whether or not to implement karst land use regulations.

These results are intriguing, and seem worthy of future study. Perhaps one direction of future research could be to examine some of these results in greater detail, using larger samples. 


\section{Setback ordinances: are they effective in controlling density in karst areas? A case study from Kentucky and Missouri}

\section{Introduction}

As we have seen in the preceding chapters, karst land use regulation is common throughout the United States. While these regulations and ordinances are usually adapted to meet local conditions, some regulatory techniques are employed in markedly different karstic terrains. This chapter examines one of these common regulatory techniques- the setback - and its impacts on patterns of human settlement and density. Specifically, this chapter asks whether or not setback-style regulations are effective at controlling development near sinkholes; evidence of such effectiveness could be present in housing or structural densities near sinkholes in communities that employ setbacks. The question is an important one to ask, considering the widespread use of setbacks and no-build areas to control development on karst terrains. Additionally, this research question fits into the larger narrative of this dissertation because it concerns how human populations react (in this case, through choices on which areas are or are not suitable for dense human settlement) to certain karst-aware land use regulations.

\section{Setbacks}

Setbacks (also called no-build areas in some municipal codes) are simply buffers placed in certain spots to prevent unwanted encroachment of human structures (buildings, roads, etc.) into sensitive areas. In the cases studied here, these setbacks are applied to 
sinkholes, which means that there is theoretically a buffer between the edge of a sinkhole and the point at which construction or land-disturbing activities are permitted to occur. This buffer zone is therefore intended to act as a passive means of protecting the karst system from the impacts of human settlement, and of protecting human-built structures from the expansion of karst landforms. Polluting activities and land stress are kept away from the sinkholes, and new buildings are not permitted so near a sinkhole edge as to leave the structure vulnerable to sinkhole expansion. Use of setbacks as a technique for controlling development on karst terrains is not unusual: as discussed in Chapter 5 of this dissertation, setbacks are found in communities in Kentucky, Tennessee, Missouri, Florida, Pennsylvania, New Jersey, and Virginia, among other locations (see codes of ordinances for Pasco County, FL; Lower Saucon, PA; Lexington-Fayette County, KY; and Springfield, MO for examples).

From this brief description of setbacks, we might expect them to have an impact on housing density because a setback, by its very design, limits the amount of developable land in the immediate vicinity. Any land enclosed by a setback is removed from that inventory, which should therefore result (in residential areas) in larger parcels or more undevelopable lots. This, of course, relies on two assumptions: first, that all sinkholes are correctly identified and properly catalogued; and second, that the ordinance is actually enforced by city government. (This last factor is critical, as city government may have neither the resources nor the inclination to adequately enforce their own sinkhole ordinances.) 
Figure 7-1

The study area (Lexington-Fayette County, KY; Louisville, KY; Springfield, MO; St. Louis, MO)

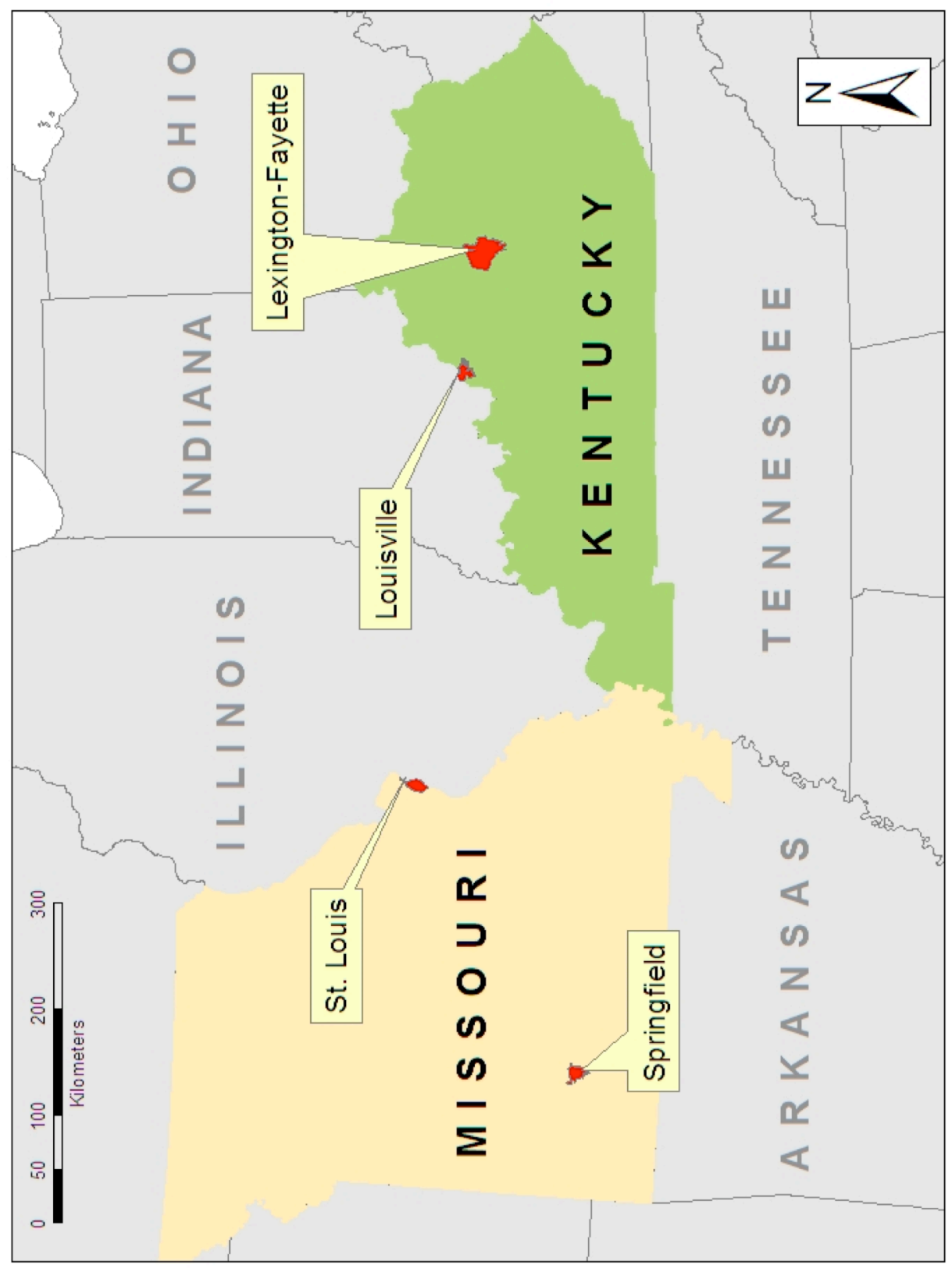

Source: US Census Bureau 


\section{The study areas}

This analysis explores the impact of setbacks on housing density by examining data drawn from four study areas: Lexington-Fayette County, Kentucky; Louisville, Kentucky; Springfield, Missouri; and St. Louis, Missouri (Figure 7-1). Lexington-Fayette and Springfield were selected as study areas because both municipalities employ setbackstyle regulations to limit development near sinkholes, and because data on sinkhole location was readily available for each location. Louisville and St. Louis were chosen to act as "control" sites: both have sinkholes within the city limits, but neither uses setbacks as a means to control nearby development. Thus, it may be possible to identify the impact of setback ordinances on housing density by comparing densities between these two pairs of study areas.

All four study areas are underlain by geology favorable to the development of karst landforms (Figures 7-2 through 7-5), and all four are urban: the smallest (Springfield) had a 2000 population of just over 150,000, while the largest (St. Louis) had a population of just over 360,000 that same year; Louisville and Lexington-Fayette's populations that year were approximately 256,000 and 260,000, respectively (U.S. Census Bureau). These four sites met my criteria for data availability, urbanization, and location (i.e., all within the same general region). I intentionally chose urban areas for this analysis because the generally higher population and housing densities may make compliance with setback regulations more challenging. In rural areas where developable land is plentiful, such restrictions could be more easily complied with by relocating development to less sinkhole-prone areas, and impacts of setback ordinances on housing density patterns would likely be more difficult to detect. 
Figure 7-2

Potential for karst landform development in Lexington-Fayette County, KY and vicinity

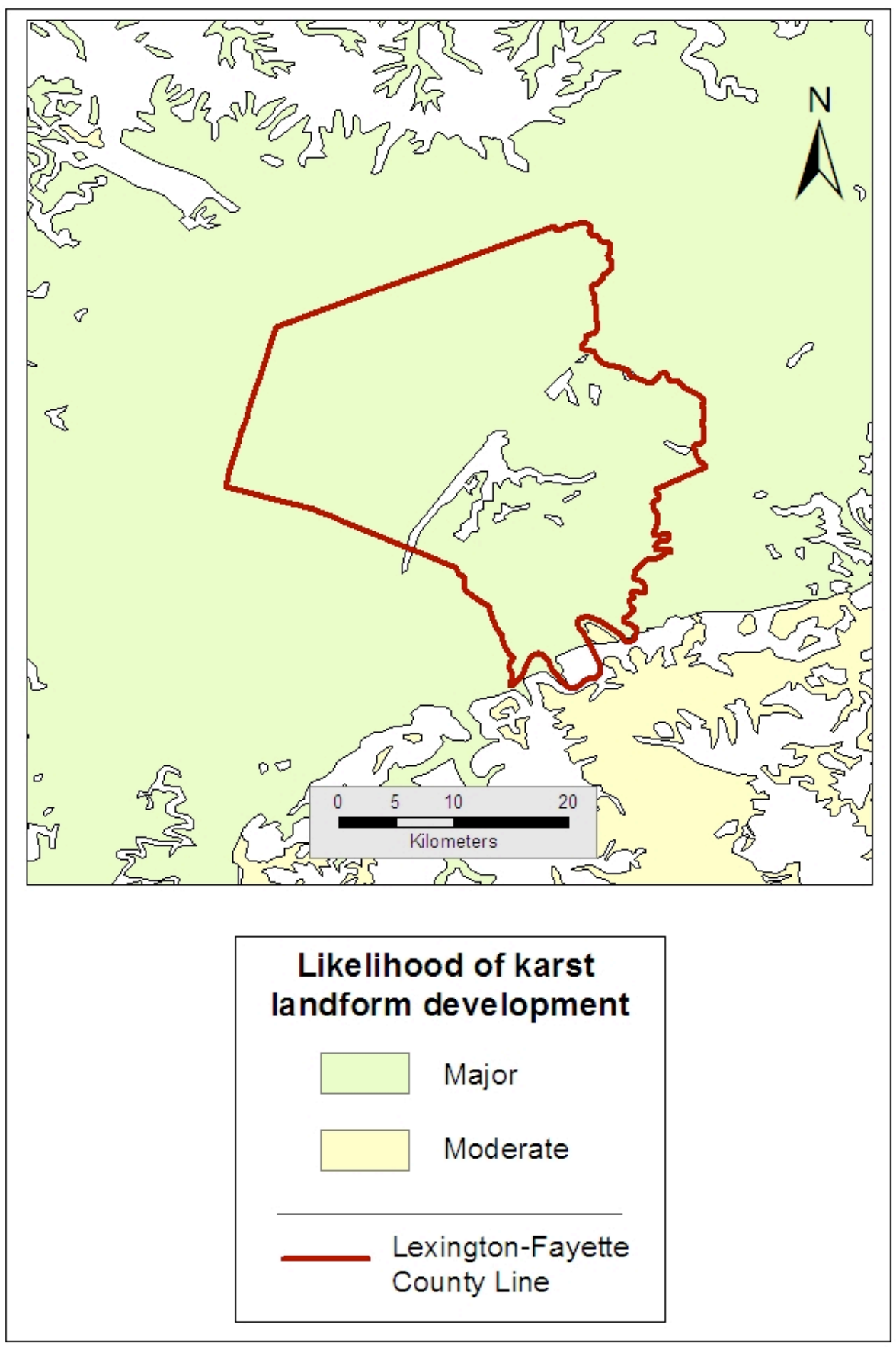

Source: Kentucky Geological Survey 
Figure 7-3

Potential for karst landform development in Louisville, KY and vicinity

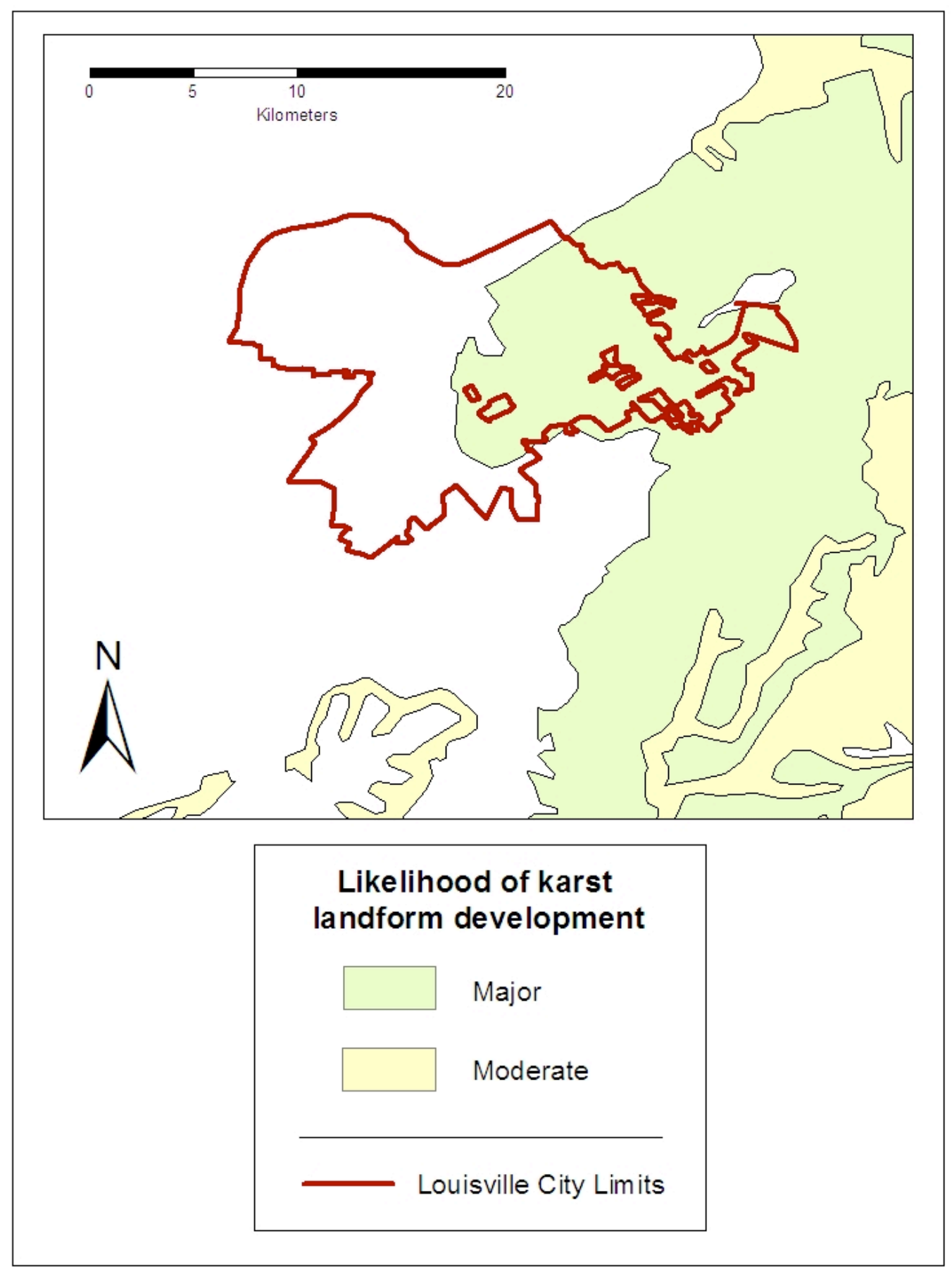

Source: Kentucky Geological Survey 
Figure 7-4

Bedrock composition in Springfield and Greene County, MO

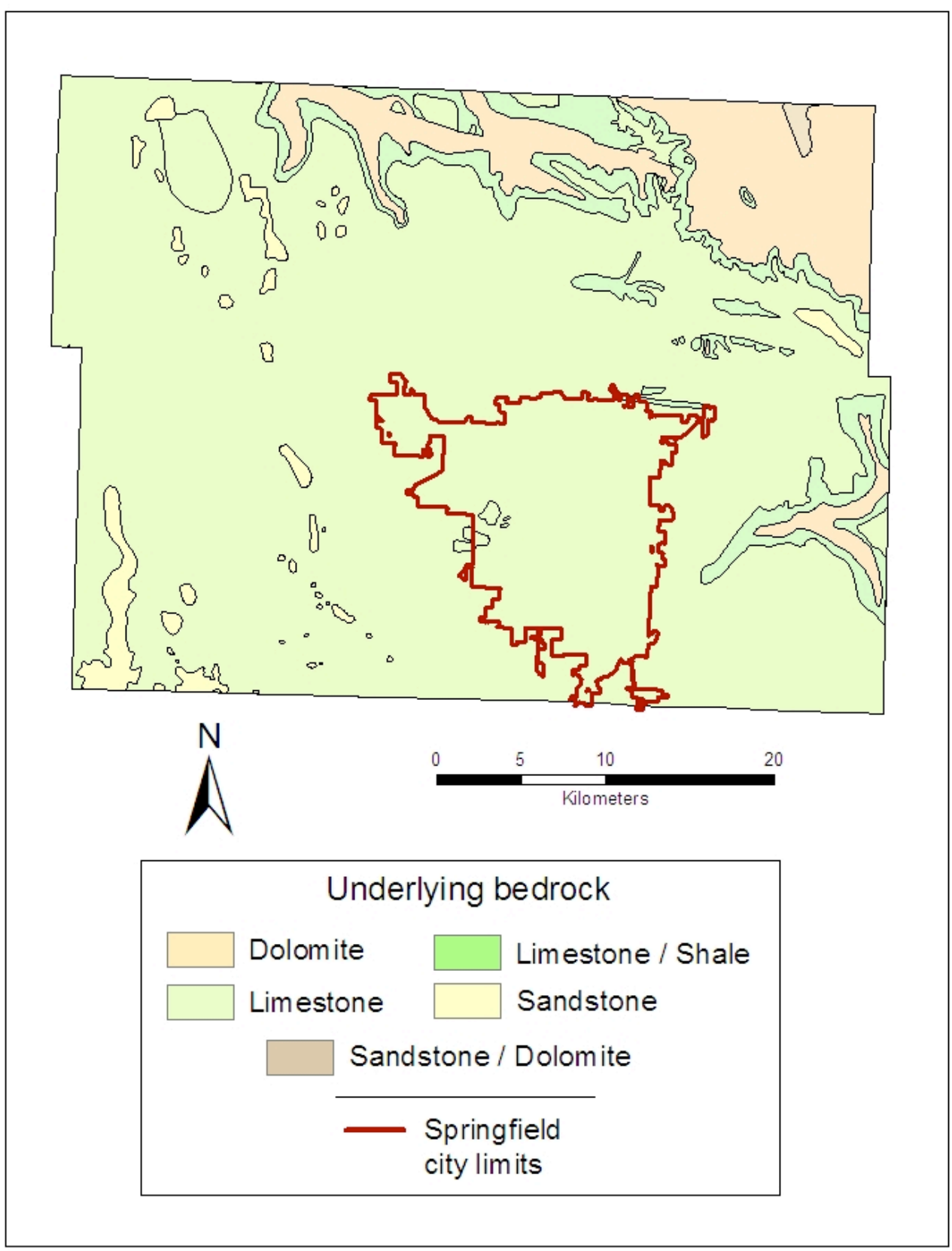

Source: Missouri Spatial Data Information Service 
Figure 7-5

Bedrock composition in St. Louis, MO

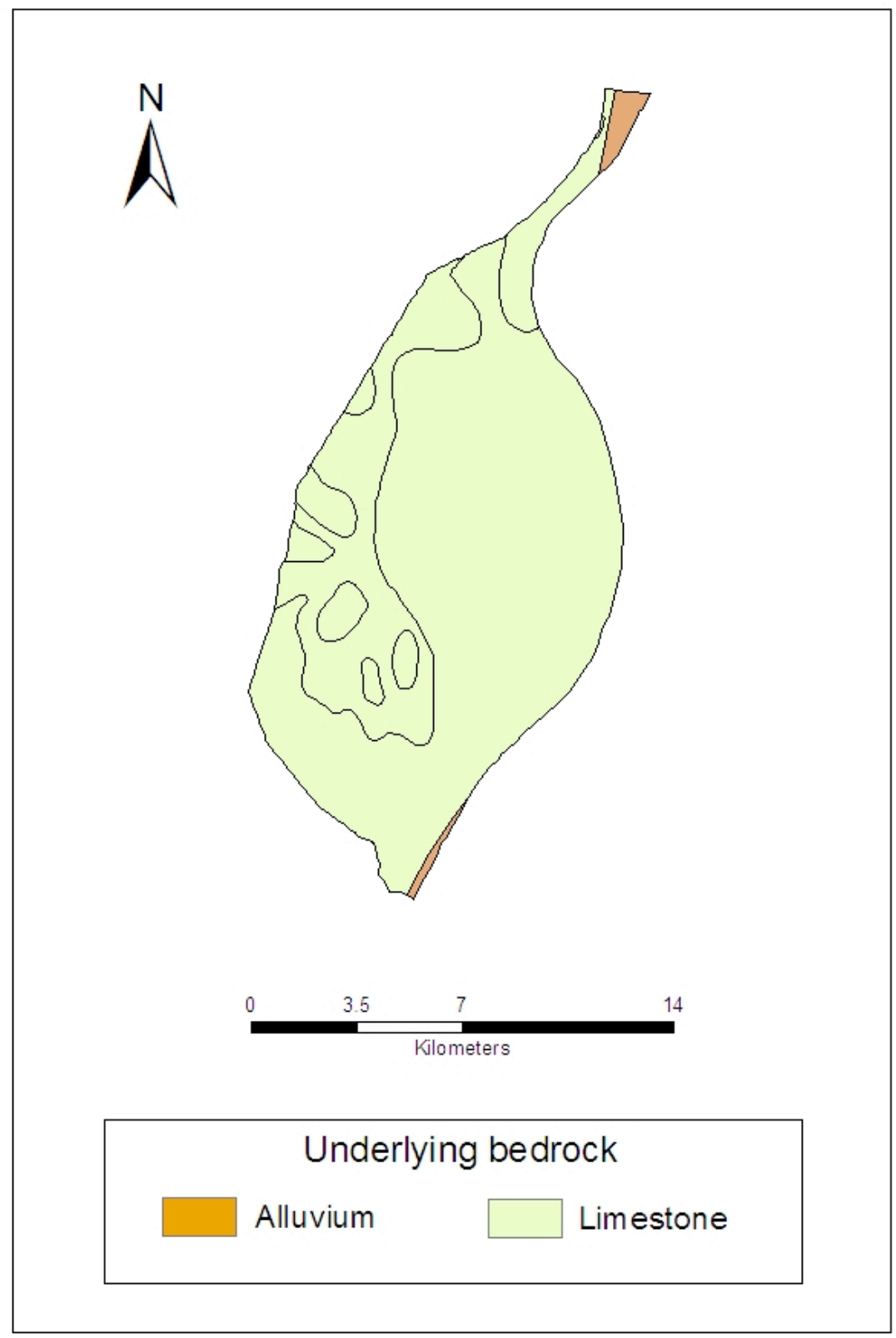

Source: Missouri Spatial Data Information Service 
Lexington and surrounding Fayette County have operated as a consolidated citycounty government since 1958. The county lies in the middle of north-central Kentucky's Blue Grass region, a topographical region that encompasses about 8,000 square miles. Gently rolling hills dominate the landscape here. The southern border of this region is where the Knobs, a semi-circle of higher hills, begin; to the west, the dividing line between the regions is the Salt River; and the northern border comes at the Ohio River. The region is an exposed area of the Cincinnati Arch, resting atop some of the oldest exposed rock layers in Kentucky (Ordivician). There are two large river systems here, the Kentucky and the Licking, with smaller, winding streams found throughout the region. The meanders in these surface waters probably developed as the streams cut their beds; gravel found on the shoulders of gorges in the region suggests that this is exactly what happened (Davis, 1927; Raitz, 1973).

Fayette County is in the Inner Blue Grass regional subdivision (the Inner Blue Grass comprises 30percent of the total area of the Blue Grass Region). The entire area was once heavily forested, but even as early as the 1920s there was little of the original forest stands left. The soils here are very fertile, thanks to the high levels of phosphorous in the limestone beneath, and the farms there were quite large in the early $20^{\text {th }}$ century. These productive soils have given the Inner Blue Grass region a reputation for prime agricultural land; in fact, Davis (1927) suggests that it was once perhaps the most attractive agricultural land in North America, as reflected by the high prices commanded by parcels there (Raitz, 1973).

The city of Louisville and surrounding Jefferson County were two separate administrative entities prior to 2003; in that year, they merged to form a consolidated 
city-county government (for the purposes of this chapter, Louisville and Jefferson County are treated as separate entities). Jefferson County is situated along the boundary between the Blue Grass region and The Knobs region, a topographical zone of about 2200 square miles. The Knobs are a series of conical hills and detached ridges that run for about 233 miles, forming a sort of horseshoe shape around the northern tip of the state, with one end touching the Ohio border and the other touching the Indiana line about a hundred miles to the west. The Blue Grass region lies within the semicircle delineated by the Knobs. The Knobs themselves are generally composed of Waverly sandstone; some are capped by Mississippian limestone, where decent farmland could be found. Surface waters in the northern half of the region drain into the Ohio River via Salt Lick and the Licking River; the southern part of the Knobs drains into the Kentucky River system. Sinking surface waters can be found throughout the region. Overall, karst landscapes seem to be more common in the Blue Grass region than in the Knobs (Burroughs, 1926).

The Blue Grass Region is one of several Kentucky regions to feature extensive karst. White et al. (1970) describe the karst in central Kentucky as being typical of North America, but not especially common throughout the rest of the world - "temperate, humid-climate karst on flat-lying limestone" (p. 88) with bedrock-surface features commonly found under the soil mantle. The limestone is capped by impermeable beds of clastic rock, which has led to the enlargement of underground features like cave passages and vertical shafts. Limestone areas within the Bluegrass include the LexingtonCynthiana Limestone Area and the Marysville-Richmond Limestone Belt. The combination of limestone and abundant rainfall (44 inches annually) has resulted in a "mildly developed karst topography" (Raitz, 1973, p. 55). Within the Inner Blue Grass 
Figure 7-6

Sinkhole near Lexington, KY

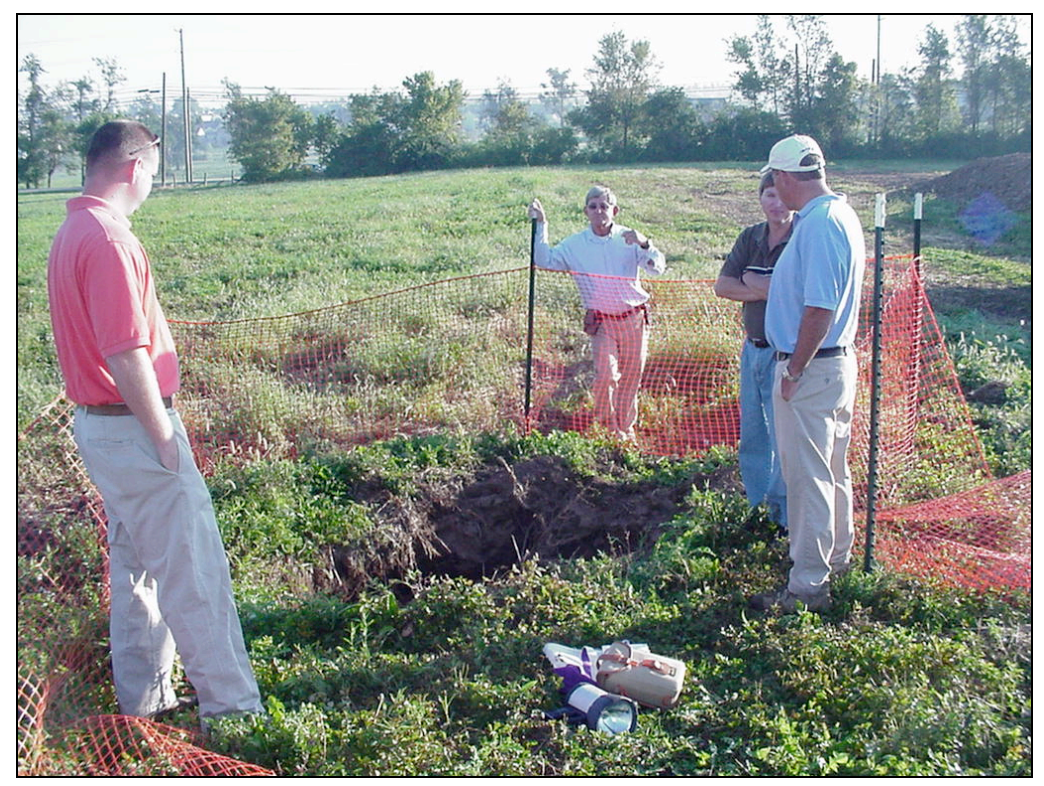

(Photo provided by Jim Rebmann)

Figure 7-7

Sinkhole near Lexington, KY

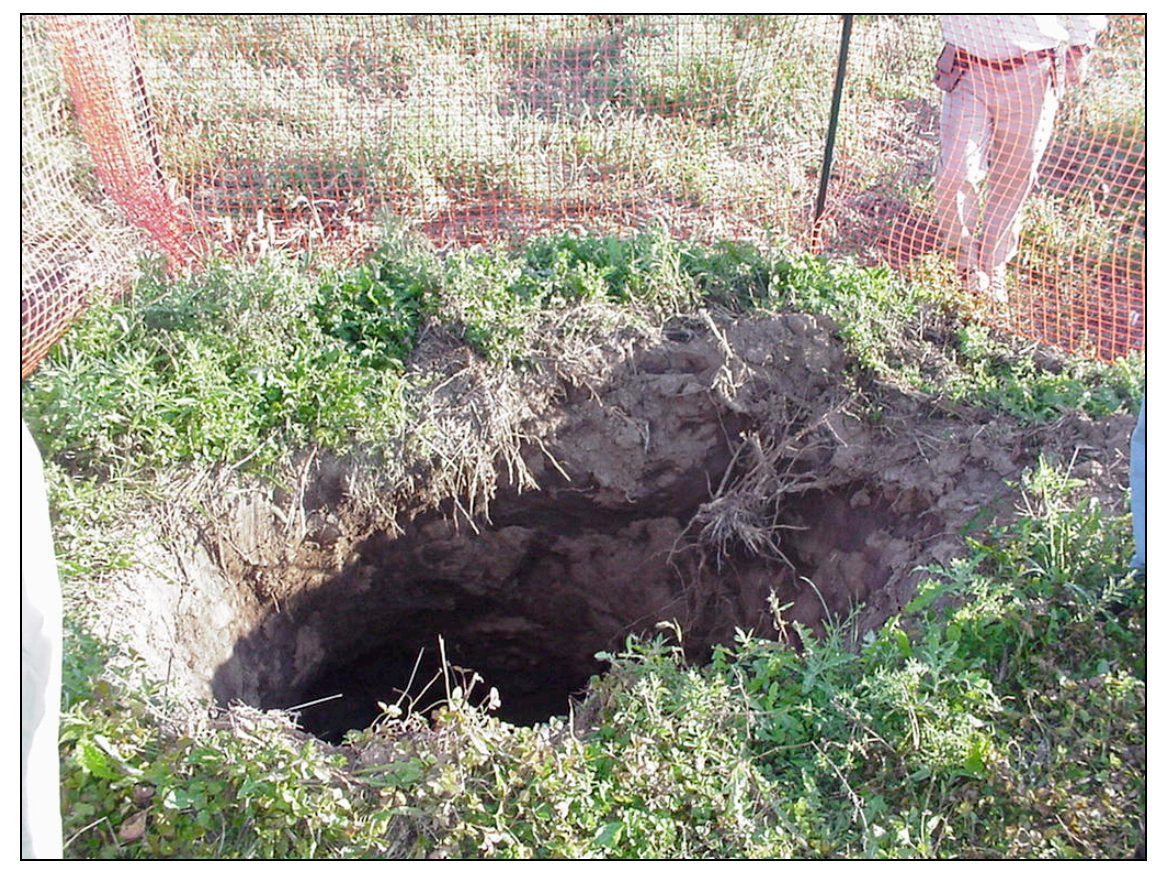

(Photo provided by Jim Rebmann) 
Figure 7-8

Underground passage near Lexington, KY

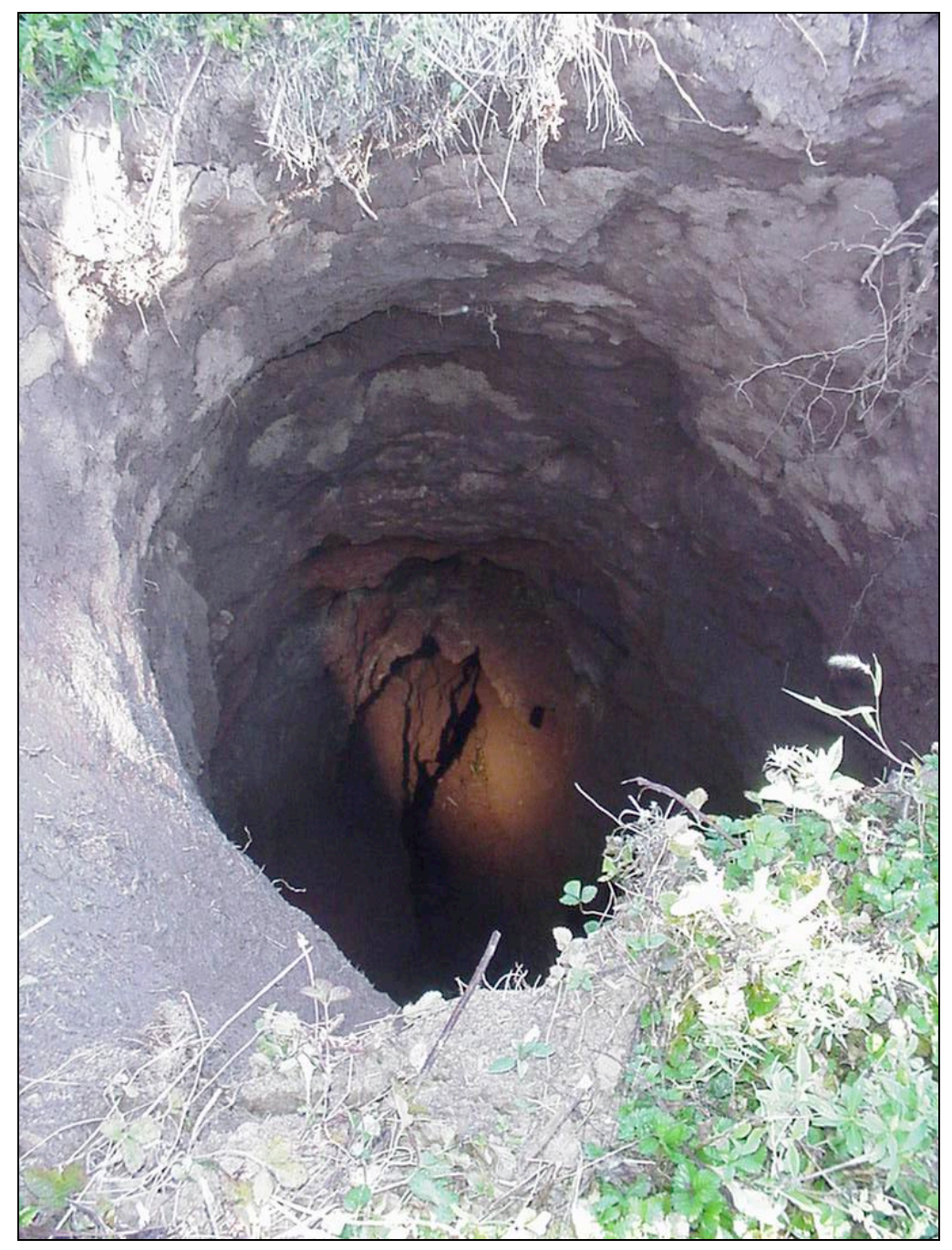

(Photo provided by Jim Rebmann)

region, the limestone bedrock is soluble and prone to fracturing, leading to the formation of sinkholes and underground drainage channels (figs. 7-6 through 7-9). These subsurface drainage channels are better developed than those found elsewhere in the Blue Grass 
Figure 7-9

Sinkholes near Lexington, KY

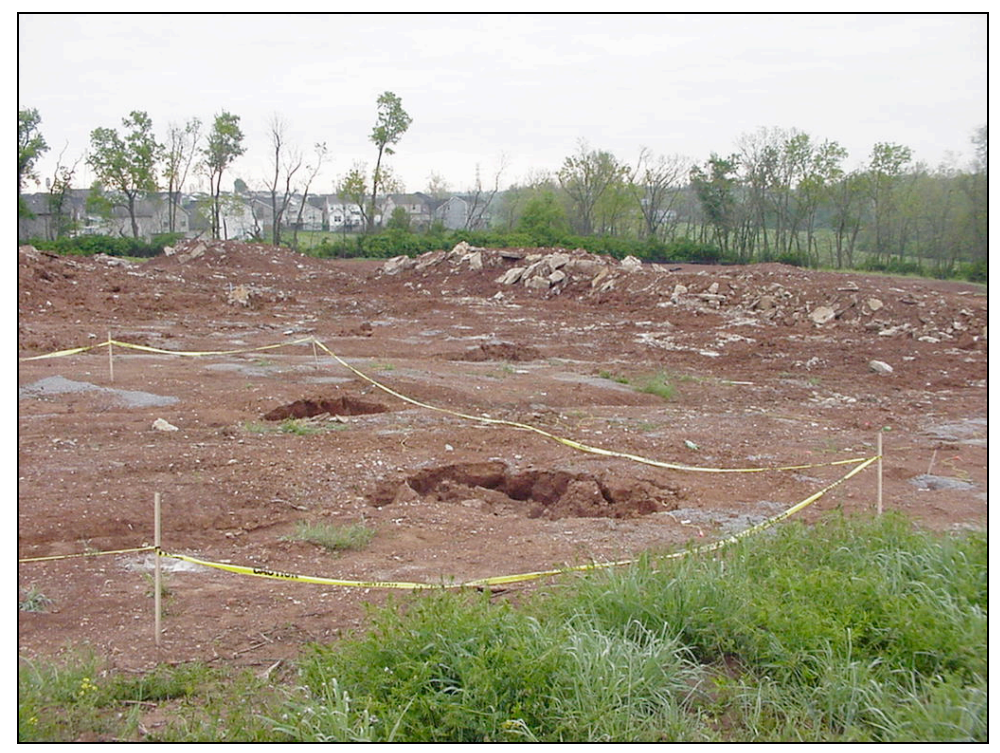

(Photo provided by Jim Rebmann)

region, which helps explain the absence of artificial drainage systems here. Sinkholes here almost never contain standing water; sometimes they swallow entire streams (Davis, 1927; Raitz, 1973).

In the western half of this study area, Springfield and St. Louis are both located on the Ozark Highlands, which spreads across parts of five states. Approximately 33,000 square miles of the Highland are located in southern and central Missouri. Some parts of the Highlands are more mountainous and rugged, like in northern Arkansas on the southern edge of the region. However, in Missouri, topography in the Highlands is less mountainous and more of a plateau that has developed on highly erosion-resistant rocks. Much of the Highlands region is made up of cherty dolomitic limestone; dolomite and 
limestone layers are sometimes as much as 1500 feet thick, while in other areas, shales and sandstones are more prevalent. Solution processes are very active here, and have resulted in the formation of countless underground passages and caves. These passages will often collapse and form sinkholes; the fact that they formed from underground flow patterns is often apparent because streams are frequently visible flowing below the sinkhole, a phenomenon known as a karst window (Palmer, 2007). These sinkholes are most likely to appear in undissected limestone regions (Sauer, 1968). Around Springfield, cavernous Burlington / Keokuk limestones are very common; by contrast, the St. Louisarea karst was almost completely destroyed by the pressures of urbanization (Elliott, 2000).

Throughout the karstic regions of Kentucky, particularly the south-central part of the state, human interaction with the karst systems has frequently resulted in problems. A combination of overenthusiastic land clearing and poor agricultural practices in the Sinking Valley increased runoff quantities while decreasing drainage capacity, resulting in floods known as "valley tides" (Dougherty, 1983). As late as the 1920s and 1930s, the city of Bowling Green (which at that time had no manmade sewer system) used the caves beneath the city as a de facto waste disposal system. Indeed, even today the city has only incomplete records regarding which homes are connected to the sewer system and which are not; it is entirely possible that some homeowners who think their homes are connected are actually using old, malfunctioning septic tank systems instead, which pose severe threats to the caves and karst below (Crawford, 2003). Also in Bowling Green, a segment of Dishman Road directly above the Mudderhorn Room of State Trooper Cave collapsed in 2002 because of the concentration of stormwater runoff and the rapid 
removal of sediments; the resulting sinkhole was 60 meters wide and 7 meters deep (Kambesis et al., 2003).

\section{Karst regulation in the study areas}

In Lexington-Fayette, karst systems and the issues inherent to human interaction with them influence the planning process from several different angles. In Chapter 2 of the county's comprehensive plan, protection of sinkholes is listed as an objective of the county's environmental framework. The comprehensive plan recognizes the presence of karst geology, and the importance of karst issues and sensitivity to maintaining groundwater quality - in particular, as it relates to manure piles. Chapter 3 of the plan includes clusters of sinkholes in its definitions of Other Hazardous Areas, and karst areas are also included in the definition of Environmentally Sensitive Lands, as well as the accompanying overlay district (Lexington-Fayette County Comprehensive Plan, 2001).

Karst and karst landforms are mentioned frequently in the Springfield comprehensive plan. For example, the plan notes the threat posed by karst to groundwater supplies in the Fulbright Spring area, a major source of Springfield's drinking water; it recommends limiting densities in certain watersheds, in part due to the presence of karst topography; it acknowledges the potential environmental problems of living on a fractured limestone terrain and recommends steps to mitigate these problems; and it recommends enactment of setbacks for individual sinkholes in Fulbright Spring Basin, among other places. In several places, the plan's authors urge the city to review and update its sinkhole ordinance to require water quality concerns be taken into consideration when permitting construction projects in sinkhole floodplains (Springfield Comprehensive Plan, Nov. 2001). 
Lexington-Fayette attempts to control development in karst areas through their zoning and subdivision ordinances. These controls pertain mostly to establishing more extensive approval requirements for landfills in karst terrain, and for certain conditional uses (e.g., cemeteries, mining operations, mineral and gas extraction) located in karstic agricultural areas (Zoning ordinance, Lexington-Fayette Urban County, 2005). Other controls include considering the presence of sinkholes in its tree protection standards (for example, according to the zoning ordinance, no tree may be removed from a sinkhole that will remain open space). In 1985, the Lexington-Fayette Urban County Government strengthened its karst protections by passing ordinance SRA 85-2, otherwise known as the Sinkhole Ordinance. While it is in some ways redundant to the county's zoning and subdivision ordinances, SRA 85-2 still offers significantly higher levels of karst protection than they do. First, it establishes "non-buildable areas" around sinkholes. These non-buildable areas will usually "follow the limits of the sinkhole," but can be expanded or contracted as appropriate by the Planning Commission. The sinkhole ordinance restricts—-but still permits, under specified circumstances—development in the sinkhole drainage area. Sinkholes can, in certain circumstances also be used for drainage purposes. Buildings may not be constructed on sinkhole fill (Lexington-Fayette ordinance SRA 85-2, Articles 6-7(1)).

Springfield's sinkhole ordinance was enacted four years later, in 1989, as a response to rapid urbanization and the stormwater runoff problems that came with it. It was hoped that this ordinance would prevent the discharge of potentially contaminated surface runoff into sinkholes, and thus directly into the aquifer below. While the ordinance requires additional steps in the permitting process for developments in sinkhole 
drainage areas, it is the setback / no-build component that most interests us here (Barner, 1999). Like Lexington-Fayette's sinkhole ordinance, the non-buildable area specified by the Springfield ordinance generally does not extend beyond the limits of the sinkhole itself; any deviations from this standard can be implemented by local government (Springfield, MO Code of Ordinances, sec. 96-6).

While many karst regulations are enacted with the goal of protecting an aquifer or a unique and fragile cave system, neither was the primary goal of the Lexington-Fayette sinkhole ordinance. Instead, one of the more important motivations behind the passage of the Sinkhole Ordinance was to prevent future sinkhole-related legal actions against the county (Rebmann, pers. comm., 2006). Because of this, it seems probable that the Planning Commission would be more likely to resist pressure from landowners and developers to shrink non-buildable areas on the sites of proposed construction projects than they would be if the primary motivation behind the ordinance were ecological protection.

\section{Data and Methodology}

The analysis conducted in this chapter focuses on the question of what impact, if any, karst-related setback-style ordinances have on housing density in areas where sinkholes are present. I chose to examine housing density rather than population density because the setback ordinances under examination here restrict construction activities. While it's undeniable that housing density and population density are closely related, for this reason housing density seems likely to provide a more direct illustration of the impacts of the setback ordinances than population density would. 
Because the effects I am looking for are more likely to be observable at a smaller scale, I chose to conduct this analysis at the Census block level, the smallest geographic unit used by the Census Bureau. Earlier analyses suggest that these effects are likely to be overlooked at larger scales. Shapefiles were obtained from several sources, including the US Census Bureau, the Kentucky GIS office, and the Missouri Spatial Data and Information Service. Block-level housing data were obtained from the Census Bureau. Sinkhole location data came from the Kentucky Geologic Survey and the Missouri Department of Natural Resources.

For the Census Bureau data, I chose to limit data collection to observations taken in 1990 and 2000. This decision was the result of several factors. First, the Census block was not used as a unit of Census geography prior to 1990. High levels of geographic precision in the data are required in order to answer the research question posed in this chapter, and I strongly felt that collecting data on a larger scale would have obscured the results. Second, the city of Springfield's sinkhole ordinance was originally implemented in 1990, which provided a good opportunity to observe the density-related effects of such an ordinance over its first decade of existence. I felt that, even if the data had been available for the appropriate Census geography prior to 1990 , reaching further into the past for observations would not have provided much more in the way of illumination.

Before any relationship between sinkhole density, housing density and setback regulation could be uncovered, the data had to be brought together and represented geographically. The first step was importing block-level shapefiles of all four cities for both 1990 and 2000 into ArcGIS; next, I added the sinkhole location shapefiles. Using the Join feature of ArcGIS, I spatially joined the blocks to the sinkholes so that each 
block record contained a count of the sinkholes contained within that block. From there, I added housing data tables and joined them to the appropriate block layers; this added the total count of housing units contained within each block to the appropriate block record. At this point, each block record contained data on the number of housing units and the number of sinkholes contained within it.

Next I used the Calculate Areas function to generate the area of each block. At that point, I was able to calculate both housing density (hdens) and sinkhole density (sinkdens) at the block level, and was therefore ready to begin my analysis. These densities, along with the distributions of individual sinkholes, are displayed geographically in Figures 7-10 through 7-21; Table 7-1 summarizes the data used for this analysis.

In this analysis, I included data only for blocks in each city that contained sinkholes. The reason for this is that setback-style ordinances would only be an issue in blocks that actually contain sinkholes; for other blocks, such regulation is a moot point, since there are no sinkholes to be concerned about. Additionally, it meant that I wouldn't have to worry about potentially unmapped sinkholes that may have a detectable impact on density, but would themselves be invisible for purposes of my analysis. Another reason for examining only blocks with sinkholes is that doing so helped ensure that I looked at roughly the same geographic areas in 1990 and in 2000; because Census geographies change with every Census, block boundaries are not constant and block-level data cannot be directly compared between Censuses. Table 7-2 enumerates sinkholes in each of the four municipalities. 
Figure 7-10

Census block-level housing density in Lexington-Fayette County, KY, in 2000

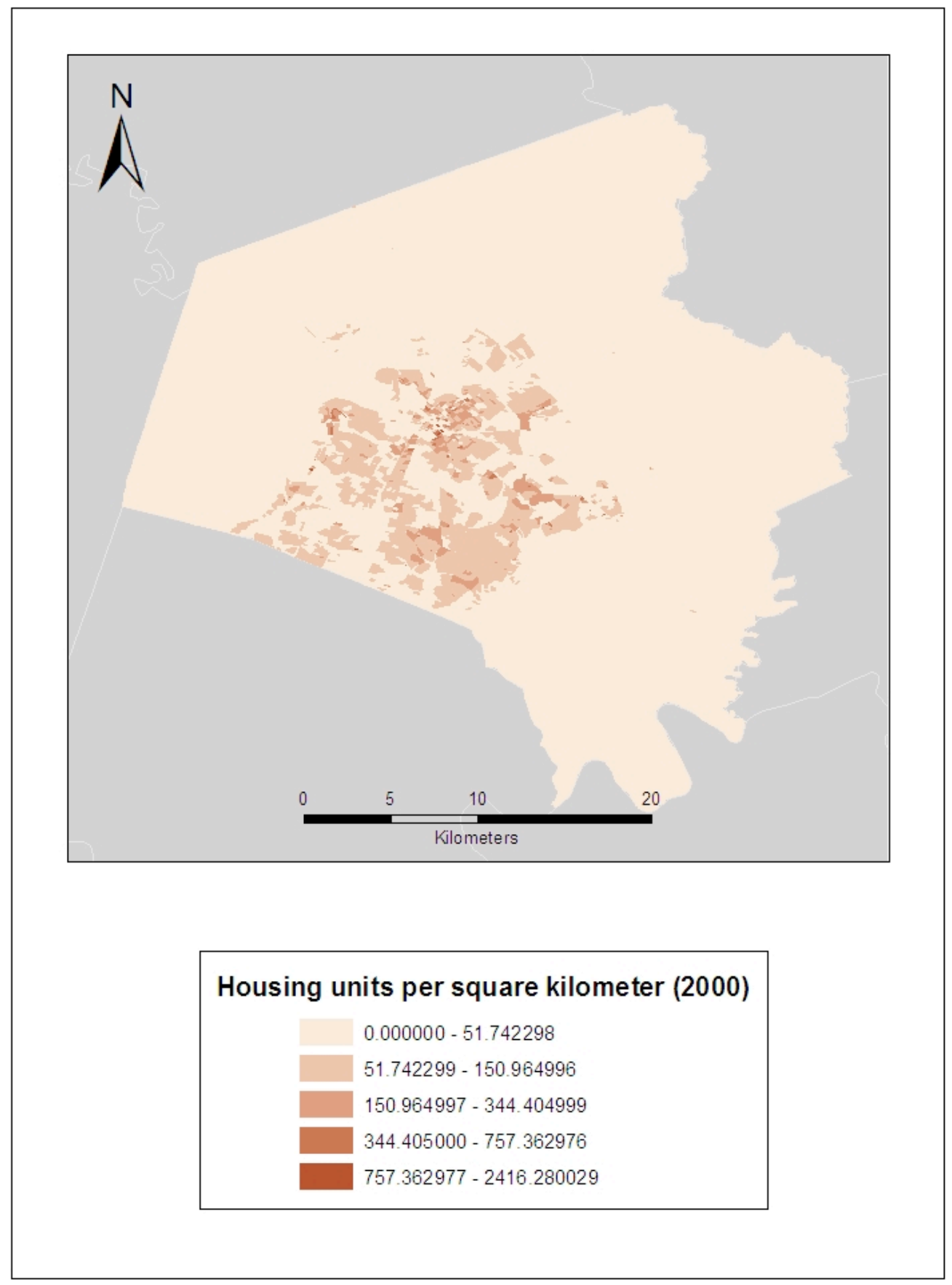

Source: US Census Bureau 
Figure 7-11

Sinkhole locations in Lexington-Fayette County, KY

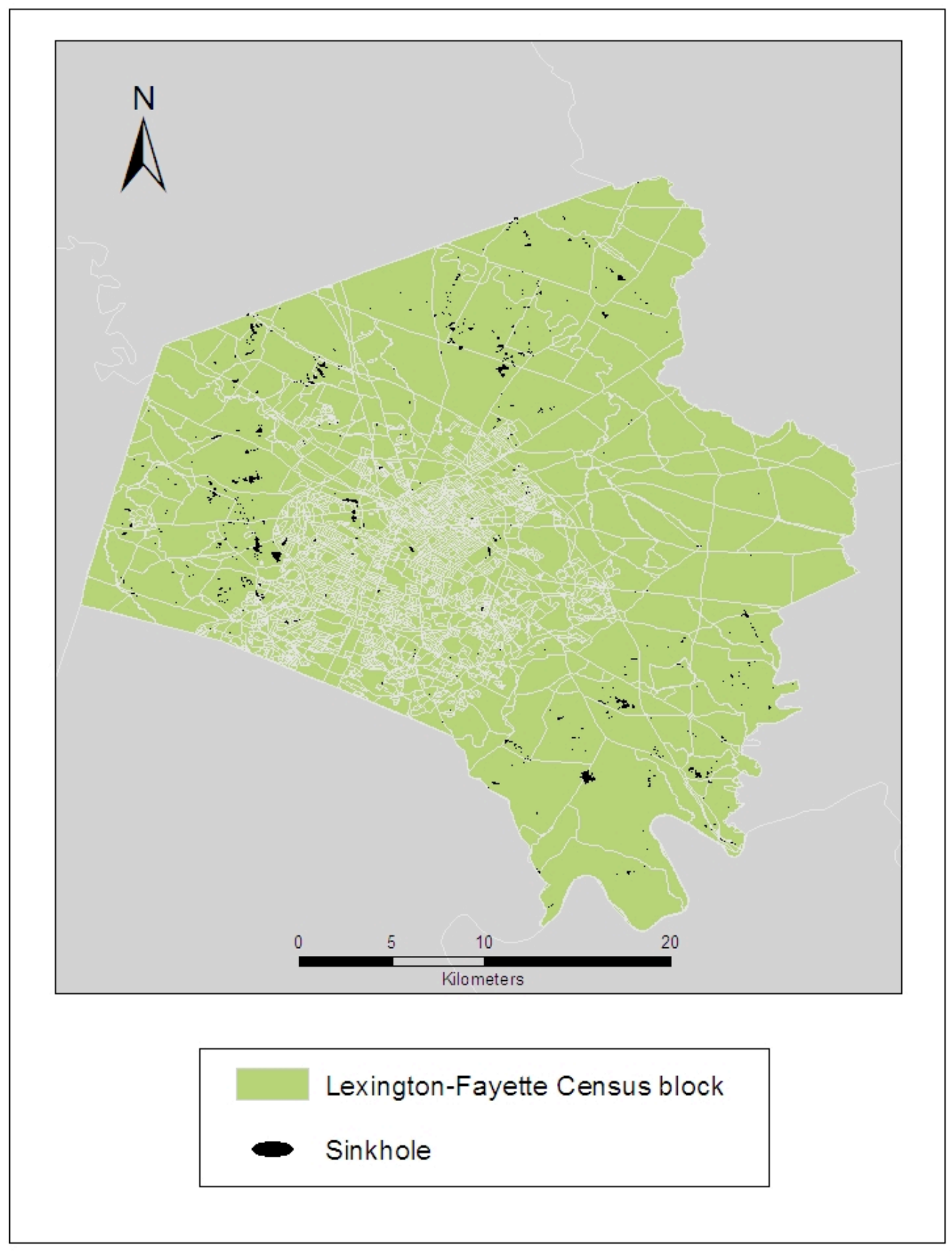

Source: US Census Bureau, Kentucky Geological Survey 
Figure 7-12

Census block-level sinkhole density in Lexington-Fayette County, KY

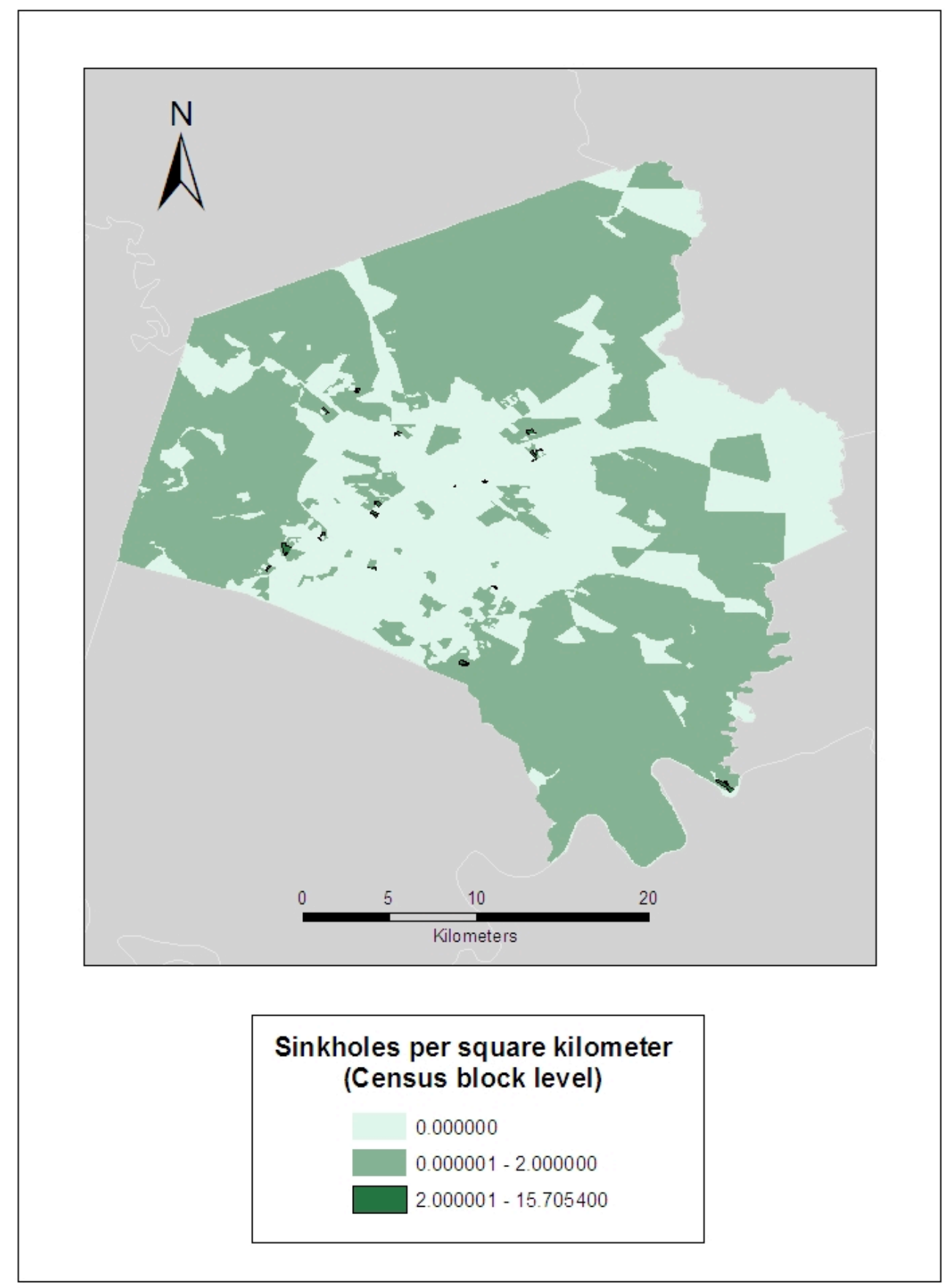

Source: US Census Bureau, Kentucky Geological Survey 
Figure 7-13

Census block-level housing density in Louisville, KY, in 2000

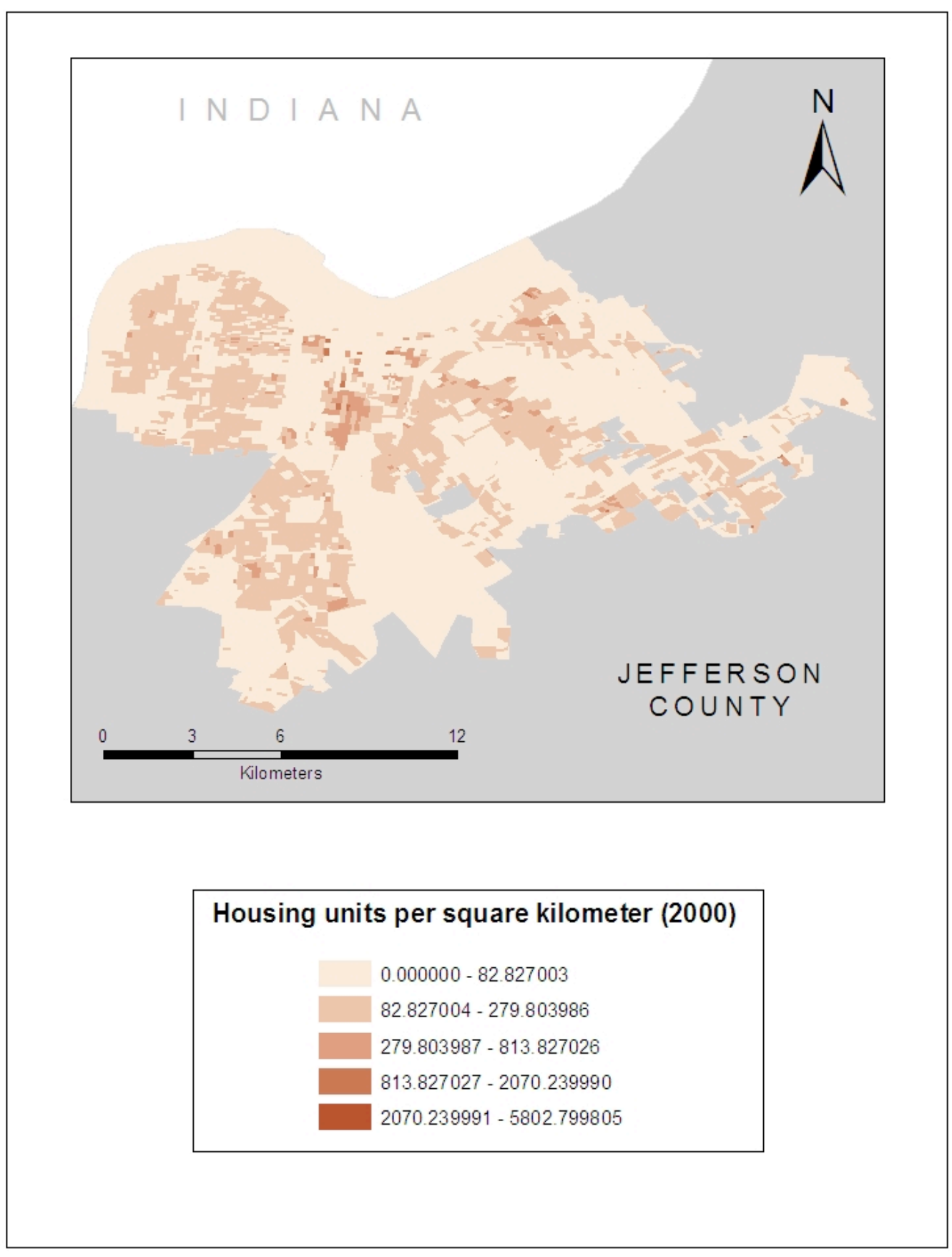

Source: US Census Bureau 
Figure 7-14

Sinkhole locations in Louisville, KY

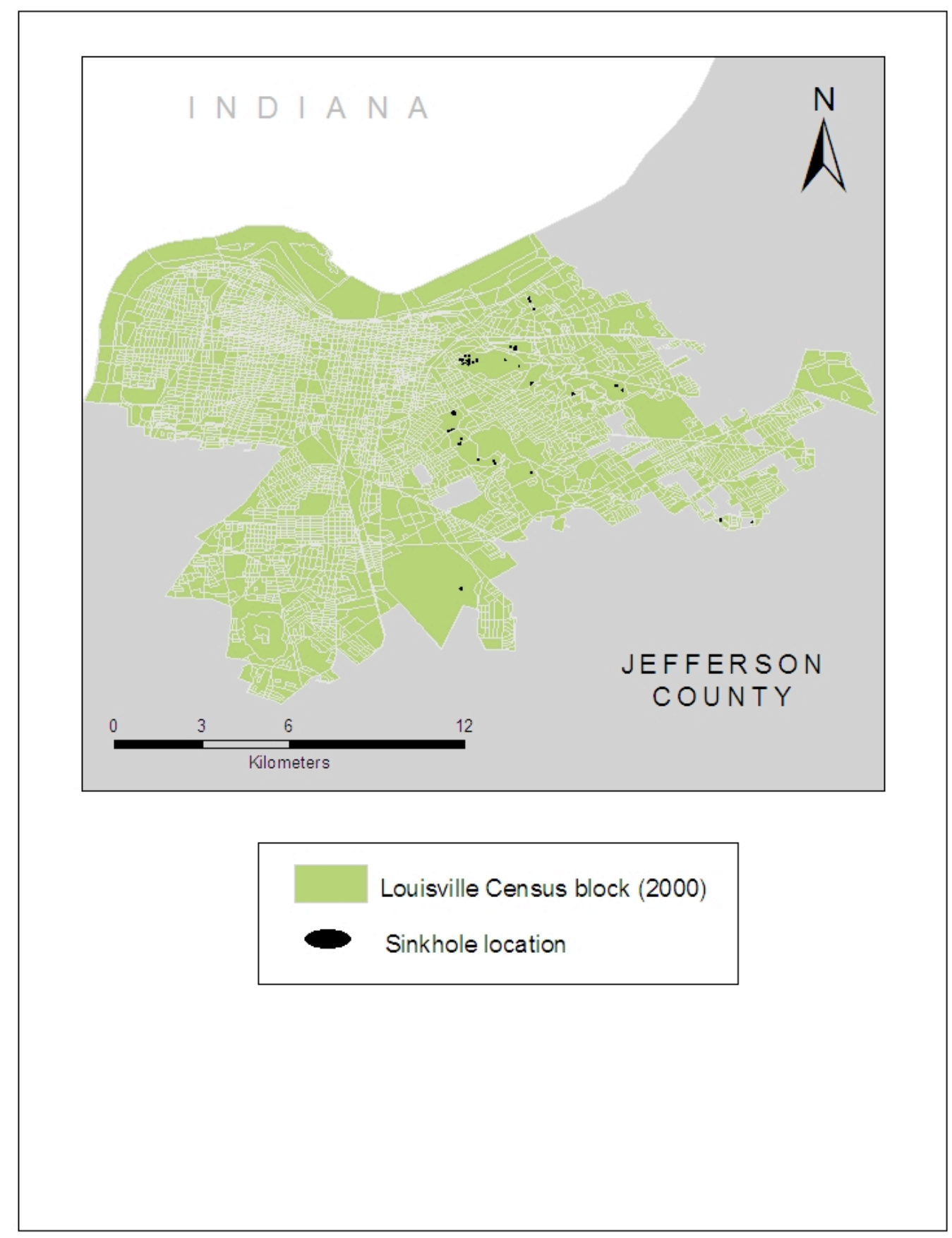

Source: US Census Bureau, Kentucky Geological Survey 
Figure 7-15

Census block-level sinkhole density in Louisville, KY

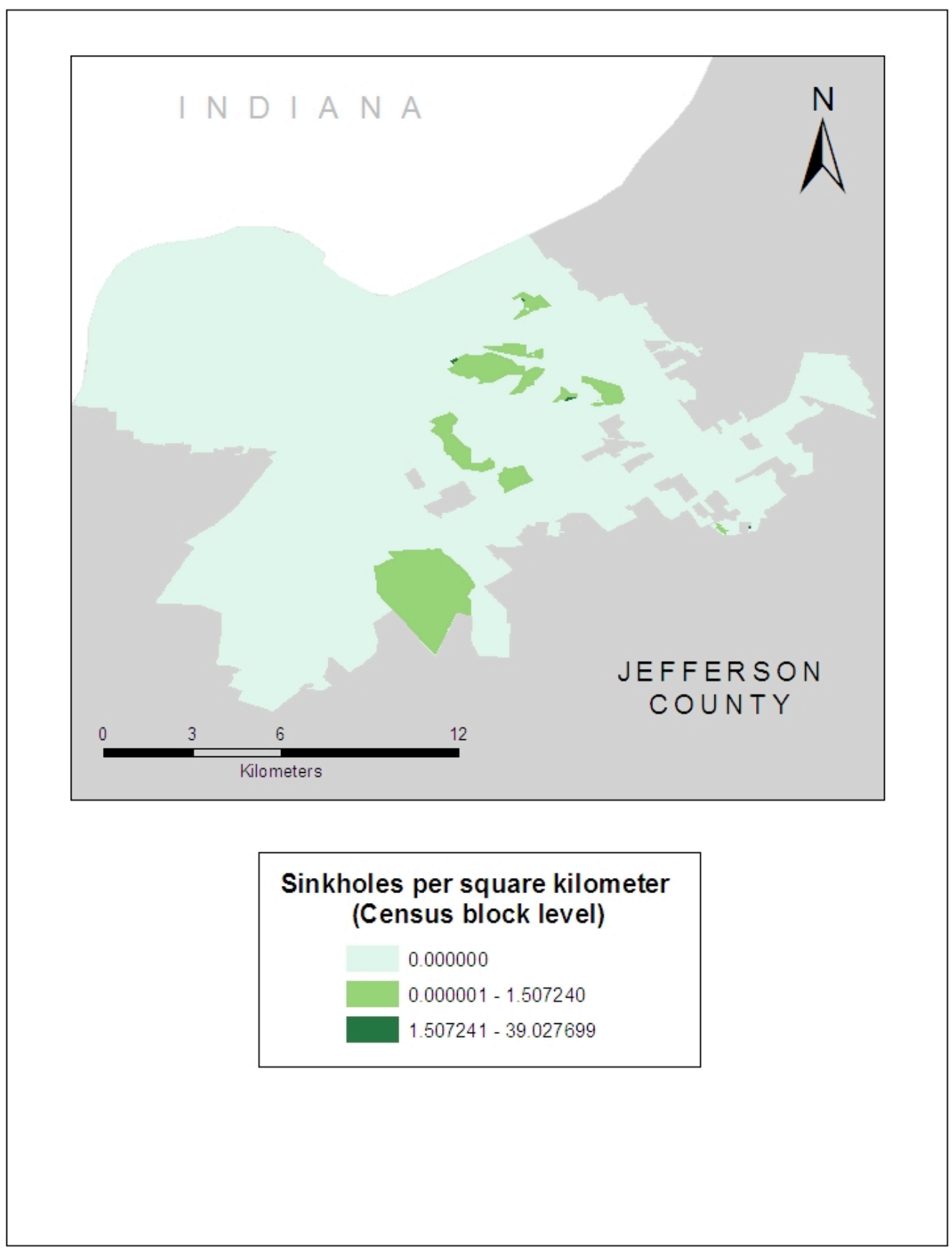

Source: US Census Bureau, Kentucky Geological Survey 
Figure 7-16

Census block-level housing density in Springfield, MO in 2000

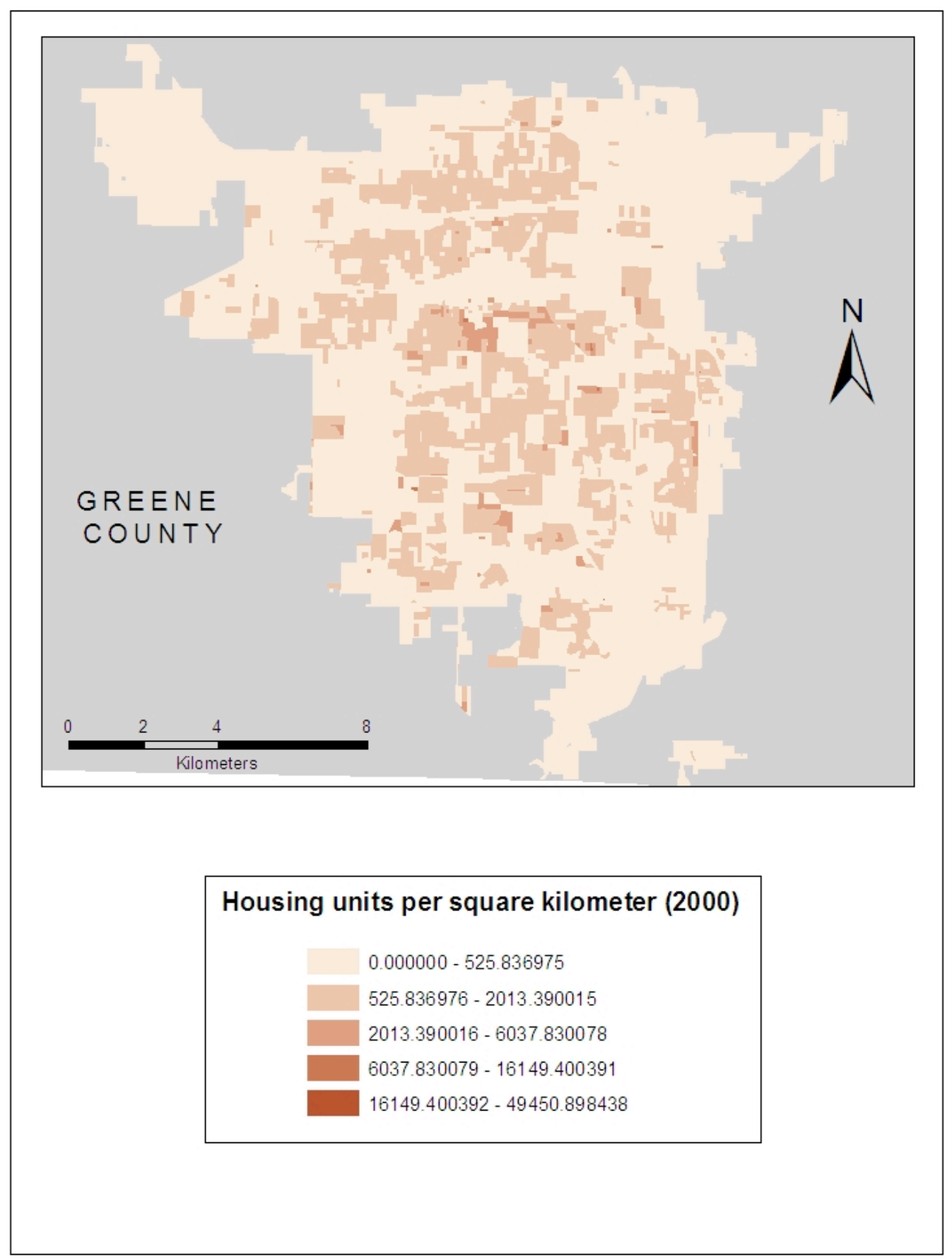

Source: US Census Bureau 
Figure 7-17

Sinkhole locations in Springfield, MO

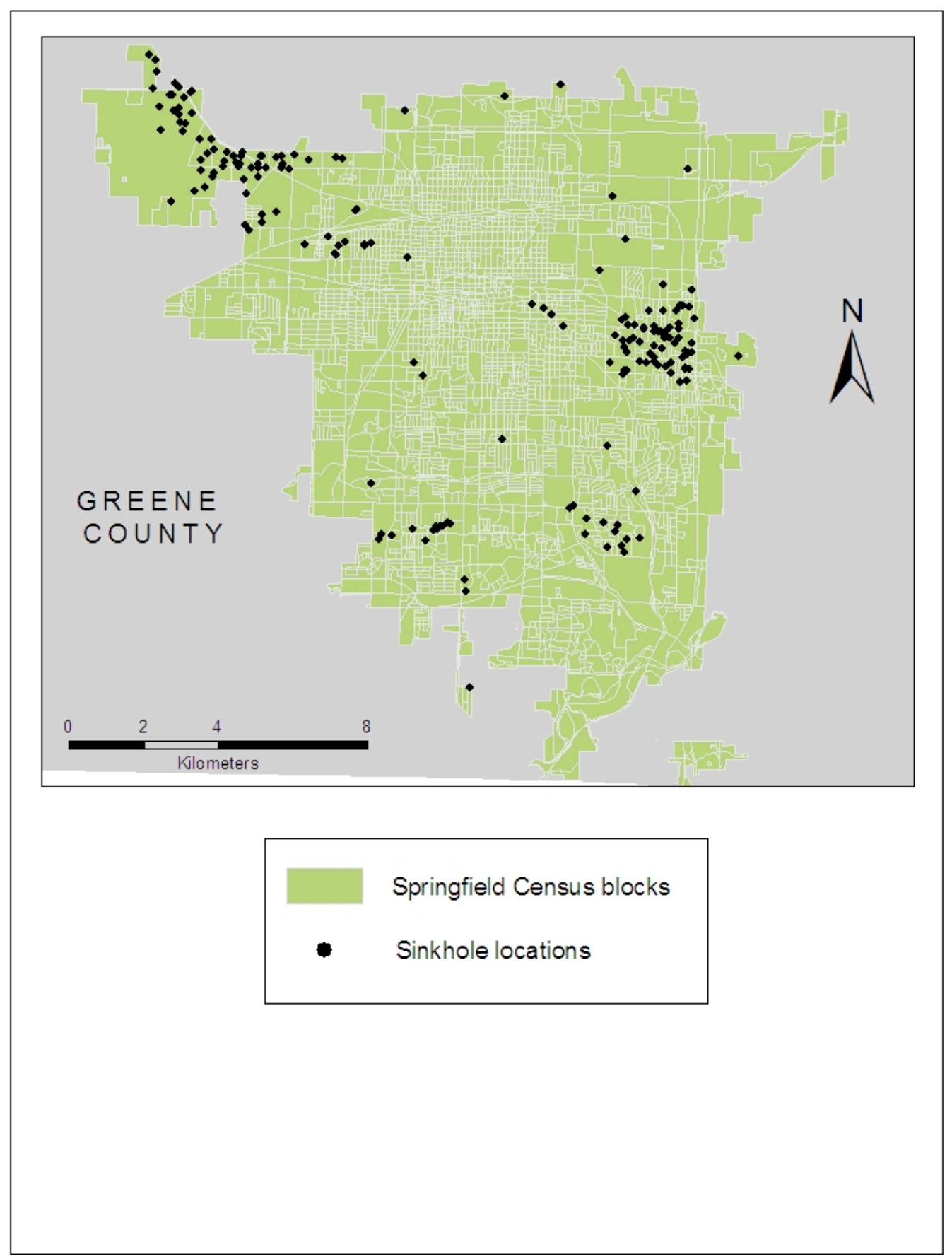

Source: US Census Bureau, Missouri Spatial Data Information Service 
Figure 7-18

Census block-level sinkhole density in Springfield, MO

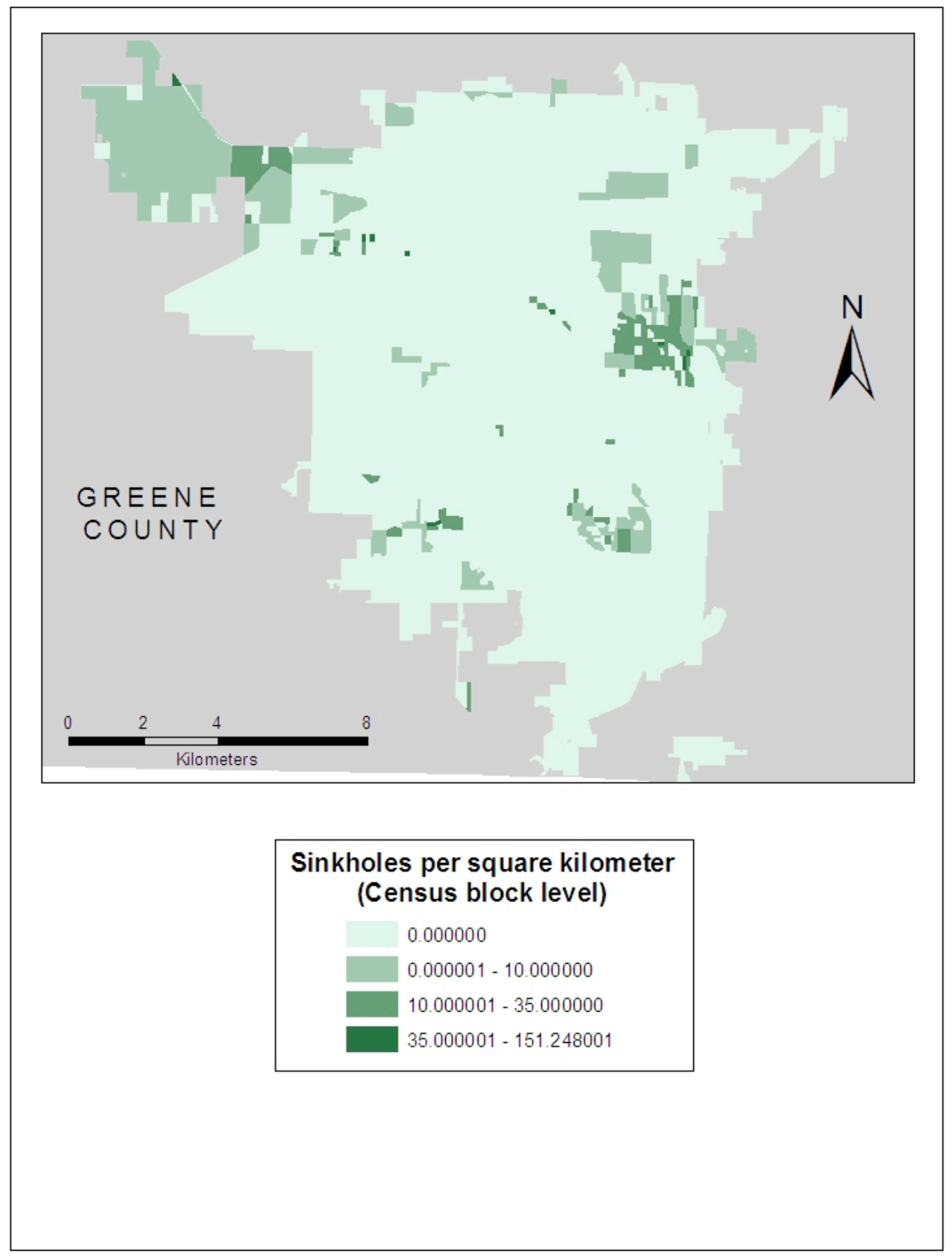

Source: US Census Bureau, Missouri Spatial Data Information Service 
Figure 7-19

Census block-level housing density in St. Louis, MO in 2000

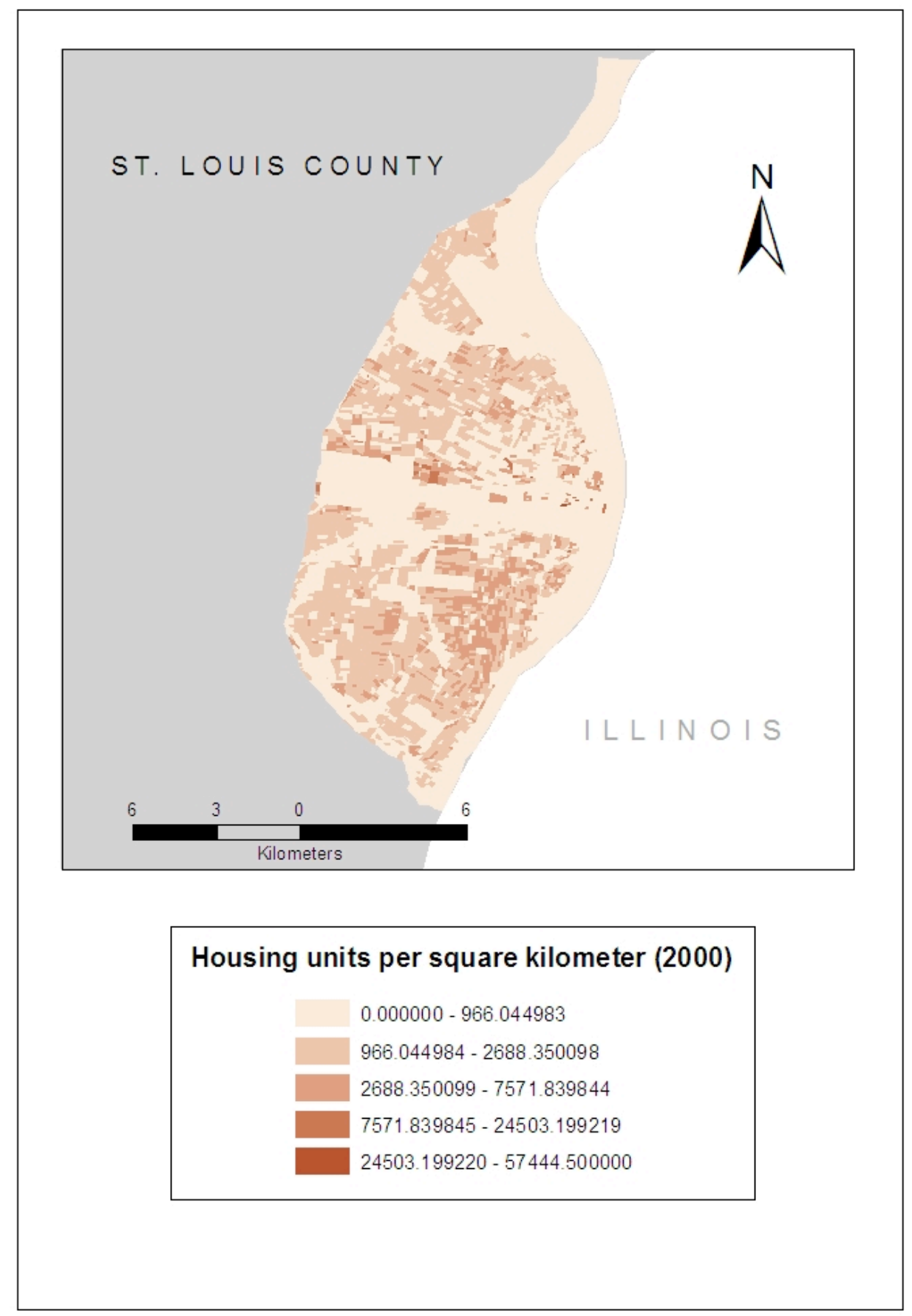

Source: US Census Bureau 
Figure 7-20

Sinkhole locations in St. Louis, MO

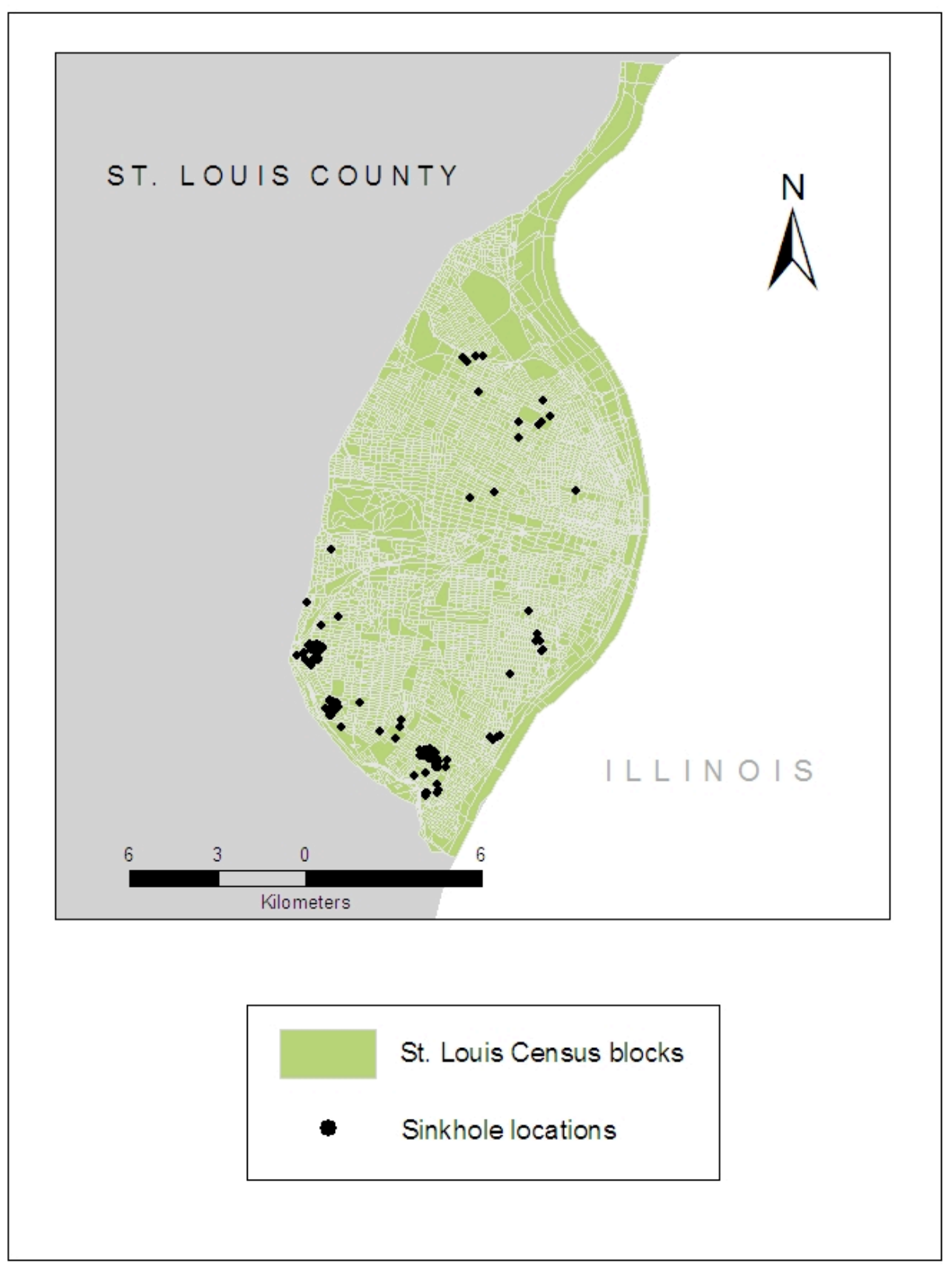

Source: US Census Bureau, Missouri Spatial Data Information Service 
Figure 7-21

Census block-level sinkhole density in St. Louis, MO

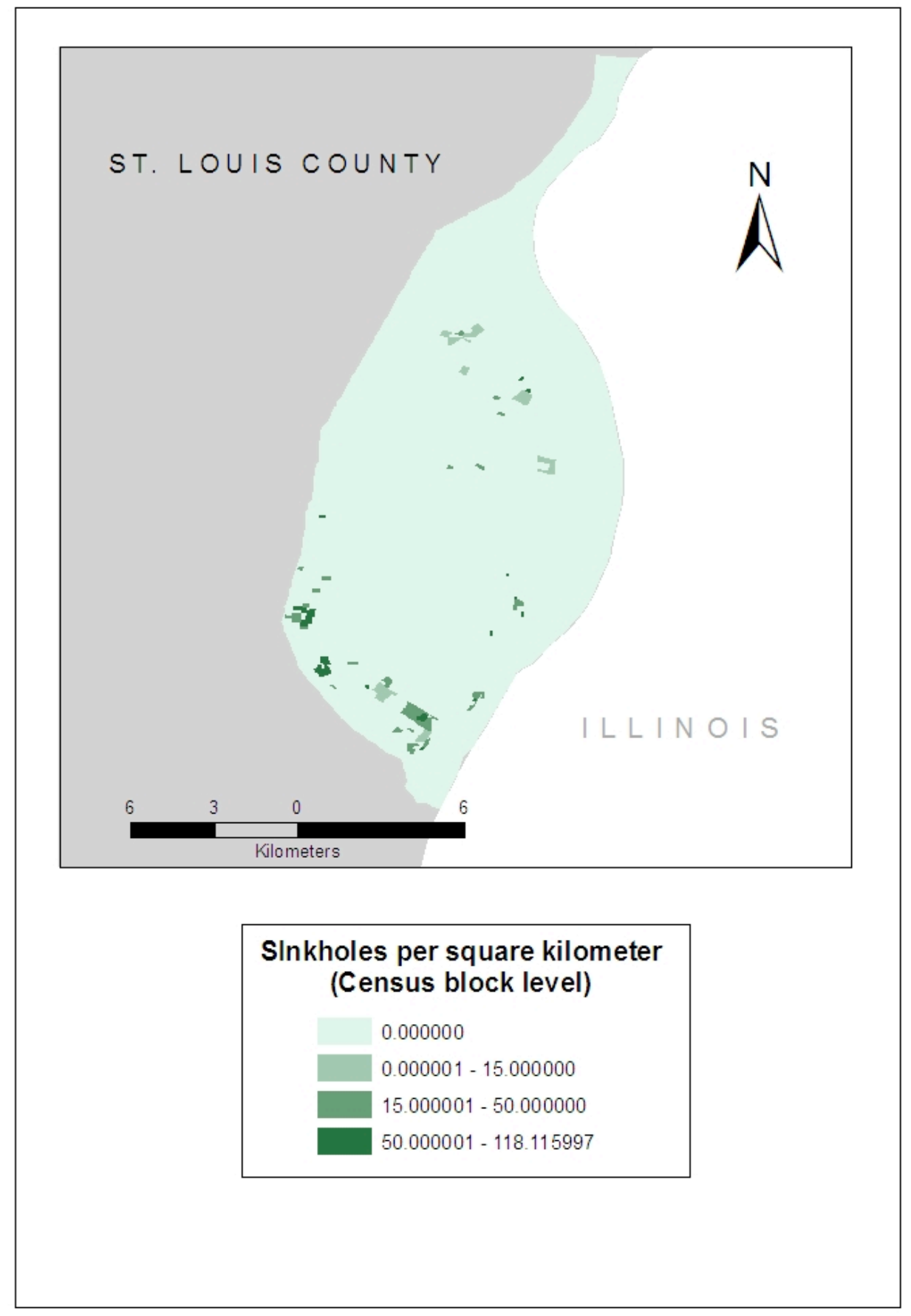

Source: US Census Bureau, Missouri Spatial Data Information Service 
Table 7-1

Summary of data used for regressions

\begin{tabular}{l|l|c|c|c|c|}
\hline \multicolumn{1}{c}{ Variable } & \multicolumn{1}{c}{ Description } & Mean & Std. Dev. & Min & Max \\
\hline SQKM & $\begin{array}{l}\text { Area of Census } \\
\text { block, in square } \\
\text { kilometers }\end{array}$ & 7.694 & 20.662 & 0.002 & 229.568 \\
SinkDens & $\begin{array}{l}\text { Number of sinkholes } \\
\text { per square kilometer }\end{array}$ & 16.765 & 34.747 & 0.008 & 472.143 \\
\hline HousDens & $\begin{array}{l}\text { Number of housing } \\
\text { units per square } \\
\text { kilometer }\end{array}$ & 389.486 & 693.758 & 0 & 4166.088 \\
Setbacks & $\begin{array}{l}\text { Binary variable } \\
\text { indicating the use of } \\
\text { setback regulations } \\
\text { Temporal binary }\end{array}$ & 0.686 & 0.464 & 0 & 1 \\
\hline yr_K & $\begin{array}{l}\text { variable } \\
\text { Difference-in- } \\
\text { differences binary } \\
\text { variable }\end{array}$ & 0.447 & 0.497 & 0 & 1 \\
\hline DIDvar & & 0.496 & 0 & 1 \\
\hline
\end{tabular}

$n=695$ for all variables

Table 7-2

Sinkhole counts for each city in the study area

City

Number of

Number of Census sinkholes blocks (year 2000) that contain sinkholes

\begin{tabular}{|l|c|c|}
\hline Lexington-Fayette County, KY & 1017 & 217 \\
\hline Louisville, KY & 39 & 17 \\
\hline Springfield, MO & 181 & 95 \\
St. Louis, MO & 109 & 65 \\
\hline
\end{tabular}


My analysis used two statistical methods: an ordinary least squares (OLS) regression to determine the relationship between sinkhole density, housing density and the presence of karst-related setbacks/ no-build ordinances at the block level; and a difference-in-differences regression to measure the change, if any, in that relationship between 1990 and 2000. The correlation coefficients and the OLS regressions were run separately for observations taken in 1990 and in 2000.

Several 1990 observations were dropped because housing data were not available for those particular blocks. This partially accounts for the different number of observations in 1990 and 2000; changes to Census geographies between 1990 and 2000 account for the rest.

\section{Regression models}

Two slightly different OLS regressions were run during this analysis. The first regression used hdens as the dependent variable, with sinkdens and setbacks (a binary variable set to 1 in blocks where karst-related setback-style ordinances were in force) as explanatory variables. The second regression included SQKM (block area in square kilometers) as an additional explanatory variable. The $S Q K M$ variable was added to account for the fact that in some areas block size varied considerably, which could conceivably impart bias onto any analysis of density; this was of particular concern in Lexington-Fayette County, where many of the Census blocks outside the city's urban growth boundary are quite large.

Because Lexington-Fayette County's sinkhole ordinance dates back to 1985, the setbacks variable was set to 1 for all observations taken there in both 1990 and 2000; this is based on the assumption that five years was enough time for the setbacks to show at 
least some initial impacts on density. By contrast, Springfield's ordinance was passed in 1989; it seems likely that any density-related impacts would not be strong enough to be observable by the following year. For that reason, Springfield's 1990 observations were assigned a setbacks value of 0 , while the 2000 observations were assigned a value of 1 . All observations from both St. Louis and Louisville were assigned a setbacks value of 0 .

The difference-in-differences (DD) regression is designed to measure the difference in the rate of change of a given statistical relationship between two distinct groups of observations. In this case, those groups are blocks with karst-related setbackstyle ordinances in place, and those without them.

DD models are often used for detecting changes caused by a specific event or policy. Examples are plentiful throughout the economics literature: Meyer, Viscusi and Durbin (1995) use a DD model to measure changes in the behavior of injured workers after an increase in worker's compensation benefits; similarly, Kiel and McClain (1995) use a DD model to capture changes over time to prices of homes sited near an incinerator. My analysis uses a DD model to capture changes over time to the relationship between housing density and sinkhole density in Census blocks where setback-style regulation is in effect.

In the DD regression used here, hdens is once again the independent variable, with sinkdens, setbacks, and $S Q K M$ included as explanatory variables. In addition to those, the DD regression also includes two other binary variables: $y r 2 k$, for observations taken in the year 2000; and Change over time, which was created by multiplying setbacks by $y r 2 k$. This interaction variable therefore captures the change in the relationship between housing density and sinkhole density between 1990 and 2000 for blocks in 
which sinkhole setbacks were applicable. In other words, if setback ordinances had any impact on the relationship between housing density and sinkhole density between 1990 and 2000 - for example, by slowing housing density growth during that time in areas with higher sinkhole densities - this effect will be captured by this variable.

\section{Results}

OLS regression results indicate a positive, statistically significant relationship between sinkhole density and housing density (Tables 7-3 through 7-6). However, the setbacks variable is statistically significant in all the OLS models; additionally, the variable's coefficient has the expected negative sign in all four sets of results, which means that housing densities are uniformly lower in blocks where karst setbacks are applied. Overall, this negative impact of setback regulations on housing density generally outweigh the positive impact of sinkhole density; in order for sinkhole density's positive effect to overtake the negative effect of setbacks in a given Census block, a sinkhole density of around 45 per square kilometer (in 1990) or around 170 per square kilometer (in 2000) would be required. The geographic size of each block was also statistically significant at 1 percent for the 1990 regression, but at only 5 percent for the 2000 regression. However, due to the potential collinearity between this variable and the dependent variable, and because adding the block area variable does not significantly change the results of the regressions, it is preferable to remove it from the model. 
Table 7-3

Ordinary Least Squares regression results

Model 1: regression using housing density as the dependent variable, using year 2000 data.

\begin{tabular}{l|c|c|c|}
$\begin{array}{l}\text { Explanatory } \\
\text { variable }\end{array}$ & Coefficient & Standard error & t value \\
\hline sinkdens* & 4.473153 & 0.8849802 & 5.05 \\
\hline setbacks* & -696.3605 & 68.81667 & -10.12 \\
Constant & 786.5795 & 65.94134 & 11.93 \\
\hline \multirow{2}{*}{$*$ statistically significant at 0.01} & & \\
$\mathrm{n}=393 ;$ Adjusted $\mathrm{R}^{2}=0.3597 ; \mathrm{F}=111.11$
\end{tabular}

Table 7-4

Ordinary Least Squares regression results

Model 2: regression using housing density as the dependent variable and including area in square kilometers as an explanatory variable, using year 2000 data.

\begin{tabular}{l|c|c|c|}
$\begin{array}{l}\text { Explanatory } \\
\text { variables }\end{array}$ & Coefficient & Standard error & t value \\
\hline sinkdens** & 4.307066 & 0.8878616 & 4.85 \\
\hline SQKM* & -1.690906 & 0.9733227 & -1.74 \\
\hline setbacks** & -675.7607 & 69.65601 & -9.70 \\
\hline Constant & 793.738 & 65.90035 & 12.04 \\
\hline
\end{tabular}

$* *=$ statistically significant at 0.01

* = statistically significant at 0.05

$\mathrm{n}=393 ;$ Adjusted $\mathrm{R}^{2}=0.3630 ; \mathrm{F}=75.46$ 
Table 7-5

Ordinary Least Squares regression results

Model 3: regression using housing density as the dependent variable, using year 1990 data.

\begin{tabular}{l|c|c|c|}
$\begin{array}{l}\text { Explanatory } \\
\text { variables }\end{array}$ & Coefficient & Standard error & t value \\
\hline sinkdens* & 9.473081 & 0.9976324 & 9.50 \\
\hline setbacks* & -376.6513 & 76.36333 & -4.93 \\
\hline Constant & 521.6412 & 63.68262 & 8.19 \\
\hline
\end{tabular}

$*$ = statistically significant at 0.01

$\mathrm{n}=302 ;$ Adjusted $\mathrm{R}^{2}=0.3622 ; \mathrm{F}=84.89$

Table 7-6

\section{Ordinary Least Squares regression results}

Model 4: regression using housing density as the dependent variable and including area in square kilometers as an explanatory variable, using 1990 data.

$\begin{aligned} & \text { Explanatory } \\ & \text { variables }\end{aligned}$
Coefficient

\begin{tabular}{|l|c|c|c|}
\hline sinkdens* & 9.130907 & 0.9976601 & 9.15 \\
\hline SQKM* & -37.2631 & 14.61945 & -2.55 \\
\hline setbacks* & -308.9506 & 80.19713 & -3.85 \\
\hline Constant & 544.533 & 63.7411 & 8.54 \\
\hline
\end{tabular}

$*$ = statistically significant at 0.01

$\mathrm{n}=302 ;$ Adjusted $\mathrm{R}^{2}=0.3695 ; \mathrm{F}=59.80$ 
The DD regression provides somewhat less straightforward results (Table 7-7).

Here, the sinkdens, setbacks and $S Q K M$ variables retain their overall significance as well as their signs, while $y r 2 k$ is not statistically significant. The ambiguity in these results comes from the Change over time interaction variable: its coefficient is negative, as we might expect — this suggests that housing density in blocks subject to setback-style ordinances either fell or increased more slowly than it did in the other blocks. However, this variable is statistically significant only at the 10percent level, with a $t$ value of -1.45 . This significance level is notably weaker than that observed for the sinkdens and setbacks variables. Ultimately, the DD model confirms the influence of sinkhole density and setback regulation on housing density.

\section{Discussion}

Before beginning the discussion of these results, it seems appropriate to mention the limitations of this analysis. First, there is some concern with the timing of sinkhole formation. The sinkhole location data used here were collected around the year 2000, and not as they occurred; as a result, there is no way to tell when any individual sinkhole actually formed. It is entirely possible that some of the sinkholes referenced in this analysis did not exist in 1990, which may make the sinkdens variable for 1990 observations somewhat less reliable. Second, this study looks only at housing density: other types of construction and development (commercial, infrastructure, etc.) are not addressed by this analysis. These types of construction are significant components to urbanization, and a similar analysis of the impact of setback regulations on nonresidential construction would be worth conducting. However, such a study goes beyond the scope of this chapter and is left to future work. Finally, different methods of 
Table 7-7

Difference-in-differences regression results

Dependent variable: housing density

\begin{tabular}{l|c|c|c|}
$\begin{array}{l}\text { Explanatory } \\
\text { variables }\end{array}$ & Coefficient & Standard error & t value \\
\hline sinkdens** & 7.156558 & 0.668893 & 10.70 \\
\hline SQKM* & -1.627839 & 1.092564 & -1.49 \\
\hline setbacks** & -436.76 & 66.65946 & -6.55 \\
\hline yr2k & 68.87032 & 77.61555 & 0.89 \\
\hline Change over time* & -137.9186 & 95.30439 & -1.45 \\
\hline Constant & 604.5628 & 53.16731 & 11.37 \\
\hline
\end{tabular}

$* *=$ statistically significant at 0.01

$*=$ statistically significant at 0.1

$\mathrm{n}=695$

Adjusted $\mathrm{R}^{2}=0.3618$

$\mathrm{F}=79.68$

displaying sinkhole location in GIS are used for the Kentucky and Missouri data, which may limit the extent to which they are directly comparable.

The results of the regression analyses described in this chapter indicate that setbacks do in fact appear to be related to housing density in areas where sinkholes are present. The fact that the interaction variable (which measured the change in the impact of setback regulations on housing densities over time) was significant in the DD regression is interesting, especially when one considers the fact that the time period studied here coincided almost exactly with the first decade after implementation of Springfield's sinkhole ordinance. One can therefore argue that these results mean that 
Springfield's sinkhole ordinance has had a noticeable impact on housing density in sinkhole-prone areas during the 1990s: even if housing densities in Lexington-Fayette stayed the same — as their ordinance had already been in place for four or five years—one would expect that the effect on housing densities in Springfield would have been detected by that variable.

Another factor that should be acknowledged is the urban service area (USA) that rings the urbanized section of Lexington-Fayette County (Figure 7-22). The urban service area was first defined in an amendment to the 1958 comprehensive plan as a method of controlling urban growth and protecting the region's famous horse farms from urban encroachment (Fleming, 2001). The definition of this area is provided by a map contained within the comprehensive plan. It is worth noting that although the border of the urban service area does act as a growth boundary by imposing a minimum lot size outside the area, the city-county government implicitly denies that it is any such thing. In the Lexington-Fayette County Code, the phrase "urban service area" is used, while "urban growth boundary" is not found (the hybrid "urban service boundary" is used once).

Originally, the urban service area (USA) was simply a line beyond which the city would refuse to provide services such as water, electricity, roads, schools or sewer. Initially, the USA did not work particularly well, primarily because of the fragmentation effect described by Carruthers (2002): new developments that were dependent on septic systems (and thus able to go without access to the city's sewer system) continued to spring up in rural Fayette County. This began to change only with the merger of the 
Figure 7-22

Lexington-Fayette County's urban service area

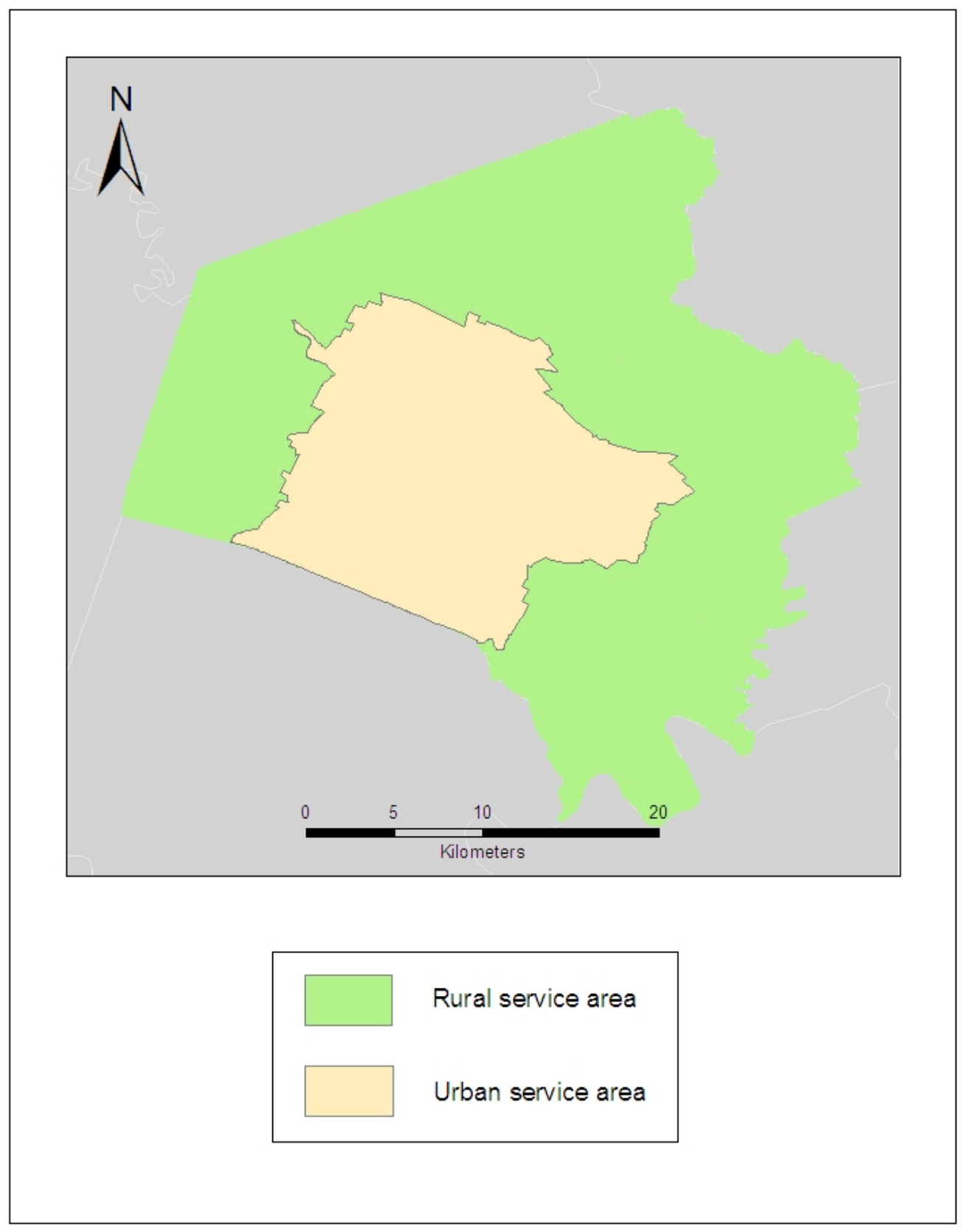

Source: US Census Bureau, Lexington-Fayette Urban County Government 
governments of the City of Lexington and Fayette County in 1973. At that point, a minimum lot size beyond the USA of ten acres per lot was implemented; this was increased recently to 40 acres per lot in an effort to stop the phenomenon of "estate sprawl" (Fleming, 2001).

In general, the goal of implementing an urban service area or urban growth boundary (two similar but distinct regulatory approaches) is to keep development constrained within a limited geographical area. However, that doesn't stop an urban area from adding population. All things being equal, when this growth is contained within a non-expandable geographic area, it eventually leads to smaller residential lots and higher land rents (Alonso, 1964; Mills, 1973). This general idea is somewhat complicated in the case of Lexington-Fayette. As discussed earlier, in a city with no urban service area boundary, the effect of a sinkhole ordinance would likely be more rapid outward growth of the urban area, with larger residential lots to compensate for the loss of buildable square footage. But the urban service area boundary puts opposite pressures on urban growth, acting as a method of confinement and limiting growth (Ambrose, 2003).

Ultimately, what we have in Lexington-Fayette is a city that wishes to restrict outward growth and instead redirect it inwards, while at the same time limiting the intensity of development (and thus the structural density) in sinkhole-prone areas within the city. The regulations enacted to achieve these goals should have conflicting effects on population and structural density: one works to increase density, while the other would have lower density as a side effect, at least in some areas. Could the fact that so many sinkhole-containing blocks are located in an area (Lexington-Fayette County) with an 
artificial (i.e., non-market driven) constraint on the supply of buildable land have imparted any bias onto the results?

At least two factors argue against this hypothesis. For one thing, the majority of Lexington-Fayette sinkholes occur outside the urban growth boundary: out of a countywide total of 936 sinkholes, only 200 are found within the UGB. Secondly, if the UGB were actually a factor, we'd expect setbacks to have a weaker effect—or none at all—on housing density because of the density-increasing effect of the UGB.

Finally, the counter-intuitive phenomenon of positive correlation between sinkhole densities and housing densities should be addressed. One possible explanation is reporting bias, i.e., sinkholes in highly populated areas are more likely to be reported than those in areas with fewer people. However, because sinkhole location data from both states were compiled from USGS topographical maps, reporting bias is an unlikely explanation. A second explanation is that karst features are being used as water features in new residential developments, where they would be more likely to be seen as amenities and not as hazards. Finally, it is also possible that higher housing densities bring higher sinkhole densities with them-as discussed in Chapter 2 of this dissertation, we do know that human populations can place enough stress on karstic terrains to induce subsidence. But without some indication of when individual sinkholes formed, it is extremely difficult to test this hypothesis. Perhaps this information can be gleaned from aerial photographs or other remote sensing images; if so, this is certainly a worthwhile avenue for future research. 


\section{Summary}

When housing densities in sinkhole-prone areas are compared between municipalities that employ setback-style ordinances for sinkholes and those that do not, we see that structural density in these areas is lower in cities with setback ordinances. When the entire study area is taken as a whole, we also see a positive correlation between sinkhole densities and housing densities, another result we might not instinctively expect. This phenomenon could be due to reporting bias, to the use of sinkholes as water features in newer developments, or to excessive stress placed on the karst by new development projects. The results of the analysis conducted here suggests that setbacks can be an effective regulatory tool to control development in karst terrains; however, it would be worthwhile to examine why setback ordinances seemed to have no effect on structural density in sinkhole-prone areas during the 1990s, with specific attention paid to localized factors. 


\section{Strategic behavior in the development of karst regulations: Does it pay off? A case study from Pennsylvania}

\section{Introduction}

Karst systems are shared resources. But because these systems do not recognize administrative or jurisdictional boundaries, karst-related problems generated by human activities in one municipality can easily spread to neighboring communities. If all communities connected to a particular karst system implement regulations intended to protect the system, the costs of doing so are spread evenly among the same communities that enjoy the benefits that emanate from those regulations. However, such regulations are often perceived as carrying high costs, in terms of lost opportunities for economic growth. This could encourage some communities to try to avoid the costs by refraining from implementing karst-related land use regulation, while reaping the benefits of neighboring communities' efforts at karst protection (i.e., the free rider problem—see Varian, 1992). But is such a strategy worthwhile? Using socioeconomic and regulatory data from cities and towns in karstic areas of Pennsylvania, this chapter examines the question of whether towns that do not implement karst regulations enjoy an economic advantage over towns that do.

This chapter begins with a brief description of the study areas, followed by a discussion of land use regulation in Pennsylvania, with a focus on how it relates to karst 
issues. Next, the regression models used in this chapter are explained, followed by the results and discussion.

\section{The study area}

The Lehigh Valley region of Pennsylvania is located in the eastern portion of the state, approximately 60 miles north of Philadelphia and 90 miles due west of New York City. As the name suggests, the region is in a valley of the Appalachian Mountains, with areas of relatively high relief along the northwestern and southeastern edges. The highest elevation for the region is 1689 feet above sea level, with a low elevation of 133 feet above sea level (Lehigh Valley Comprehensive Plan, 2005).

At the center of the Lehigh Valley are Lehigh and Northampton counties. Both counties are highly urbanized — taken together, they had a population of about 579,000 in 2000 (US Census Bureau), with an economic base that was once highly industrial. Socioeconomic statistics are pretty uniform across the region, with Northampton County having slightly higher household incomes and median home values, and slightly lower poverty rates, while a larger percentage of Lehigh County residents hold bachelor's degrees or higher. Centers of population include the cities of Allentown, Bethlehem and Easton; combined, Lehigh and Northampton counties have 62 municipalities. Forty-two of these (Table 8-1) are at least partially underlain by carbonate bedrock (Lehigh Valley Comprehensive Plan, 2005), which has led to the development of karst landforms throughout the region.

To the southwest is Berks County, which is not usually considered to be part of the Lehigh Valley region but is included here because its urbanized nature and extensive karst are characteristics it shares with Lehigh and Northampton counties. Berks County 
had a population of roughly 373,000 in 2000 (US Census Bureau), which is larger than the population of either Lehigh County or Northampton County that year. Nearly 80,000 of Berks County residents lived in Reading, the county's largest city. Berks County is

Table 8-1

Municipalities in Lehigh and

Northampton Counties underlain by karst

\begin{tabular}{|c|c|}
\hline Portland & Allentown \\
\hline Upper Mt. Bethel & Hanover (Lehigh) \\
\hline Lower Mt. Bethel & Catasauqua \\
\hline Forks & North Catasauqua \\
\hline Stockertown & Northampton \\
\hline Tatamy & Coplay \\
\hline Palmer & Whitehall \\
\hline Nazareth & North Whitehall \\
\hline Upper Nazareth & Upper Saucon \\
\hline Lower Nazareth & South Whitehall \\
\hline Easton & Emmaus \\
\hline West Easton & Upper Macungie \\
Wilson & Lower Macungie \\
\hline Williams & Macungie \\
\hline Glendon & Lower Milford \\
\hline Bethlehem Twp. & Upper Milford \\
\hline Bethlehem City & Alburtis \\
\hline Freemansburg & Weisenberg \\
\hline Hellertown & Salisbury \\
\hline Allen & Hanover (Northampton) \\
\hline East Allen & Fountain Hill \\
\hline
\end{tabular}


similar demographically to Lehigh and Northampton counties, but there are noteworthy differences: of the three, Berks had the lowest percentage of residents with bachelors degrees, the lowest median housing value, and the highest poverty rate (exceeding Lehigh County's rate by one-tenth of one percent). Berks County contains 76 municipalities within its boundaries, many of which have implemented at least some level of karstrelated land use regulation.

The remaining three counties in the study area - Cumberland, Franklin and Lancaster-are located along the western edge of Pennsylvania's karst belt, towards the center of the state and extending to the Maryland state line (Figure 8-1). While Cumberland and Franklin counties are smaller in terms of population than the counties in the Lehigh Valley (with populations of 213,000 and 129,000 in 2000, respectively), Lancaster County has the highest population of any in the sample: nearly half a million people lived there in 2000. Franklin County has the lowest population, the lowest concentration of college graduates, and the lowest median home values of all counties in the sample. Franklin County's largest city is Chambersburg, with a 2000 population of just under 18,000 (Table 8-2).

\section{Pennsylvania's karst landscape}

The southeastern quarter of Pennsylvania contains part of a long band of karst topography that begins in Missouri and Arkansas and stretches eastward and northward, all the way to New Jersey and New York (Figure 8-1). As discussed in Chapter 2, karst landscapes form via dissolution of carbonate bedrock, which is widespread in Pennsylvania: different types of carbonate commonly found in Pennsylvania are limestone, which is the most common; dolomite (sedimentary) and marble 
Figure 8-1

Mapped karst points in the six counties of the study area

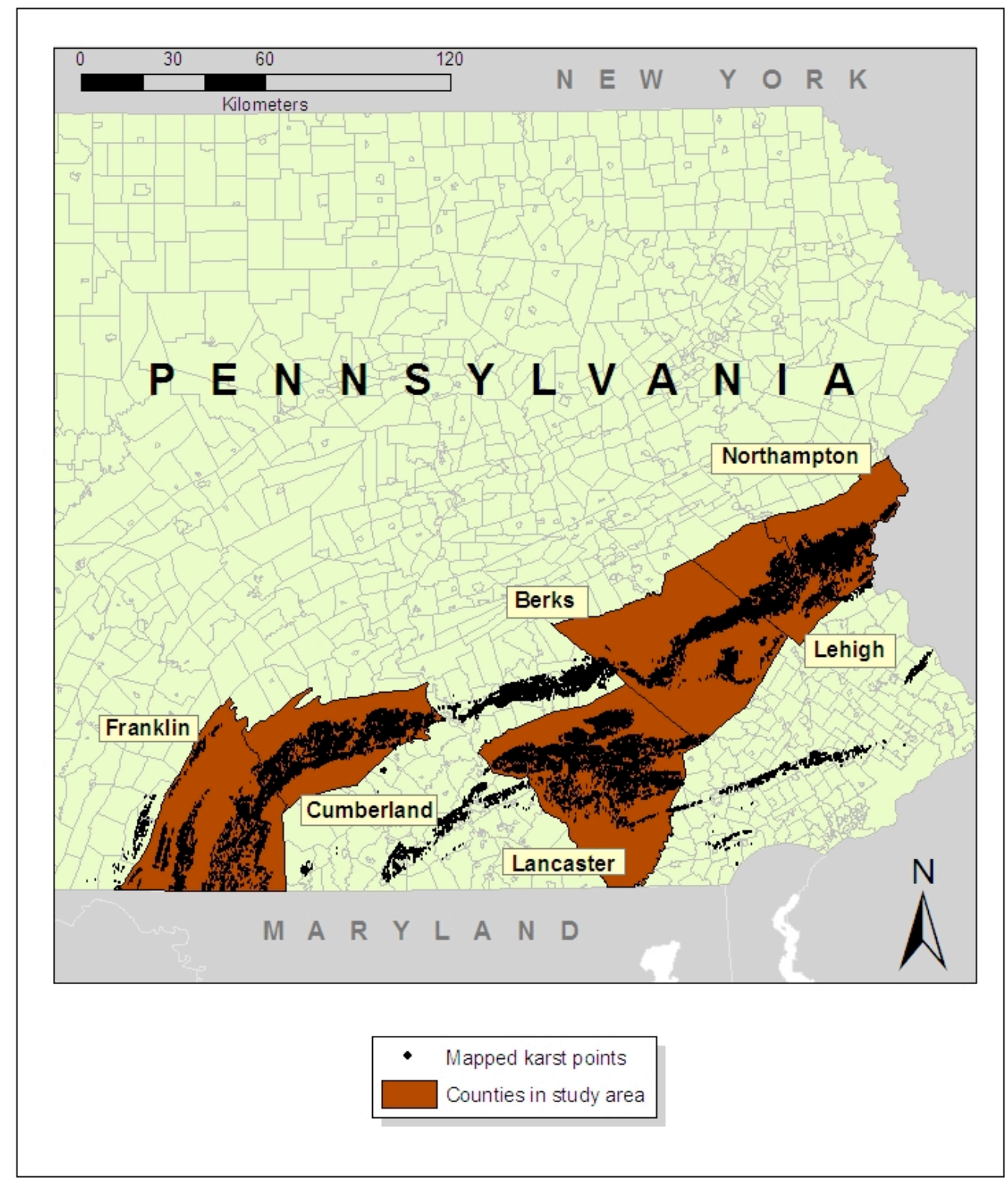

Source: US Census Bureau, Pennsylvania Department of Conservation and Natural Resources 
Table 8-2

Year 2000 demographic data for the six Pennsylvania counties in the study area

\begin{tabular}{|l|c|c|c|c|c|}
\multicolumn{1}{|c}{ County } & \multicolumn{1}{|c}{ Population } & $\begin{array}{c}\text { Median } \\
\text { household } \\
\text { income }\end{array}$ & $\begin{array}{c}\text { Median } \\
\text { home } \\
\text { value }\end{array}$ & $\begin{array}{c}\text { Percent of } \\
\text { population } \\
\text { in poverty }\end{array}$ & $\begin{array}{c}\text { Percent of } \\
\text { population with } \\
\text { college degree }\end{array}$ \\
\hline Berks & 373,638 & $\$ 44,714$ & $\$ 104,900$ & 9.4 & 18.5 \\
\hline Cumberland & 213,674 & $\$ 46,707$ & $\$ 120,500$ & 6.6 & 27.9 \\
\hline Franklin & 129,313 & $\$ 40,476$ & $\$ 97,800$ & 7.6 & 14.8 \\
\hline Lancaster & 470,658 & $\$ 45,507$ & $\$ 119,300$ & 7.8 & 20.5 \\
\hline Lehigh & 312,090 & $\$ 43,449$ & $\$ 113,600$ & 9.3 & 23.3 \\
\hline Northampton & 267,066 & $\$ 45,234$ & $\$ 120,000$ & 7.9 & 21.2 \\
\hline
\end{tabular}

Source: U.S. Census Bureau fact sheets

(metamorphic). Throughout Pennsylvania's carbonate bedrock band, conditions are suitable for karst topography to develop, and landforms like sinkholes, springs and caves are common (Kochanov, 1999). Sinking streams are another karst feature commonly found in Pennsylvania's karstic zones, often running considerable distances before disappearing into the earth. Scott (1806) noted that these particular landscape features were limited to limestone regions; however, no causal mechanism was proposed. An early description of the source of Penn's Creek in Centre County reads like that of a karst spring, and the large cave in Dauphin County, near the Susquehanna River, was already well-known by the beginning of the $19^{\text {th }}$ century (Scott, 1806). Other caves have long been known to exist near Easton, Carlisle, and elsewhere, many of which are "embellished by all kinds of dripstone" (Schopf, 1787; p. 91). 
In the Lehigh Valley area, sinkholes are more or less evenly distributed throughout the rocks of the Beekmantown Group and Allentown Dolomite (each has about 40 percent of the total). Jacksonberg limestone seems to be most resistant to sinkhole development (USGS / Sloto, 1991). Leakage from storm sewers and water mains are common drivers of sinkhole development in southeastern Pennsylvania; sudden subsidence on the surface is often the result, sometimes with near-disastrous results (see Kochanov, 1999; Gillespie, 1999; Memon et al., 2001; Memon et al.., 2002).

Karst accounts for nearly the entire drainage system in some southeastern Pennsylvania communities, where karst aquifers are the source of groundwater (Chichester, 1996; Kochanov, 1999). In those areas, some of that surface water instead sinks through the soil into the saturation zone, where it becomes recharge, and eventually returns to the surface via streams, natural springs or human-made wells (Longwood and Wood, 1965; Gerhardt and Lazorchick, 1988). In Northampton's Limestone Belt, it is estimated that more than half of all precipitation finds its way into the bedrock system below. Often there is no surface runoff, as the area's sinkholes are very well-developed in places. Between Monocacy and Bushkill Creeks, and between Monocacy and Catasauqua Creeks, there is little if any surface drainage: nearly every drop of surface water disappears into the underground drainage system (Miller et al., 1939).

There are serious problems with both water supply and water quality in some of the study area's limestone regions. Because groundwater flows through—and is concentrated in - defined open channels created by solution processes, a well driller has to actually hit one of these channels to get access to the groundwater. And even if a channel is struck, these waters are easily polluted from the contaminants carried by 
surface runoff: as early as 1940, many shallow household wells were being abandoned for exactly this reason (Miller, 1941). More recently, water drawn from wells in the area was found to contain high levels of total coliforms and streptococcus bacteria, as well as e. coli; higher concentrations of e. coli showed a statistically significant positive correlation with the presence of carbonate bedrock (Bickford et al., 1996). Carbonate aquifers in agricultural areas were also shown to contain median nitrate levels that exceeded those found in local surface waters, as well as in carbonate aquifers in urbanized zones; this could be related to both higher specific conductance of groundwater in these agricultural areas and to more intensive use of nitrate-based fertilizers for agriculture (Hippe et al., 1994; Lindsey et al., 1997). Deeper wells of 200 feet or more are much more successful at finding groundwater in these limestone areas (deeper wells are successful 70 percent of the time) (Miller, 1941). In some areas, the limestone has been shattered by complex folding and faulting processes; these areas tend to be good sources of groundwater, as it is not concentrated into well-defined channels. However, drilling in these places can be tricky because of the fragmented nature of the limestone; these fragments can easily damage drilling equipment if drillers are not careful. Often, drillers must go pretty deep to get "clear" water, since there's a lot of fine clay in suspension (Miller, 1941).

In some karstic parts of central Pennsylvania, one can find shallow depressions in karst terrains that contain small wetlands. These wetlands generally rest above the local water table, and are therefore not connected to the groundwater system; instead, they get most of their water from direct precipitation. However, they are usually very sensitive to local, seasonal climate conditions. In some cases, the water table is relatively shallow, 
and during recharge events water is discharged into these wetlands. Most of these small wetland areas have combined contributing catchment areas extending to a maximum of about 150 meters away. These particular landforms are not found elsewhere in the state, and are not even especially common in this region (O’Driscoll and Parizek, 2003).

\section{Land use regulation in Pennsylvania, and how karst relates}

There is a wide variety in approaches to managing growth and development across the karstic regions of Pennsylvania. The Pennsylvania Planning Code grants authority to municipalities to implement ordinances governing both subdivision and land development and zoning. These two types of ordinances address related issues but differ in scope. A subdivision and land development ordinance (SALDO) simply requires that all subdivision and land development plats of land must be submitted to the appropriate municipal agency for approval. SALDOs generally include (among other things) descriptions of the processes required for plat submission, provisions designed to ensure a particular style of urban form, setback requirements, and procedures for waivers and appeals. Municipalities can refuse to approve projects begun in violation of the SALDO, and such violations can carry a fine, set by the state Planning Code at a maximum of \$500 (Act 247, Pennsylvania State Planning Code, 1967).

Zoning ordinances, on the other hand, have a more ambitious purpose: the Pennsylvania Planning Code grants municipalities the authority to enact zoning ordinances in order to "implement comprehensive plans and to accomplish any of the purposes of this act” (p. 45). The goals of a zoning ordinance include protecting and promoting public health and general welfare, preservation of the natural landscape (in part or as a whole), and managing density and providing for reasonable growth. Zoning is 
therefore to be used as a tool through which the development and physical nature of the human landscape of a given municipality can be guided and directed at a macro level, while SALDOs can be seen as working toward similar goals on the micro level of individual subdivisions and developments. Despite differences in focus and scope, the two types of ordinances are clearly complementary.

A third method of land use management employed in Pennsylvania is the comprehensive plan. Comprehensive plans are intended to identify areas where growth is expected to occur, so that the municipality may then plan for service and infrastructure provision to those areas. According to the state planning code, they should take a wideranging ("comprehensive") view of future growth and identify objectives regarding the timing and nature of future development. Long- and short-term strategies for achieving these objectives are also appropriate for inclusion. State law requires counties to have a comprehensive plan in place; municipalities may adopt a county plan in its entirety, a modified form of the county plan, or a completely separate plan. Any municipal plan should be generally consistent with the county plan; however, the state planning code notes that an act of government shall not be declared invalid or subject to challenge on the sole basis that it is inconsistent with the adopted comprehensive plan (Act 247, Pennsylvania Planning Code, 1967). In other words, the plan is for guidance only, even though zoning ordinances are supposed to work to promote the goals and objectives of the comprehensive plan. Because they do not carry the same force of law as a local zoning ordinance or SALDO, comprehensive plans are not included in the analysis that follows this section, and are mentioned here only for the sake of completeness. 
The importance of karst geology is acknowledged in comprehensive plans across the region. The Lehigh Valley Comprehensive Plan, for example, sets forth two policies related to sinkholes: one, that developments should be designed in such a way as to minimize the occurrence of sinkholes and sinkhole-related problems; and two, that municipalities on carbonate bedrock develop sinkhole management programs. The plan also recommends adopting SALDOs to manage development in carbonate areas, as well as subdivision ordinances designed to mitigate risk posed by sinkholes (Lehigh Valley Comprehensive Plan, 2005). However, it should be noted that some comprehensive plans make no effort to address karst as a factor in planning for future growth: while the Berks County Comprehensive Plan mentions karst as a factor in generating development pressures, nowhere does the plan lay out any policies intended to address the issue. It is also important to remember that policies and recommendations put forth in a comprehensive plan are not legally binding upon the municipalities subject to them (Act 247, Pennsylvania Planning Code, 1967). In this regard, the Pennsylvania comprehensive planning process has much in common with those in other states.

Many counties in Pennsylvania have implemented their own SALDOs and zoning ordinances. Under state law, these countywide regulations apply only to municipalities without their own ordinances: the Lehigh Valley Comprehensive Plan notes that while "municipal plans are required to be generally consistent with the adopted county plan ... county comments cannot override local zoning" (Lehigh Valley Comprehensive Plan, 2005; p. 51) (emphasis mine). In other words, local governments in Pennsylvania have the power to override county governments on subdivision, land development, and zoning issues (Act 247, Pennsylvania Planning Code, 1967). In practice, this can mean that 
county-level ordinances are applicable in only small portions (i.e., boroughs and townships without similar or contradictory regulations) of the county that passed them, since counties in Pennsylvania are completely divided into smaller jurisdictions (townships, boroughs and cities): there is no "unincorporated" land that rely exclusively on county ordinances for management. This is a distinct difference from prevailing practice in some other heavily-karstified states like Florida, where large populations on unincorporated lands are common.

It is difficult to generalize with regard to characteristics of municipalities that choose to regulate human activities on karst landscapes. According to an examination of online municipal codes and to data provided by the Pennsylvania Department of Conservation and Natural Resources (DCNR), municipalities with mapped karst are just as likely to have chosen not to implement karst land use regulations as they are to have chosen to do so. Figure 8-2 is a map generated from the sample used for the regression analyses described later in this chapter. Within that sample, there were 42 municipalities with mapped karst points in which no karst-aware land use regulations were found; there were 43 municipalities with mapped karst points that did have this type of regulation on the books. One might be inclined to suspect that this might be related to differences in urbanization or populations levels. However, there does not seem to be any correlation between the level of urbanization of a municipality and the likelihood of finding karstrelated regulations or ordinances on the books. It is true that Allentown, the city with the highest population in the sample, does have a weak form of karst regulation on the books; however, the cities of Reading (with a population near 80,000 in 2000), Bethlehem City (approximately 70,000) and Lancaster (approximately 50,000) do not even provide the 
Figure 8-2

Distribution of karst and regulation practices in selected Pennsylvania municipalities

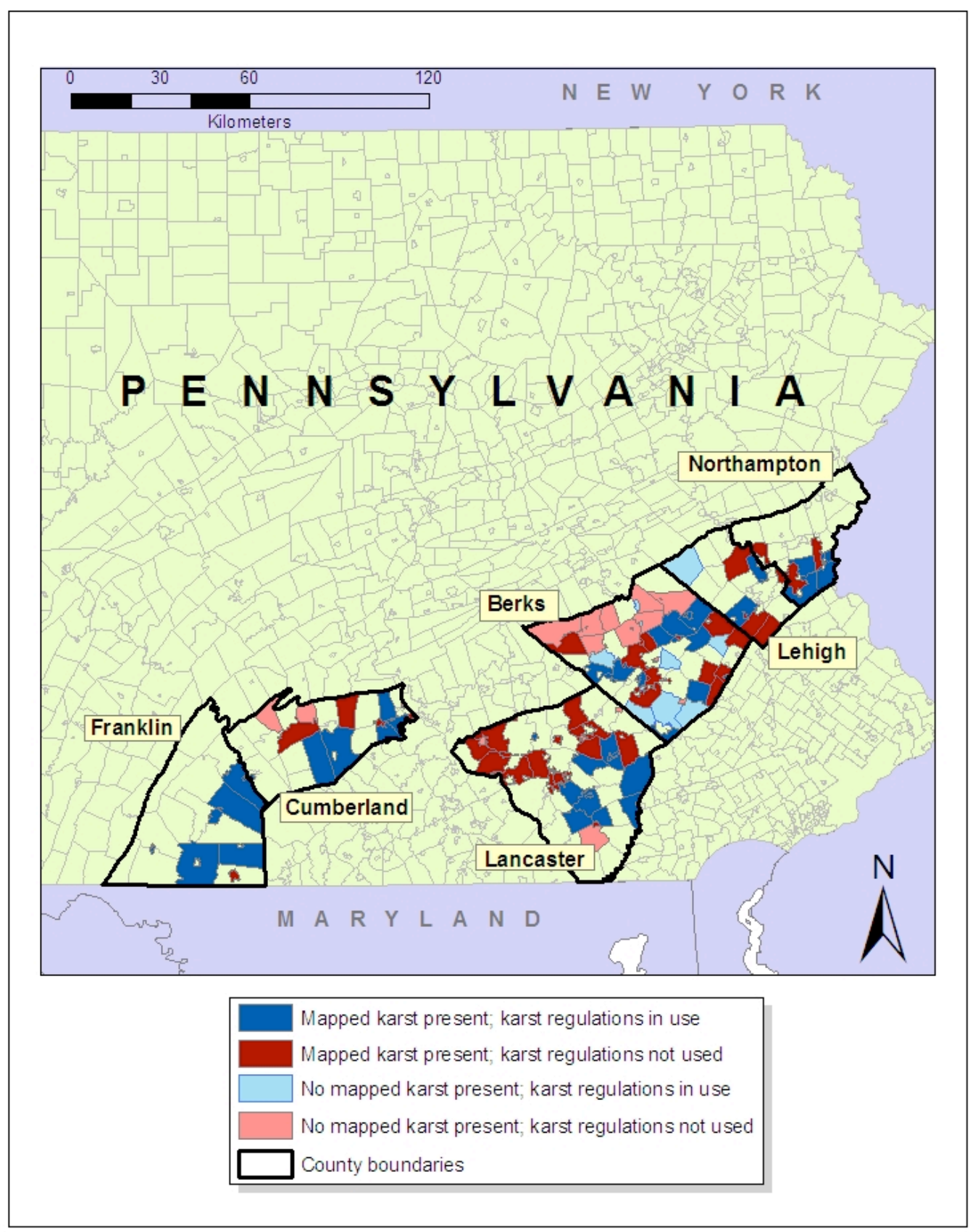

Sources: US Census Bureau; Pennsylvania Department of Conservation and Natural Resources; individual municipal codes 
minimal level of karst protection that Allentown does.

Townships in Pennsylvania thus have a wide degree of latitude when it comes to implementing land use regulations that affect development near karst landforms. The variety of approaches taken in regulating development in those areas reflects this freedom. Table 8-3 displays a summary of techniques used to regulate development on karst by the 64 municipalities in the sample that have such regulations in place. There is significant variability within the sample, but some commonly used techniques can be easily identified. The most commonly used techniques for regulating land use and development in karst terrains are stormwater-related components (in particular, more stringent design standards for stormwater retention basins), and requirements for inclusion of karst landforms in development plans at the sketch, preliminary or final plan stages. Raising the level of design standards in other areas — specifically, as they relate to groundwater flow and quality standards and to reducing the risk of sinkhole formation from improvements or new construction - is another fairly common approach. Intuitively, it may seem that the zoning overlay approach (discussed in Chapter 5) would be the approach that's most effective and easiest to manage in this context. However, very few jurisdictions in the sample actually use it: Lower Saucon and Lower Macungie include karst or carbonate geology overlay zones in their zoning ordinances, while a handful others use more general overlay districts that affect development in karst areas but are not karst-specific. Several municipalities in the study area explicitly claim powers to reject or stop projects that do not meet certain karst-related requirements. In many of these cases, this power is included in a component of a SALDO. Often this is related to a 
Table 8-3

Municipalities included in the sample where land use in karst terrains faces additional regulations or management

SALDO Zoning Regulatory techniques used

\begin{tabular}{|c|c|c|c|}
\hline Allentown city & $\mathrm{N}$ & $\mathrm{Y}$ & Planning, stormwater \\
\hline Alsace township & $\mathrm{Y}$ & $\mathrm{N}$ & Planning, design \\
\hline Amity township & $\mathrm{Y}$ & Y & Planning, hazard \\
\hline Antrim & $\mathrm{Y}$ & $\mathrm{N}$ & Planning \\
\hline Bechtelsville borough & $\mathrm{Y}$ & $\mathrm{Y}$ & $\begin{array}{l}\text { Planning, design, setbacks, } \\
\text { stormwater }\end{array}$ \\
\hline Bethlehem township & $\mathrm{Y}$ & $\mathrm{Y}$ & Planning, stormwater \\
\hline Boyertown borough & Y & $\mathrm{N}$ & Planning, design, stormwater \\
\hline Brecknock township & $\mathrm{Y}$ & $\mathrm{N}$ & Design, stormwater \\
\hline Caernarvon township & $\mathrm{Y}$ & - & Planning, design \\
\hline Camp Hill & $\mathrm{N}$ & $\mathrm{N}$ & Other \\
\hline Carlisle & $\mathrm{Y}$ & $\mathrm{N}$ & Planning \\
\hline Dickinson & $\mathrm{N}$ & $\mathrm{N}$ & Other \\
\hline District township & $\mathrm{N}$ & $\mathrm{Y}$ & Other \\
\hline East Allen township & Y & $\mathrm{N}$ & $\begin{array}{l}\text { Planning, design, setbacks, } \\
\text { stormwater }\end{array}$ \\
\hline East Pennsboro & $\mathrm{Y}$ & $\mathrm{N}$ & Planning, design, hazard \\
\hline Easton city & $\mathrm{N}$ & $\mathrm{Y}$ & Planning \\
\hline Exeter township & $\mathrm{Y}$ & $\mathrm{N}$ & Planning, other \\
\hline Hamburg borough & $\mathrm{Y}$ & $\mathrm{N}$ & Design \\
\hline Hampden & $\mathrm{Y}$ & $\mathrm{N}$ & Design \\
\hline Heidelberg township & $\mathrm{Y}$ & $\mathrm{Y}$ & Planning, other \\
\hline
\end{tabular}


Table 8-3 continued

SALDO Zoning Regulatory techniques used

\begin{tabular}{|c|c|c|c|}
\hline Kutztown borough & $\mathrm{Y}$ & $\mathrm{N}$ & $\begin{array}{l}\text { Planning, design, stormwater, } \\
\text { other }\end{array}$ \\
\hline Lower Allen & $\mathrm{Y}$ & $\mathrm{Y}$ & Planning, design \\
\hline Lower Heidelberg township & $\mathrm{Y}$ & - & Planning \\
\hline Lower Macungie township & $\mathrm{Y}$ & $\mathrm{Y}$ & $\begin{array}{l}\text { Planning, setbacks, zoning } \\
\text { overlays }\end{array}$ \\
\hline Lower Saucon township & $\mathrm{Y}$ & $\mathrm{Y}$ & $\begin{array}{l}\text { Planning, design, stormwater, } \\
\text { zoning overlays, setbacks }\end{array}$ \\
\hline Lynn township & $\mathrm{Y}$ & $\mathrm{Y}$ & Planning \\
\hline Maidencreek township & $\mathrm{Y}$ & $\mathrm{N}$ & Design \\
\hline Maxatawny township & $\mathrm{N}$ & $\mathrm{Y}$ & Planning \\
\hline Mercersburg & $\mathrm{Y}$ & $\mathrm{N}$ & Hazard \\
\hline Muhlenberg township & $\mathrm{Y}$ & $\mathrm{Y}$ & $\begin{array}{l}\text { Planning, design, stormwater, } \\
\text { zoning overlays }\end{array}$ \\
\hline New Morgan borough & $\mathrm{Y}$ & $\mathrm{N}$ & Other \\
\hline North Heidelberg township & $\mathrm{Y}$ & $\mathrm{Y}$ & Planning, other \\
\hline North Middleton & $\mathrm{N}$ & $\mathrm{Y}$ & Planning \\
\hline Pike township & $\mathrm{Y}$ & $\mathrm{N}$ & Planning \\
\hline Quincy & $\mathrm{Y}$ & $\mathrm{N}$ & Planning, stormwater \\
\hline Richmond township & $\mathrm{Y}$ & $\mathrm{N}$ & Planning, design, stormwater \\
\hline Robeson township & $\mathrm{Y}$ & $\mathrm{Y}$ & Planning, design \\
\hline Robesonia borough & $\mathrm{N}$ & $\mathrm{Y}$ & Other \\
\hline Rockland township & $\mathrm{Y}$ & $\mathrm{N}$ & Design \\
\hline Shillington borough & $\mathrm{Y}$ & - & Planning, design, stormwater \\
\hline
\end{tabular}


Table $8-3$ continued

SALDO Zoning Regulatory techniques used

\begin{tabular}{|c|c|c|c|}
\hline Shippensburg & $\mathrm{Y}$ & $\mathrm{N}$ & Planning, design, setbacks, hazard \\
\hline Shippensburg Township & $\mathrm{Y}$ & $\mathrm{N}$ & Planning \\
\hline Shoemakersville borough & $\mathrm{Y}$ & $\mathrm{N}$ & Planning, design, stormwater \\
\hline Silver Spring & $\mathrm{N}$ & $\mathrm{Y}$ & Planning \\
\hline South Middletown & $\mathrm{Y}$ & $\mathrm{Y}$ & $\begin{array}{l}\text { Planning, design, setbacks, } \\
\text { stormwater }\end{array}$ \\
\hline Southampton & $\mathrm{Y}$ & $\mathrm{N}$ & Planning \\
\hline Strausstown borough & $\mathrm{Y}$ & $\mathrm{N}$ & Design \\
\hline Walnutport borough & $\mathrm{Y}$ & $\mathrm{N}$ & Planning \\
\hline Washington & $\mathrm{Y}$ & $\mathrm{N}$ & Planning, hazard \\
\hline Wernersville borough & $\mathrm{Y}$ & - & Planning, design, stormwater \\
\hline Whitehall township & $\mathrm{Y}$ & $\mathrm{N}$ & Planning, other \\
\hline Williams township & $\mathrm{Y}$ & $\mathrm{N}$ & Planning \\
\hline Wilson borough & $\mathrm{Y}$ & $\mathrm{N}$ & Planning \\
\hline Womelsdorf borough & $\mathrm{N}$ & $\mathrm{Y}$ & Other \\
\hline Wyomissing borough & $\mathrm{Y}$ & - & Design, stormwater \\
\hline Wyomissing Hills borough & $\mathrm{Y}$ & - & Planning, design, stormwater \\
\hline
\end{tabular}

declaration of unsuitability for building on a particular plot, a declaration which can usually be addressed and then changed.

There is often no clear distinction between regulatory techniques that are used in SALDOs and those that are used in zoning ordinances. There are exceptions to this generalization - zoning overlays and Planned Residential Development regulations are 
used in zoning ordinances only, for example — but the fact that some regulatory

techniques (in particular, requirements to include carbonate landform locations in plans at various stages of the development process; requirements for additional analysis in carbonate areas; and retention basins and stormwater issues) are found in both types of ordinances in different towns suggests that the main difference may be in how stringently a municipality wants or intends to enforce the karst regulations.

Finally, many karst-related land use ordinances are very similar, if not identical, to those found in the codes of other towns in the area. For example, several different towns have identical or nearly identical statutory language addressing retention basin issues. Other towns have passed identical ordinances relating to groundwater contamination and spring flow, preventing subsidence-related damage, and the power to deny unsatisfactory applications based on karst-related requirements (in fact, it is not uncommon for municipalities to share precisely this regulatory language). This suggests at least two possibilities: one is that towns in each region are simply copying ordinances used by their neighbors; another is that these ordinances all have another common source.

\section{Strategic behavior and land use regulation}

As discussed, regulating development in karst areas - and particularly in the vicinity of karst landforms - is an important tool for protecting local aquifers. In an area like the Lehigh Valley, where there are dozens of municipalities of vastly different size, groundwater contaminated in one township does not typically stay beneath that township. It also seems clear that aquifer protection is at least one major goal of the area's karst regulations, because drainage and runoff into sinkholes is a frequently addressed issue 
within these regulations (of course, appropriate runoff management techniques can also help prevent the formation of sinkholes).

However, simple game theory would suggest that it is in the interest of any township not to regulate development near karst landforms (see Nash, 1951). In theory, such regulation drives up the cost of development, both to the developer (who must spend more time investigating potential project sites, and more money on mitigation) and to the town (which must spend more money enforcing its karst ordinances and hearing appeals from developers whose projects have been turned down). These ordinances potentially have another cost to municipalities, the cost of lost growth as developers choose to build in lower-regulation, lower-cost neighboring towns. In effect, jurisdictions with karst regulations on the books would then be paying the entire cost of protecting the regional groundwater supplies, while non-regulating towns would be free to undo that protection and attract new development opportunities that have chosen to bypass regulating communities. Put another way, if a small township like Lower Saucon cannot influence what its neighbors choose to do to regulate development near sinkholes or other karst features, what incentive does it have to implement its own karst regulations?

Intuitively, it would seem that this patchwork approach enables developers to "play one town against the other" when selecting a location for a large project, and that the sensible course of action for any town hoping to encourage growth would be to implement no karst development regulations, out of concern that such regulations would drive growth to neighboring towns. Yet despite this, many of the municipalities in the Lehigh Valley do regulate development on and near karst landforms. 
The question I intend to address in this chapter is this: when contemplating the implementation of karst-related land use ordinances, should land use planners and public officials take into account whether or not neighboring communities have implemented such regulations? Do non-regulating towns enjoy some sort of growth-related economic benefit at the expense of towns that choose to regulate development in karst areas? Or are karst regulations generally neutral in matters of growth and development?

To answer these questions, I collected data from the US Census Bureau, the Department of Housing and Urban Development, and from the land use regulations of municipalities in the sample. I then constructed a multiple regression model to look for a statistical relationship between the presence of karst regulations and certain economic indicator variables, specifically, the total number of residential construction permits issued for each jurisdiction between 1990 and 2000, and the change in median housing value over that same time. These variables were chosen because they were easily quantifiable, they were available for nearly every municipality in the sample, and a clear hypothetical connection between both of them and the presence of karst land use regulation could be made (this was not the case for most other economic prosperity indicators: for example, it may be the case that the presence of karst regulation results to higher unemployment rates in towns that implement those regulations, but a credible and direct mechanism by which that process occurs is difficult to imagine). This process is described in detail in the next section, followed by the results.

\section{Data and methodology}

Two sets of regressions were run as part of this analysis. The first ordinary least squares (OLS) regression set is intended to measure the impact of karst-related land use 
regulations on median home value. There are two general schools of thought regarding the impact of land use restrictions on home values: one is that the restrictions on the homeowner's ability to use private property in whatever way he or she sees fit will be capitalized into the value of the home (as a decline, usually), while the other approach holds that because land use restrictions can act to preserve the character and natural amenities of an area in which they are applied, they can just as easily have a positive impact on home values (McCann, 2001). Assuming that both effects are possible, it seems more likely that karst regulations would have a positive impact on home values than a negative one. This hypothesis is based on the fact that karst-related land use regulations often act to indirectly encourage preservation of open space and the natural environment, and lower density development.

In this first set of regressions, the change in median home value for each town between 1990 and 2000 is the dependent variable. All 1990 values have been normalized to year 2000 dollars. The following data were obtained from the US Census Bureau and included in the regression as explanatory variables:

- Total population in 1990. Median home values are often lower in rural, sparsely populated areas than in areas with higher population. Including the total population of each town in 1990 is a convenient way to account for the inherent differences between rural towns and urbanized areas.

- Rate of population change between 1990 and 2000. Rapid population growth will usually drive housing prices — and thus value — higher at a faster rate than is seen in communities with slower or negative growth rates.

- Rate of urban population change between 1990 and 2000. This variable is 
intended to account for increased populations in the most densely-populated areas of each town, as changes in those areas can have more noticeable impacts on median home values than do changes in rural locations.

- Change in median rent between 1990 and 2000: Renting a house or apartment is a "substitute good" for owning one's own home. Because both rented and owned properties are part of the same housing market, prices often respond to similar sets of influences. Except in periods of heavy real estate speculation, we would expect to see rents and home values move in the same direction, though not necessarily at the same rates, or even at the same time. Again, these 1990 values have been normalized to 2000 dollars.

- Change in the percentage of workers who are "long-distance commuters" (i.e., who commute more than thirty minutes each day to work): If this variable is statistically significant, its sign can help explain why median home values have changed (a positive sign could mean the town in question is a growing bedroom community for well-paid white collar employees; a negative sign suggests that residents may find themselves forced to look further afield for work as their town's economic base contracts).

- Change in the percentage of larger (meaning with four or more bedrooms) homes: Naturally, homes with four or more bedrooms tend to be more expensive than smaller domiciles, all things being equal. We would therefore expect that towns in which more large homes were added to the local housing stock would experience more rapid increases in housing values.

- Change in the percentage of residents who have a bachelor's degree or 
higher: College-educated individuals have an increased ability to pay for housing, which could result in price inflation in areas that are attractive to them.

In addition to the variables listed above, four dummy variables were also included as explanatory variables. These were obtained from an analysis of each town's zoning ordinances and subdivision / land development ordinances (SALDOs), and from data provided by the Pennsylvania DCNR. These are the variables of most interest to us in this set of regressions:

- Karstregs: This binary variable is set to 1 for all towns that contain some karst-related provisions in their zoning ordinance or SALDO. This actually includes a very wide range of regulatory requirements, ranging from a requirement to include karst features on preliminary subdivision plans to complex zoning overlay ordinances in which the ability to build near karst landforms is severely limited. It should be immediately apparent that regulations as different as the two examples given here are unlikely to have identical impacts on median housing values, a fact that necessitated the inclusion of the next variable.

- Strong: The strong variable is intended to account for the wide range of differences in regulatory techniques employed by communities in the sample. The strong variable contains a value of 1 for all towns whose ordinances were classified as strong. More details about this variable are provided in the next section.

- MappedKarst: The MappedKarst dummy variable is coded 1 for all 
municipalities that contain karst points mapped by the Pennsylvania DCNR. This variable is included to account for the possibility that some municipalities may pass karst-related land use ordinances even if there is no known karst within the town limits. In those hypothetical cases, the presence of karstrelated land use ordinances should have little to no effect on development and growth patterns.

- Inter: This is an interaction variable, generated by multiplying Karstregs by MappedKarst. This variable therefore carries a value of 1 for any municipalities in the sample that have karst land use regulations or ordinances in place, and have known (i.e., mapped) karst points located within the town limits.

Karstregs, MappedKarst and Inter are included in both regressions in this set; strong is included only in the first regression. This was done in part to account for the subjective nature of the strong variable.

The second set of regressions is similar to the first, but includes the total number of residential construction permits issued between 1990 and 2000 as the dependent variable. The intention is to identify any effect on building and development patterns that implementing karst land use regulations may have brought about. Because karst-related land use regulations often add steps (and expense) to the development process - and in some cases, can stop a development in its tracks - it is likely that we may see some direct impacts of such regulation reflected in the number of residential permits granted in towns with these ordinances on the books, as developers seek out locations with fewer obstacles to new projects. My hypothesis is that this impact will be negative; in other words, the 
presence of karst regulations, and in particular strong karst regulations, will act to depress the number of permits issued relative to municipalities that do not use such regulations.

Data on the number of permits issued in each town were obtained from the US Department of Housing and Urban Development. The following data were obtained from the US Census Bureau and were included as explanatory variables:

- Total population in 1990. This is included to account for the fact that towns with small populations will generally issue fewer permits than cities with large populations, regardless of the growth rate.

- Rate of population change: Population changes drive demand for new housing options, which is directly tied to the issuance of construction permits. "Hotter" housing markets-i.e., the ones that would be more attractive to developers as locations for new projects—are usually the markets experiencing the fastest population growth rates. The rate of change is used here because using raw counts of population induces a bias favoring larger communities.

- Change in median home value: A home's value is only partially derived from the physical characteristics of the house itself. Much of a home's value comes from benefits directly tied to its location. If an area is widely considered a desirable place to live, it's likely that more permits would be issued, provided other growth controls are not in place.

- Change in median rent: Higher rents indicate a higher demand for places to live, which implies a higher willingness to pay for housing in general and in turn suggests a higher level of attraction for developers.

- Rate of change in urban housing units: Urbanizing towns tend to have 
higher population (and therefore structural) densities; if a town is adding urban housing units, it's likely that town will be issuing more permits than a town adding more rural units.

- Percent change in long-distance commuters.

- Percent change in larger (4 or more bedrooms) homes: High rates of growth in the number of large homes could indicate a particularly profitable market for builders; it could also be reflective of restrictive, large-lot zoning ordinances. In either case, trends described by this variable should have some impact in the number of residential construction permits issued.

The four binary variables described earlier in this section—karstregs, mappedkarst, strong and inter - are also included here. These four variables are again our variables of interest, and once again, strong is included only in the first regression.

Because these regressions rely heavily on these two dummy variables, an explanation of how they were developed is in order. First, zoning ordinances and SALDOs were downloaded for cities and towns in each of the seven counties in the study area. Once these documents were collected, keyword searches were conducted using several karst-related terms, in an effort to identify karst-related components of these ordinances. All "hits" were investigated; several did not relate to land use, and many others were "false positives" (for example, searches on the keyword "carbonate" sometimes returned results addressing the business practices of termite exterminators). All relevant results were then inventoried by city; this inventory is the basis for the karstregs variable.

Next, a more thorough reading of each relevant result was conducted, and each 
regulatory component was evaluated for its potential to significantly influence the decision to build or not build in a given town. Strong regulations display one of the following characteristics: a section specifically set aside to address development in karst or carbonate areas, explicit power to stop or reject a development based on karst-related issues, or generally-applied setbacks; those classified as "weak" lack these features (repeated use of the word "may" in a karst context, instead of "shall" or "must," was another frequent indicator of a set of weak regulations). Those that were deemed to have more potential impact on development patterns were classified as "strong." Categorizing a set of ordinances as weak or strong was, first and foremost, a subjective process; in some cases, a collection of individually weak requirements was classified as strong, based on the overall potential for impact on the development process. The key question in making this determination was this: is a particular set of regulatory requirements onerous enough to potentially make a developer think twice about building on a given piece of land with karst-related issues? However, the criteria used were applied consistently to all ordinances in the sample, and should at least be a useful indication of relative regulatory strength.

The sample itself contains observations taken in cities and towns located in six different Pennsylvania counties: Berks, Cumberland, Franklin, Lancaster, Lehigh and Northampton. These counties range from mostly urbanized to mostly rural; the common thread linking all seven is the presence of significant karst within their borders, which means that towns located within these counties could be expected to have karst-related land use regulation on the books in some form.

Taken together, these six counties contain 253 individual municipalities, 
according to the US Census Bureau. Many of these cities and towns were not included in the sample used for these regressions. Exclusion from the sample was based on one of two general criteria: timing (relevant zoning ordinances or SALDOs had to be in place by 2000; those with unclear dates of implementation were excluded), and data availability (the sample includes towns with both SALDOs and zoning ordinances available online, and towns with only one set of regulations available online, provided these available ordinances contained karst-related provisions and that these karst provisions could be categorized as strong). These documents are not universally available online for every city and township in Pennsylvania; the fact that the sample includes only communities that have made these documents available online may introduce some amount of bias into the results. However, I could detect no obvious pattern to explain why some communities chose to make these documents available in electronic format and others did not. This resulted in a sample size of 120, which is 47.4 percent of the population of 253 .

Individual observations that met these general criteria but lacked certain data were dropped from the regressions when appropriate; for example, all observations from Franklin County were dropped from the second round of regressions (using total permits as the dependent variable) because permitting data were not available for those towns. This is why $n$ varies slightly between regressions. Figures 8-3 and 8-4 display changes in the dependent variables for municipalities in the sample between 1990 and 2000.

\section{Regression results}

The regressions found one statistically significant relationship (significant at 10percent) between a variable of interest and a dependent variable: the interaction 
Figure 8-3

Changes in median home value for municipalities in sample, 1990-2000

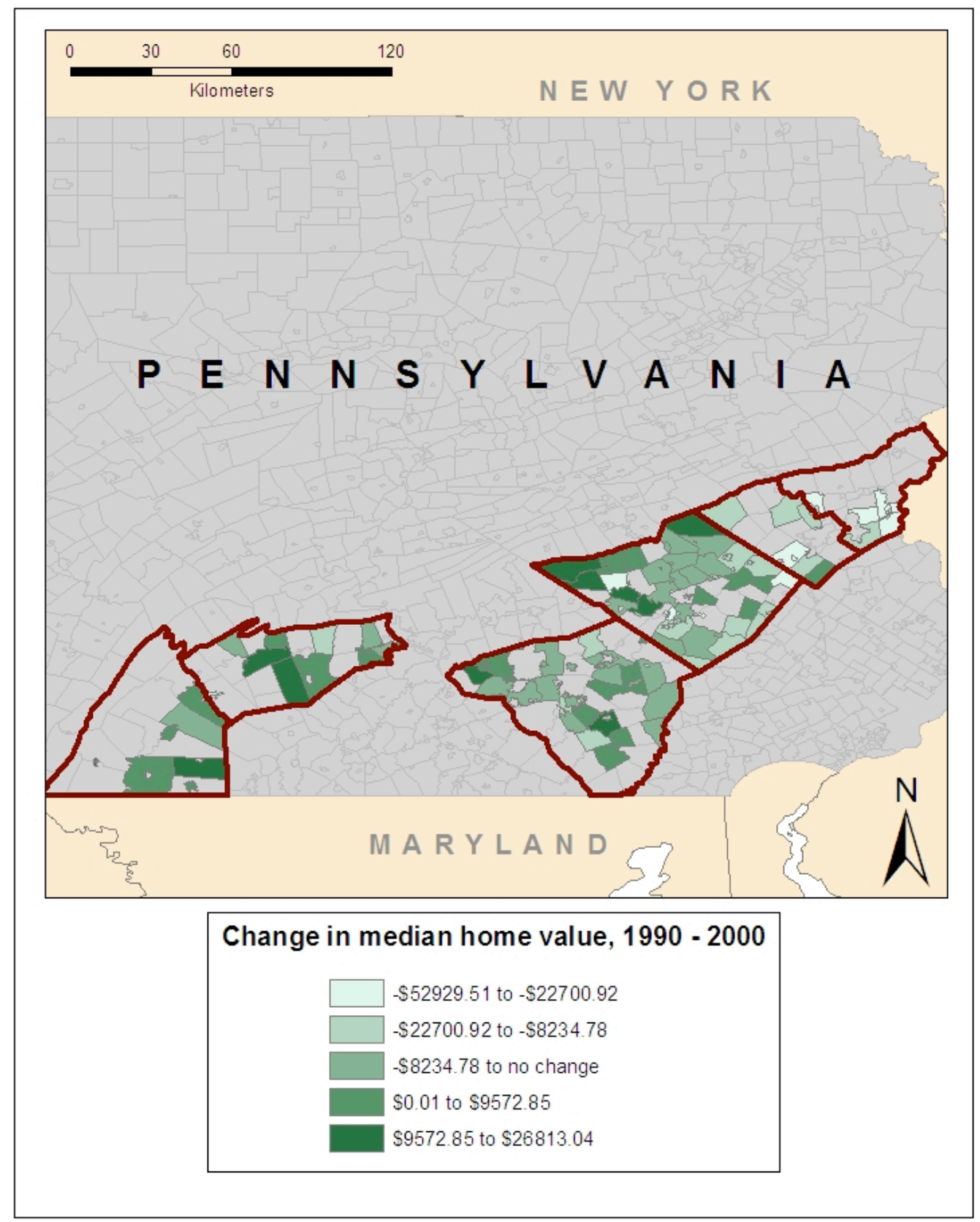

Source: US Census Bureau 
Figure 8-4

Total residential permits issued for municipalities in sample, 1990-2000

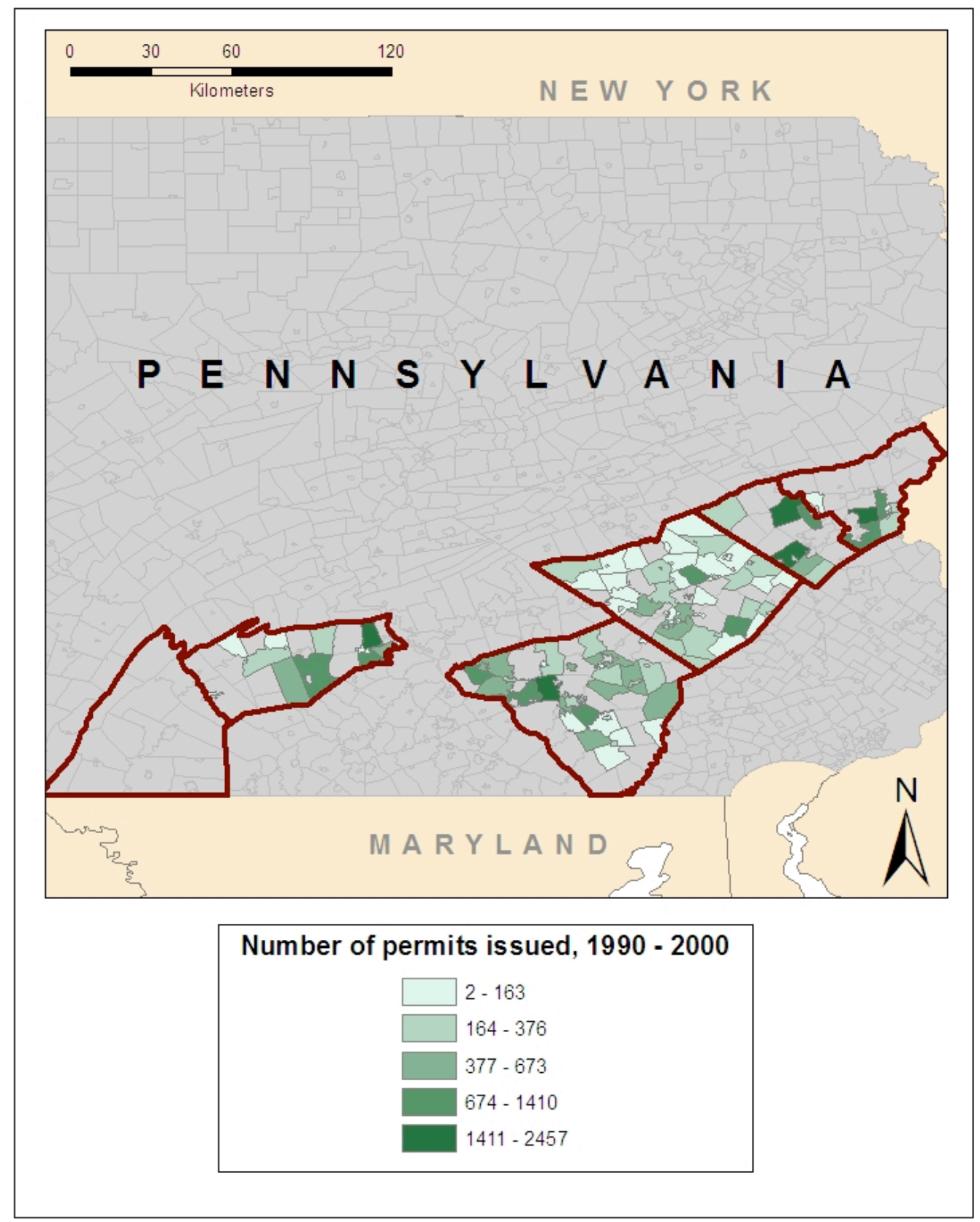

Source: US Census Bureau, US Department of

Housing and Urban Development 
Table 8-4

Ordinary Least Squares regression results

Model 1: ordinary least squares regression with robust standard errors, using total residential building permits as the dependent variable

\begin{tabular}{|c|c|c|c|}
\hline Explanatory variables & Coefficient & Standard error & t value \\
\hline Total population, $1990 *$ & .0148708 & .0059324 & 2.51 \\
\hline $\begin{array}{l}\text { Population growth rate, } 1990-2000 \\
\text { (percent) * }\end{array}$ & 12.75187 & 2.810637 & 4.54 \\
\hline $\begin{array}{l}\text { Change in percentage of "long- } \\
\text { distance" commuters }\end{array}$ & -3.653832 & 5.864986 & -0.62 \\
\hline Growth rate of urban housing units & 1.811643 & 1.3552 & 1.34 \\
\hline $\begin{array}{l}\text { Rate of change in the percentage of } \\
\text { "large" homes * }\end{array}$ & 22.50077 & 9.33764 & 2.41 \\
\hline $\begin{array}{l}\text { Change in median gross rent, } 1990- \\
2000\end{array}$ & .2378838 & .4161294 & 0.57 \\
\hline $\begin{array}{l}\text { Change in median housing value, } \\
1990-2000\end{array}$ & -.0039291 & .0034126 & -1.15 \\
\hline Karst regulations present? & -69.8021 & 87.08814 & -0.80 \\
\hline $\begin{array}{l}\text { Karst regulations classified as } \\
\text { "strong" }\end{array}$ & 13.10388 & 139.6921 & 0.09 \\
\hline Mapped karst points present? & 77.51629 & 66.51265 & 1.17 \\
\hline $\begin{array}{l}\text { Interaction variable (both } \\
\text { regulations and mapped karst } \\
\text { points are present) * }\end{array}$ & 264.1354 & 138.5633 & 1.91 \\
\hline Constant & -29.41458 & 49.66519 & -0.59 \\
\hline
\end{tabular}

Variables of interest in italics

$*=$ statistically significant results at 0.10

$\mathrm{n}=105$

Adjusted $\mathrm{R}^{2}: \quad=0.4673$ 
Table 8-5

Ordinary Least Squares regression results

Model 2: ordinary least squares regression with robust standard errors, using total residential building permits as the dependent variable

\begin{tabular}{|c|c|c|c|}
\hline Explanatory variables & Coefficient & Standard error & t value \\
\hline Total population, $1990 *$ & 0.0146225 & 0.0058305 & 2.51 \\
\hline $\begin{array}{l}\text { Population growth rate, } 1990-2000 \\
\text { (percent) * }\end{array}$ & 11.19164 & 2.841066 & 3.94 \\
\hline $\begin{array}{l}\text { Change in percentage of "long- } \\
\text { distance" commuters }\end{array}$ & -3.893057 & 5.765894 & -0.68 \\
\hline Growth rate of urban housing units & 1.727809 & 1.458323 & 1.18 \\
\hline $\begin{array}{l}\text { Rate of change in the percentage of } \\
\text { "large" homes * }\end{array}$ & 16.4858 & 9.322062 & 1.77 \\
\hline $\begin{array}{l}\text { Change in median gross rent, } 1990- \\
2000\end{array}$ & 0.0311469 & 0.3794541 & 0.08 \\
\hline $\begin{array}{l}\text { Change in median housing value, } \\
1990-2000\end{array}$ & -0.0045279 & 0.0034124 & -1.33 \\
\hline Karst regulations present? & -72.97573 & 79.97385 & -0.91 \\
\hline Mapped karst points present? & 70.12362 & 68.48701 & 1.02 \\
\hline $\begin{array}{l}\text { Interaction variable (both } \\
\text { regulations and mapped karst points } \\
\text { are present) }\end{array}$ & 201.7053 & 129.5102 & 1.56 \\
\hline Constant & 0.1563617 & 49.39859 & 0.00 \\
\hline
\end{tabular}

Variables of interest in italics

$*=$ statistically significant at 0.10

$\mathrm{n}=112$

Adjusted $\mathrm{R}^{2}=0.4051$ 
Table 8-6

Ordinary Least Squares regression results

Model 3: ordinary least squares regression with robust standard errors, using change in median home value as the dependent variable

\begin{tabular}{l|c|c|c|}
\hline Explanatory variables & \multicolumn{1}{l}{ Coefficient } & Standard error & t value \\
\hline Total population, 1990 & -0.1233191 & 0.0829727 & -1.49 \\
\hline $\begin{array}{l}\text { Population growth rate, 1990-2000 } \\
\text { (percent) }\end{array}$ & 112.6703 & 93.63839 & 1.20 \\
\hline $\begin{array}{l}\text { Growth rate of urban housing units } \\
\text { Change in percentage of "long- }\end{array}$ & -10.87793 & 64.47095 & -0.17 \\
\hline distance" commuters & -327.9395 & 267.3179 & -1.23 \\
\hline $\begin{array}{l}\text { Change in population with bachelors } \\
\text { degree (percentage) }\end{array}$ & -749.3715 & 405.4695 & -1.85 \\
\hline $\begin{array}{l}\text { Rate of change in the percentage of } \\
\text { "large" homes }\end{array}$ & 557.9663 & 380.3822 & 1.47 \\
\hline $\begin{array}{l}\text { Change in median gross rent, 1990- } \\
\text { 2000 }\end{array}$ & 18.80939 & 13.12235 & 1.43 \\
\hline $\begin{array}{l}\text { Karst regulations present? } \\
\text { Interaction variable (both regulations } \\
\text { and mapped karst points are present) }\end{array}$ & 2940.861 & 5368.743 & 0.55 \\
\hline $\begin{array}{l}\text { Karst regulations classified as } \\
\text { "strong" }\end{array}$ & -1176.088 & 4287.548 & -0.27 \\
\hline \begin{tabular}{l} 
Mapped karst points present? \\
\hline
\end{tabular} & -3734.006 & 4317.497 & -1.60 \\
\hline
\end{tabular}

Variables of interest in italics

$*=$ statistically significant at 0.10

$\mathrm{n}=105$

Adjusted $\mathrm{R}^{2}=0.1732$ 
Table 8-7

Ordinary Least Squares regression results

Model 4: ordinary least squares regression with robust standard errors, using change in median home value as the dependent variable

\begin{tabular}{|l|c|c|c|}
\hline Explanatory variables & Coefficient & Standard error & t value \\
\hline Total population, 1990 & -0.1406539 & 0.0861091 & -1.63 \\
$\begin{array}{l}\text { Population growth rate, 1990-2000 } \\
\text { (percent) }\end{array}$ & 122.9927 & 82.45413 & 1.49 \\
\hline $\begin{array}{l}\text { Growth rate of urban housing units } \\
\text { Change in percentage of "long- } \\
\text { distance" commuters }\end{array}$ & -3.222844 & 61.00146 & -0.05 \\
\hline $\begin{array}{l}\text { Change in population with bachelors } \\
\text { degree (percentage) * }\end{array}$ & -283.8614 & 254.122 & -1.12 \\
\hline $\begin{array}{l}\text { Rate of change in the percentage of } \\
\text { "large" homes * }\end{array}$ & 783.9302 & 354.0678 & 2.21 \\
\hline $\begin{array}{l}\text { Change in median gross rent, 1990- } \\
\text { 2000 }\end{array}$ & 18.1366 & 12.2212 & 1.48 \\
\hline $\begin{array}{l}\text { Karst regulations present? } \\
\text { Mapped karst points present? }\end{array}$ & -3165.006 & 4070.196 & -0.78 \\
\hline $\begin{array}{l}\text { Interaction variable (both } \\
\text { regulations and mapped karst points } \\
\text { are present) }\end{array}$ & -3790.971 & 3315.346 & -1.14 \\
\hline \begin{tabular}{l} 
Constant \\
\hline
\end{tabular} & 3071.677 & 5188.513 & 0.59 \\
\hline
\end{tabular}

Variables of interest in italics

$*=$ statistically significant at 0.10

$\mathrm{n}=120$

Adjusted $\mathrm{R}^{2}=0.1715$ 
variable was found to have a statistically significant relationship to the total permits issued dependent variable (Table 8-4). However, the coefficient is positive, meaning that total permits issued were higher in communities that had both mapped karst points and karst-aware land use regulations. This significance disappears when the strong variable is dropped from the model (Table 8-5); there was also no statistically significant relationship discovered between the change in median housing value dependent variable and any of the binary variables of interest (Tables 8-6 and 8-7). Further, the differences in $\mathrm{R}^{2}$ values demonstrates that while the model does explain a respectable amount of the variation in total permits issued, it is not very useful in explaining changes in median home values.

These results argue very forcefully against the idea that the presence of karst regulations has much of an effect on development, at least with respect to the residential market, or on median home values. It therefore follows that towns choosing to implement karst-related land use regulation are not putting themselves at a disadvantage in competing for development and growth opportunities with their non-regulating neighbors.

There are several possible explanations for these results:

- Development pressures may be causing the development of mappable karst features. This hypothesis was also advanced as a potential explanation of the results in Chapter 7, and would explain the positive coefficient on the interaction variable in the first regression (Table 8-4).

- Karst protections may act to increase the desirability of living (and thus the demand for available housing) in a community that employs them, by forcing 
more land to remain open and undeveloped.

- Even the strongest karst regulations may not really be that onerous. We know from the regression results that the strength of karst regulation did not have an impact on the indicator variables for jurisdictions in the sample. When combined with the knowledge that the presence of karst regulations also had no impact, perhaps this can be taken to mean that karst regulations and ordinances generally aren't very restrictive, and cannot counteract the influence of market forces.

- Karst regulations may be going unenforced. The lack of impact of karst ordinances could be a reflection of a lack of enforcement. Certainly, variances and waivers can be obtained in most jurisdictions; whether there is a lack of will to regulate in this case is unclear, and beyond the scope of this chapter.

- $\quad$ Timing may be a factor. It seemed plausible that the short-term impacts of enacting this type of regulation could be different from the long-term effects - perhaps it takes a few years for karst regulations to make a noticeable impact on these indicator variables. By including a dummy variable indicating the year a karst ordinance was enacted, any such relationship could be identified. Unfortunately, this goal was out of reach for this analysis, because there was no way to determine the actual enactment date (as opposed to possibly being re-enacted) with any degree of certainty. It's possible that this could be done using different data, and is a worthwhile direction for future research. 


\section{Summary}

The tests conducted in this chapter do not support the hypothesis that municipalities employing restrictions on development and construction in karstic areas suffer an economic disadvantage, relative to municipalities that do not employ such restrictions. Therefore, it seems that there is no rational economic basis for planners and policymakers to take into account the actions of neighboring towns and cities when considering the possible future implementation of karst regulations in their own jurisdictions. As far as growth and development are concerned, the presence or absence of karst regulations does not seem to make a difference either way. 


\section{The development of a protected area approach to karst protection and management: A case study from Apuseni Natural Park, Romania Introduction}

The preceding chapters of this dissertation demonstrate the widespread use of land use ordinances and regulations in managing the challenges inherent to large urbanized populations existing on karst lands. However, this practice is not limited to urbanized areas. Karst landscapes also exist in less developed and "wild" areas; in many cases, these landscapes exist in close proximity to natural resources, and could easily suffer serious damage if those resources were to be exploited without regard for the karst. Governments will therefore often establish protected areas in these locations, with the intent of protecting the karst landscape from human activities generally related to resource exploitation. Protected areas are areas in which land use restrictions are implemented with the specific purpose of protecting the integrity of the natural resources of an area. In some cases, the protection afforded by protected area status addresses resources not directly related to karst, including forests and surface waters. However, applying protections to resource bases like these can often have beneficial spillover effects for local karst systems.

In this chapter, I will discuss the concept of the protected area approach and describe examples in which this approach is applied to karst lands in the United Kingdom, the United States and Australia. I will then examine the application of the 
protected area approach to the Apuseni Natural Park in Romania. My goal is to identify ways in which social and economic factors introduced by a park's population might impact the development of a park's management plan. Through this process, I hope to better understand the different circumstances and context of protected area regulation and management in less-developed (economically speaking) countries, and how those circumstances affect the development and effectiveness of protected area regulations.

\section{Methodology}

In contrast to much of the rest of this dissertation, the analysis conducted in this chapter is much more qualitative. The primary methods used for this chapter were an analysis of the Apuseni Park's management plan, which was placed into context by interviews with individuals involved in the development of the plan, an analysis of existing literature on the Apuseni Park, a brief examination of park management plans from elsewhere in the world, and by personal observations from a trip to the park in early summer, 2006.

\section{The study area: Romania's Apuseni Natural Park}

Several factors contributed to the selection of Apuseni Natural Park as the study area. First, the park is a large, non-urbanized area where the interaction between humans and the underlying karst system has the potential to adversely affect both the karst itself and the local human population. Second, the park is at the appropriate stage in its lifecycle, in that it is relatively well-established as a nature park, but has only recently developed any sort of official management plan that attempts to address the issues of 
human-karst interaction. Finally, because Romania is one of Europe's poorer countries ${ }^{1}$ (World Bank Development Indicators, 2006), any karst management approaches implemented by the management plan will have to work within strict budgetary and funding constraints; these approaches would therefore be more likely to be transferable to other low-wealth countries with significant karst resources.

In the late spring of 2006 , I had the opportunity to conduct several weeks of field work in the Apuseni Natural Park. During that time, I observed and recorded general conditions on the ground in the park, and I conducted open-ended interviews of park residents and park service employees. Much of this chapter is based on these observations and interviews.

The Apuseni Mountains are part of the larger Carpathian mountain range, and are located in the western part of the country, where much of Romania's karst can be found. This is the location of the Apuseni Natural Park (Figures 9-1 and 9-2), which contains approximately 80 percent of the karstic rocks of the Bihor-Vladeasa range. Boasting well over a dozen "superlative" karst features, including the Scarisoara Ice Cave and one of the deepest caves in Romania, the development of a natural park in the Apuseni range was several decades in the making. The idea was first raised in the 1940s by noted Romanian biologist Emil Racovita, as a way to protect the area's karst landforms and features. The park was officially created in 2003 , with the understanding that a park management plan would follow (a draft was completed in 2006). This plan would be designed to manage the natural park and the natural resources inside it, and would have to

\footnotetext{
1 According to the 2006 edition of the World Bank Development Indicators, Romania is categorized as a "lower middle income" country. Seven other European countries-Albania, Belarus, Bosnia and Herzegovina, Bulgaria, Macedonia FYR, Serbia and Montenegro, and Ukraine - also share this designation. Most of the balance of Eastern Europe can be found in the "upper middle income" category, with all of Western Europe categorized as "upper income." Moldova is the only European country found in the "low income" category.
} 
balance the twin objectives of protecting the natural resources of the park, while simultaneously enabling the park's significant population to develop economically.

The establishment of the park itself it rooted in the legal authority provided by a government order issued in 1990 (MAPPM Order no. 7/1990). The park management plan draws upon Romanian federal law (Law No. 462/2001) as the legal basis of its authority, with various other federal laws, orders and government decisions providing a legal framework for day-to-day operations of the park and the implementation of the plan. Of particular interest for this chapter is the plan's cave management components, which will be explored in detail later in this chapter.

Overall, Romania is not a highly karstic country. Less than 2 percent of Romania's land area is underlain by carbonate bedrock; 13 percent of the country's overall water supply comes from groundwater, with only 2 percent of that coming from karst lands. In each case, these are among the lowest levels in Europe (Zwahlen, 2003). However, much of the karst that can be found in Romania exists in the general vicinity of the Apuseni Natural Park, and within the park itself, which contains dozens of significant caves and countless sinkholes, many of which are used as makeshift trash dumps (Mos, pers. comm., 2007).

Ordinarily, protecting karst landforms within a natural park could be a relatively simple matter of restricting access and usage of karstified lands. However, in the case of the Apuseni park, the solution is not quite as simple as that. The reason has to do with the area's human population and the anthropogenic impacts on the park's karst. As late as the $19^{\text {th }}$ century, Apuseni peasants were more commonly engaged in industries like handicrafts and trade instead of timbering. These economic activities were not 
detrimental to the karst, as large-scale timbering would have been. The beginning of the railway age at approximately that time helped change the nature of the local economy, simultaneously contributing to a general overdevelopment of the area and to biodiversity changes (new transportation technology made it easier to import alien species as well as

Figure 9-1

Apuseni Natural Park, Romania

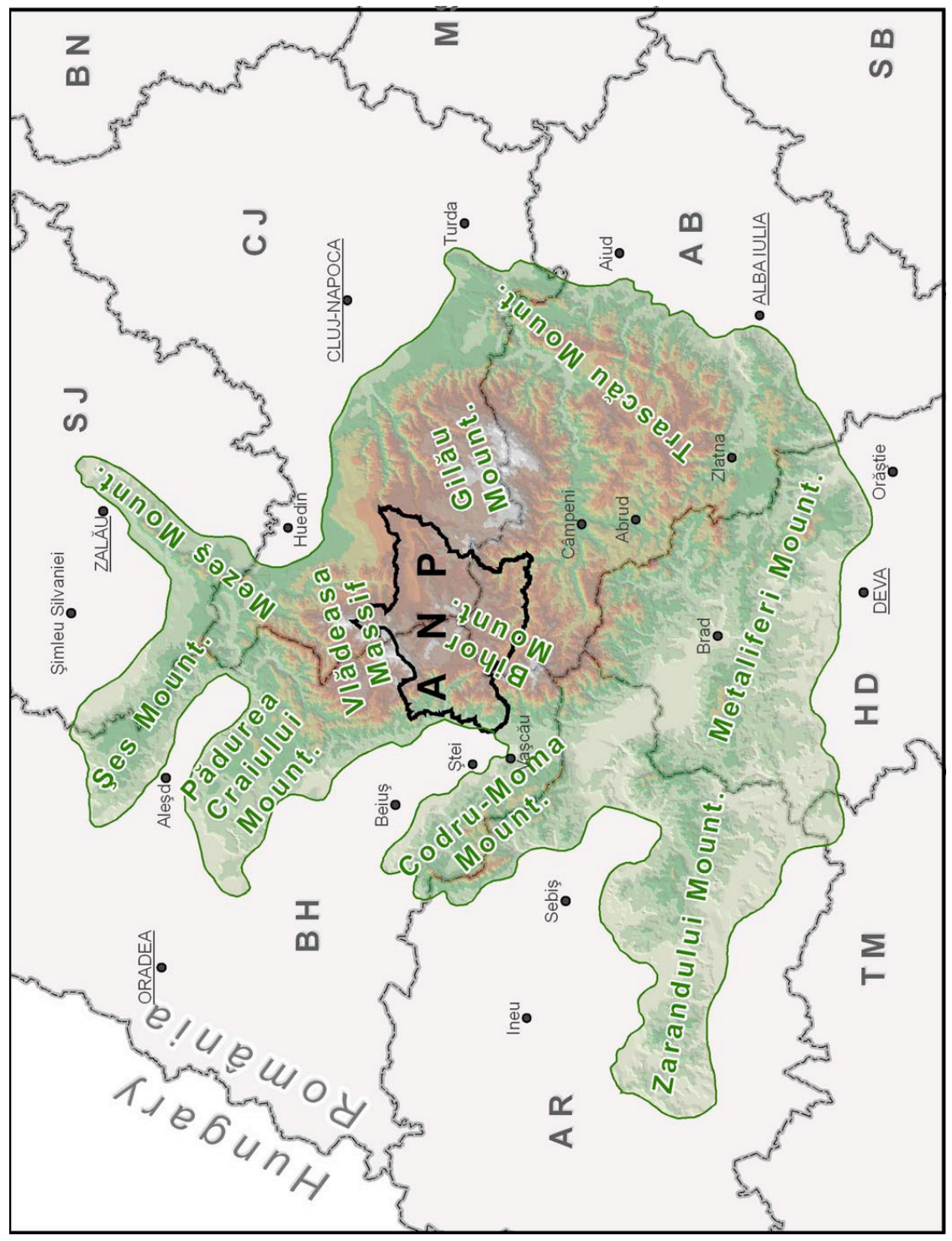

Map author: Apuseni Natural Park management. Used by permission. 
Figure 9-2

Land use management zones in Apuseni Natural Park

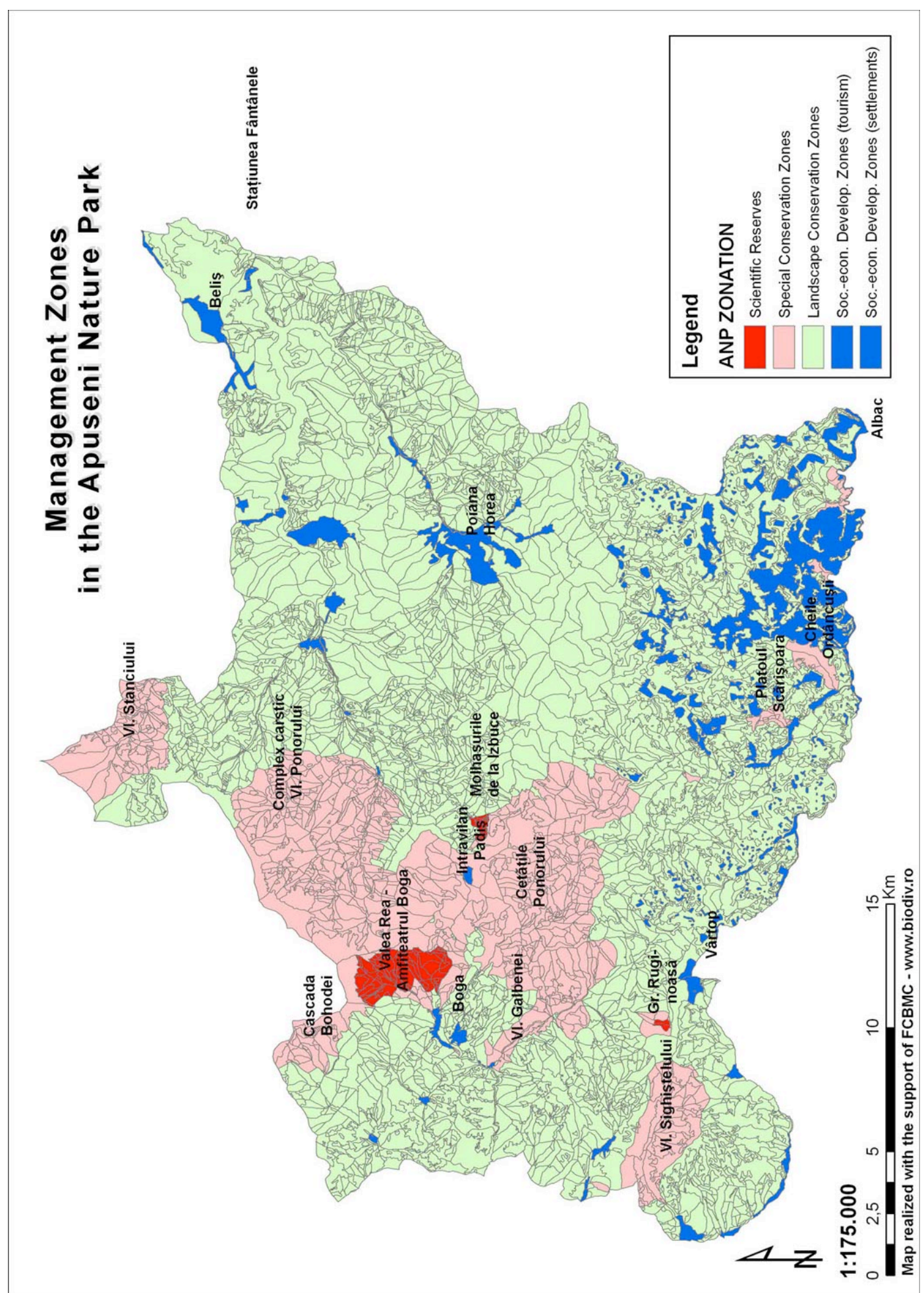

Map author: Apuseni Natural Park management. Used by permission. 
to export timber products) (Turnock 2000).

Today, the area of the Apuseni Natural Park has a total population of approximately 10,000 people, dispersed among the park's 75,786 hectares. Certainly this is not a high population density in an absolute sense. However, while some Western protected areas do contain populations of that size, most generally do not; this adds a complicating factor to any analysis of the management plan in place at Apuseni. Despite the high overall population (relative to that of other parks), the individual settlements themselves tend to be quite small — for example, Scarisoara, located at the southern end of the park, has only about 600 residents and is characterized by scattered clusters of between two and eight houses. Small-scale agriculture is widely practiced; most houses are adjacent to at least a small agricultural plot, and the landscape is dotted with sinkholes that have been converted to agricultural use (Figures 9-3 and 9-4).

Electricity is available in some areas of the park, as evident from the presence of power lines (Figure 9-5). However, access to electricity is not universal, and not all homes that have access are actually connected to power lines. Groundwater quality in some areas of the park is poor; however, these problems are quite localized, and are not widespread enough to prevent park residents from drinking directly from local streams. Some communities within the park have begun using waters from the local karst system as the source waters for new, modern water supply systems, which are being developed and implemented as a means of modernizing the mountain lifestyle and of attracting tourism opportunities (Mos, pers. comm., 2007). Much of the park lacks direct access to sewage services; in some areas, residents just dump their wastes wherever they can. This is a tricky problem to solve, as the dispersed population within the park makes it difficult 
to cost-effectively implement any kind of sewage infrastructure. Biological pollution of the groundwater has occurred as a result of certain actions on the part of tourists and local residents — including inappropriate dumping of wastes — but it is not considered a major problem yet. In some areas, fecal contamination is significant enough to render the water non-potable. Chemical pollution has not yet been encountered, perhaps because there are no potential sources of such contamination within the park (Mos, pers. comm., 2007; personal observation, 2006). Still, the current version of the park's management plan notes that "the majority of water sources in ANP are affected by pollution; some of them are even not potable" (draft management plan, 2006, sec. 3.2.1.2).

Figure 9-3

Agriculture in a doline near Scarisoara, Apuseni Natural Park

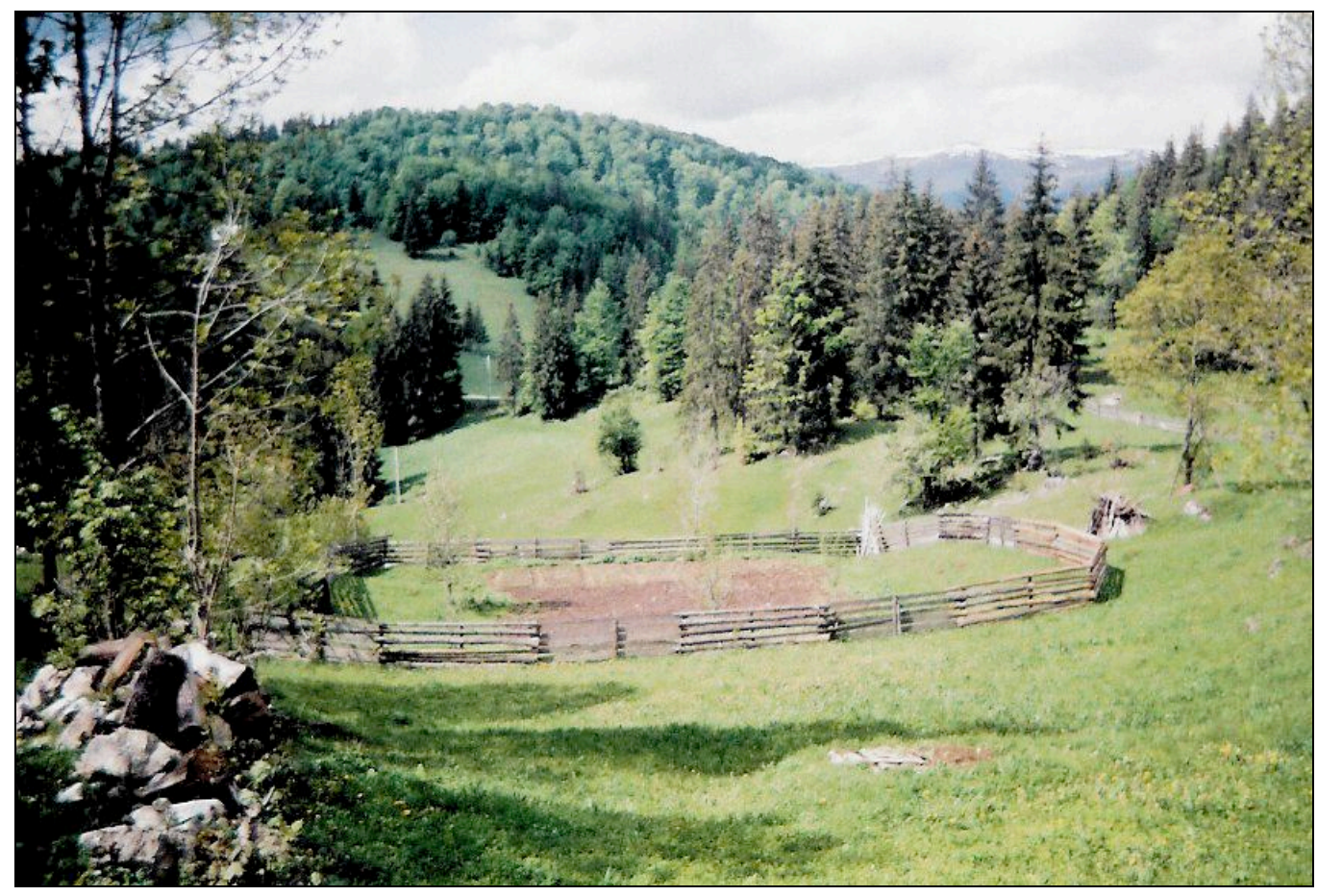


Figure 9-4

Agriculture in a doline at Scarisoara, Apuseni Natural Park

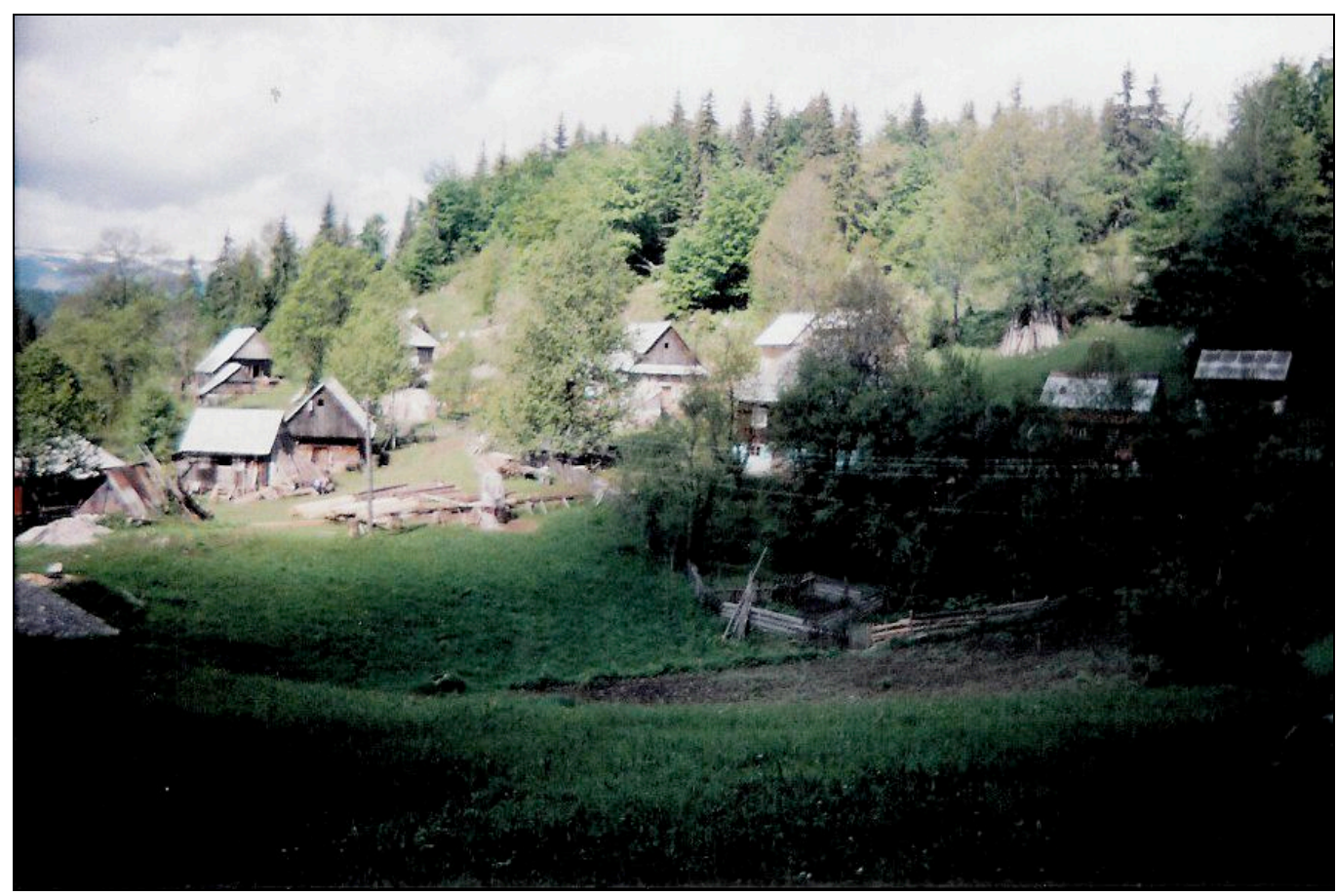

Figure 9-5

Newer structures near Scarisoara, Apuseni Natural Park. The concrete pole in the foreground is a utility pole for local electricity supply.

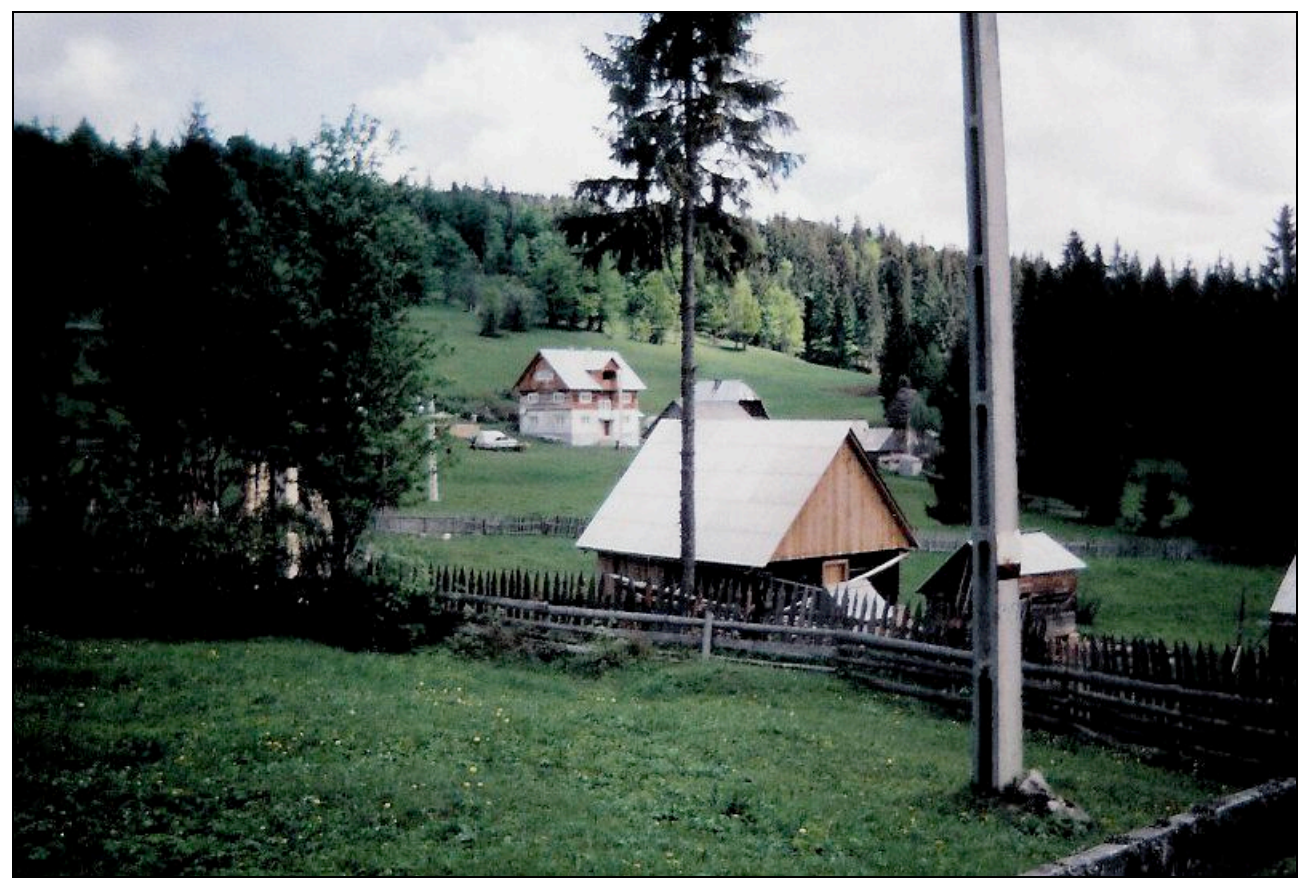




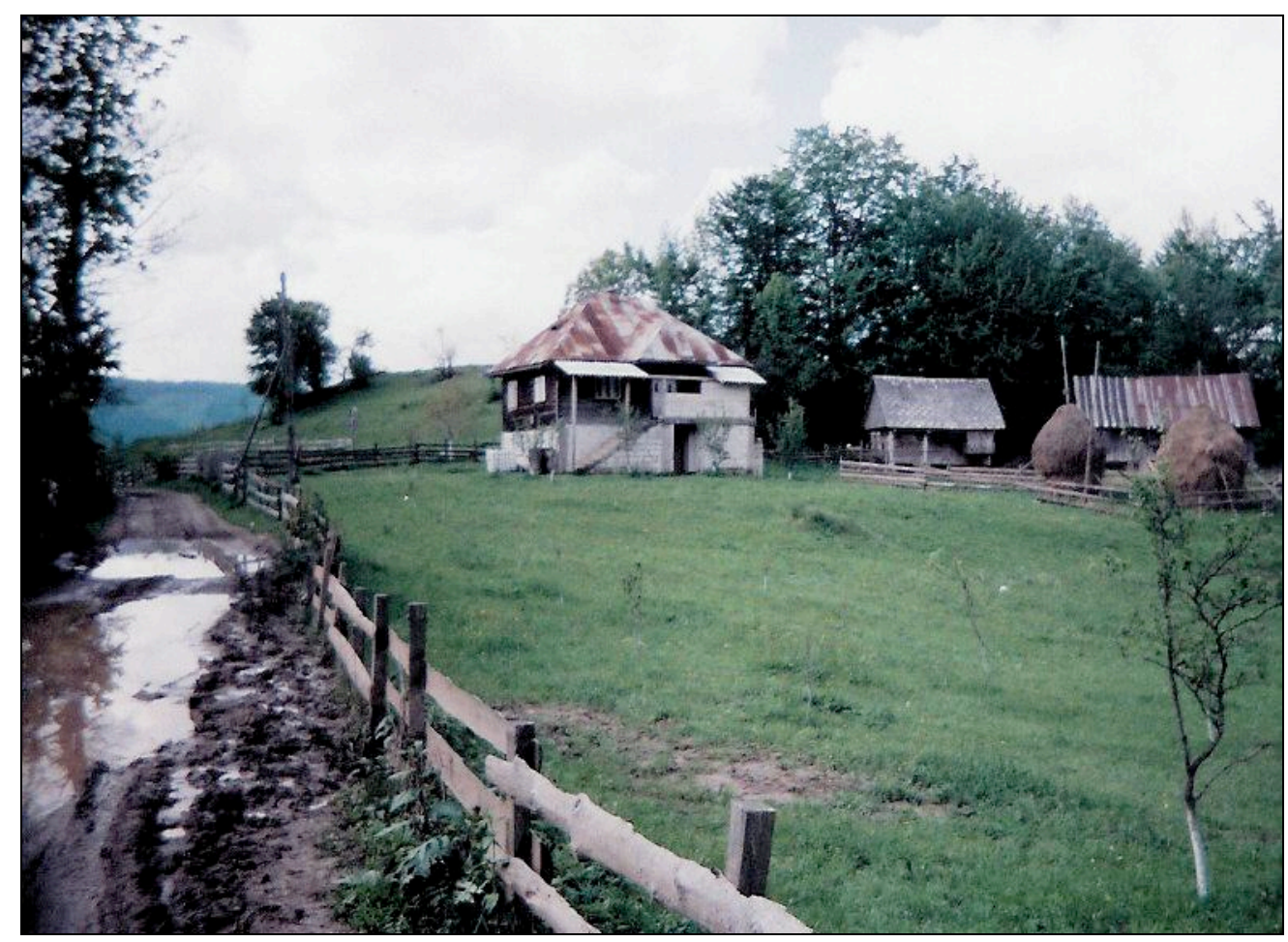

Roads in the Apuseni Natural Park tend to be very rough, with some being little more than trails. The entire park has only a single paved road; for most of the park, vehicular access is only possible via potholed dirt roads (Figure 9-6). Some park personnel and local speleologists argue that the park's paved road situation actually works to the park's advantage by limiting access for logging trucks and tourists, which in turn makes it easier to preserve the park landscape (personal observation, 2006).

Preventing excessive logging and timbering is seen by park management personnel as paramount in efforts to preserve the natural state of the park, as deforestation has welldocumented negative impacts on karst systems and landforms (draft park management plan, 2006; Mos, pers. comm., 2006 and 2007). 
Protecting a karst landscape such as this one would likely be very difficult, if not impossible, using the regulatory tools described in earlier chapters of this dissertation. Instead, park managers have decided to take the protected area approach. As the next section demonstrates, this approach is often used in isolated, less economically developed landscapes; however, it is not without its drawbacks.

\section{The protected area approach: an overview}

The World Conservation Union (IUCN) defines a protected area as "an area of land and/or sea especially dedicated to the protection and maintenance of biological diversity, and of natural and associated cultural resources, and managed through legal or other effective means" (World Conservation Union, 2000, p. 12). Six different types of protected areas are identified by the IUCN: the strict nature reserve; the natural park; the natural monument; a habitat/species management area; protected landscapes and seascapes; and managed resource protected areas. All of these area types incorporate different levels of protection, from preserving nature in an undisturbed state to protecting the sustainability of an area's natural resources in order to ensure that future use of the resource is possible.

Within protected areas, some sort of federal authority is generally cited as justification for the implementation of karst protection policies. For example, the Grand Canyon Recreational Area cites the Federal Cave Protection Act as well as National Park Service Management Policies as the source of its authority to regulate the park. A set of 1998 revisions to these NPS policies explicitly state that "local and regional hydrological systems resulting from karst processes can be directly influenced by surface and subsurface land use practices ... If existing or proposed developments such as buildings, 
roadways and other infrastructure do or will significantly alter or adversely impact karst processes, these impacts will be mitigated. If mitigation is not possible, alternatives outside of the karstic area will be sought" (National Park Service Management Policy Revision, 1998). These sources are also cited by management plans published for Carlsbad Cavern in New Mexico, USA, and Sequoia and Kings Park in California and Nevada, USA.

Many karst landscapes throughout the world fall under the umbrella of IUCN protection. According to the organization's Guidelines for Cave and Karst Protection, karst landscapes merit this protection for the following reasons:

- "As habitat for endangered species of flora and fauna.

- As sites containing rare minerals or unique land forms.

- As important sites for the study of geology, geomorphology, palaeontology and other disciplines.

- As culturally important sites, both historic and prehistoric.

- As spiritual or religious features.

- For specialised agriculture and industries.

- As "windows" into understanding regional hydrology.

- As sources of economically important materials.

- For tourism and its associated economic benefits." (World Conservation Union, 2005a, p. 7)

The IUCN considers the concept of Outstanding Universal Value when determining eligibility for inclusion as a World Heritage Site. The IUCN defines Outstanding Universal Value as "cultural and/or natural significance which is so exceptional as to transcend national boundaries and to be of common importance for present and future generations of all humanity" (World Conservation Union, 2005b, p. 1). Essentially, karst landforms can be considered examples of Outstanding Universal Value 
by virtue of the fact that they are "outstanding examples representing major stages of earth's history, including the record of life, significant on-going geological processes in the development of landforms, or significant geomorphic or physiographic features" (World Conservation Union, 2005b, p. 7).

The IUCN's guidelines for cave and karst protection are intended as a way to boost awareness of karst-related issues within the IUCN and other associated agencies. The emphasis here is on national parks and protected areas, rather than urbanized environments. The guidelines acknowledge that karst systems routinely interact with wider ecological and environmental systems, and that such interaction can easily lead to damage or contamination even when stringent protection programs are in place. In essence, the establishment of protected areas is not enough; the guidelines highlight the importance of protecting entire karst systems, rather than limiting protection to only those landforms located within park boundaries:

Where a karst area as a whole, or any part of such an area, is under consideration, the protection strategy chosen should provide for protection of the total catchment wherever possible. Where this is not practicable, there should at least be an extensive buffer surrounding the key features to be protected. (World Conservation Union, 2005a, p. 15)

Accomplishing this will require a holistic approach toward managing water and air quality and movement between the surface and karst environments. In some countries where karst protection is a pressing issue, the expertise required to do so is not present, and must be brought in from abroad. As more and more management agencies implement karst-specific management policies, the importance of international information exchanges has become magnified. Indeed, such exchanges become all the more important in cases where effective, well-recognized policies and practices are followed but not formally documented. 


\section{Viewpoints on the effectiveness of the protected area approach}

The protected area approach is a controversial one. Watson et al. (1997) specifically recommend applying the protected area approach to caves and karst areas; such an application is currently underway in the Apuseni Natural Park. As previously discussed, the area is quite rural and mostly undeveloped, yet it also has pockets of higher population densities. Economic opportunities are limited for those living in the park, as access to nearby cities is tricky, and the rough topography prevents the development of large-scale agriculture. Many area residents see the exploitation of the Apusenis' natural resources as their ticket to prosperity; however, the karstic nature of the area means that it would be particularly susceptible to the negative impacts of mining and forestry, which are two traditional natural resource-based economic activities in the region. Romania's natural park plan — which includes the Apuseni park — was designed with the intent of balancing conservation needs with access to woodlands and grazing. While the details are still being worked out, it seems that efforts to achieve this balance will focus on promoting the growth of certain low-impact industries (specifically, rural / eco-tourism and traditional crafts) at the expense of other, high-impact activities. In general, the landuse implications of such an approach include a greater priority for conservation of biodiversity resources, maintenance and possible expansion of woodlands, and no growth in agricultural intensity (Turnock, 2000); however, in Apuseni, agricultural intensity is already very low. There is reason to be optimistic about the prospects for the protection efforts underway in the Apuseni Natural Park, as Jepson et al. (2002) note the connection between the economic potential of a landscape and the chance of success for conservation and protection efforts there: "Conservation attributes that occur in economically marginal hill and montane landscapes are relatively safe from degradation, whereas conservation 
attributes confined to lowland and coastal landscapes are under serious threat and are poorly protected" (Jepson et al., 2002, p. 39).

However, Day and Urich (2000) and Urich, Day and Lynagh (2001) contend that the entire protected-area approach is problematic: "Considerable controversy surrounds protected area theory—which illustrates a positive and worthwhile concept — and practice, where little contextual evidence proves that protected areas are effective" (Urich, Day and Lynagh, 2001, p. 307). Day and Urich (2000) note that the effectiveness of protected-area and conservation legislation fluctuates widely from region to region, as does the nature of such regulations. Approximately 12percent of the world's karst landscape has been provided some protection via designation as a protected area of some form; however, this amount is not distributed evenly throughout the world's karst lands. As an example, approximately 18 percent of Central American karst lands are covered by protected area legislation (Kueny and Day, 2002), with as much as 86 percent of Belize's karst enjoying such protection (Day, 1996). Specific levels of protection vary from country to country, which is seen as a reflection of population, economic and political conditions. Even when such protection is offered, conditions within the federal government have a noticeable impact on whether or not protection is actually meaningful: does the federal government have the capacity, in terms of budget, manpower, and central authority, to plan and enforce large-scale natural resource management programs? Are attitudes toward conservation favorable or unfavorable? Asking these and similar questions may help gauge the potential for success of a protected area program before it begins (Day, 1996; Jepson et al., 2002; Kueny and Day, 2002). 
Urich, Day and Lynagh (2001) note that the trend in karst protection policy is toward global and national protected areas, despite the fact that establishing protected areas is almost always a local affair, with effects and impacts that are borne primarily by local residents. They point out that the establishment of a protected area in the Chocolate Hills region of the Philippines — home to one of the world's best-known kegelkarst environments - has led to conflicts between the federal government and local populations. In general, one problem with these kinds of conservation issues is that management rights and responsibilities can rest with either the central government or the local people. Often, government intrusion into land use practices and regulations extends beyond the boundaries of the protected area itself. More ominous is the fact that, in the past, protected area creation has led to forced relocation of indigenous populations, impoverishment, and the collapse of traditional resource management systems. The authors also cite McNeely et al. (1994) as identifying issues that must be addressed before protected areas in the Philippines can become a standard fixture of natural development planning: these issues include improving relations between protected area managers and local communities; improving protected area management practices; increasing international involvement and cooperation; and making these areas a standard and accepted part of society via education, training and research (Urich, Day and Lynagh, 2001).

\section{Protected area regulations in the UK, US and Australia}

Criticisms of the approach notwithstanding, administrators at the Apuseni Natural Park in Romania have pressed ahead with developing a park management plan that is heavily rooted in the protected area approach. With Romania's recent admission to the 
European Union, the next several years promise to be a time of significant change for the entire country, as it attempts to transition from a struggling economy with strong structural ties to the old Communist system to a country that is, in terms of economics and governance, a peer of western European nations. To that end, the management plan for Apuseni Natural Park should be examined in a more western context, compared to existing plans from karstic areas in western nations.

This next section contains several brief descriptions of karst areas under protected area management programs within the UK, the US and Australia. These particular areas were chosen for reasons of data accessibility and because they have much in common with Apuseni Natural Park — not only in terms of the physical landscape, but because the well-developed tourism trade in these parks embody one of the key aspirations of Apuseni park managers, who hope to develop an ecotourism-based economy for park residents. The specific park plans examined here include those for Mammoth Cave National Park, Mole Creek Karst National Park and Conservation Area, Naracoorte Caves National Park, and Yorkshire Dales National Park.

\section{Mammoth Cave National Park, Kentucky, USA}

Mammoth Cave National Park's original master plan is dated 1970, making it an excellent early example of protected area management plans in the United States. Mammoth Cave National Park has many characteristics that make it a useful comparison point for Apuseni Natural Park in Romania: the park's population lives above a highly karstified terrain that was, in 1970, still strongly rural in character but was facing threats from encroaching development and growth. The Mammoth Cave Plateau has nearly $600 \mathrm{~km}$ of mapped cave passages beneath it, with many major caves. There is also a 
100,000 acre sinkhole plain to the south and east of the park where surface drainage issues are important. The cave has been explored by visitors and tourists since at least 1816. Currently, land inside the park is used for tourism and recreation, and for scientific research. The park itself was officially established in 1940; before then, about 45 percent of the land area was either under cultivation or used for grazing.

The master plan was designed to address several major concerns that could have impacts on the park's karst system. First among them was the issue of visitor congestion, which had apparently been causing problems as far back as 1967 . The recommended solution was to open more existing cave passages to the public and to dig out a new tunnel for cave entry in order to more easily facilitate larger numbers of tourist expeditions each day. Perhaps anticipating that this level of modification might be seen as running counter to the goals of karst protection, the plan suggests that saltpeter mining and initial construction of tourist infrastructure had already caused so much damage that these changes would have only a minimal impact on the health of the caves. Additionally, monitoring technology would be installed to keep an eye on the effects of these changes, in particular the increased foot traffic, with the implication that if the data demonstrate the environment is deteriorating, corrective action can be taken.

The plan also addressed threats to caves posed by visitor car congestion (new parking facilities were located in an area underlain by an impervious layer of clay) and by the high demands of the park's water system; essentially, the park's water supply system used so much water that flow into the caves was reduced. The recommendation included in the master plan was termination of certain heavy water-use activities within the park, so as to enable the water system to better accommodate more day-to-day visitors. 
Recommendations to address all of the issues discussed above included a plan to embark on a communications and information campaign with park neighbors and relevant local organizations, like the local Chamber of Commerce or local development district, as a way to keep everyone on the same page with regard to National Park Service policies on development and protection of the park resources. In 1970, agriculture had long been the dominant land use around the park. Planners of that era wanted those conditions to remain, or for that land to revert to forest, as a way of avoiding water pollution that could damage the caves. The plan acknowledged that changes in the intensity and scope of development outside the park would drive park planning priorities in the future.

The plan also recommended the implementation of a new land classification plan as a way to classify and manage land uses within the park. There were six classes included in the proposed classification scheme: class I is for high intensity recreation areas, while a class $\mathrm{V}$ designation applies to primitive lands and VI is for historic and cultural areas. The master plan acknowledges that no Class V or VI lands existed within the park's borders in 1970; however, all Class IV lands (outstanding natural features) contained by the park are listed and described therein.

The "cave-centric" nature of the Mammoth Cave National Park master plan was most evident in its cave classification system. In this system, caves are assigned letters from A to E, which are intended to designate the level of intensity of use and development of each cave. Zone A designations are limited to places with limited esthetic or scientific value; areas designated as Zone B caves are generally caves with lights, footpaths, handrails, and other amenities designed to facilitate large-scale touristic 
activities; Zone $\mathrm{C}$ caves include passages which are only partially developed or have since been abandoned; Zone D caves are natural passages and are for use by experienced cavers only; and a Zone E designation means that the area in question is reserved for scientific study or contains passages that would be irreparably damaged by heavy use. An additional zone, Zone F, consists of areas with unique natural or historic features. Additionally, the Cave Superintendent has the authority to further regulate and restrict entry into caves and passages. According to the plan, this system was designed with the intention of guiding cave resource management policies and practices in such a way that the resources remain available and accessible for research and recreation purposes.

In this plan, we see an early example of a protected area attempting to balance the seemingly contradictory priorities of karst protection and increased visitor access to park resources. It could be argued that the most logical first step for karst protection might be to sharply limit the amount of human traffic through the park's caves and passages; however, this seems unlikely to occur in an existing national park, particularly one that has been so heavily visited over the last century.

\section{Mole Creek Karst National Park and Conservation Area, Tasmania, Australia}

The park management plan for the Mole Creek Karst National Park faced several unusual and inherent difficulties from the start. Any resource management goals are complicated significantly by the fact that the park is disjointed and non-contiguous, with much of the karst system actually located outside the park's boundaries:

The park comprises twelve separate blocks which individually encompass only minor parts of larger catchments subject to a variety of land uses. Several of the blocks are small parcels which surround cave entrances, although the major part of the caves extend outside the park. In no case does an individual portion encompass the entire catchment of the caves located within it. (Mole Creek Karst National Park 
management plan, 2004, p. 39)

The plan goes on to identify logging, agriculture, waste disposal and land clearance for general purposes as specific potential threats to the karst system; these are analogous to the threats identified in the management plan for Romania's Apuseni Park (discussed later in this chapter). Certainly, the dependence of the park's karst on water flowing in from areas outside the park's jurisdiction has the potential to render any management plan ineffective from the start; in this, Mole Creek faces some of the same management challenges faced by GCRA and the Apuseni Natural Park, among many others.

The plan outlines three main categories of caves: public presentation caves, special value caves, and wild and unclassified caves. There are also restricted access caves as well, which can be found among caves in each of the primary classifications. These restricted access caves are each allocated a maximum number of annual visits; once that number is reached, the cave is closed for the remainder of the year. The list of prohibited activities has much in common with the list outlined in other western plans; these restrictions seem to be widely applicable to sensitive karst landscapes and not specifically designed for each individual karst system.

The Mole Creek plan recognizes that some caves have entrances or passages that are not on park grounds; therefore, the park cannot be solely responsible for the management and protection of these caves. In order to better manage impacts from land uses occurring outside the park's boundaries, the plan proposes a joint karst management program with the local forestry service, and a policy of collaboration and liaison with park neighbors and other users of the nearby Mill Creek-Kansas Creek catchment area. The park identifies as an objective growing support for the park and its overall goals within the community. Actions to accomplish this include developing opportunities and 
mechanisms through which people interested in the management of the park will be consulted; the establishment of a forum for communication between stakeholders and the park; working with and involving caving clubs in relevant and appropriate aspects of park management and development; and liaising with local landowners regarding the management of Wet Cave. The plan also recognizes that stronger interaction may be required between the park and the park's immediate neighbors. Plan objectives for working with neighbors include encouraging complementary land management practices on adjacent parcels and enlisting cooperation from neighbors in conserving park values. Actions proposed to accomplish these objectives include working with neighbors to prevent livestock access, collaboration on any issues that affect both the neighbors and the park, and implementing joint management protocols with the forestry service.

In fact, such a joint management protocol for the entire Mill Creek / Kansas Creek catchment area is included in the Mole Creek plan. The protocol covers everything from catchment management to fire to erosion hazards to grazing to caves and karst. Ultimately, under this protocol each agency is responsible for what occurs on the lands for which they are responsible. While this may seem like nothing more than common sense, it does have the effect of identifying a specific party that is responsible for maintenance and protection of sensitive lands that are outside the park's boundaries but still have the potential to impact the karst system within the park.

The Mole Creek plan includes a detailed set of performance indicators. These include both measurements of natural environment health and of visitor interest and enjoyment of the park; as in Mammoth Cave National Park and elsewhere, these two goals have the potential to work against each other. Further, the plan proposes 
implementing a visitor research program "to build a comprehensive visitor management model to better predict and respond to visitor growth and impact trends, over the long term” (Mole Creek Karst National Park management plan, 2004, p. 5).

\section{Naracoorte Caves National Park, Australia}

The Naracoorte Caves National Park Management Plan explicitly states that cave protection was the goal of obtaining and managing the land in the first place. The park's management framework is broken down by park components (flora, fauna, etc). Each component has a list of issues associated with it, which is accompanied by management objectives and proposed actions, which in turn are prioritized. The cave management section is the largest and most detailed of these, and includes a classification system.

The goals of the cave management section of the plan seem to be designed to simultaneously protect resources while permitting some public access to the resource; however, protection generally takes precedence. The classification system in use at Naracoorte places caves into one of three broad categories-Public Access, Special Purpose, and Wild and Unclassified. Public Access caves are actively presented to the public, and are subdivided into Show Caves and Adventure Caves categories. By contrast, special purpose caves (subdivided into Reference, Special Value and Dangerous caves) grant access by permit only, with the exception of Dangerous caves. There are also caves classified as wild caves, as well as those that are listed as unclassified. According to the plan, wild caves will be managed in such a way that provides opportunities for research, exploration and recreation; unclassified are usually awaiting classification. Each individual cave is listed and categorized within the plan itself; it is therefore a simple 
matter to determine which activities are permitted within a specific cave. Several of the park's caves have multiple classifications, applicable to different parts of each cave.

\section{Yorkshire Dales National Park}

Located in the Pennines, in England, the Yorkshire Dales National Park has many characteristics that make it an appropriate comparison point to Apuseni Natural Park. The southern end of the park has some of the best examples of limestone karst landscapes in all of Britain; highlights include several major cave systems and some textbook examples of pavement karsts. The park also contains significant limestone-based habitats, including upland pastures, limestone pavements, and wooded areas, that merit protection. Like Apuseni, Yorkshire Dales is not exclusively a karst park; park management hopes to preserve not only geologically significant features, but also the biodiversity found in the park and the cultural characteristics of the people living there (Yorkshire Dales Park Management Plan, 2007).

This leads to another point of similarity with Apuseni. People live in the Yorkshire Dales National Park — the park has nearly 20,000 residents today—and have in fact lived in the area for thousands of years, dating back to the Paleolithic era. Traditionally the local economy was based on agricultural and pastoral activities, like livestock farming and cheesemaking. Agriculture is still important there today, but its viability as a sustainable commercial enterprise is threatened by larger forces beyond the park's control (Yorkshire Dales Park Management Plan, 2007).

Demand for recreational services in the park has been growing for some time. Demand for vacation homes in the area is also growing, which has the effect of pushing housing costs beyond the range of affordability for the generally lower-wage inhabitants 
of the park. The park also has difficulty with the increasing amounts of waste generated by individuals and business enterprises, despite the establishment of recycling programs; the landfill sites that do exist there are limited in their future capacity, so waste reduction is a priority (Yorkshire Dales Park Management Plan, 2007).

The park's management plan is markedly different from any of the plans examined in this chapter, including the Apuseni plan, in that there are no explicit karst or cave management protocols laid out within it. The overarching goal of the park, like all national parks in Britain, is to protect and conserve the natural beauty, wildlife and cultural heritage of the park area, as well as to contribute to the economic and social well being of any communities located within the park. The Yorkshire Dales management plan sets out to accomplish this by broadly addressing seven components of the park: landscape, community and culture, access and recreation, understanding and enjoyment, nature conservation, historic environment, and economy and employment. It is emphasized that no element can really be addressed in isolation, due to the large number of connections between them all. However, the point that preserving the geology and geomorphology of the park is essential to properly understanding the overall landscape is made several times; one of the plan's objectives is to maintain all geologically important sites in "favourable" condition, though this term is never defined within the management plan itself. Recurring themes throughout the plan include sustainable development and sustainable land management (for example, farming using traditional methods is more expensive than using modern methods, but should be practiced nonetheless in order to preserve the park's unique cultural qualities).

As in Apuseni, park managers in Yorkshire Dales recognize the importance of 
maintaining the traditional lifestyle of park residents, since that is a key component of any plan to develop and grow economic activities centered around low-impact tourism. Indeed, the plan objective to develop a wide range of tourism initiatives driven by the park's image and its natural and cultural assets is supported by several of the other objectives laid out by the management plan. For example, the plan specifies that largescale commercial agricultural operations are not permitted within the park, so as not to interfere with the more traditional agricultural activities practiced by park residents. More generally, the plan stipulates that environmentally sustainable economic activity should be actively promoted as good business practice and efficient in terms of resource consumption, with at least 9 hectares of park land set aside for this type of economic development; further, the park's Sustainable Development Fund will be used to support future projects that are expected to bring desired economic, social and environmental benefits to park communities and their residents. Finally, some of the transportationrelated goals of the plan include reducing the impacts of vehicle traffic within the park, in particular in the villages, and better integration of community transport services.

Increasing levels of tourist traffic to the park will require a bit of work in improving the park's overall exposure to the general public; apparently fewer than 10percent of English and Welsh people actually know that Yorkshire Dales is a national park. In fact, the plan also claims that a significant number of park visitors are not even aware that they are in a national park (the exact percentage is not specified).

As is seen with several other park plans, including Apuseni, successful implementation of the plan will require cooperation from external entities that have interests within the park's borders. In order to accomplish the goals of the plan, park 
management must develop working partnerships with the private entities that control fully 95percent of the park's land. However, the specific nature of these partnerships is not spelled out within the plan itself, presumably to allow management to retain some flexibility.

The Yorkshire Dales National Park Management Plan takes a much different approach toward landscape and cultural protection than any other plan examined here. The management plan is not detailed, and instead seems to offer broad latitude to managers of how the plan's objectives should be accomplished. It is worth noting a second time that there is no section on cave or karst management within the plan, despite the fact that the park contains some of Britain's most important karst formations. Whether such an approach would be appropriate for the Apuseni Natural Park is questionable, for reasons that should become apparent in the remainder of this chapter.

\section{The Management Plan for Apuseni Natural Park}

\section{Introduction}

Earlier, this dissertation discussed the protected area approach to regulating land use in karst terrains. Literature on the subject points to several major weaknesses of such an approach, including local attitudes toward preservation and the ability to enforce regulations that mandate protection and preservation. Recently, Romania's Apuseni Natural Park published a draft management plan that outlines strategy and tactics for implementing a protected area approach to park land management. The following section examines the plan, comparing its approach to those taken in the protected areas discussed in the previous section. 


\section{Apuseni Natural Park's plan}

In the summer of 2006, park managers completed a draft management plan for the Apuseni Natural Park. While it does contain noteworthy karst-related components, the main goal of the park itself is to manage the forest resources it contains. The park plan notes that Romania's admission to the European Union means the Apuseni Park plan will be required to conform to European Union rules set up under the Natura 2000 program, and was written with that goal in mind. (The Natura 2000 network is a network of environmentally sensitive lands throughout Europe. The primary goal of Natura 2000 is species and biodiversity protection; however, network managers acknowledge that a broad-based approach to land management is needed to achieve this goal. European Union website, http://ec.europa.eu/environment/nature/index_en.htm, accessed November 10, 2007.)

The Apuseni Natural Park falls under the $5^{\text {th }}$ management category of IUCN land use rules; this is the most permissive of the IUCN categories, in terms of land use types permitted, because of the need to accommodate local populations. The primary purpose of designating an area as $5^{\text {th }}$-category lands is to protect the landscape in the park, regardless of the specific form it takes; another important purpose is habitat preservation, which is obviously related. The karst protection aspects of the plan work by dividing the park into various "management zones," with each zone having a different level of acceptable access and use (Figure 9-2). These zones are based on the IUCN categories, even allowing for the fact that the park itself is an IUCN Zone 5 landscape.

Zone 1 (Scientific Reserve) is the most restrictive, with the only human impact coming from scientific observation and monitoring activities. No other activities are permitted. Much of the significant karst lands in the park-including parts of the Padis 
plateau (Figure 9-7), the Varasoaia plateau, and the Ocoale-Ghetar plateau—are classified as Zone 2 (Special Conservation Zones). All activities permitted in Zone 1 areas are also permitted in Zone 2 areas. Other Zone 2-acceptable activities include controlled tourism, mostly limited to the use of visitor trails; pasturing with domestic animals under certain controlled conditions; and vehicular access. Specifically forbidden activities include anything that involves the construction of permanent buildings, other than those necessary for the administration of the park, and mass tourism; there is also a sweeping catch-all clause that says any activities not specifically approved for the zone are forbidden.

Figure 9-7

\section{Padis karst plateau, Apuseni Natural Park}

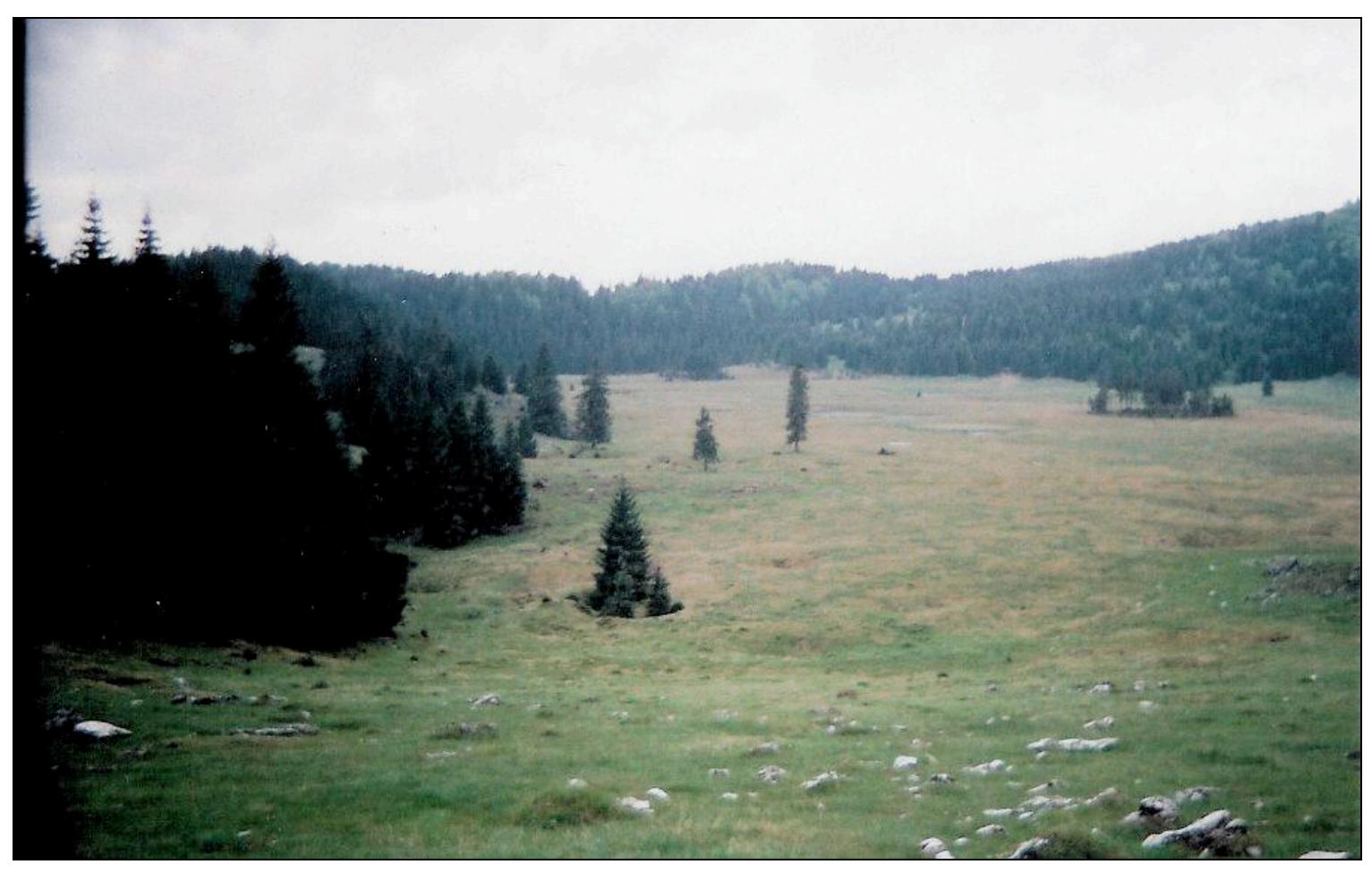

However, not all the karst areas in the park are contained in areas labeled as zone

1 or 2 . This is apparent from a walk in the park itself, because there are people living 
adjacent to dolines in the vicinity of Scarisoara. These lands and others like them are most likely contained in Zone 3, the landscape protection zone, or zone 4, the socioeconomic development zone. Zone 3 contains lands reserved for traditional land uses, like forestry, pasturing, or temporary dwellings, and in which visitor access is encouraged. Zone 4 includes building areas of the communities spread across the park's territory, and more types of land use are permitted here (though construction and development is restricted in the vicinity of the Padis tourist zone, due to the sensitivity of the surrounding area). There are, however, still restrictions on the development of new residential and industrial buildings that go beyond the capacity of the local ecosystem to accommodate them, or that are inconsistent with ANP management objectives.

Beyond this large-scale zoning system, the Apuseni plan contains a cave classification system similar to those discussed earlier in this chapter. In the Apuseni system, there are four categories of caves, ranging from Class A to Class D. Class A caves are those with "exceptional value," and all activities other than scientific research and monitoring are prohibited. Newly-discovered caves are automatically classified as Class A caves until further study permits a more appropriate reclassification. Class B and $\mathrm{C}$ caves are also protected, due to national or local importance, respectively; organized tourism or explorations are permitted in both classes with park approval. Class D caves are described as those that lack the specific qualifications to be placed in any of the other three categories.

Park management plans like this one are often difficult to implement because of conflicts with or between stakeholders. Here, those stakeholders encompass more than those individuals wishing to use or preserve the landscape. The park itself is actually split 
between three of Romania's counties, and there are 21 villages or communes that are stakeholders in the park; perhaps 15 of these are directly involved with park business, with the others simply owning property within the park. This adds an extra layer of administrative stakeholders that must be navigated, making the plan development process all the more difficult.

\section{Threats and solutions}

The karst within the Apuseni Natural Park faces threats from several different sources; however, in section 3.2.1, the draft management plan concludes that the state of conservation of the park's karst is "at a rather satisfying level." This is attributed directly to the remote locations and lack of convenient access routes for a large number of the park's caves (Apuseni Natural Park Management Plan draft, 2006). Still, future alterations to the park's physical and human landscape could result in a dramatic change in that assessment.

As discussed earlier, sinkholes provide a direct pathway to the aquifer for surfacelevel contaminants; in many agricultural areas, this leads to high concentrations of nitrates in the groundwater. However, in the Apuseni Natural Park, agriculture in sinkholes is not actually a significant threat to the local karst aquifer, despite the fact that the general lack of arable land makes the interiors of dolines and other karstic depressions more attractive for agriculture, particularly growing potatoes. That is due in part to the fact that the agriculture is very small-scale, mostly subsistence-level; generally, the agriculture practiced here was often intended to supplement the food supply brought in via trade with lowland farmers, who needed timber from the Apuseni forests. Additionally, chemical fertilizers are generally not used because their cost places them 
out of reach for most park residents (Mos, pers. comm., 2007). That said, in section 3.2.1.2 of the plan, farming is nonetheless identified as one of the major contributing factors to the area's degraded aquifer. In addition to threats from fertilizers, intensive grazing can have an indirect negative impact on the karst aquifer by removing the vegetation that acts as natural filtering mechanisms for surface water prior to entering the karst system (draft management plan, 2006). This is a perfect illustration of the potential conflict between different objectives of the management plan (in this case, preservation of traditional ways of life vs. protection of the karst and groundwater resources) discussed earlier.

Illegal logging, on the other hand, is indisputably a major problem within the park. RomSilva, the Romanian forestry service, conducts timbering operations within the park and profit from the exploitation of the park's natural resources; however, because the logging takes place in a national forest, park residents do not control the timber resources, and little if any of this money ever makes its way into their pockets. Some park residents are unable to resist the profitable nature of forestry and continue to make their living from the trees, without official supervision or approval. Even so, these small-scale timbering operations do not pose the threat to the forest resource that is posed by larger corporations (Persoiu, pers. comm., 2007). Timbering issues in general have become a focal point for a bureaucratic turf war within the Apuseni Natural Park. There is a conflict between the park administration and the national forestry service, which now supervises the park administration. The park service sees its role as preserving the landscape, including the forest; the forestry service sees its role as encouraging and managing the 
use of the forest resources - in other words, to promote logging and timbering within the park (Mos, pers. comm., 2006; Persoiu, pers. comm., 2007).

The development of summer homes also threatens the park's karst systems. Illegal construction was once common in the area near the Cabana Padis, located towards the center of the park (Figures 9-8 and 9-9). While the newer cabins and seasonal homes under construction there in the summer of 2006 were being built legally, there were several others in the vicinity for which no permits or approval papers were ever issued. Since the park's lands have been inhabited for centuries, buildings and settlements long predated the legal establishment of the park. However, much of the construction that has taken place since then has been illegal, and the park ultimately has no recourse against illegal construction (Figure 9-9). At most, violators are fined a nominal amount, but are never actually required to remove any illegally-built structures. Park rangers in Romania have very little power, which is a sharp contrast to other countries in the region like Poland; because the park lacks sufficient enforcement authority, the highly profitable nature of illegal development means that nature and ecological concerns within the park are often ignored (personal observation, 2006; Mos, pers. comm., 2006 and 2007).

Nearly all the park's natural systems are threatened by the aggressive and unchecked development of tourist infrastructure (Mos, pers. comm., 2007). This is not to say that park managers wish to prohibit development within the park, or envision such a prohibition as part of the park management plan. In fact, quite the opposite is true: they recognize that some development is necessary to provide an economic framework for the park's residents. The real question is one of how to accommodate economic growth while simultaneously preserving as much of the park's landscape as possible. For both social 
Figure 9-8

Cabana Padis, Apuseni Natural Park

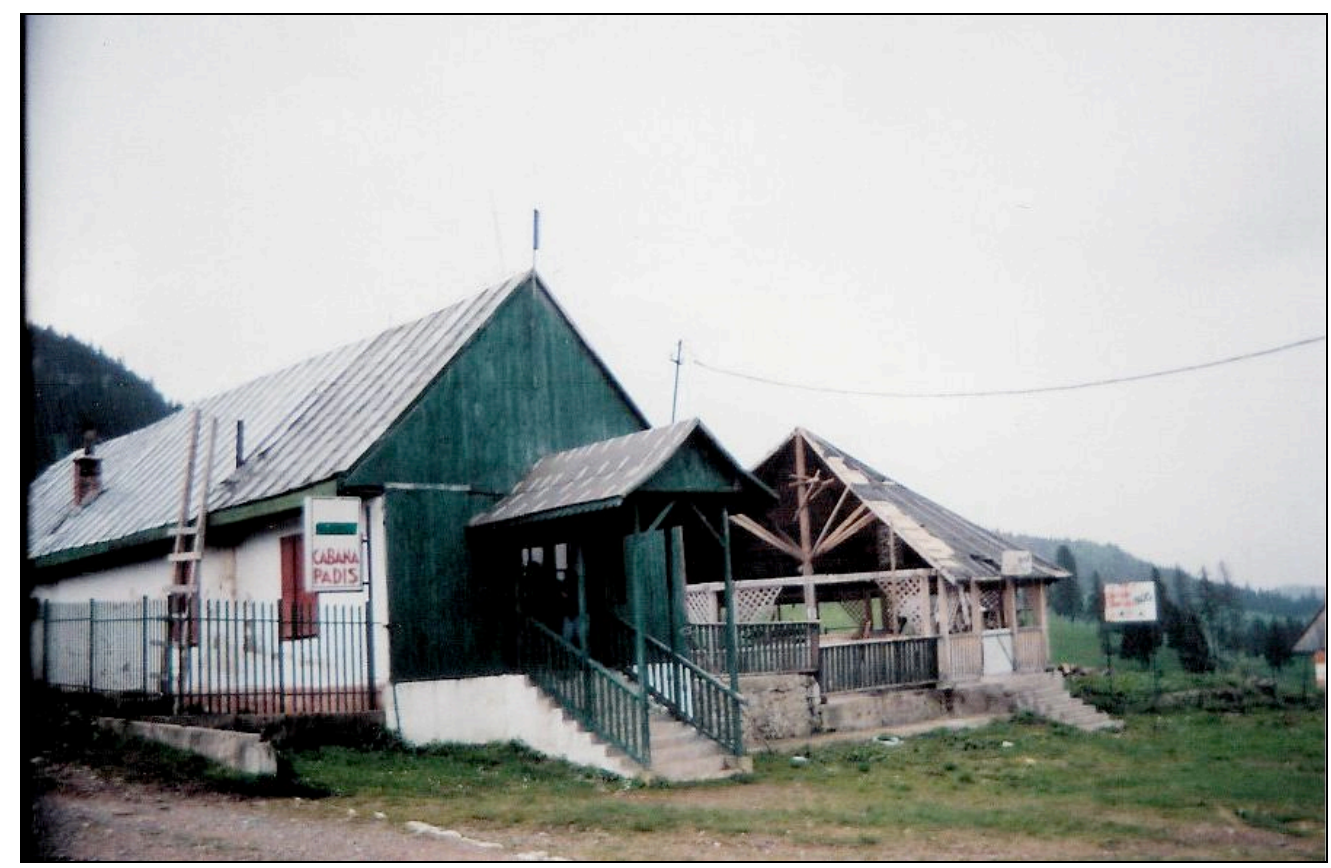

Figure 9-9

Illegal construction near Cabana Padis, Apuseni Natural Park

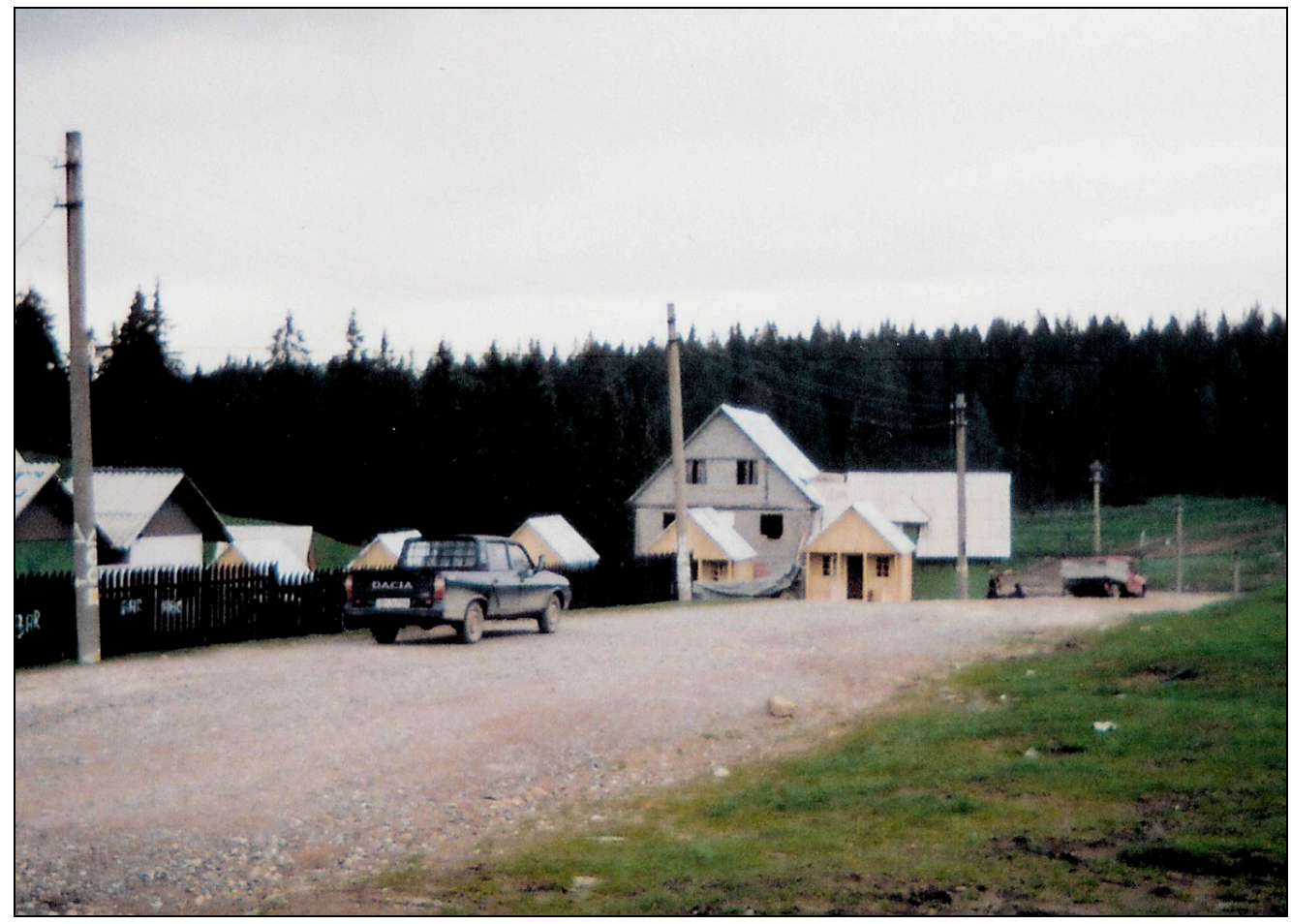


and ecological reasons, the most widely desired type of development is small-scale, sustainable rural tourism (Buza et al., 2001). Tourism is often thought to be a potential gold mine for places like Apuseni. However, many southeastern European countries, including Romania, have also proved either unwilling or unable to invest in tourism development, or to secure outside investment for such ventures (Hall, 2004). This is not uniform throughout the region, as national parks in Poland and Slovakia have experienced booming business (Turnock, 2000).

The draft management plan is clearly intended to position the Apuseni Natural Park for a transition to a major tourist attraction within the region, while still maintaining and protecting the park's natural environment. The plan's goals were determined with input from stakeholder workshops, as well as by the core team in charge of developing the plan. Stakeholders in the Apuseni Natural Park area include:

- Romanian national government agencies, like the Ministry for Environment and Water Management, the Ministry for Agriculture, Forests and Sustainable Development, the Ministry for European Integration, and Romsilva, the Romanian forestry administration;

- Administrators from the three county governments with land inside the park boundaries (the counties of Alba, Bihor and Cluj);

- Various control and regulatory agencies at the federal and county levels, including the forestry directorates, environmental protection agencies and building inspection agencies from each of the three counties; 
- Various partner parks in Hungary and Italy;

- Non-governmental organizations (NGOs), including speleological clubs and societies, ornithological societies, bat protection organizations, and ecotourism organizations;

- The Natura 2000 network;

- Local land owners, including communes, churches, schools, and private owners, as well as owners of weekend homes within the park; and

- Various schools, universities, museums, and research institutions.

This list is not an all-inclusive list, but does provide a representative description of the largest stakeholders in the development of the park and the writing of the management plan. According to the draft management plan, these stakeholders had input in the writing of the plan in general, and in the setting of park goals in particular. These goals are summed up on page 86 of the draft management plan:

"Apuseni Natural Park will be: an internationally important area of mountain karst landscape, with well-conserved biodiversity, specific and quality tourism, sustainable use of resources, and an infrastructure designed for sustainable development; and with local communities that maintain their unique traditions and a good standard of life."

Specific objectives are wide-ranging, as the park contains resources other than karst and the plan itself is obligated to address these resources as well. However, objectives relating directly or indirectly to karst formations within the park include the following:

- Conservation of the park's karst, and protection of the karst from damage and pollution;

- Increasing scientific understanding of karst; 
- Boosting visitor awareness of, and improving visitors' experience with, the park's karst;

- Protection and restoration of aquatic habitats within the park, as well as prevention and reduction of pollution of the park's surface water and groundwater;

- Promote ecotourism and "nature-oriented recreation," as long as those activities are compatible with and appropriate for the park's karst formations;

- Promote and protect the local traditional lifestyle and cultural heritage of the Apuseni Mountains;

- Promote the development of "sustainable economic activities."

There are potential internal conflicts here; in particular, protecting resources like karst formations and groundwater can very easily come into conflict with the objectives of protecting traditional lifestyles and promoting sustainable economic development. Of course, that is probably why the word "sustainable" is included in that particular objective, with the implication that any sustainable development would, almost by definition, be compatible with the resource-related objectives.

\section{Growing tourism and protecting the natural environment: are they mutually exclusive goals?}

Establishing a thriving tourism sector faces a problem from the lack of infrastructure, especially water and roads. Nearly all roads in the park are unpaved forestry roads; some formerly paved roads within the Apuseni Natural Park have reverted to an unpaved condition due to a long-term absence of maintenance. Waste disposal is another segment of infrastructure that will have to be improved to support a strong push 
into the ecotourism sector. While there are trash-collecting sites for tourists using the four approved camping locations within the park, there are no actual trash removal services because the park claims removal is the responsibility of the towns, which generally lack the money needed to actually provide the service (Persoiu, pers. comm., 2007; pers. obs., 2006). Abrudan and Turnock (1998) recognize that the success of any strategy with an emphasis on private farming and expanding tourism would depend on improvements to these public services. Transportation is particularly critical, since the very roads that are needed to bring tourists to these hamlets have proved to be especially difficult to maintain since the end of the Communist era. Provision of other types of services is made all the more difficult by the settlement pattern of dispersed, "hamlet"-style villages scattered across rugged terrain. Some of these hamlets are not accessible to vehicle traffic at all. Perhaps these problems of accessibility offer a partial explanation of why relatively few Apuseni farmers participate in the young agrotourism industry, even though many of them consider agrotourism to be highly desirable (Abrudan and Turnock, 1998).

If the park is to develop a thriving tourism industry, the park management plan will be the tool that provides the blueprint for it. The plan outlines specific acts that will be taken to achieve the twin goals of tourism development and environmental protection. Because this dissertation is concerned with land use regulation in karst terrains, I will focus here on proposed management actions related to the karst-centered aspects of environmental protection.

The plan describes four broad objectives related to protecting and preserving the park's karst: conserving the "patrimony" of the karst, increasing scientific knowledge and understanding of karst, facilitating and improving visitor awareness of karst, and 
reducing damage and pollution to the park's karst features and landforms. Each objective is connected to a list of the specific management actions that will be taken to achieve these goals. Each of these management actions has a priority indicator of 1, 2 or 3, where 1 is the highest level of priority. An examination of these priority indicators can help illuminate what aspects of the plan are considered most important by park management and the other stakeholders. The "facilitating and improving visitor awareness" objective has five management actions with a priority of 1 (out of nine total actions); reducing damage and pollution has only one action (out of seven) with as high a priority. Likewise, the objective of increasing scientific knowledge has only one top-priority action, out of a total of five (park management plan, 2006).

The top priority management action relating to reducing damage and pollution to the park's karst is an educational campaign to inform residents about the consequences of polluting and littering upon the karst system. Two other actions listed in this category are designed to "promote" changes in infrastructure or in park resident behavior (specifically, to promote the application of organic fertilizer, and to promote installation of rural wastewater collection and treatment systems, respectively); these are given a priority of 2. In the former case, this lower priority might be because the poverty of park residents makes organic fertilizer a choice often made from necessity; likewise, the lower priority for promotion of wastewater systems could reflect the awareness that the cost of installing such a system is very high and likely out of reach at the moment. Interestingly, the one action likely to yield more immediate and visible results—clearing trash out of dolines - also has a priority of 2. Within the "facilitate and improve visitor awareness" category, the park administration seems intent on walking a fine line between increasing 
access to the park's karst, and simultaneously imposing better controls on that access. High priority management actions include improving visitor access via thematic, selfguiding karst trails and developing a more comprehensive agreement relating to access to karst sites within the park.

At this point, the park's infrastructure is likely inadequate to support a profitable ecotourism sector. The Romanian government has attempted to help shore up the area's infrastructure with an 8000 billion lei program that also attempts to grow the region's tourist trade by providing "seed money" investments for local handcrafts and other businesses likely to reinforce the industry (Abrudan and Turnock, 1998). Governmentsponsored grants and financing for the promotion of ecotourism and nature preservation are crucial for the success of the project, because most developers and investors are reluctant to invest their own money in what is admittedly a very risky venture at this stage. It is hoped that, as development continues, word will spread throughout Europe about the recreation opportunities available in the park, which will then lead to an increase in visitors and a justification of further investment in the park, perhaps even without the inducements of grants (Mos, pers. comm., 2007). Other proposals for boosting tourism in the area—not specifically tied to this federal grant program—include improving mountain activities and establishing a Large Animal Center that would make it easier to observe large animals in their natural environment (Turnock, 2000). The park administration is also trying to promote and support the development of other sustainable economic opportunities for park residents. These include, but are not limited to, sustainable production of natural medicines using plants found in the park, and sustainable use of forestry products in the production of handcrafts. These activities are 
already occurring in the park, but at very small scales; still, they do provide potential investors with an example of the types of non-tourism economic initiatives that are considered suitable by park management (Mos, pers. comm., 2007). Even with the scale of financial assistance offered by the government, however, agrotourism in the Apuseni Natural Park would find itself competing for dominance with mining for bauxite, copper and limestone - all traditional economic activities that hold very little appeal for the average pleasure traveler. On the other hand, there is also a strong conservation movement afoot in the region, with 35 environmental non-governmental organizations (ENGOs) active in the Apuseni Mountains as of 2001 (Abrudan and Turnock, 1998; Buza et al., 2001). This movement could potentially hamper attempts at any type of economic and industrial development, perhaps by seeking the implementation of regulatory tools like controls on grazing and woodcutting (Abrudan and Turnock, 1998).

Apuseni Park officials clearly believe that the promotion of ecotourism in the region is important. In fact, tourism and possible ways to promote it are discussed at length within the plan itself. The section of the plan addressing the managing of visitors, tourism and recreation is well developed and detailed, with significant attention devoted to the image of the park, promotion of the park as a tourist destination, and general public relations. The very first goal is to develop a separate visitor management plan; both this and the development of a visitor infrastructure are listed as top-priority items. Clearly, this section has received a good deal of thought, and is reflective of the park administration's emphasis on developing ecotourism as an economic base for the residents. In addition to ecotourism, park administrators have expressed a willingness to encourage any other activities that simultaneously impose a minimal impact on the 
landscape, while also providing maximum income to park residents. In any case, planners will have to take great care to avoid what Hall (2004) describes as the paradox of rural tourism: the growth and development of a successful rural tourism industry may very easily destroy the features and qualities that made such tourism possible in the first place.

It is this very realization that has led to some resistance to the promotion of ecotourism as an engine of economic development for the people of the Apuseni Natural Park. Some cavers argue that there is an inherent contradiction in attempting to protect caves by introducing them to the tourist circuit, which would increase the number of visitors who enter the caves. Park management claims that any caves opened to the tourist circuit would still enjoy a significant amount of protection, since no lights or footpaths would be installed; speleologists counter that any promotion of caves for tourism will by definition lower the level of protection provided, due simply to the increased human contact (Persoiu, pers. comm., 2007).

It is interesting to note that none of the management actions listed in the "Sustaining and Promoting Local Culture and Traditions" section are given top-priority billing. This, combined with what we see in the section on managing visitors, strongly suggests that developing the tourist trade is more important to park administrators, and could very easily crowd out the development and growth of small-scale traditional economic activities (draft park management plan, 2006).

\section{Authority and attitudes}

The issue of protected areas in Romania is still widely regarded as a peripheral one that is not particularly significant to the nation's development. Foresters and ecologists must make obvious the benefits of a sustainable relationship between 
community and nature in order to be successful. A major drawback to the protected area approach is that it can lead to friction when protected areas are placed adjacent to developing communities. There is also no functional system to maintain protected areas on a national level in Romania (Day, 1996; Ioras, 2003).

Earlier in this chapter, this dissertation discussed the role of enforcement capabilities and attitudes toward preservation in protected area establishment and management (see Day, 1996; Jepson, et al., 2002; Kueny and Day, 2002). Judging from the plan itself, and from discussions with stakeholders, the Apuseni Natural Park may find itself in the same situation as countless other protected areas around the world: unable to actually provide protection to the park's natural resources, regardless of what the management plan says.

In a park with as large a population as Apuseni, obtaining buy-in from residents is critical to the success of any management plan. The park's large population made it impossible to consult each individual resident when attempting to incorporate their priorities into the park management plan; additionally, the sheer number of stakeholders other than park residents makes it necessary to work with representatives of each stakeholder group (major stakeholders are listed earlier in this chapter). Representatives of each stakeholder group then come together to form a workgroup, which was selected by park management; indeed, the entire process of collecting input from stakeholders seems to have been strongly guided by the park administration (Mos, pers. comm., 2007).

Park residents were initially hostile to the idea of a management plan; this was due to misunderstandings of the intentions of the park's administration. These misunderstandings were apparently capitalized upon and encouraged by interest groups 
who opposed the development and implementation of a management plan. Most of these misunderstandings were related to restrictions on permissible activities and access to natural resources for park residents. Ultimately, it took two full years of work to turn these hostile and reluctant attitudes around. Park administrators conducted workshops, informal meetings, and organized exchanges between other European natural parks in their efforts to convince the residents of Apuseni Natural Park of the benefits of implementing a management plan. In particular, they see the European system of subsidies for nature conservation and tourism development as a tool to help them prosper in the still-developing free market economy of Romania (Mos, pers. comm., 2007).

However, even as the idea of preservation has gained acceptance, the concept of a tourism-based economy has been slower to develop buy-in from park residents. It has been suggested that the park residents find forestry easier, in large part because the paperwork required for tourism can be challenging; additionally, forestry is still far more profitable. This is related to the general problem with enforcement and with bureaucratic issues; many park residents seem to be waiting for these things to change before moving in to tourism. Additionally, some villagers are simply not motivated to start businesses and become entrepreneurs, particularly in a new and exotic field like ecotourism. This can potentially be overcome by convincing one person to establish a tourism business and helping him succeed; his neighbors may then attempt to emulate his success (Persoiu, pers. comm., 2007).

While park administration seems to have been successful in their efforts to bring about more favorable attitudes toward preservation among park residents, other stakeholders have not been as receptive. In particular, RomSilva (the Romanian forest 
service) is more focused on exploitation than preservation of the park's forested lands and has resisted buying into the application of the protected area management concept to the Apuseni Natural Park (Mos, pers. comm., 2006; Persoiu, pers. comm., 2007). The draft management plan itself, however, aggressively promotes resource preservation rather than resource exploitation (draft management plan, 2006). The nature of RomSilva's official mission and the high potential economic value of timber products made from park trees suggest that the forestry service's institutional attitude toward preservation in the park will be difficult to change; for this reason, some park administrators are actively pursuing the possibility of severing the park's official (and subordinate) relationship with RomSilva. However, such an approach could be counterproductive, especially if the park management lacks RomSilva's access to the various levers of Romania's federal government. Romania's forests are an important natural resource; RomSilva's control over them (and, by extension, the revenue their exploitation would generate) is in and of itself a source of significant political power. It seems unlikely that, in the event of a separation, a newly-independent park administration would have the political resources to prevent RomSilva from doing as they like in the park. For that reason, a more constructive engagement with RomSilva should be considered, though it seems that the forestry service has little motivation for agreeing to such an engagement.

Enforcement authority is also a significant potential obstacle to the success of the management plan. Some stakeholders have asked not whether the park management plan is an appropriate tool with which to protect the karst; rather, the question is whether it can be put into practice and enforced. The lack of enforcement authority is a key problem 
from the standpoint of cave and resource protection. Even if the park administration tells people not to cut down the forest, the management plan and Romanian law do not provide the authority to actually prevent anyone from doing so (Apuseni Park draft management plan, 2006; Persoiu, pers. comm., 2007). Certainly, the park management plan carries with it the imprimatur of the Romanian government. The establishment of the park itself it rooted in the legal authority provided by a government order issued in 1990 (MAPPM Order no. 7/1990). The park management plan draws upon Romanian federal law (Law No. 462/2001) as the legal basis of its authority, with various other federal laws, orders and government decisions providing a legal framework for day-to-day operations of the park and the implementation of the plan. Unfortunately, without the ability to impose significant fines or other penalties, the park is not likely to have much success in preventing illegal timbering operations or illegal resort home construction within its boundaries.

Another example of the difficulty faced by park administration can be found in a disagreement between park management and the Romanian speleological clubs that operated within the park. Traditionally, the discovery of a new cave in the park did not result in the cave becoming the private property of the discoverer. Instead they remained (with some exceptions) in the public domain, which meant that anyone could access them. Management of these caves fell to the caving clubs. Each club had its own "territory" within the park, and each club was responsible for the caves within its territory. Speleologists affiliated with one club could still enter caves in other clubs' territories; however, by convention they mapped only the caves within their clubs' territory. Currently, the Romanian Academy of Sciences grants permission to enter 
protected area caves. Previously, when the park was first established, the park administration wanted to take control of all caves; this naturally would have included handing over the keys. The speleological clubs disputed the legal right of the park to do this, based on a different interpretation of the relevant Romanian law. The dispute was resolved by permitting the clubs to retain control over the keys, with the clubs agreeing to notify park management when they decide to enter a particular cave. The arrangement seems to be a workable one, but periodically the park administration suggests it might prefer to increase the level of control they are able to exert over the caves (Persoiu, pers. comm., 2007).

\section{Summary}

It seems clear that the Apuseni Natural Park faces many of the same issues that have been faced by other nature parks and addressed via management plans in karst regions throughout the world, going back to at least 1970 with Mammoth Cave National Park's first master plan - in particular the vexing question of balancing karst protection with increased visitor access. The current version of the Apuseni Natural Park management plan is only the first version, with updates planned at five-year intervals, as required by Romanian law. This version of the plan is not very restrictive; this is partially due to the fact that the park administration is still trying to generate goodwill among the park residents by not placing undue burdens on their efforts to develop and improve their own local economy. Rather, park managers are exploring the use of other tools to control development within the park, including local development plans and general environmental protection legislation (Mos, pers. comm., Feb. 2007). 
In terms of karst protection techniques, the Apuseni plan differs from the western plans discussed earlier only in the level of detail; four of the five plans examined here use cave classification systems, which are relatively well-developed in the western plans. By contrast, the Apuseni plan hinges on a simple, four-category cave classification system within a broader system of zoning intended to identify and protect larger tracts of land. This zoning system is designed to drive land use patterns and trends within the park, and can therefore act as a more indirect method of protecting the park's karst. Such a dual system could prove to be workable in the context of simultaneously managing development and protecting the park's natural resources, provided the resources and authority for enforcement are present.

From that perspective, the Apuseni plan seems to compare well with the more mature, western plans described earlier, especially considering that this is the first attempt at developing such a plan for the Apuseni Natural Park (Table 9-1). However, I think there are other, more structural problems that relate to the potentially conflicting objectives of natural environment protection and local economic development. Active pursuit of both of these goals could easily result in neither being achieved; what seems more likely is that natural environment protection will suffer at the hands of economic development. Certainly we can already see an example of this in the fact that RomSilva does not abide by the spirit of the plan and continues to exploit the forest resources in a way that is not consistent with the protected area concept (according to section 3.2.4.1 of the Apuseni draft management plan, forestry issues are addressed in separate Forestry Plans, which had yet to be revised at the time the draft was published). This activity is the result of two factors: the inherent conflict that exists between the plan's main goals, and 
from a lack of enforcement authority over RomSilva, which in fact has authority over park management. These do not appear to be issues that can be resolved through future drafts of the park management plan; intervention at higher levels of government may be necessary (i.e., either separating the park service from RomSilva or more constructively engaging the forestry service; improving the park service's ability to enforce its own rules).

The ultimate problem is that neither the issue of economic growth nor the issue of resource protection can be ignored. The economic problems facing the park's 10,000 residents are very real, and would only be exacerbated by too-strict controls on the use of park land and other natural resources. Yet the karst contained within the park's borders is unquestionably valuable, from scientific, ecological and aesthetic viewpoints. It is possible that the draft management plan takes too traditional an approach, one designed with only (or primarily) natural resource protection in mind. Achieving both goals simultaneously may require a completely new approach. 
Table 9-1

Park management plans discussed in this chapter

\begin{tabular}{|c|c|c|c|}
\hline Park name & Country & $\begin{array}{l}\text { Unique conditions } \\
\text { in park }\end{array}$ & $\begin{array}{l}\text { Distinguishing } \\
\text { features of plan }\end{array}$ \\
\hline $\begin{array}{l}\text { Apuseni Natural } \\
\text { Park }\end{array}$ & Romania & $\begin{array}{l}\text { Relatively high }(\sim 10,000) \\
\text { indigenous population } \\
\text { with little access to jobs or } \\
\text { economic growth } \\
\text { opportunities }\end{array}$ & $\begin{array}{l}\text { Attempts to balance } \\
\text { natural resource } \\
\text { protection with } \\
\text { development of } \\
\text { economic opportunities } \\
\text { for park residents }\end{array}$ \\
\hline $\begin{array}{l}\text { Yorkshire Dales } \\
\text { National Park }\end{array}$ & UK & $\begin{array}{l}\text { Large local population } \\
(\sim 20,000) \text {; encroachment } \\
\text { on traditional lifestyles }\end{array}$ & $\begin{array}{l}\text { No specific karst or } \\
\text { cave management } \\
\text { components at all; very } \\
\text { broad-based approach } \\
\text { to accomplishing } \\
\text { economic development } \\
\text { and environmental } \\
\text { preservation goals }\end{array}$ \\
\hline $\begin{array}{l}\text { Mammoth Caves } \\
\text { National Park }\end{array}$ & US & $\begin{array}{l}\text { Highly developed caves; } \\
\text { very high levels of tourist } \\
\text { traffic }\end{array}$ & $\begin{array}{l}\text { Uses a combination of } \\
\text { land classification and } \\
\text { cave classification to } \\
\text { manage karst resources }\end{array}$ \\
\hline $\begin{array}{l}\text { Mole Creek Karst } \\
\text { National Park and } \\
\text { Conservation Area }\end{array}$ & Australia & $\begin{array}{l}\text { Park lands are disjointed } \\
\text { and non-contiguous, } \\
\text { making effective karst } \\
\text { protection more difficult }\end{array}$ & $\begin{array}{l}\text { Requires and facilitates } \\
\text { cooperation between } \\
\text { park management and } \\
\text { owners of surrounding } \\
\text { lands }\end{array}$ \\
\hline $\begin{array}{l}\text { Naracoorte Caves } \\
\text { National Park }\end{array}$ & Australia & $\begin{array}{l}\text { Sole purpose for the } \\
\text { park's existence is to } \\
\text { protect and manage the } \\
\text { local caves }\end{array}$ & $\begin{array}{l}\text { Resource protection } \\
\text { generally takes } \\
\text { precedence over public } \\
\text { access to caves }\end{array}$ \\
\hline
\end{tabular}




\section{Conclusion: Moving Toward a Framework for Karst Land Use Regulations \\ Introduction}

In the preceding chapters, I have presented the results of research into karstrelated land use regulation involving three separate study areas and a survey of land use professionals from across the United States. The goal of these studies was to answer the question of whether the impacts of karst land use regulations on human and social systems are significant enough to merit consideration by land use planners and professionals during the regulation writing and implementation process. In the course of answering this overarching question, I addressed five separate research questions:

- How do local karst land use regulations differ across the US from state to state or region to region?

- What can the attitudes, opinions and experiences of planners explain about local karst land use regulation?

- Do setback ordinances have a perceptible effect on housing density?

- Is it worthwhile for planners to engage in strategic behavior in the regulation development process?

- How can social and economic factors affect the development of protected area management plans?

Conclusions drawn from the answers to these questions include the following: 
- In the United States, karst-related land use regulations are often similar, if not identical, to other regulations found elsewhere in the same state. This suggests that municipalities may be more concerned with implementing regulations that will withstand legal challenges within their own states than they are with developing regulations that are carefully suited to the specific physical nature of the karst system below.

- There does not seem to be any relationship between levels of urbanization and regulatory methods used, or indeed between urbanization and the very existence of karst regulations or ordinances. Several large, highly urbanized areas on karst have nothing more than rudimentary karst protections on the books; in many cases there are no regulations whatsoever. Conversely, some rural municipalities have taken more proactive approaches to regulating development on karst terrains. However, it should be noted that the data do not support the presence of an inverse relationship between government sophistication and regulatory sophistication.

- Stormwater runoff is a very common way_indeed, perhaps the most common way - to regulate land use on karst terrains in the United States.

- Overlay zones can be found in rural settings as well as urban areas. This is surprising, as it seems reasonable to expect that issues of human-karst interaction in less-populated areas could be resolved with less intrusive regulatory tools than the overlay zone.

- Employing mandatory setbacks as a regulatory tool is a more common choice for municipalities with more extensive karst formations. Setback or "no-build" 
ordinances can be an effective way to limit or control structural density when applied to areas where sinkholes are prevalent.

- Planners' attitudes toward karst land use regulation seem to have an influence on whether or not such regulations are implemented in the first place.

- The expected results of karst regulation, particularly "secondary effects" like changes in population density or growth rates, often are not observed in municipalities where such regulations are implemented.

- Higher levels of input into the regulation process from non-elected, technical professionals (for example, geologists, engineers, hydrologists) do not lead to inherently more restrictive regulations.

- No clear relationship can be identified between the restrictiveness of the regulations and the identity of the initiator of the regulation implementation process.

- "Reactive" regulations - in other words, those that are implemented to address a specific problem that is already occurring — tend to be more restrictive than preventative regulations.

- Often, planners believe that karst regulations are effective methods of achieving a particular goal, even if they haven't actually witnessed it.

- The presence of setback-style karst land use ordinances is correlated with lower housing densities in sinkhole-prone areas. However, higher housing densities are also correlated with higher sinkhole densities.

- Strategic behavior does not seem to be an issue in the process of deciding whether or not to implement karst land use regulations. Indeed, analysis 
suggests that there is no rational reason to engage in such strategic behavior in the first place, since the presence of karst-aware land use regulations does not appear to put a municipality at an economic disadvantage relative to neighboring towns that do not employ such regulations.

- In areas where local populations are more heavily dependent on natural resource exploitation as an economic foundation, attempts to manage and protect the local karst could very easily interfere with economic development for the local population. Successfully achieving both goals may well require an approach that differs from the traditional protected area approach.

Ultimately, the role of regulation in karst terrains is twofold: first, to protect human-built structures from damage caused by some of the more hazardous aspects of karst terrains, like sinkholes or flooding; and second, to mitigate and prevent damage to local karst systems and the resources (for example, groundwater supplies or tourist attractions) that they provide. The research described in previous chapters shows that there is no single, unified approach to the implementation of this type of regulation, and that these differences cannot be completely explained by factors such as region, population, the extent of the local karst system, or the nature of the specific karst-related issues. Nor are the impacts of karst regulations clear and unambiguous: this research also suggests that the results of implementing karst-aware land use regulations are often not the results expected by planners or other land use professionals.

By examining a wide range of karst-aware regulatory techniques in diverse settings (including highly urbanized and isolated, rural environments), this dissertation acts to connect much of the existing research on land use in karst terrains under a single, 
unifying umbrella, while simultaneously offering new insights into the development of these regulations and their impacts on the human settlements that choose to implement them. Most of the prior research into karst land use regulation focused on a single type of regulation or a particular environment, like protected area management, and generally has produced a great deal of valuable knowledge about karst management under specific conditions: In protected area management, see Urich, Day and Lynagh (2001), who describe how conflicts between federal governments and local populations can develop in lands subject to protected area management plans; or Jepson et al. (2002), who note the inverse correlation between a landscape's economic potential and the likelihood that resource protection efforts will be successful. Likewise, Dinger and Rebmann (1986), Butler (1987), Dougherty (1993), Fischer (1997), Davis (1997), Reese et al. (1997) and Barner (1999) all examine karst-aware land use regulations in specific locations, each studying different stages of the regulatory process as it unfolded in different locations. Several of the authors listed above examine karst land use regulations from a historical or developmental perspective: motivations ranged from protecting local groundwater supplies to flood prevention to a desire to reduce legal action against the city. None of these motivating factors is unique to any of the locations in which these studies were conducted; each author treats each case study as an isolated incident, without placing the regulation in the wider context of karst land use regulation. Davis (1997) conducted a wider-ranging study, in geographical terms; however, his study was limited to regulations governing landfills in karst terrains. Fischer (1997) used his vantage point as a land use planning practitioner to evaluate several different approaches to karst land use regulation in Pennsylvania and New Jersey, and determined that the NNJRC\&D model ordinance 
was best able to balance competing demands (economic and environmental), and therefore offered the best chance of success. It is worth noting that Fischer's and Davis' approach differs from the others in that theirs were more broadly-defined study areas; the other papers discussed in the previous paragraph were much more localized in their foci. Other authors (Rubin, 1992; LaMoreaux et al., 1997; Richardson, 2003) have undertaken analyses of karst land use regulation on a regional or nationwide level; however, out of necessity these efforts tend to take a very broad view, and do not generally delve into the details of karst land use regulation.

This pattern—narrowly-focused, detailed studies of a single location existing side by side with broad, general analyses of the state of karst regulation on a regional or national level—is repeated throughout the karst policy literature; however, to date there has been little effort to integrate this knowledge into a broader understanding of karst land use regulation in general. This dissertation represents an effort to begin to bridge that gap, as it were, by combining both types of studies; indeed, in doing so we are presented with a muddier picture than we might have expected, with some results that are at first unclear, or even seem to contradict each other. Many of these results provide promising avenues for future research, which are discussed at the end of this chapter. Additionally, this dissertation relies on quantitative methods for many of its conclusions. For the most part, research methods into karst and land use have been primarily qualitative (though it should be noted that other branches of karst studies have highly developed quantitative traditions). This study makes a serious attempt to quantify the impact of karst regulations on local growth and on home values, as well as the impact of setback regulations on structural density in sinkhole-prone areas. It is my hope that this 
work may lead to further development of quantitative techniques for analysis of karstrelated land use issues.

Karst regulations are not developed and implemented in a vacuum. There must be a perceived threat, either to or from the karst formations underlying a municipality that chooses to regulate land use in this way. The results discussed here offer insight into the role of humans in generating or exacerbating threats to karst landscapes, or reacting to threats posed by those landscapes. This clearly fits White's approach to geography (White, 1993), and extends the tradition in the discipline epitomized by White, Marsh (1864) and Sauer $(1925 ; 1956)$. It also fits within and advances the developing tradition of karst studies at the University of South Florida, in that it is a large-scale interdisciplinary study of human-karst interaction that draws heavily from both the physical and social sciences to generate its results.

In this chapter, I will pull these results together in such a way that a clearer understanding of karst-aware land use regulations can emerge. On a practical level, the idea is to identify and discuss the contributions of various inputs into the land use regulation process in a way that enables planners or other land use professionals to make sensible, research-based decisions on how such legislation or regulation should be constructed in their own jurisdictions. But the larger goal is to further develop our understanding of how humans react and how human settlements change in response to both the presence of karst, and to the use of this particular type of land use regulation.

Indeed, it should be emphasized that what is presented in this chapter is not intended to be viewed as a completed framework, and instead should be considered a work-in-progress or a starting point, as there is certainly much work yet to do. For 
example, there are almost certainly some variables that are not examined within this dissertation that may warrant inclusion once more research has been conducted. Also, it should be clarified that it is not my intent to offer a step-by-step recipe for implementing karst-aware land use regulations, or a "fill-in-the-blanks" template for such regulations, along the lines of the Northern New Jersey Resource Conservation and Development Council document discussed in Chapter 5 of this dissertation. That document is successful because it is intended for communities in a particular region, where geologic conditions and other variables do not differ widely between towns. On the other hand, this dissertation adheres to the premise that communities located in karst areas in different regions will have different needs to consider, as well as different initial conditions and different influences on the policy process.

\section{Application of system theory}

As discussed in chapters 3 and 4 of this dissertation, system theory is a flexible framework for analyzing causal relationships between related components. While there have been valid critiques of the explanatory power of system theory, Boulding's (1964)

position that general system theory is more a matter of perspective and a way to look at the world than it is a body of doctrine provides the grounding for the application of this particular theoretical body of knowledge.

Ultimately, the subject under examination in this dissertation is a system of systems: it is the interaction of karst systems and two types of human systems - specifically urban systems, or at the very least clustered settlements, and policymaking systems. The components of karst systems include limestone or carbonate bedrock, precipitation, temperature, and carbon dioxide derived from organic material (this is usually found in 
the overburden, but not always) (Figure 10-1). Urban system components include humans, land, artificial structures, economic inputs, outputs, and byproducts (including fertilizers, industrial wastes and pollution, trash generated by packaged consumer goods), and other wastes. When urban systems are located above or very near to karst systems, the two systems interact to become a single system (i.e., groundwater is withdrawn to help fuel growth; land subsidence damages artificial structures and opens new pathways from the surface to the aquifer; more surface-level pollutants end up in the groundwater). Urban systems are also usually at least partially governed by constraints and rules, at least in practice if not necessarily in theory. These constraints are produced by the local policymaking system, the nature of which can differ greatly from locality to locality. In general, inputs include public opinion, business and economic interests, ambitions and goals of the policymakers themselves, and specialized technical analysis. This is a very broad generalization, of course; in many places, the local policymaking system is quite complex. Ultimately, these constraints can be produced by policymaking systems to govern or regulate the ways in which an urban system interacts with a karst system.

Certainly, urban systems, karst systems and policy systems meet several of the traditional definitions of systems. Both types of systems are a set of interrelated elements, as per von Bertalannfy (1973). The system under examination in this dissertation includes the components and interrelationships of all three of these systems. As von Bertalannfy (1973) points out, all living systems are open systems; the system under examination here is as well. Forces and entities external to the system are able to provide inputs and influence the end state. Beyond the simple open / closed system dichotomy, this system meets the definition of a mechanical system (systems that are driven by changes to a set 
Figure 10-1

A karst system

(Not to scale)

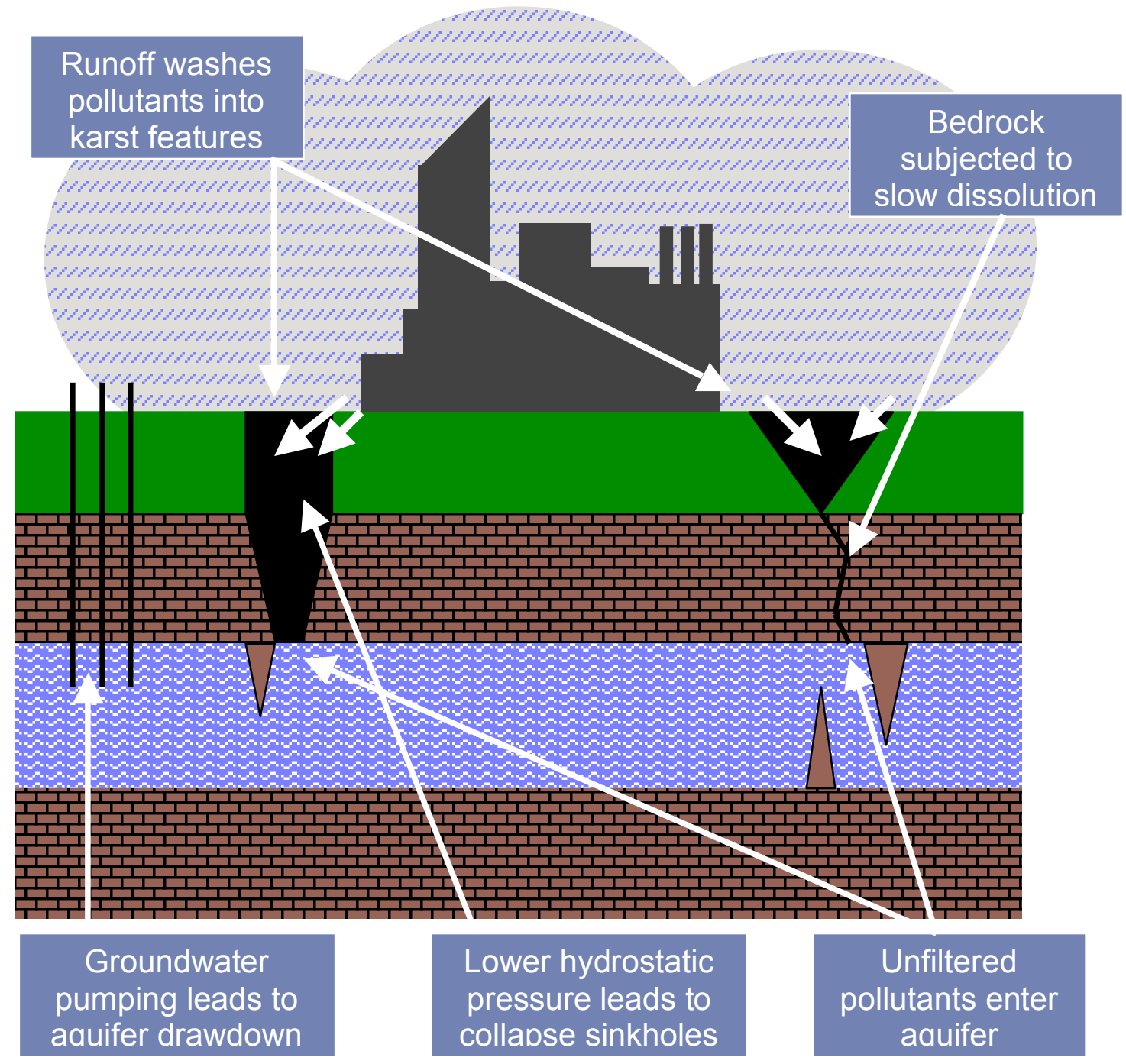


of relatively simple parameters). It could also be argued that it meets the definition of a social system as well; however, while social systems do address the interaction of humans with their physical artifacts, they also tend to emphasize symbolic artifacts as well, which are not as important here.

The most significant difficulty in applying system theory to this research is that the most important component of the system-humans - is also its least predictable component (von Bertalannfy, 1973). However, this is perhaps the single most common difficulty in conducting research in any of the social sciences, and should not stand in the way of drawing sound conclusions from the data gathered here.

\section{Inputs}

In the preceding chapters, I examined the effects of certain inputs into the karst land use regulating process and their impacts on both the regulations themselves and the human systems to which they were applied. Specifically, I explored how setback-style sinkhole ordinances affect residential structural density in sinkhole-heavy areas; I examined whether there were economic incentives for policy makers in Pennsylvania to engage in strategic behavior when deciding whether or not to implement karst-aware land use regulations; and I looked at the challenges facing karst protection efforts in Romania's Apuseni Natural Park, in particular those relating to a lack of enforcement authority. I also examined the perceived impacts of karst-aware land use regulations, as viewed from the perspective of planners, geologists and other land use professionals in the United States.

Figure 10-2 depicts a general conceptual framework of the process of karst-aware land use regulation; it is highly generalized, and the specifics will vary widely from 
Figure 10-2

The karst regulatory process

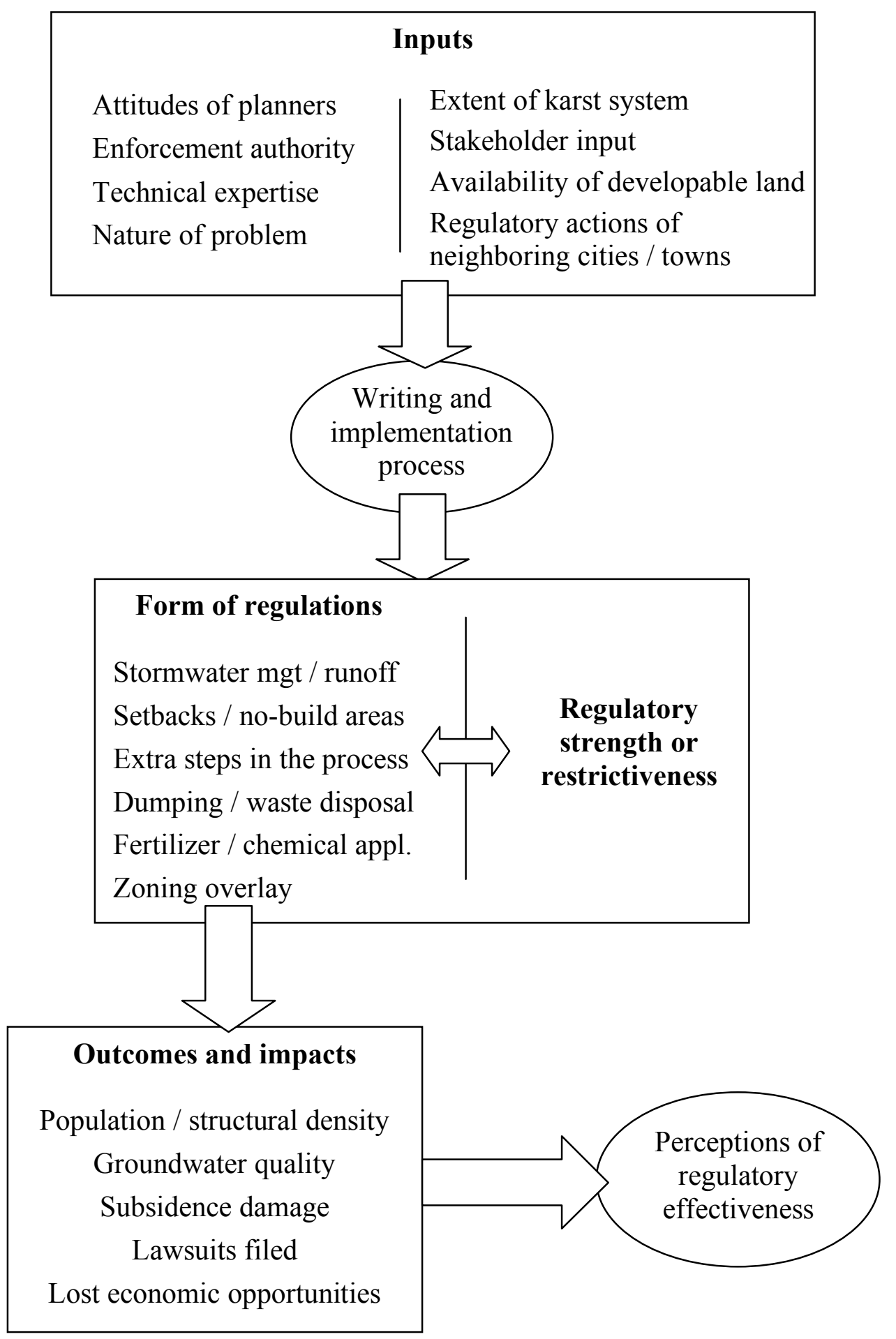


locality to locality. I will begin with an examination of a group of inputs into the regulation development process. The discussion is limited to a handful of inputs that I considered important for one of two reasons: each input was either a significant factor in the process of writing and developing these regulations, or it seems to have an unexpectedly weak impact on the process. Precisely quantifying the significance of each input to the system is almost certainly an impossible task; indeed, it is challenging enough to simply identify each input. However, based on the results of the research described in the preceding several chapters, we can see that some inputs generally seem to have greater impact on the regulatory process and results than others. Some of the more interesting inputs from both groups are described in this section.

Technical expertise: In Chapter 6, input from non-elected professionals like geologists and hydrologists was cited by a large number of respondents as being a critical factor in the development of karst-related land use regulations. This is unsurprising, as Sabatier (1988) emphasized the importance of specialist knowledge ("policy-oriented learning") in his Advocacy Coalition Framework of the policy process. My results suggest that consulting technical experts has significant benefits (i.e., acquisition of the theoretical and practical knowledge required to target and design effective karst-related regulations) that are not accompanied by significant drawbacks (these professionals do not seem to be inclined to promote excessively restrictive regulations, even as their influence over the process increases). But because of the generally intangible nature of the benefits of technical expertise, its impact on the regulation writing and implementation process is almost impossible to quantify. There do seem to be some tangible results of higher levels of influence from non-elected professionals: Survey 
results also show that the use of extra steps in the permitting process, of dumping and waste disposal regulations, and of fertilizer and chemical application regulations is more frequent in municipalities where non-elected professionals were more influential on the karst land use regulation process.

Attitudes of planners and land use professionals: The survey results in Chapter 6 demonstrated that the attitudes of land use professionals are critical in the process of crafting and implementing karst land use regulations. Most generally feel that regulating development on karst or near karst features is appropriate; opinions diverge on the question of what will happen as a result of any such implementation. As was demonstrated in Chapter 6, counties, cities and towns without karst-aware land use regulations on the books are more likely to employ land use professionals who expect karst land use regulations to result in mostly negative outcomes than are municipalities where such regulations can be found. Planners and land use professionals must be convinced that benefits will accrue, or the regulations are highly unlikely to get off the ground; this is almost certainly due to their role as "gatekeepers" in the process.

Enforcement authority: The experience of the authors of the Apuseni Natural Park's management plan demonstrates that enforcement authority is also crucial, a point raised within the protected area context by Jepson et al. (2002) and Kueny and Day (2002). Without the ability to enforce karst protections, stakeholders with an incentive (particularly a financial incentive) to ignore regulations are very likely to do exactly that. Outside of a protected area context, both the existing literature (Day, 1996; Jepson et al., 2002; Kueny and Day, 2002) and interviews suggest that enforcement authority is also a factor in karst land use regulation in non-protected areas in the US; for example, a 
comprehensive plan that attempts to control growth in carbonate areas is not likely to be effective absent a zoning ordinance to implement and enforce the priorities of the comprehensive plan. Additionally, subdivision and land development ordinances with karst-related components are easier to waive than zoning ordinances, and thus do not provide the same level of protection or enforcement authority.

Nature and "framing" of the problem: The nature of the specific karst problem quite naturally has a strong influence on the character of the land use regulations; addressing a groundwater contamination issue, for example, would require a different (if partially overlapping) set of tools than addressing a land subsidence problem. Results from the survey suggest that developing and implementing karst regulations is more likely to succeed if the underlying problem is highly visible, and if the proposed regulations can be readily connected to that specific problem. But even when the problem is visible and urgent, regulation can die on the vine if it is not properly framed. Contamination of groundwater resources and structural damage from land subsidence seem to be effective ways to frame the problem.

Stakeholder input: In this case, the term "stakeholder" is given a broad definition, and includes both local residents and those with an economic interest in the location (i.e., the construction industry, or resource users). The influence of each group of stakeholders varies widely. My results suggest that, for the most part, local residents do not seem to have a major influence on the development and implementation of karst regulations; the ones who do, are generally the ones who are both well-informed and most likely to be affected by such regulations. This group may not be representative of the general population. Data collected from follow-up interviews indicate that this can 
change with time, through public education programs; one respondent argues that such education programs can help preserve the regulation itself by mitigating any shifts in political priorities that occur with changing administrations (for example, a new mayor may be more sympathetic to the perspective of the construction industry than her predecessor; in that case, a voting public with a well-developed understanding of karst and the need for its protection can act as an obstacle to weakening existing regulation).

Follow-up interviews indicate that the construction industry is generally hostile to such regulations; however, the survey results suggest the industry is not always able to exert a significant amount of influence over the process (whether this is by choice or not is unclear). According to the survey, in some cases (less than 20percent) construction interests are the most influential group in the process of developing regulations, but the construction industry was one of the least-frequently selected responses for the question of which group or entity had the most influence on the process. This strongly suggests that construction industry opposition can be overcome by those wishing to implement karst-related land use regulations, and fear of such opposition should not be a major factor in the process of developing karst-aware land use regulations.

Extent of the karst system: The size of the underlying karst system seems to play a role in determining the form of the karst-aware land use regulations that are ultimately implemented, but not on the restrictiveness of those regulations. According to the survey results in Chapter 6, municipalities with more extensive karst systems were more likely to employ mandatory setbacks / non-buildable areas and dumping / waste disposal regulations than those with less extensive karst; simultaneously, there is no 
strong connection between the extent of a particular karst system and the strength of the karst regulations that are ultimately implemented.

"Keeping up with the neighbors," or the need for strategic behavior: It is appropriate to take into consideration what neighboring municipalities have done with regards to regulating development on karst terrains, but only to a point. Follow-up interviews with planners and land use professionals suggest that the experiences of other towns can be illuminating in identifying effective regulatory techniques for preventing karst degradation and aquifer damage. One reason for this is that towns in close proximity to each other are more likely to be subject to the same external influences (geologic, economic, political, etc). However, results from Chapter 8 suggest that there is little reason to consider the mere existence of such regulations in neighboring towns as a factor in deciding whether to implement karst-aware regulations or not, as they seem to have no statistically detectable impact on indicators of economic growth and health; additionally, results from the survey confirm that this is generally understood by land use professionals to be the case. This contradicts expectations rooted in economics and game theory, and may indicate that karst regulations are generally not sweeping enough to have a widespread impact on growth and development patterns.

\section{Outcomes}

This dissertation does not examine the effectiveness of karst-aware land use regulations with respect to karst protection, or at least not directly (i.e., through water quality tests, or quantifiable measures of cave protection). Instead, it looks at indirect measures of the effectiveness of karst protection, generally in terms of regulatory impact on human systems and human behavior. This includes settlement patterns, density, and 
economic considerations, among others. This section includes discussion of these outcomes and their implications.

Expectations and perceived outcomes: Survey results and follow-up interviews indicate that the most commonly observed outcomes of implementing a set of karst-aware land use regulations are a decline in damage from subsidence, and an improvement in groundwater quality. However, as was shown in chapter 6, these outcomes are expected to occur more frequently than they are actually reported to occur. Whether this is due to inadequate methods of regulation or something else is not yet known; indeed, it is not even known if these perceptions are in fact accurate. It is entirely possible, for example, that groundwater quality improves far more frequently than survey respondents reported. This suggests that expectations for the benefits of implementing karst-related land use regulations may be too high, perhaps leading to an eventual consensus that the regulatory route is not adequate for managing development on karst, and that the benefits of these regulations are not worth the time and effort of implementation.

Lawsuit prevention: According to survey results and follow-up interviews, karstsensitive land use regulations seem to be an effective way to discourage lawsuits filed against the city or county. Typically, these lawsuits arise from unanticipated land subsidence activity that significantly damages property. In Lexington-Fayette County, for example, reducing lawsuits filed against the county was an explicit goal of the development and implementation of the county's sinkhole ordinance (the ordinance takes the form of a minimum setback / non-buildable area restriction); the ordinance has been successful in this goal (Rebmann, pers. comm., 2006). The presence of such ordinances or similar regulations may make it more difficult for potential plaintiffs to successfully 
argue that any subsidence damage to structures built near a sinkhole is actually the city's fault for negligently issuing a building permit for an unsafe area.

Economic growth and development: Higher housing costs and lost development opportunities were both cited by several respondents to the survey as expected outcomes of implementing karst regulation. However, the same survey results indicate that these outcomes are not often observed. While it is true that both of these outcomes are difficult to quantify, or at least present difficulties in identification of the primary cause, it is still possible to draw some conclusions from the data gathered in this dissertation. Data from karstic areas in Pennsylvania suggest that the implementation of karst regulations does not, in fact, have a statistically significant impact on median housing value within the community. As for lost opportunities for development, these can be directly tied to karst regulations only via anecdotal evidence at best. However, if we use the total number of residential building permits issued by each town as a proxy variable for development opportunities, we see there is once again no statistically-significant difference in the number of permits issued between municipalities that regulate development on karst and those that do not.

What are the implications of this finding? There are several possibilities. First, the fact that karst regulations do not seem to affect median housing value suggests that perhaps the "amenity factor" of more open space that should result from implementation and enforcement of karst land use regulations is generally not an important consideration in a market-based determination of home values. Conversely, the land use restrictions imposed by karst land use regulations do not seem to act as a drag on home values either. Residential building permit data suggests that karst regulations do not generally dampen 
demand for new housing, or encroach on the profitability of new residential projects. Perhaps the residential construction industry is better able to adapt to external conditions and forces than is widely assumed; it is also possible that the regulations are generally ineffective, go unenforced, or have only limited geographic applicability (and therefore only limited impact).

Population and structural density: Responses from the survey suggest that even though a sizable minority of respondents expected to see population density decrease as a result of implementing karst regulations, very few actually observed this outcome. However, if we look at block-level data from municipalities in Kentucky and Missouri, we see the expected relationships between sinkholes with mandatory setbacks and population / structural density (i.e., areas with lots of sinkholes are less dense). There is a counter-intuitive component to these results, namely the positive correlation between sinkhole density and residential structural density; however, there are several potential explanations for this phenomenon (discussed at the end of Chapter 7).

The results from Chapter 7 suggest very strongly that, up to a point, setback and non-buildable area ordinances do act as a drag on density growth rates in sinkhole-prone areas. So why wasn't this outcome reported more frequently? The answer to that question may lie in the fact that these effects are simply too localized to be widely noticed, or that changes in density are perhaps too subtle and occur over too long a time period to be accurately perceived by most casual observers on the ground.

Regulatory strength and restrictiveness: Most survey respondents describe their local regulations as either "not very restrictive" or "somewhat restrictive." There is some relationship between perceived restrictiveness and the increased rates of implementation 
of many commonly applied regulatory tools (this relationship does not apply to stormwater runoff regulations, which are almost universally applied); however, whether or not regulatory restrictiveness has any tangible impact on the urban system itself is an open question. Using my own (admittedly subjective, but consistently applied) definition of regulatory restrictiveness and applying it to my Pennsylvania data, I found that restrictiveness (represented by the strong binary variable) had no impact on either median home values or on the number of residential construction permits issued.

Form of regulations: Survey results suggest that stormwater runoff regulations are the easiest type of karst-related land use regulation to get implemented; follow-up interviews indicate that the reason for this is the straightforward nature of the problems they generally address, as well as the straightforward nature of the regulations themselves. Respondents seem to generally feel that, if done properly, stormwater runoff and management ordinances can be effective tools in karst land use regulation. They are extremely common in Pennsylvania local land use regulation, possibly the most common.

While mandatory setbacks / non-buildable areas are based on a similarly straightforward idea, interviews suggest that it can be difficult to make these effective, unless it's difficult for developers and landowners to get variances. In order for that to occur, the body responsible for issuing variances must be sympathetic to the goals of regulating land development and use in karst areas; it also must have the ability to resist political pressure to grant variances in cases where a variance would be inappropriate (Interview, Rebmann, 2006). However, statistical analysis conducted in Chapter 7 suggests otherwise, that in fact these ordinances can have some effect on human density near sinkholes. 
Follow-up interviews suggest that zoning ordinances may often be too blunt a tool for karst-related land use regulation. This is due to the oft-localized nature of karst landform development; regulations intended to manage development near such landforms may not be appropriate for all development in a given area. Instead, it may be best to use less intrusive methods, like stormwater and runoff management, when they are appropriate.

\section{General conclusions}

Speaking more generally, the research conducted in this dissertation finds scant evidence to support anti-regulation argument based on loss of economic growth opportunities in urban locations. The extent to which karst regulations have any effect at all on human systems varies widely from location to location, and in some cases seems undetectable. It is difficult to pinpoint the exact reasons why this might be, though some possibilities are a lack of enforcement, generally weak regulations, or generally low costs imposed by this type of regulation. An exception to this general rule can be found in some cases where the local economy is or could be based on the extraction and exploitation of natural resources; certainly, any karst-related regulations implemented in this context will have an impact on the local economic system. That notwithstanding, it seems that planners and policymakers generally should not overestimate the potential economic impacts of karst regulations, and should use the benefits of protecting the karst as their primary metric when drafting these regulations and ordinances.

\section{Future research needs and directions}

At the beginning of this chapter, I emphasized that these conclusions should not be considered a comprehensive, finished framework for developing karst land use 
regulations. There is still plenty of work to be done in our goal of understanding the relationship between karst systems, urban systems and policy systems. Some potentially promising avenues for future study include:

- A more generalized approach to the understanding of how karst regulations are affected by constraints on the availability of developable land. While the results from Lexington-Fayette County are clear, it is by no means obvious if those results are applicable to other cities where land availability is constrained. It would be particularly useful to look at cities where these constraints are the result of the surrounding natural landscape, as opposed to artificially-imposed constraints like an urban growth boundary.

- A more detailed understanding of the economic impacts of implementing karst-aware land use regulation. In particular, a study of how such regulations affect commercial and industrial development projects would be illuminating.

- An examination of the effectiveness of different types of land use regulations, in terms of how well those regulatory tools protect karst landforms and aquifers.

- An examination of how well karst-aware land use regulations are actually enforced. 


\section{References}

1. Abrudan, Ioan; Turnock, David. 1998. A rural development strategy for the Apuseni Mountains, Romania. GeoJournal, v. 46, pp. 319-336.

2. Pennsylvania State Planning Code, Act 247. 1967.

3. Allentown, PA, Code of Ordinances, 12779 §14. 1987.

4. Alonso, W. 1964. Location and Land Use: Toward a General Theory of Land Rent. Harvard University Press, Cambridge, MA.

5. Ambrose, Brent W. 2003. Urban growth controls and affordable housing: The case of Lexington, Kentucky. Report prepared for the Lexington-Fayette County Human Rights Commission and Lexington-Fayette Urban County Government Division of Community Development.

6. Apuseni Natural Park draft management plan. 2006.

7. Axelrod, Robert. 1984. The Evolution of Cooperation. Basic Books, New York.

8. Back, William. 1983. Degradation of groundwater resources caused by inadvertent land misuse. Relation of Groundwater Quality and Quantity, pp. 181188. Wellingford, Oxfordshire, UK.

9. Barner, Wendell L. 1999. Comparison of stormwater management in a karst terrane in Springfield, Missouri—case histories. Engineering Geology, v. 52, pp. 105-112.

10. Beck, Barry F. 1986. A generalized genetic framework for the development of sinkholes and karst in Florida, USA. Environmental Geology, v. 8, nos. 1-2, pp. 5-18.

11. Berndt, M.P.; Oaksford, E.T.; Mahon, G.L. 1998. Groundwater. In Fernald, Edward A.; Purdum, Elizabeth D. (Eds.), Water Resources Atlas of Florida. Florida State University, Tallahassee.

12. Bethlehem, PA, Subdivision and Land Development Ordinances, 1349.13

13. Betson, Roger P. 1977. The hydrology of urban karst areas. In Dilamarter and Csallany (Eds.), Hydrologic Problems in Karst Regions (), pp. 162-175. Western Kentucky University, Bowling Green, Kentucky.

14. Bickford, Tammy M.; Lindsey, Bruce D.; Beaver, Mark R. 1996. Bacteriological Quality of Ground Water Used for Household Supply, Lower Susquehanna River Basin, Pennsylvania and Maryland. USGS Water resources investigations report 96-4212.

15. Bloom, Arthur L. 1998. Geomorphology: A Systematic Analysis of Late Cenozoic Landforms. Prentice-Hall, Inc. Upper Saddle River, NJ. 
16. Bobrow, D.B.; Dryzek, J.S. 1987. Policy Analysis by Design. University of Pittsburgh Press, Pittsburgh, PA.

17. Bögli, Alfred. 1980. Karst Hydrology and Physical Speleology. Springer-Verlag, Berlin.

18. Boulding, Kenneth E. 1964. General systems as a point of view. In Mihajlo D. Mesarovic (Ed.), Views on General System Theory, pp. 25-38. John Wiley and Sons, New York City.

19. Boulding, Kenneth. 1956. General systems theory: The skeleton of science. Management Science, v. 2, no. 3, pp. 197-208.

20. Brinkmann, R., Parise, M., Dye, D. In review. Sinkhole distribution in a rapidly developing urban environment: Hillsborough County, Tampa Bay area, Florida. Engineering Geology.

21. Brucker, Roger W. 2003. Can the Transpark contaminate Mammoth Cave? In Barry F. Beck (Ed.), Sinkholes and Karst 2003: Sinkholes and the Engineering and Environmental Impacts of Karst, Geotechnical Special Publication no. 122.

22. Buchanan, J.M.; Tullock, G. 1965. The Calculus of Consent. University of Michigan Press, Ann Arbor, MI.

23. Burroughs, W.G. 1926. The Geography of the Kentucky Knobs. Kentucky Geological Survey, Frankfort, KY.

24. Burton, Ian; Kates, Robert W.; White, Gilbert F. 1978. The Environment as Hazard. Oxford University Press, New York.

25. Butler, Kent S. 1987. "Urban Growth Management and Groundwater Protection: Austin, Texas." In Page, G. William (Ed.), Planning for Groundwater Protection. Academic Press, Inc. San Diego.

26. Buza, Mircea; Dimen, Levente; Pop, Grigor; Turnock, David. 2001. Environmental protection in the Apuseni Mountains: The role of Environmental Non-Governmental Organisations. GeoJournal, v. 54, pp. 631-653.

27. Carruthers, John I. 2002. Growth at the fringe: The influence of political fragmentation in United States metropolitan areas. Papers in Regional Science, v. 82, pp. 475-499.

28. Catasauqua Township, PA, Code of Ordinances.

29. Chichester, Douglas C. 1996. Hydrogeology of, and simulation of ground-water flow in, a mantled carbonate-rock system, Cumberland Valley, Pennsylvania. USGS water resources investigations report 94-4090.

30. Crawford, Nicholas C. 2003. Karst hydrogeologic investigation for proposed Kentucky trimodal Transpark. In Sinkholes and Karst 2003: Sinkholes and the Engineering and Environmental Impacts of Karst. Barry F. Beck, ed. Geotechnical Special Publication no. 122.

31. Cvijic, Jovan. 1893. Das Karstphanomen. Geogr. Abhandlungen von A. Penck, Leipzig. 
32. Davies, W.E.; Simpson, J.H.; Ohlmacher, G.C.; Kirk, W.S.; Newton, E.G. 1984. Engineering aspects of karst: U.S. Geological Survey national atlas, scale $1: 7,500,000$.

33. Davis, Darrel Haug. 1927. The Geography of the Blue Grass Region of Kentucky. Kentucky Geological Survey, Frankfort, KY.

34. Davis, S.B. 1997: Interstate assessment of governmental regulations on landfills in karst areas. In Beck, B.F.; Stephenson, J.B. (Eds.), The Engineering Geology and Hydrogeology of Karst Terranes: Proceedings of the sixth multidisciplinary conference on sinkholes and the engineering and environmental impacts of karst, Springfield, Missouri, 6-9 April 1997. Pp. 433-438. A.A. Balkema, Rotterdam.

35. Day and Chenoweth, 2004. Cockpit Country Cone Karst, Jamaica. In Encyclopedia of Caves and Karst Science, John Gunn, ed., pp. 233-235. Fitzroy Dearborn.

36. Day, Michael. 1996. Conservation of karst in Belize. Journal of Cave and Karst Studies, v. 58, no. 2, pp. 139-144.

37. Day, Michael; Reeder, Philip. 1989, Sinkholes and land use in southwestern Wisconsin, in Beck, B.F., (Ed.), Engineering and Environmental Impacts of Sinkholes and Karst: Rotterdam, A.A. Balkema, p. 107-113

38. Day, Michael; Urich, Peter. 2000. An assessment of protected karst landscapes in Southeast Asia. Journal of Cave and Karst Science, vol.27, no.2, pp.61-70.

39. Dery, D. 1984. Problem Definition in Policy Analysis. University Press of Kansas, Lawrence, Kansas.

40. Dinger, James S.; Rebmann, James R., 1986. Ordinance for the control of urban development in sinkhole areas in the Blue Grass Karst region, Lexington, Kentucky. In Proceedings of the Conference on Environmental Problems in Karst Terranes and Their Solutions, October 28-30,1986, Bowling Green, Kentucky, pp. 163-180. National Water Well Association.

41. District Township, PA, Code of Ordinances, 1975.

42. Dougherty, Percy H. 1983. Valley tides-land-use response floods in a Kentucky karst region. In Environmental Karst, pp. 3-15. Geospeleo Publications, Cincinnati, $\mathrm{OH}$.

43. Dougherty, Percy H. 1989. Land use regulations in the Lehigh Valley: zoning and subdivision ordinances in an environmentally sensitive karst region. In Beck, B.F. (Ed.) Engineering and Environmental Impacts of Sinkholes and Karst: Proceedings of the third multidisciplinary conference on sinkholes and the engineering and environmental impacts of karst, St. Petersburg Beach, Florida, 2-4 October 1989. Pp. 341-348. A.A. Balkema, St. Petersburg Beach

44. Dougherty, Percy H., 1993. Karst management through zoning and subdivision ordinances. In Proceedings of the 1993 National Cave Management Symposium, pp. 57-65.

45. Drew, David. 1984. The Effect of Human Activity on a lowland karst aquifer. In Castany, G; Groba, E.; Romijn, E. (Eds.), Hydrogeology of Karstic Terrains: Case Histories, pp. 195-199. International Association of Hydrogeologists. 
46. Drew, David. 1996. Agriculturally induced environmental changes in the Burren karst, western Ireland. Environmental Geology, v. 28, no. 3, pp. 137-144

47. Dreybrodt, Wolfgang. 1988. Processes in Karst Systems. Springer Verlag, Berlin.

48. Dreybrodt, Wolfgang. 2004. Dissolution: Carbonate rocks. In John Gunn (Ed.), Encyclopedia of Caves and Karst Science, Routledge. New York.

49. Duval, Melanie. 2006. Tourism and preservation policies in karst areas: Comparison between the Skocjan Caves (Slovenija) and the Ardeche Gorge (France). Acta Carsologica, v. 35, no. 2, pp. 25-35.

50. Dye, Thomas. 1987. Understanding Public Policy. Prentice Hall, Englewood Cliffs, NJ.

51. Easton, David. 1951. The decline of modern political theory. The Journal of Politics, v. 13, no. 1, pp. 36-58.

52. Elliott, William R. 2005. Protecting Caves and Cave Life. In David C. Culver and William B. White (Eds.), Encyclopedia of Caves, pp. 458-469. Elsevier Academic Press.

53. Elliott, William R. Below Missouri Karst. Missouri Conservationist Online, available at http://mdc.mo.gov/conmag/2000/03/10.htm. Downloaded July 2007.

54. Field, Malcolm S. 2002. A Lexicon of Cave and Karst Terminology with Special Reference to Environmental Karst Hydrology. U.S. Environmental Protection Agency, Washington, DC.

55. Field, Malcolm S., 1992. Karst hydrology and chemical contamination. Journal of Environmental Systems, v. 22, no. 1, pp. 1-26.

56. Fischer, Joseph A., 1997. Limestone ordinances of New Jersey and Pennsylvania: A practitioner's experiences. In The Engineering Geology and Hydrogeology of Karst Terranes, pp. 473-476. A.A. Balkema, Rotterdam and Brookfield, Massachuestts.

57. Fistanic, Ivana. 2006. Sustainable management of brackish karst spring Pantan (Croatia). Acta Carsologica, v. 35, no. 2, pp. 65-72.

58. Fleming, Ronald A. 2001. Land use planning and farm land protection in the Blue Grass. In John C. Bergstrom (Ed.), Current Issues Associated with Land Values and Land Use Planning: Proceedings of a Regional Workshop. Southern Rural Development Center and Farm Foundation.

59. Fleury, E. Spencer. 2007. Are home values affected by sinkhole proximity? Results of a hedonic price model. Florida Geographer, v. 38, pp. 74-82.

60. Fleury, E. Spencer; Carson, Steve; Brinkmann, Robert. In press. Testing Reporting Bias in the Florida Sinkhole Database: An Analysis of Sinkhole Occurrences in the Tampa Metropolitan Statistical Area. Southeastern Geographer.

61. Florea, Lee J. 2006. The karst of west-central Florida. Ph.D. dissertation, Department of Geology, University of South Florida, Tampa, FL.

62. Ford, Derek C.; Williams, Paul W. 2007. Karst Geomorphology and Hydrology. Chapman \& Hall. 
63. Forray, Ferenc Lazar. 2002. Geochemistry of the environment in the areas of mining works from Aries Valley, Apuseni Mountains, Romania. PhD. thesis, Babes-Bolyai University, Cluj-Napoca, Romania.

64. Fratesi, Sarah E.; Florea, Lee; Chavez, Todd; Vacher, H. Leonard. 2006. A snapshot of the body of karst literature. Geological Society of America Abstracts with Programs, v. 38, no. 7, p. 141.

65. Gatzweiler, Franz and Hagedorn, Konrad (eds.). 2003. Institutional Change in Central and Eastern European Agriculture and Environment. The Central and Eastern European Sustainable Agriculture Project.

66. Gerhardt, James; Lazorchick, George. 1984. Evaluation of the Ground-water Resources of Parts of Lancaster and Berks Counties, Pennsylvania. USGS Water resources investigations report 84-4327.

67. Gerhardt, James; Lazorchick, George. 1988. Evaluation of the Ground-water resources of the Lower Susquehanna River Basin, Pennsylvania and Maryland. USGS Water-Supply Paper 2284. USGPO.

68. Gillespie, Thomas D., 1999. The 1994 sinkhole at North 7th Street, Centre City, Allentown, Pennsylvania: sinkhole hazards in the Lehigh Valley and the implications for land use and development decisions. In Economic \& Environmental Geology and Topography in the Allentown-Bethlehem Area: Guidebook for the 64th Annual Field Conference of Pennsylvania Geologists, pp 49-65.

69. Gillieson, David. 1996. Caves: Processes, Development, Management. Blackwell Publishers, Cambridge, MA.

70. Gupta, Dipak K. 1994. Decisions by the Numbers. Prentice Hall. Englewood Cliffs, NJ.

71. Hall, Derek. 2004. Rural tourism development in southeastern Europe: Transition and the search for sustainability. International Journal of Tourism Research, v. 6, pp. 165-176.

72. Hall, Larry E.; Metcalfe, Susan J., 1984. Sinkhole collapse due to groundwater pumpage for freeze protection irrigation near Dover, Florida, January 1977. In Castany, G; Groba, E.; Romijn, E. (Eds.), Hydrology of karstic terrains: case histories. International Association of Hydrogeologists.

73. Hamilton-Smith, Elery. 2006. Spatial planning and protection measures for karst areas. Acta Carsologica, v. 35, no. 2, pp. 5-11.

74. Hanover Township, PA, Code of Ordinances, Chapter 53.

75. Hippe, Daniel J.; Witt, Emitt C.; Giovannitti, Rhonda M. 1994. Hydrogeology, herbicides and nutrients in ground water and springs, and relation of water quality to land use and agricultural practices near Carlisle, Pennsylvania. USGS Water resources investigations report 93-4172.

76. Hofferbert, R.I. 1974. The Study of Public Policy. MacMillan.

77. Ioras, Florin, 2003. Trends in Romanian biodiversity conservation policy. Biodiversity and Conservation, v. 12, pp. 9-23. 
78. Jepson, Paul; Momberg, Frank; van Noord, Hans. 2002. A review of the efficacy of the protected area system of East Kalimantan province, Indonesia. Natural Areas Journal, v. 22, no. 1, pp. 28-42.

79. Kacaroglu, Fikret. 1999. Review of Groundwater Pollution and Protection in Karst Areas. Water, Air and Soil Pollution, v. 113, pp. 337-356.

80. Kambesis, P.; Crawford, N.; Croft, L.A.; Moore, R.; Pfaff, R. 2004 Dishman Lane Collapse, Bowling Green, Kentucky. In Beck, Barry F. (Ed.), Sinkholes and the Engineering Impacts of Karst. Huntsville, AL.

81. Katz, Brian G.; Chellete, Angela R.; Pratt, Thomas R. 2004. Use of chemical and isotopic tracers to assess nitrate contamination and ground-water age, Woodville Karst Plain, USA. Journal of Hydrology, no. 289, pp. 36-61.

82. Kiel, Katherine; McClain, Katherine, 1995. House prices during siting decision stages: The case of an incinerator from rumor through operation. Journal of Environmental Economics and Management: Vol. 28, pp. 241-255.

83. Kingdon, John. 1995. Agendas, Alternatives and Public Policies. HarperCollins.

84. Kochanov, William E. 1999. Sinkholes in Pennsylvania. Pennsylvania Geological Survey Educational Series 11.

85. Kueny, Jeffrey A.; Day, Michael J. 2002. Designation of protected karstlands in Central America: A regional assessment. Journal of Cave and Karst Studies, v. 64, no. 3, pp. 165-174.

86. LaMoreaux, P.E.; Powell, W.J.; LeGrand, H.E. 1997. Environmental and legal aspects of karst areas. Environmental Geology, v. 29 1/2, pp. 23-36.

87. LeGrand, Harry E. 1984. Pollution of karst water in the Ozark region, Missouri. In Castany, G; Groba, E.; Romijn, E. (Eds.), Hydrogeology of Karstic Terrains: Case Histories, pp. 200-201. International Association of Hydrogeologists.

88. Lehigh Valley Comprehensive Plan, 2001.

89. Lexington-Fayette County Comprehensive Plan, 2001

90. Lexington-Fayette ordinance SRA 85-2, 1985.

91. Lindsey, Bruce D.; Loper, Connie A.; Hainly, Robert A. 1997. Nitrate in Ground Water and Stream Base Flow in the Lower Susquehanna River Basin, Pennsylvania and Maryland. USGS Water resources investigations report 974146.

92. Longwood, Stanley M.; Wood, Charles R. 1965. Ground-water resources of the Brunswick Formation in Montgomery and Berks Counties, Pennsylvania. Pennsylvania Geological Survey, 4th ser., Water Resource Report 22, 59 p., web edition.

93. Lower Macungie Township, PA, subdivision and land development ordinance, 2004.

94. Mammoth Cave National Park master plan, 1970

95. Marsh, George Perkins. 1864. Man and Nature. Cambridge Belknap Press of Harvard University Press. 
96. McKnight, Tom L.; Hess, Darrel. 2002. Physical Geography: A Landscape Appreciation. Prentice-Hall, Inc., Upper Saddle River, NJ.

97. Memon, Bashir A. and Azmeh, M. Mumtaz. 2001. Failure of an industrial wastewater lagoon in a karst terrain and remedial action. Environmental Geology, v. 40, pp. 1424-1432.

98. Memon, Bashir A.; Azmeh, M. Mumtaz.; Pitts, Mary Wallace. 2002. The environmental hazards of locating wastewater impoundments in karst terrain. Environmental Geology, v. 65, pp. 169-177.

99. Meyer, Bruce; Viscusi, W. Kip; Durbin, David, 1995. Workers compensation and injury duration: Evidence from a natural experiment. American Economic Review, v. 85, no. 3, pp. 322-338.

100. Miller, B.L. 1941. Lehigh County, Pennsylvania: Geology and Geography. Pennsylvania Geological Survey, Fourth Series (Bulletin C39).

101. Miller, B.L.; Fraser, D.M.; Miller, R.L. 1939. Northampton County, Pennsylvania. Pennsylvania Geological Survey, Fourth Series (County Report 48).

102. Miller, E. Willard (Ed.), 1995. A Geography of Pennsylvania. Pennsylvania State University Press, State College, PA.

103. Mills, Edwin. 1972. Urban Economics. Glenview, Illinois.

104. Mitchem, P.S.; Hallberg, G.R.; Hoyer, B.E.; Libra, R.D. 1988. Ground-Water Contamination and Land Management in the Karst Area of Northeastern Iowa. In Ground-Water Contamination: Field Methods. American Society for Testing and Materials, Philadelphia PA. Pp. 442-458.

105. Mole Creek Karst National Park management plan.

106. Mos, Alin; personal communication, 2006.

107. Mos, Alin; personal communication, 2007.

108. Mueller, Dennis C. 2003. Public Choice III. Cambridge University Press.

109. Naracoorte Caves National Park management plan.

110. Nash, John. 1951. Non-cooperative games. Annals of Mathematics, v. 54, no. 2, pp. 286-295.

111. North Jersey Resource Conservation \& Development Council, 1993. A karst model ordinance. In Applied Karst Geology, pp. 273-276. Swets \& Zeitlinger.

112. O’Driscoll, Michael A.; Parizek, Richard R. 2003. The Hydrologic Catchment Area of a Chain Of Karst Wetlands in Central Pennsylvania, USA. Wetlands, v. 23, no. 1, pp. 171-179.

113. Ostrom, Elinor. 1990. Governing the Commons: The Evolution of Institutions for Collective Action. Cambridge University Press.

114. Palmer, Arthur N. 2005. Passage Development. In David C. Culver and William B. White (Eds.), Encyclopedia of Caves, pp. 440-444. Elsevier Academic Press.

115. Palmer, Arthur N. 2007. Cave Geology. Cave Books, Dayton, OH. 
116. Patton, D.; DeHan, B., 1998. Water Issues: Global, National, State, Ecosystem. In Fernald, Edward A.; Purdum, Elizabeth D. (Eds.), Water Resources Atlas of Florida. Florida State University, Tallahassee.

117. Patton, Michael Q. 1980. Qualitative Evaluation Methods. Sage Publications, London.

118. Paulachok, Gary; Wood, Charles. 1988. Water Resources of Oley Township, Berks County, Pennnsylvania. USGS water resources investigations report 874065.

119. Raitz, Karl B. 1973. The Bluegrass. In Kentucky, a Regional Geography. Pradyumma P. Karan ed. Kendall/Hunt, Dubuque, IA.

120. Rebmann, James. Personal communication, 2006.

121. Reese, A.J.; Cantrell, A; Scarborough, J. 1997. Sinkhole and drainage planning in Johnson City, Tennessee. In Beck, B.F. and Stephenson, Brad (Eds.), The Engineering Geology and Hydrogeology of Karst Terranes, Balkema, Rotterdam, pp. 265-271.

122. Renken, R.A.; Cunningham, K.J.; Zygnerski, M.R.; Wacker, M.A.; Shapiro, A.M., Harvey, R.W.; Metge, D.W.; Osborn, C.L.; Ryan, J.N. 2005. Assessing the vulnerability of a municipal well field to contamination in a karst aquifer. Environmental and Engineering Geoscience, v. 11, no. 4, pp. 319-331.

123. Richardson, Jesse J., Jr., 2003. Local land use regulation of karst in the United States. In Sinkholes and Engineering / Environmental Impacts of Karst.

124. Ritter, D.F.; Kochel, R.C.; Miller, J.C. 1995. Process Geomorphology. McGraw-Hill Publishing.

125. Rubin, Paul A., 1992. Land use planning and watershed protection in karst terranes. In Proceedings of the Third Conference on Hydrogeology, Ecology, Monitoring and Management of Ground Water in Karst Terranes, pp. 769-793. Ground Water Management Series, Book 10, National Ground Water Association, Dublin, Ohio.

126. Sabatier, Paul A. 1991a. Toward better theories of the policy process. Political Science and Politics, v. 24, no. 2, pp. 147-156.

127. Sabatier, Paul A. 1991b. Political science and public policy. Political Science and Politics, v. 24, no. 2, pp. 144-147.

128. Sabatier, Paul A.; Jenkins-Smith, Hank C. 1988. The advocacy coalition framework: an assessment. In Theories of the Policy Process, pp. 117-166. Paul Sabatier, ed. Westview Press, Boulder, CO.

129. Sauer, Carl O. 1925. The morphology of landscape. University of California publications in geography. Vol. 2, no. 2, pp. 19-53.

130. Sauer, Carl O. 1930. Historical Geography and the Western Frontier. In James F. Willard and Colin B. Goodykoontz (Eds.), The Trans-Mississippi West: Papers Read at a Conference Held at the Univ. of Colorado June 18-June 21, 1929. Univ. of Colorado, pp. 267-289. 
131. Sauer, Carl O. 1936. American Agricultural Origins: a Consideration of Nature and Culture. In Essays in Anthropology Presented to A.L. Kroeber in Celebration of His Sixtieth Birthday, June 11, 1936. Univ. Calif. Press, pp. 279297.

132. Sauer, Carl O. 1941. Foreword to Historical Geography. Annals of the AAG, v. 31, pp. 1-24.

133. Sauer, Carl O. 1952. Folkways of Social Science. In The Social Sciences at Mid-Century: Papers delivered at the Dedication of Ford Hall, April 19-21, 1951, pp. 100-109. University of Minnesota Press, Minneapolis, MN.

134. Sauer, Carl O. 1956. The agency of man on the earth. In Man's Role in Changing the Face of the Earth, pp. 49-69. University of Chicago Press, Chicago, IL.

135. Sauer, Carl O. 1962. Homestead and Community on the Middle Border. Landscape, vol. 12, no. 1, pp. 3-7.

136. Sauer, Carl O. 1968. The Geography of the Ozark Highland of Missouri. Greenwood Press, New York.

137. Schopf, Johann David. 1787. The Geology of Eastern North America. Translated by Edmund Speiker; edited by George White. Harper's Publishing Company, New York City, 1972.

138. Scott, Joseph. A Geographical Description of Pennsylvania: Also the counties respectively, in the order in which they were established by the legislature, with an alphabetical list of the townships in each county, and their population in 1800. 1806.

139. Smith, Roger P. 2000. What makes my baby blue? Dartmouth Medicine, summer 2000, pp. 26-31.

140. Soriano, M.A.; Simon, J.L. 2002. Subsidence rates and urban damages in alluvial dolines of the Central Ebro basin (NE Spain). Environmental Geology, v. 42 , pp. $476-484$.

141. Springfield, Missouri Comprehensive Plan, 2001.

142. Turk, L. Jan. 1976. Predicting the environmental impact of urban development in a karst area. In Yerjevich, V. (Ed.), Karst Hydrology and Water Resources, Volume 2, pp. 683-700. Water Resources Publications, Ft. Collins, Colorado.

143. Turnock, David. 2002. Ecoregion-based conservation in the Carpathians and the land-use implications. Land Use Policy, v. 19, pp.47-63.

144. U.S. Census Bureau, 1990.

145. U.S. Census Bureau, 2000.

146. U.S. Department of Housing and Urban Development; dataset downloaded February 2007.

147. U.S. Geological Survey, 1991. Hydrogeology and ground-water flow in the carbonate rocks of the Little Lehigh Creek basin, Lehigh County, Pennsylvania. Water Resources Investigations Report 90-4076. 
148. United States Geologic Survey, 1999. Sinkholes of West-Central Florida. Washington, DC.

149. Upchurch, S.B.; Randazzo, A.F. 1997. Environmental geology of Florida. In Randazzo, A.F. and Jones, D.S. (Eds.), The Geology of Florida, pp. 217-250. University Press of Florida.

150. Urich, Peter B. 2002. Land use in karst terrain: review of impacts of primary activities on temperate karst ecosystems. Department of Conservation, Wellington, New Zealand.

151. Urich, Peter B.; Day, Michael J.; Lynagh, Fiona. 2001. Policy and practice in karst landscape protection: Bohol, the Philippines. The Geographical Journal, v. 167 , no. 4, pp. 305-323.

152. Van Beynen, Philip; Townsend, Kaya. 2005. A disturbance index for karst environments. Environmental Management, v. 36, no. 1, pp. 101-116.

153. Varian, Hal R. 1990. Intermediate Microeconomics. W.W. Norton, New York.

154. Vineyard, Jerry D. 1976. The concept of a government catalyst in the planning and management of water resources in karst regions. In Yerjevich, V. (Ed.), Karst Hydrology and Water Resources, Volume 2, pp. 829-845. Water Resources Publications, Ft. Collins, Colorado.

155. Von Bertalanffy, Ludwig. 1973. General System Theory: Foundations, Development, Applications. Fourth Edition. George Braziller, Inc., New York City.

156. Von Bertalanffy, Ludwig. 1981. In Paul A. LaViolette (Ed.), A Systems View of Man.. Westview Press, Boulder, CO.

157. Waltham, A.C.; Fookes, P.G. 2003. Engineering classification of karst ground conditions. Quarterly Journal of Engineering Geology and Hydrogeology, v. 36, pp. 101-118.

158. Watson, John; Hamilton-Smith, Elery; Gillieson, David; Kiernan, Kevin, eds. 1997. Guidelines for Cave and Karst Protection: IUCN World Commission on Protected Areas. WCPA Working Group on Cave and Karst Protection. Cambridge, UK.

159. Weisberg, Herbert F.; Krosnick, Jon A.; Bowen, Bruce D. 1989. An Introduction to Survey Research and Data Analysis. Scott, Foresman and Company, Glenview, IL.

160. Weiss, Gerhard. 2000. Evaluation of policy instruments for protective forest management in Austria. Forest Policy and Economics, v. 1, pp. 243-255.

161. White, Gilbert F. 1936. The Limit of Economic Justification for Flood Protection. The Journal of Land \& Public Utility Economics, Vol. 12, No. 2, pp. 133-148.

162. White, Gilbert F. 1949. Toward an Appraisal of World Resources: New Views of Conservation Problems. Geographical Review, Vol. 39, No. 4. (Oct., 1949), pp. 625-639.

163. White, Gilbert F. 1960. Industrial Water Use: A Review. Geographical Review, Vol. 50, No. 3. (Jul., 1960), pp. 412-430. 
164. White, Gilbert F. 1962. Social and Economic Aspects of Natural Resources: A report to the Committee on Natural Resources of the National Academy of Sciences-National Research Council. Publication 1000-G. National Academy of Sciences-National Research Council, Washington, DC.

165. White, Gilbert F. 1980. Environment. Science, New Series, Vol. 209, No. 4452, Centennial Issue, pp. 183-190.

166. White, Gilbert F. 1985. Geographers in a perilously changing world. Annals of the Association of American Geographers, v. 75, no. 1, pp. 10-16.

167. White, Gilbert F. 1993. Water resources people and issues: interview with Gilbert F. White by Martin Reuss. Publication EP-870-1-43. US Army Corps of Engineers, Fort Belvoir, Virginia.

168. White, Gilbert F. 1994. Coping with Environmental Degradation. Proceedings of the American Philosophical Society, Vol. 138, No. 3, pp. 394-396.

169. White, Irvin L. 1979. An interdisciplinary approach to applied policy analysis. Technological Forecasting and Social Change, v. 15, pp. 95-106.

170. White, William A.; Watson, Richard A.; Pohl, E.R.; Brucker, Roger. 1970. The central Kentucky karst. Geographical Review, v. 60, no. 1, pp. 88-115.

171. White, William B.; Culver, David C.; Herman, Janet S.; Kane, Thomas C.; Mylroie, John E., 1995. Karst Lands. American Scientist, v. 83, Sept/Oct, pp. 450-459.

172. White, William. 1988. Geomorphology and hydrology of karst terrains. Oxford University Press, New York.

173. Williams Township, PA, Grading Ordinance, 2005.

174. Williams, Paul W. 1993. Environmental change and human impact on karst terrains: An introduction. Catena supplement, v. 25, pp. 1-19.

175. Williams, Paul W. 2004. Dolines. In John Gunn (Ed.), Encyclopedia of Caves and Karst Science, pp. 304-310. Fitzroy Dearborn.

176. Wilson, Robert L. 1984. Karst induced subsidence in the Chattanooga-Rossville area, Hamilton County, Tennessee, and Walker County, Georgia. In Castany, G; Groba, E.; Romijn, E. (Eds.), Hydrogeology of Karstic Terrains: Case Histories, pp. 258-260. International Association of Hydrogeologists.

177. World Bank Development Indicators. http://devdata.worldbank.org/wdi2006/contents/income.htm. Accessed October 2007.

178. World Conservation Union, 2000. Application of IUCN Protected Area management Categories, Draft Australian Handbook.

179. World Conservation Union, 2005. Guidelines for Cave and Karst Protection. IUCN World Commission on Protected Areas. IUCN Publication Services Unit, Cambridge, UK.

180. Yorkshire Dales National Park Management Plan, 2007.

181. Zoning ordinance, Lexington-Fayette Urban County, 2005. 
182. Zwahlen, Francois (ed.). 2003. Vulnerability and risk mapping for the protection of carbonate (karst) aquifers: scope, goals, results. European Commission for Science, Research and Development. Luxembourg. 
Appendices 


\section{Appendix A: Survey of land use professionals in karstic areas in the United States}

Conducted online via SurveyMonkey, Nov. 252006 - Jan. 2, 2007

$1 \quad$ Are you familiar with karst?

\begin{tabular}{l|r|r}
\multicolumn{3}{c}{ Response } \\
& Total & \multicolumn{1}{c}{ Percent } \\
\hline Yes & 59 & 89.39 \\
No & 7 & 10.61 \\
\hline
\end{tabular}

Total Respondents

66

(skipped this question)

0

By which type of organization are you

2 employed?

\begin{tabular}{l|r|r} 
& \multicolumn{2}{c}{ Response } \\
& Total & Percent \\
\hline Local government & 47 & 82.46 \\
\hline State government & 6 & 10.53 \\
\hline Federal government & 1 & 1.75 \\
\hline Private consulting / contracting & 1 & 1.75 \\
Other & 2 & 3.51 \\
\hline & \multicolumn{3}{|c}{} \\
Total Respondents & 57 & 86.36 \\
(skipped this question) & 9 &
\end{tabular}

This survey deals with local land use regulations. Please enter the name of the city or county on whose regulations you will

3 be commenting.

Total Respondents

(skipped this question) 
Appendix A (Continued)

$4 \quad$ In which state do you work?

\begin{tabular}{l|r|r} 
& \multicolumn{2}{c}{ Response } \\
& Total & Percent \\
\hline Florida & 24 & 42.11 \\
\hline Kentucky & 6 & 10.53 \\
\hline Missouri & 8 & 14.04 \\
\hline New Jersey & 2 & 3.51 \\
\hline Pennsylvania & 13 & 22.81 \\
\hline Tennessee & 4 & 7.02 \\
\hline & & \\
Total Respondents & 57 & 86.36 \\
(skipped this question) & 9 &
\end{tabular}

5 What is your job title?

Total Respondents $\quad 55$

(skipped this question) 11

To the best of your knowledge does your city or town currently have any form of karst-

6 related land use regulations on the books?

\begin{tabular}{|c|c|c|}
\hline & $\begin{array}{l}\text { Response } \\
\text { Total }\end{array}$ & Percent \\
\hline Yes & 32 & 56.14 \\
\hline No & 21 & 36.84 \\
\hline $\begin{array}{l}\text { Not applicable - I work at the state or federal } \\
\text { level }\end{array}$ & 4 & 7.02 \\
\hline Total Respondents & 57 & 86.36 \\
\hline (skipped this question) & 9 & \\
\hline
\end{tabular}


Appendix A (Continued)

In your opinion why has your city or town declined to enact karst-related land use

7 regulation? (Select all that apply)

\begin{tabular}{l|r|r} 
& \multicolumn{2}{c}{ Response } \\
& Total & Percent \\
\hline Philosophical opposition to regulation in general & 3 & 16.67 \\
\hline Fear of lawsuits & 0 & \\
\hline Pressure from developers & 3 & 16.67 \\
\hline $\begin{array}{l}\text { Fear of losing opportunities for growth to } \\
\text { neighboring towns without such regulations }\end{array}$ & 1 & 5.56 \\
There is no karst within the town limits & 2 & 11.11 \\
Citizen input & 0 & \\
Other (please specify) & 11 & 61.11 \\
\hline & & \\
Total Respondents & 18 & 27.27 \\
(skipped this question) & 48 &
\end{tabular}

Were you involved in the creation or implementation of karst-related land use

8 regulations in your jurisdiction?

\begin{tabular}{|c|c|c|}
\hline & $\begin{array}{l}\text { Response } \\
\text { Total }\end{array}$ & Percent \\
\hline Yes & 16 & 45.71 \\
\hline No & 19 & 54.29 \\
\hline Total Respondents & 35 & 53.03 \\
\hline (skipped this question) & 31 & \\
\hline
\end{tabular}


Appendix A (Continued)

\section{Approximately how long ago were these \\ 9 karst regulations implemented?}

\begin{tabular}{l|r|r} 
& \multicolumn{2}{c}{ Response } \\
& Total & Percent \\
\hline Within the last two years & 5 & 14.29 \\
\hline Between two and five years ago & 5 & 14.29 \\
\hline Between five and ten years ago & 6 & 17.14 \\
\hline More than ten years ago & 16 & 45.71 \\
\hline I don't know / I don't remember & 3 & 8.57 \\
\hline
\end{tabular}

Total Respondents

$35 \quad 53.03$

(skipped this question)

31

\section{In your opinion how serious in your community are the following karst- related issues?}

Total Pct Total Pct Total Pct Somewhat Response

\begin{tabular}{l|cc|cc|cc|c}
\multicolumn{1}{c}{ Very serious } & \multicolumn{2}{c}{ serious } & \multicolumn{2}{c}{ Not serious } & Average \\
\hline $\begin{array}{l}\text { Groundwater } \\
\text { contamination }\end{array}$ & 18 & 51.43 & 13 & 37.14 & 3 & 8.57 & 1.56 \\
$\begin{array}{l}\text { Flooding } \\
11\end{array}$ & 31.43 & 15 & 42.86 & 8 & 22.86 & 1.91 \\
$\begin{array}{l}\text { Subsidence and } \\
\text { property damage from } \\
\text { sinkholes }\end{array}$ & 15 & 42.86 & 14 & 40.00 & 5 & 14.29 & 1.71 \\
$\begin{array}{l}\text { Karst ecosystem } \\
\text { protection }\end{array}$ & 12 & 34.29 & 13 & 37.14 & 10 & 28.57 & 1.94 \\
Cave protection & 6 & 17.14 & 12 & 34.29 & 16 & 45.71 & 2.29 \\
\hline
\end{tabular}

Total Respondents

$35 \quad 53.03$ 
Appendix A (Continued)

\section{Please rank the following five karst-related issues in order}

11 of seriousness: Total Pct How serious? Total Pct

\begin{tabular}{|c|c|c|c|c|c|c|c|c|}
\hline \multicolumn{5}{|c|}{ Most serious } & \multicolumn{3}{|c|}{ Least serious } & \multirow{2}{*}{$\begin{array}{c}\begin{array}{r}\text { Response } \\
\text { Average }\end{array} \\
1.82\end{array}$} \\
\hline $\begin{array}{l}\text { Groundwater } \\
\text { contamination }\end{array}$ & 17 & 48.57 & 10 & 3 & 4 & 0 & 0.00 & \\
\hline $\begin{array}{l}\text { Subsidence and } \\
\text { property damage } \\
\text { from sinkholes }\end{array}$ & 8 & 22.86 & 11 & 6 & 5 & 4 & 11.43 & 2.59 \\
\hline $\begin{array}{l}\text { Karst ecosystem } \\
\text { protection }\end{array}$ & 2 & 5.71 & 6 & 14 & 6 & 4 & 11.43 & 3.13 \\
\hline Flooding & 7 & 20.00 & 6 & 7 & 12 & 2 & 5.71 & 2.88 \\
\hline Cave protection & 1 & 2.86 & 0 & 4 & 6 & 22 & 62.86 & 4.45 \\
\hline
\end{tabular}

Total Respondents $\quad 35 \quad 53.03$

(skipped this question)

\section{In your opinion how extensive is the karst}

\section{2 system in your area?}

\begin{tabular}{l|c|c} 
& $\begin{array}{c}\text { Response } \\
\text { Total }\end{array}$ & Pct \\
\hline $\begin{array}{l}\text { Not at all extensive - less than } 10 \% \text { of the total } \\
\text { land area contains karst }\end{array}$ & 2 & 5.71 \\
\hline Not very extensive - between $10 \%$ and $30 \%$ & 6 & 17.14 \\
Somewhat extensive - between $31 \%$ and $50 \%$ & 15 & 42.86 \\
Very extensive - more than 50\% & 11 & 31.43 \\
I don't know & 1 & 2.86 \\
\hline & & \\
Total Respondents & 35 & 53.03 \\
(skipped this question) & 31 &
\end{tabular}


Appendix A (Continued)

Which of the following karst landforms are present in your area? (Select all that

13 apply.)

\begin{tabular}{l|c|c}
\multicolumn{3}{c}{$\begin{array}{c}\text { Response } \\
\text { Total }\end{array}$} \\
\hline Springs & 33 & 94.29 \\
Sinkholes & 35 & 100.00 \\
Caves & 26 & 74.29 \\
Sinking or disappearing streams & 26 & 74.29 \\
Other (please specify) & 1 & 2.86 \\
\hline \multicolumn{3}{l}{} \\
Total Respondents & 35 & 53.03 \\
(skipped this question) & 31 &
\end{tabular}

In your opinion how restrictive are the karst-related land use and development

14 regulations in your jurisdiction?

\begin{tabular}{l|c|c}
\multicolumn{3}{c}{$\begin{array}{c}\text { Response } \\
\text { Total }\end{array}$} \\
\hline Very & 4 & 11.43 \\
Somewhat & 15 & 42.86 \\
Not very & 12 & 34.29 \\
Not at all & 2 & 5.71 \\
I don't know & 2 & 5.71 \\
\hline & & \\
Total Respondents & 35 & 53.03 \\
(skipped this question) & 31 &
\end{tabular}

15 (question removed) 
Appendix A (Continued)

To the best of your knowledge which of the following karst-related regulatory components are present in your jurisdiction's land use and development

16 regulations? (Select all that apply.)

\begin{tabular}{l|c|c} 
& \multicolumn{2}{c}{$\begin{array}{c}\text { Response } \\
\text { Total }\end{array}$} \\
\hline Mandatory setbacks from karst features & 19 & 57.58 \\
$\begin{array}{l}\text { An extra step in the permit approval process } \\
\text { (for example, the county geologist is required } \\
\text { to do an analysis and provide a } \\
\text { recommendation) }\end{array}$ & 17 & 51.52 \\
$\begin{array}{l}\text { Multiple extra steps in the permit approval } \\
\text { process }\end{array}$ & 9 & 27.27 \\
$\begin{array}{l}\text { A moratorium on new construction in areas } \\
\text { where karst features are present }\end{array}$ & 0 & 0.00 \\
Stormwater drainage rules & 30 & 90.91 \\
\hline Dumping and waste disposal rules & 18 & 54.55 \\
Fertilizer and chemical application rules & 6 & 18.18 \\
Other (please specify) & 6 & 18.18 \\
\hline & & \\
Total Respondents & 33 & 50.00 \\
(skipped this question) & 33 &
\end{tabular}


Appendix A (Continued)

Which of the following factors was a goal

of regulating development in karst areas?

17 (Select all that apply.)

\begin{tabular}{|c|c|c|}
\hline & $\begin{array}{l}\text { Response } \\
\text { Total }\end{array}$ & Pct \\
\hline Environmental protection & 22 & 64.71 \\
\hline Groundwater protection & 30 & 88.24 \\
\hline Cave protection & 7 & 20.59 \\
\hline $\begin{array}{l}\text { Desire to prevent property and structural } \\
\text { damage }\end{array}$ & 28 & 82.35 \\
\hline $\begin{array}{l}\text { Desire to limit the legal liability of local } \\
\text { government }\end{array}$ & 11 & 32.35 \\
\hline Total Respondents & 34 & 51.52 \\
\hline (skipped this question) & 32 & \\
\hline
\end{tabular}

Prior to the implementation of these karst-related land use regulations had there been any actual problems with some or all of the factors listed in the previous question or were these regulations implemented as strictly a preventative measure?

\begin{tabular}{l|c|c} 
& \multicolumn{1}{c}{ Response } \\
& Total & Pct \\
\hline Strictly preventative & 11 & 33.33 \\
$\begin{array}{l}\text { Intended to address actual existing problems } \\
\text { (please specify) }\end{array}$ & 22 & 66.67 \\
\hline & & \\
Total Respondents & 33 & 50.00 \\
(skipped this question) & 33 &
\end{tabular}


Appendix A (Continued)

\section{Who initiated the process of developing \\ 19 these regulations?}

\begin{tabular}{l|c|c} 
& Response \\
& Total & Pct \\
\hline Branch or department within local government & 13 & 39.39 \\
Branch of state or federal government & 7 & 21.21 \\
County or city commission, or local equivalent & 5 & 15.15 \\
Mayor or county administrator, or local & & \\
equivalent & 0 & 0.00 \\
Environmental or science groups & 1 & 3.03 \\
Local residents & 0 & 0.00 \\
Other (please specify) & 6 & 18.18 \\
\hline
\end{tabular}

Total Respondents

32

48.48

(skipped this question)

34

\section{Who ultimately approved these} regulations?

\begin{tabular}{l|c|c} 
& Response \\
& Total & Pct \\
\hline Elected body (for example, county commission) & 21 & 61.76 \\
$\begin{array}{l}\text { Elected official (for example, mayor or county } \\
\text { administrator) }\end{array}$ & 7 & 20.59 \\
Appointed official & 1 & 2.94 \\
Career civil service official & 1 & 2.94 \\
Other (please specify) & 4 & 11.76 \\
\hline & & \\
Total Respondents & 34 & 51.52 \\
(skipped this question) & 32 &
\end{tabular}


Appendix A (Continued)

How much time elapsed between the point

at which the idea of regulating

development on top of karst was first

seriously proposed and the time those

21 regulations were finally enacted?

\begin{tabular}{l|c|c}
\multicolumn{3}{c}{$\begin{array}{c}\text { Response } \\
\text { Total }\end{array}$} \\
\hline 0-2 years & 13 & 39.39 \\
2-4 years & 4 & 12.12 \\
5-7 years & 3 & 9.09 \\
Longer & 2 & 6.06 \\
\hline I don't remember & 11 & 33.33 \\
\hline
\end{tabular}

Total Respondents

33

50.00

(skipped this question)

33

Which of the following entities or groups

had an influence on the process of

designing the karst-related land use and

development regulations in your

22 jurisdiction? (Select all that apply.)

\begin{tabular}{l|c|c} 
& \multicolumn{2}{c}{ Response } \\
& \multicolumn{1}{c}{ Total } & Pct \\
\hline Federal government & 5 & 15.15 \\
State government & 19 & 57.58 \\
Local elected officials & 18 & 54.55 \\
$\begin{array}{l}\text { Local government departments (like the Water } \\
\text { Department, for example) }\end{array}$ & 27 & 81.82 \\
$\begin{array}{l}\text { Environmental or scientific groups (non- } \\
\text { governmental) }\end{array}$ & 14 & 42.42 \\
$\begin{array}{l}\text { Members of the building or real estate } \\
\text { industries }\end{array}$ & 6 & 18.18 \\
Local residents & 14 & 42.42 \\
Other (please specify) & 6 & 18.18 \\
\hline & & \\
Total Respondents & 33 & 50.00 \\
(skipped this question) & 33 &
\end{tabular}


Appendix A (Continued)

To what degree were these regulations influenced by non-elected professionals (i.e. scientists or engineers for example) working for or in conjunction with local

23 government?

\begin{tabular}{l|c|c}
\multicolumn{3}{c}{$\begin{array}{c}\text { Response } \\
\text { Total }\end{array}$} \\
\hline Not at all & 0 & 0.00 \\
Slightly & 4 & 11.76 \\
Moderately & 7 & 20.59 \\
Strongly & 16 & 47.06 \\
I don't know & 7 & 20.59 \\
\hline
\end{tabular}

Total Respondents

34

51.52

(skipped this question)

32

\section{Please describe the nature of this influence if any:}

By using educated professionals who believe in the protection of karst features we were able to gain, (I feel) a greater influence.

Regulations reflected credible engineering and geologic knowledge and experience.

Engineering community had input.

Home owners association meetings where county commissioners were invited.

giving testimony to the Planning Commission

Such professionals on staff and via participation from citizens and special environmental interest groups having this professional background

Stormwater Taskforce involved professionals from the community

Mapping of potential karst areas and development of requirements for design of ponds, swales and underground utilities in proximity to these areas.

Input from developers and contractors

Report on Karst areas subject to fooding (USGS, FEMA mapping w/ TVA and City 
Permanent, full-time, professional Planning Staff drafted ordinance, City Engineer and Solictors reviewed. Planning Commission resolved to recommend to City Council adoption of ordinance. City Council adopted subdivision and land development regulations including land suitability requirements.

County staff doing research on the problem

Provision of the science base for understanding groundwater, the aquifers in the state, the rate of recharge, etc., affected decisions prioritizing areas that are karst sensitive and in developing the land use regulations to protect them.

Township (city) Engineer was instrumental in working on our Karst Regulations.

In our case our organization worked by committee (of non-elected professionals) to develop a model ordinance. This ordinance has been adopted by many communities in our region.

This occurred 16 years ago

direct meetings with the local TDEC office to develop stormwater regulations and coordination between county and state on injection well permits for stormwater. More codes to follow soon.

Very important

Input came from: City Planning (staff wrote ordinance), State Water Management district engineers, some public input from local residents with engineering/natural sciences backgrounds, and local real estate/development interests.

Geologist, soil scientist, hydro geologist, biologist, and others all have had a significant role in conducting solid science to be used in development of the rule.

local land use planners and elected officials rely on authoritative opinions from geoscientists and engineers, published studies and other documentation from the USGS, FDEP, etc.

Some professionals in the region had identified karst topography as potential problem for septic field related ground water contamination.

Professional opinions were sought and provided to the BOCC (Educational).

Total Respondents 
Appendix A (Continued)

To what degree were these regulations influenced by preexisting regulations relating to land use and development

\section{4} (like for example the presence of an urban growth boundary or other environmental regulations)?

\begin{tabular}{l|c|c}
\multicolumn{3}{c}{$\begin{array}{c}\text { Response } \\
\text { Total }\end{array}$} \\
\hline Not at all & 13 & 39.39 \\
Slightly & 8 & 24.24 \\
Moderately & 5 & 15.15 \\
Strongly & 2 & 6.06 \\
I don't know & 5 & 15.15 \\
\hline
\end{tabular}

Total Respondents

33

50.00

(skipped this question)

25 Please describe the nature of this influence if any.

Karst regulations represented a new field of regulation.

Knowledge of related state regulations was used in pressuring the local elected officials to push for adopting simialr rgulation

New developments going into karst areas.

state regulation interface needs

States Inject Well Regs...TDEC is asked to review impacts in sinkhole areas

Part of comprehensive plan

City had previously passed Creek regulations governing increased setbacks. City was one of first in Florida to pass Stormwater Utility fee for city-wide stormwater improvements, including retrofitting storm drains, upgrading wastewater plant water disposal, etc.

State already had regulations about setback of septic systems from karst areas (sink holes etc.) which were incorporated in development reviews.

Previous goals and objectives of our earlier comp plan and land development regulations.

Total Respondents

(skipped this question) 
Appendix A (Continued)

\section{To what degree were these regulations \\ 26 influenced by local residents?}

\begin{tabular}{l|c|c|} 
& \multicolumn{2}{c}{ Response } \\
& Total & Pct \\
\hline Not at all & 6 & 18.18 \\
Slightly & 11 & 33.33 \\
Moderately & 8 & 24.24 \\
Strongly & 3 & 9.09 \\
I don't know & 5 & 15.15 \\
\hline & & \\
Total Respondents & 33 & 50.00 \\
(skipped this question) & 33 &
\end{tabular}


Appendix A (Continued)

\section{Please describe the nature of this influence if any.}

Residents who are concerned for the general quality of the county's environment always have a voice in the decision making process.

Home owners association meetings where commissioners were invited, also news paper articles

Local residents participated in the process; were generally supportive.

Public hearings were held where the public spoke

The reporting of the various incidents provided sufficient documentation to warrant investigation of appropriate regulations and safeguards.

concerns raised relative to stormwater damage and the adverse impact on local drainageways, streams and existing infrastructure.

Where houses have been subject to flooding, there was major clamoring to solve problems...buy-outs and identification of flood limits around sinkholes

Clearly, the public is concerned about the occurance of sinkholes as it is a regular 'phenomenon' due to subsurface conditions, location between three bodies of water, and the early, dense urban development of the City pre-federal, state or local land use regulation. City Planning, Zoning and Engineering personnel took the lead develop and enforce regulations in the interest of the public health, safety and welfare.

constant complaints on the failure of government requiring permits up front - educational process on all parties

public forums, strong opinions voiced

City has small vocal environmental movement.

Some in community reflected same information as regional professionals, and general concern with ground water contaminiation.

A few residents are affiliated with environmental groups, which put on educational presentations.

Public input was a continuing part of the process of developing land use regulations, through the comprehensive planning review process.

Total Respondents 
Appendix A (Continued)

In your opinion which of the following entities or groups had the most influence on the process of developing and

28 implementing karst-related land use regulations?

\begin{tabular}{l|c|c} 
& Total & Pct \\
\hline Federal government & 0 & 0.00 \\
State government & 6 & 18.18 \\
Local elected officials & 1 & 3.03 \\
$\begin{array}{l}\text { Local government departments (like the Water } \\
\text { Department, for example) }\end{array}$ & 17 & 51.52 \\
$\begin{array}{l}\text { Environmental or scientific groups (non- } \\
\text { governmental) }\end{array}$ & 2 & 6.06 \\
$\begin{array}{l}\text { Members of the building or real estate } \\
\text { industries }\end{array}$ & 1 & 3.03 \\
Local residents & 1 & 3.03 \\
Other (please specify) & 5 & 15.15 \\
\hline & & \\
Total Respondents & 33 & 50.00 \\
(skipped this question) & 33 &
\end{tabular}

In your opinion which of the following entities or groups had the least amount of influence on the process?

\begin{tabular}{l|c|c} 
& Total & Pct \\
\hline Federal government & 17 & 51.52 \\
\hline State government & 1 & 3.03 \\
Local elected officials & 2 & 6.06 \\
$\begin{array}{l}\text { Local government departments (like the Water } \\
\text { Department, for example) }\end{array}$ & 1 & 3.03 \\
$\begin{array}{l}\text { Environmental or scientific groups (non- } \\
\text { governmental) }\end{array}$ & 1 & 3.03 \\
$\begin{array}{l}\text { Members of the building or real estate } \\
\text { industries }\end{array}$ & 10 & 30.30 \\
Local residents & 1 & 3.03 \\
\hline & 33 & 50.00 \\
Total Respondents & 33 & \\
(skipped this question) & &
\end{tabular}


Appendix A (Continued)

In your opinion is it appropriate for a municipality to attempt to regulate or manage development near karst

30 landforms?

\begin{tabular}{l|c|c} 
& \multicolumn{2}{c}{ Response } \\
& Total & Pct \\
\hline Yes & 32 & 96.97 \\
No & 0 & 0.00 \\
Don't know / no opinion & 1 & 3.03 \\
\hline
\end{tabular}

Total Respondents

33

50.00

(skipped this question)

33

In your opinion are the karst-related land use regulations in your jurisdiction

31 effective?

\begin{tabular}{l|c|c}
\multicolumn{3}{c}{$\begin{array}{c}\text { Response } \\
\text { Total }\end{array}$} \\
\hline Yes & 23 & 67.65 \\
No & 6 & 17.65 \\
Don't know / no opinion & 5 & 14.71 \\
\hline \multicolumn{3}{|}{} \\
Total Respondents & 34 & 51.52 \\
(skipped this question) & 32 &
\end{tabular}


Appendix A (Continued)

In your opinion which of the following are likely outcomes of implementing karst-related development restrictions in a

32 city of town? (Select all that apply.)

\begin{tabular}{l|c|c}
\multicolumn{2}{c}{$\begin{array}{c}\text { Response } \\
\text { Total }\end{array}$} & Pct \\
\hline An increase in residential land values & 9 & 18.37 \\
\hline An increase in housing costs & 17 & 34.69 \\
A decline in new development projects & 9 & 18.37 \\
A decline in population and structural density & 7 & 14.29 \\
A decline in development-related lawsuits filed & & \\
against the city & 8 & 16.33 \\
An improvement in groundwater quality & 37 & 75.51 \\
Some other outcome (please specify) & 14 & 28.57 \\
\hline & & \\
Total Respondents & 49 & 74.24 \\
(skipped this question) & 17
\end{tabular}

In your opinion to what extent did the existence of karst-related land use regulations (or lack thereof) in neighboring towns affect the process of developing and implementing karst regulations in your municipality?

\begin{tabular}{|c|c|c|}
\hline & $\begin{array}{l}\text { Response } \\
\text { Total }\end{array}$ & Pct \\
\hline It was the most important consideration & 0 & 0.00 \\
\hline $\begin{array}{l}\text { It was an important consideration, but not the } \\
\text { only one, and not necessarily the most } \\
\text { important one }\end{array}$ & 4 & 8.70 \\
\hline $\begin{array}{l}\text { It had some impact, but not a significant } \\
\text { amount }\end{array}$ & 10 & 21.74 \\
\hline It had no impact whatsoever & 32 & 69.57 \\
\hline Total Respondents & 46 & 69.70 \\
\hline (skipped this question) & 20 & \\
\hline
\end{tabular}


Appendix A (Continued)

From the following list please select the impacts your town or city actually experienced after enacting karst-related land use regulations. $* * *$ Please select ONLY impacts that you personally can

34 attest to. $* * *$ (select all that apply):

\begin{tabular}{|c|c|c|}
\hline & $\begin{array}{l}\text { Response } \\
\text { Total }\end{array}$ & Pct \\
\hline Higher housing costs & 3 & 11.11 \\
\hline $\begin{array}{l}\text { Lost opportunities for growth, as new } \\
\text { development projects migrated to neighboring } \\
\text { towns without regulation }\end{array}$ & 2 & 7.41 \\
\hline $\begin{array}{l}\text { An increase in lawsuits filed by landowners and } \\
\text { developers against the city }\end{array}$ & 0 & 0.00 \\
\hline An improvement in groundwater quality & 5 & 18.52 \\
\hline $\begin{array}{l}\text { A decrease in damage to structures from new } \\
\text { sinkholes }\end{array}$ & 9 & 33.33 \\
\hline A decrease in population density & 2 & 7.41 \\
\hline $\begin{array}{l}\text { I haven't witnessed any impacts of the karst } \\
\text { development regulations }\end{array}$ & 8 & 29.63 \\
\hline Some other outcome (please specify) & 11 & 40.74 \\
\hline Total Respondents & 27 & 40.91 \\
\hline (skipped this question) & 39 & \\
\hline
\end{tabular}

In your opinion can anything be done to improve the effectiveness of karst land use regulation in your jurisdiction?

\begin{tabular}{l|c|c}
\multicolumn{3}{c}{ Response } \\
\multicolumn{1}{l}{ Total } & Pct \\
\hline No & 10 & 29.41 \\
Yes (please elaborate, if possible) & 24 & 70.59 \\
\hline
\end{tabular}

Total Respondents 


\begin{abstract}
About the Author
Erik Spencer Fleury was born in Detroit, Michigan. He holds a BA in American Studies (Florida State University, 1993) and an MA in Economics (University of South Florida, 2003). From 1993 to 1997, he served in the U.S. Coast Guard, with postings aboard the medium endurance cutter CAMPBELL and in the First District headquarters.
\end{abstract}

